\title{
Reported sick from school
}

Citation for published version (APA):

Vanneste-van Zandvoort, Y. T. M. (2015). Reported sick from school: a study into addressing medical absenteeism among students. [Doctoral Thesis, Maastricht University]. Datawyse / Universitaire Pers Maastricht. https://doi.org/10.26481/dis.20151105yv

Document status and date:

Published: 01/01/2015

DOI:

10.26481/dis.20151105yv

Document Version:

Publisher's PDF, also known as Version of record

\section{Please check the document version of this publication:}

- A submitted manuscript is the version of the article upon submission and before peer-review. There can be important differences between the submitted version and the official published version of record.

People interested in the research are advised to contact the author for the final version of the publication, or visit the DOI to the publisher's website.

- The final author version and the galley proof are versions of the publication after peer review.

- The final published version features the final layout of the paper including the volume, issue and page numbers.

Link to publication

\footnotetext{
General rights rights.

- You may freely distribute the URL identifying the publication in the public portal. please follow below link for the End User Agreement:

www.umlib.nl/taverne-license

Take down policy

If you believe that this document breaches copyright please contact us at:

repository@maastrichtuniversity.nl

providing details and we will investigate your claim.
}

Copyright and moral rights for the publications made accessible in the public portal are retained by the authors and/or other copyright owners and it is a condition of accessing publications that users recognise and abide by the legal requirements associated with these

- Users may download and print one copy of any publication from the public portal for the purpose of private study or research.

- You may not further distribute the material or use it for any profit-making activity or commercial gain

If the publication is distributed under the terms of Article $25 \mathrm{fa}$ of the Dutch Copyright Act, indicated by the "Taverne" license above, 


\section{REPORTED SICK FROM SCHOOL}

A study into addressing medical absenteeism among students

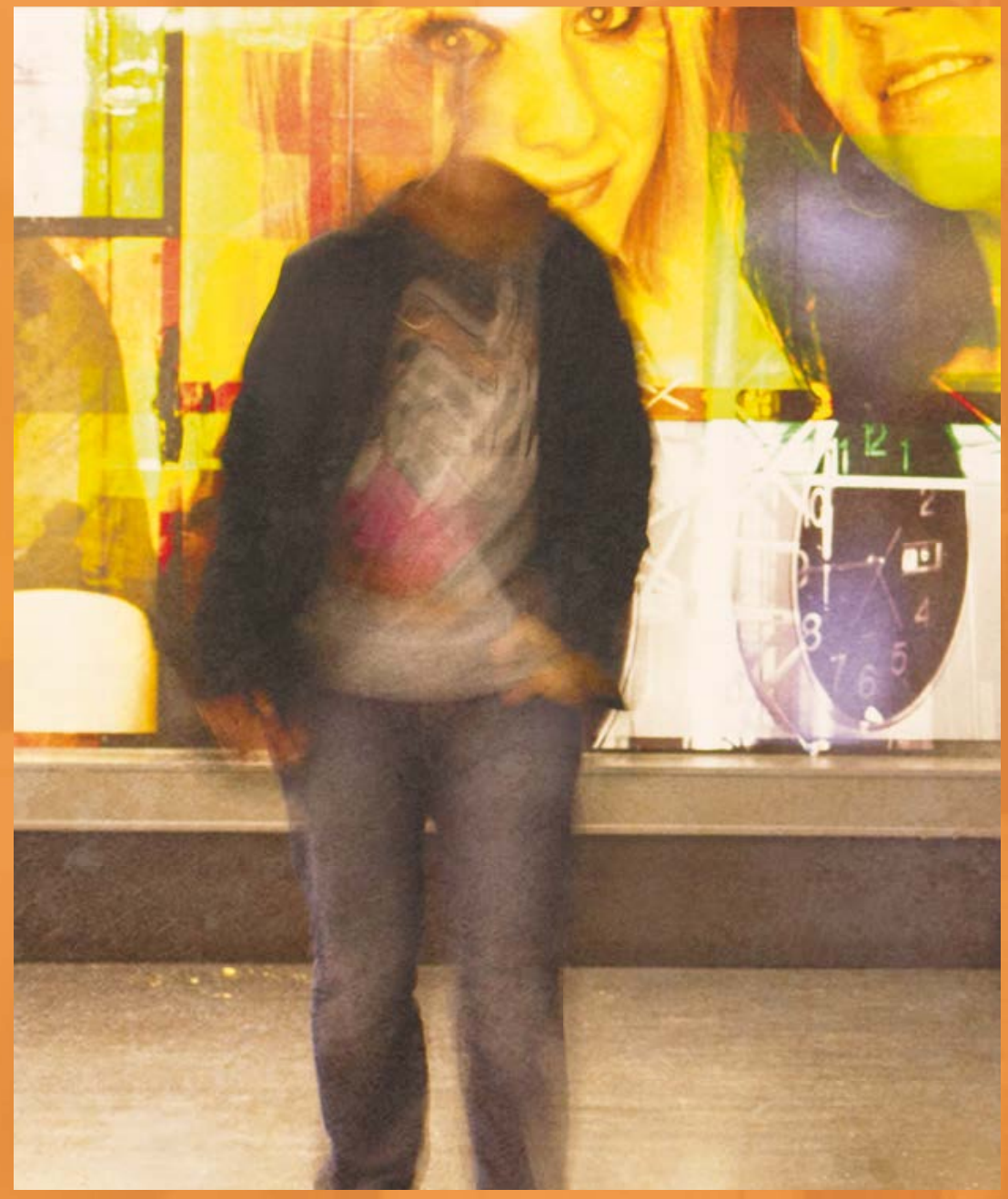

Yvonne Theodora Maria Vanneste-van Zandvoort 


\section{Colofon:}

Design and lay-out: Denise van Rijst

Photography: Robbert So Kiem Hwat

Print: Datawyse - UniverisitairePers Maastricht

ISBN: 9789461594808

All rights reserved. No parts of this publication may be reproduced in any form without permission of the author. 


\section{REPORTED SICK FROM SCHOOL}

A study into addressing medical absenteeism among students

\section{PROEFSCHRIFT}

ter verkrijging van de graad van doctor aan de Universiteit Maastricht, op gezag van de Rector Magnificus, Prof. dr. L.L.C. Soete, volgens het besluit van het College van Decanen, in het openbaar te verdedigen

op donderdag 5 november 2015 om 14:00 uur.

door

Yvonne Theodora Maria Vanneste-van Zandvoort 


\section{Promotores}

Prof. dr. F. J.M. Feron

Prof. dr. L.A.M. van de Goor (Tilburg University)

\section{Copromotores}

Dr. J.J.P. Mathijssen (Tilburg University)

Dr. M.C. Rots-de Vries (Regional Public Health Service West Brabant)

\section{Beoordelingscommissie}

Prof. dr. E. Dompeling (president)

Prof. dr. J.L.L. van der Klink (Tilburg University)

Prof. dr. J.F.M. Metsemakers

Dr. F. Pijpers (Dutch Centre Youth Health)

This study was a joint project of the faculty of Health, Medicine and Life Sciences (FHML), CAPHRI, Department of Social Medicine, Maastricht University, the department Tranzo, Faculty of Social Sciences, Tilburg University, and the Regional Public Health Service West Brabant.

The research was funded by the Dutch Organisation for Health Research and Development (ZonMw, the Hague), Dropout Committee West Brabant Region 34 and the Regional Public Health Service West Brabant. 
Voor Vincent, tu es formidable! 

Begin met het nodige. Doe daarna het mogelijke.

En dan ineens doe je zomaar het onmogelijke...

Franciscus van Assisi 



\section{Contents}

Chapter 1: General introduction and outline of this thesis

Part I

Chapter 2: Medical Advice for Sick-reported Students (MASS) in secondary school by the youth health care physician: development of an intervention

Chapter 3: Extensive medical absenteeism among secondary school students: an observational study on their health condition from a biopsychosocial perspective

Chapter 4: Addressing medical absenteeism in pre-vocational secondary students: effectiveness of a public health intervention, using a quasi-experimental design

\section{Part II}

Chapter 5: Attitudes towards addressing medical absenteeism in secondary school

Chapter 6: Family-related problems associated with extensive medical absenteeism in primary school children

Chapter 7: Towards a better understanding of medical absenteeism in adolescence: a qualitative study among Dutch intermediate vocational students

Chapter 8: General discussion and concluding remarks

Summary

Samenvatting

Dankwoord

Valorisation

The way MASS works

Publications, presentations and contributions related to this thesis 


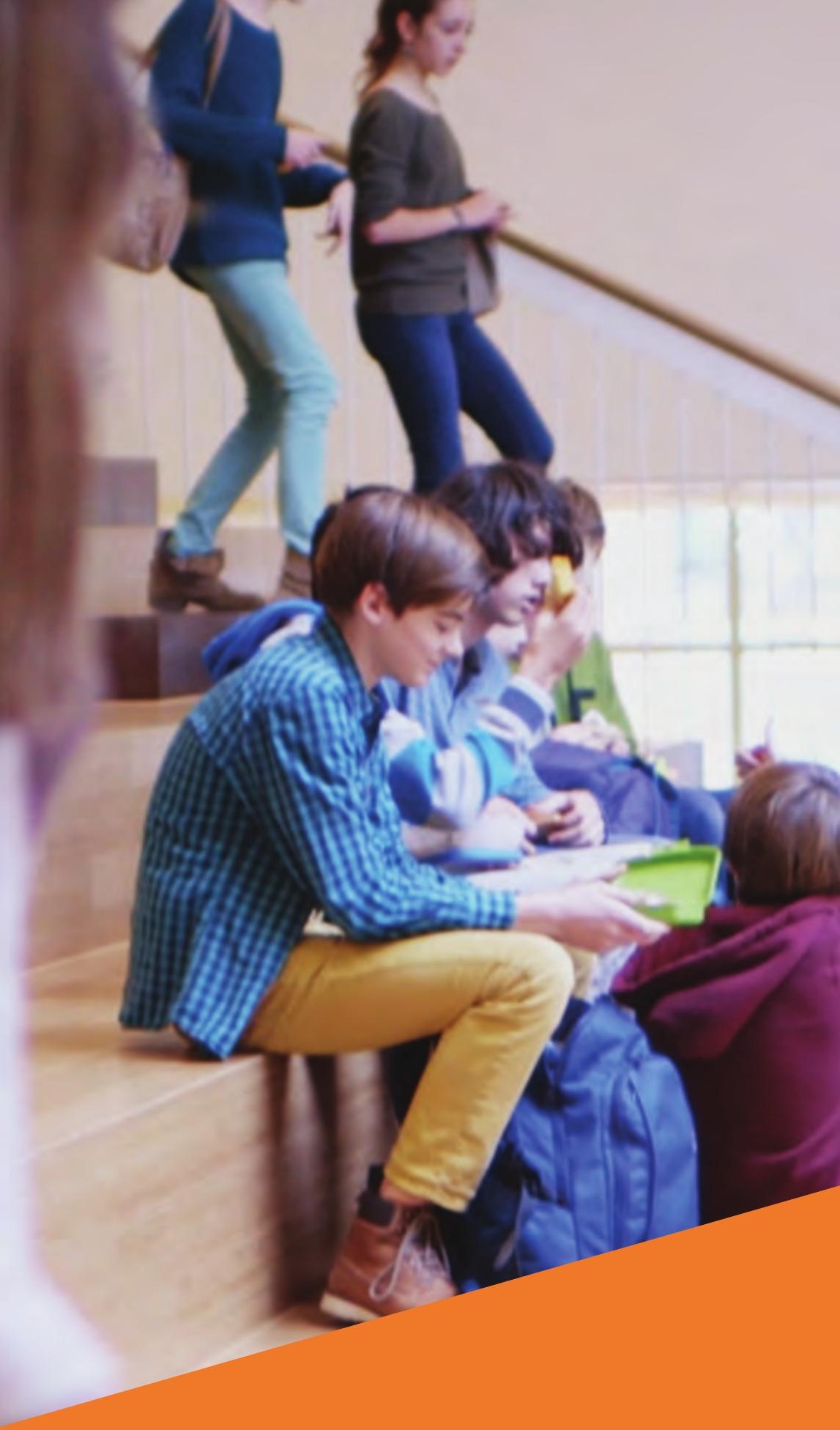




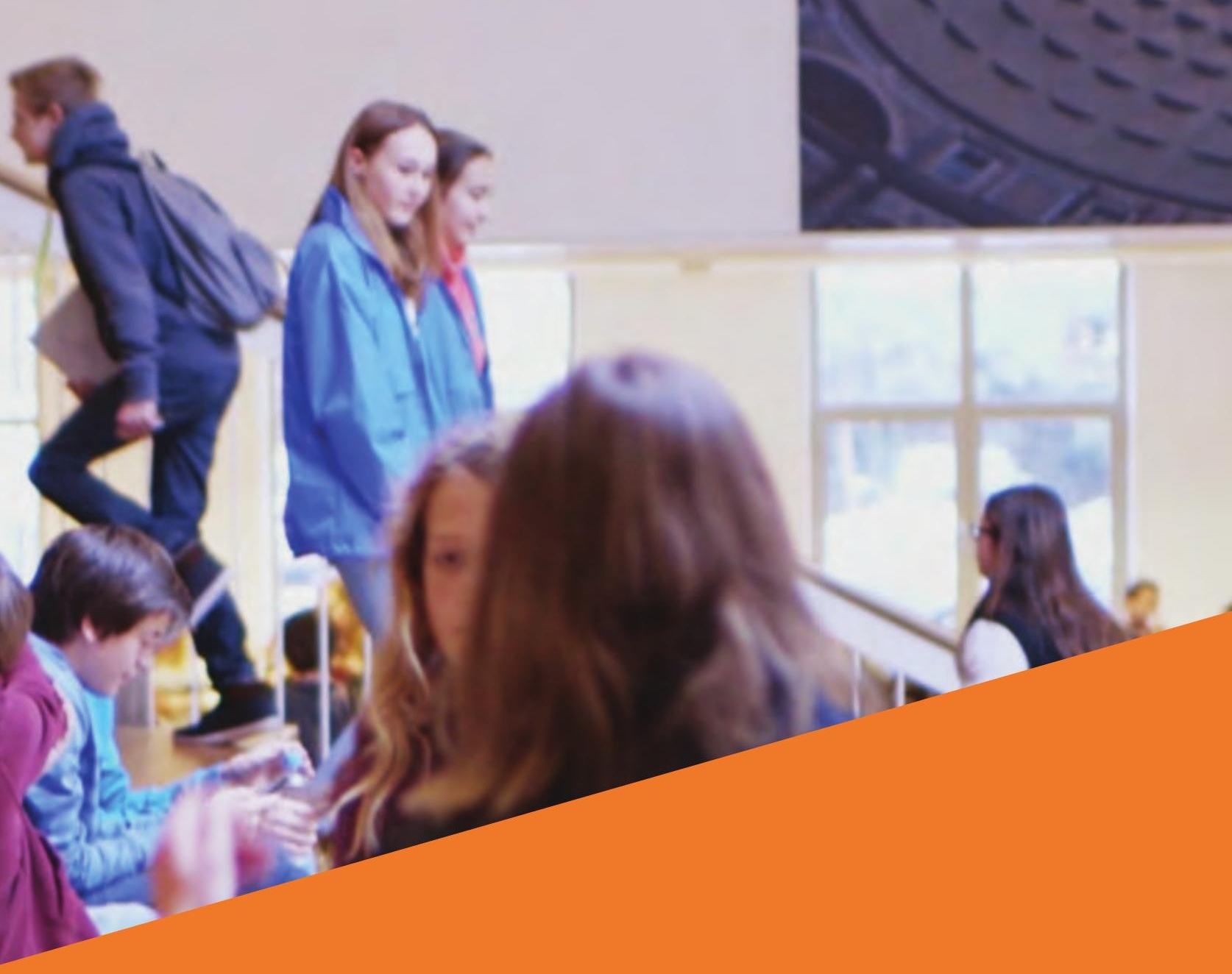

Chapter 1: General introduction and outline of this thesis 



\section{Chapter 1: General introduction and outline of this thesis}

This thesis is a compilation of studies on the Dutch intervention 'Medical Advice for Sick-reported Students', abbreviated as MASS (In Dutch: 'Medische Advisering van de Ziekgemelde Leerling', abbreviated as M@ZL). The intervention aims to address school absenteeism due to sickness reporting, so-called medical absenteeism, and consists of an integrated approach in which schools, in direct collaboration with youth health care physicians (YHCPs), are able to reach students and their parents, to discuss aspects of the student's medical absence, and to design and monitor a management plan to optimize students' health and maximize students' participation in school activities. MASS has been developed in close partnership between the youth health care (abbreviated as YHC; the Dutch equivalent of preventive paediatric primary care) $[1,2]$ department of a Regional Public Health Service, secondary schools and the municipal school attendance service for compulsory education in West Brabant, the Netherlands. A practicedriven intervention study was performed to evaluate MASS in pre-vocational secondary schools. The study aimed to investigate the health condition of pre-vocational secondary students with extensive medical absence, the effectiveness of the intervention, and implementation and dissemination issues. In addition, exploratory research into aspects of medical absenteeism in primary and intermediate vocational education was aimed to adapt the intervention for use with these new target groups.

In this chapter the policy context on tackling school absenteeism is presented, followed by explaining the relationship between medical absenteeism and socioeconomic health inequalities. Then, the unique position of YHC and the vulnerability of pre-vocational secondary students in the light of medical absenteeism are defined. Finally, after a description of the core elements of MASS and its developmental process, the general outline and aims of this thesis are displayed.

\subsection{Policy context on tackling school absenteeism}

Initially, the sense of urgency to tackle school absenteeism was caused by the fact that school absenteeism is a main risk factor for early school dropout [3-12]. Since the 1990 s there is an increased focus on reducing school dropouts worldwide. The need to prevent young people from dropping out of school is economically and socially driven. School dropouts, young people who leave the education system without a qualification, generate huge public and social costs [1317]. Moreover, in several reports it was stated that a high rate of school dropout has a negative impact on social cohesion in society $[15,18]$.

The EU countries agreed in the so-called Lisbon goals to reduce the proportion of early school dropouts in 2000. Dropout was mainly considered an educational problem, producing an approach primarily focussed on education-related risk factors for dropout. In the Netherlands, this led to a policy focused on school dropout: the 'Drive to reduce dropout rates' (In Dutch: 'Aanval op de uitval') [19]. The main programme components included an increase in the age of compulsory education and obligatory training from 16 to 18 years of age, improved guidance and counselling for students and the introduction of a 'basic qualification'. This minimum educational requirement is equivalent to higher general secondary education, pre-university education or 
intermediate vocational education level two and is considered to be the minimum education level needed for an adequate start in the labour market or for pursuing further studies [20]. The acknowledgement that preventing dropout is more cost-effective than reintegration measures after dropout, led to an additional focus on tackling school absenteeism. Therefore, the aforementioned measures were accompanied by intensified inspection of illegitimate school absenteeism by municipal attendance officers in compulsory education (school attendance officers). Despite this intensification policy, school absenteeism due to sickness reporting received little attention, primarily because it was considered to be authorized absence and therefore not an area of responsibility of compulsory education. In addition, teachers and others in education generally assumed that substantial medical absence would be due to serious medical disease and requires only standard medical treatment.

In recent years, there has been a growing awareness that school absenteeism is not only an educational but also a public health problem, due to increasing evidence on the interdependence between education and health. Whereas education optimizes children's growth and development, and is an indicator for better health and chances of full participation in society later in life [21-24], health also affects educational outcomes [24-29]. In 2014, the WHO highlights that optimising young people's access to education is a key strategy in improving health outcomes for this group [30]. As research increasingly shows that several health-related factors have an impact on school absenteeism, this allows for opportunities to tackle school absenteeism with added value of deployment of health professionals [31]. This seems all the more feasible in medical absenteeism, where the interdependence between education and health is definitely reflected.

\subsection{Defining school absenteeism as a public health problem}

Health inequalities mainly arise on social determinants indicating the socioeconomic position of individuals, their material and psychosocial circumstances, and behavioural and/or biological factors [30]. Education and health are connected through these social determinants (Figure 1).

\section{Social determinants}
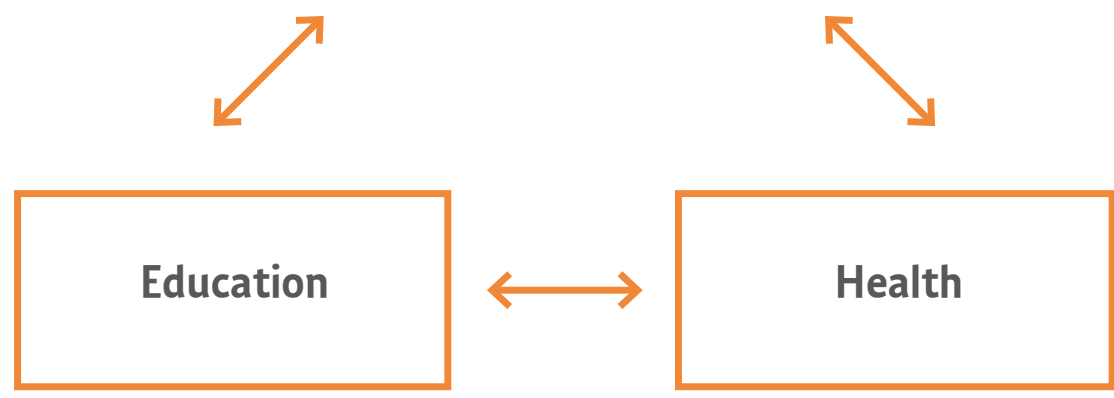

Figure 1: Visualisation of the link between education, health and social determinants (WHO, 2014) [28] 
The relationship between education and health is reciprocal: education can lead to improved health and well-being $[25,26,32]$, also called the 'causation hypothesis', and on the other hand different physical and mental health conditions and health behaviours in children and adolescents play an important role in their ability to learn and therefore contribute to educational outcomes $[24,27,33,34]$, and in the end to attaining a variation in socioeconomic position. The latter is also referred to as the 'selection hypothesis'. In a life-time perspective, accumulation of adverse socioeconomic circumstances and selection are important mechanisms, which successively may cause a downward spiral. Health problems and less educational achievement in youth may be followed by a lower socioeconomic position in adulthood. A lower socioeconomic status will lead to more health problems in adult life, which in turn may cause downward social mobility [35] and a transgenerational transmission of poor health through a lower socioeconomic status. Education can thus be a way out of a disadvantaged situation [29, 36, 37]. And as O'Toole and Kropf stated [26]: "When educational systems function, they are the best health care delivery systems in the world". The causation and selection process, and the transgenerational transmission of a low socioeconomic (health) status in a life-time perspective are visualised in Figure 2.

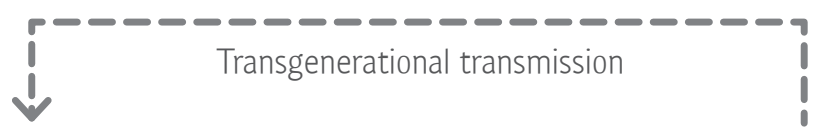

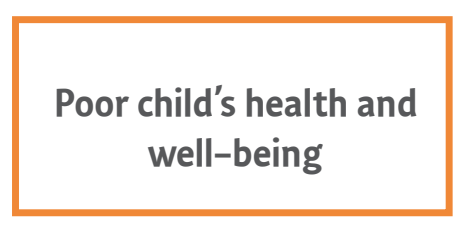
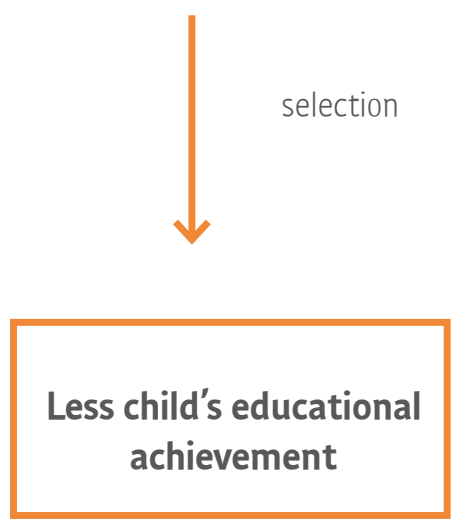

Poor adult health and low social status

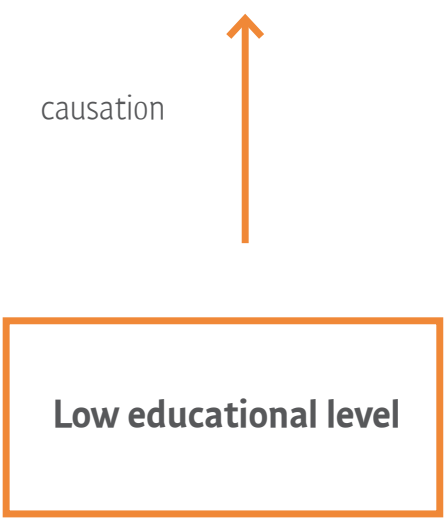

Figure 2: Visualisation of the causation and selection process, and the transgenerational transmission of a low socioeconomic (health) status in a life-time perspective. Source: Adapted from Allensworth (2010) [50] and Murray et al. (2006) [51] 
During child's school careers, the interrelationship between education and child's health and well-being can be demonstrated through and even reinforced by school absenteeism. For example, headaches can be a cause of school absenteeism. As a result, a child can fall behind and will need to catch up both in educational as well as social terms, which may cause increased stress that, in turn, can cause headaches, in this way creating a vicious circle. Substantial school absenteeism may negatively affect children's social and emotional development, and can cause children's educational development to stagnate, which, in turn, may lead to moving down to a lower level of education or even early school dropout [3-11] (Figure 3). The impact of school absenteeism on educational achievement can partly be explained by the fact that the moment school absenteeism is caused by health-related issues (see paragraph 1.3) these impaired health conditions can also affect educational outcomes [24-29, 33, 34, 38]. Subsequently, low educational level and school dropout are both strongly associated with increased risk behaviour (smoking, obesity, lack of exercise) $[39,40]$, a higher prevalence of chronic health issues, mental problems, higher mortality rates $[21-24,41-43]$, and an increased risk of social failure and delinquency $[11,20,23,44,45]$. Dropouts later in life are more often unemployed or have lower incomes, and become dependent on welfare and other government programmes more frequently $[13,18]$. Especially dropouts from the lowest educational levels experience the highest labour market integration problems $[46,47]$. And in particular, those dropouts with (mental) health problems appear to be subsequently less successful in their career development and lives $[48,49]$.

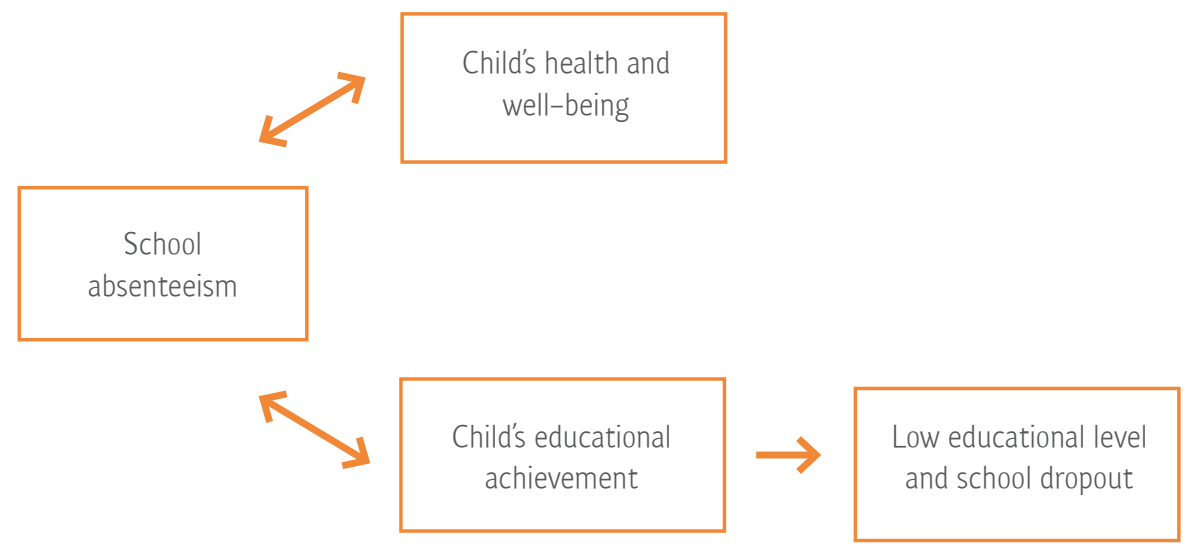

Figure 3: Visualisation of the correlation between school absenteeism, young people's development and low educational level and school dropout

Given that school absenteeism undermines educational opportunities and negatively affects health outcomes, allowing to effect on socioeconomic health inequalities, school absenteeism is not only an educational but also a public health problem. School absenteeism as a public health problem is visualised in Figure 4. Efforts to improve educational outcomes can improve health outcomes, and vice versa. Effective interventions that have the power to improve both students health and their educational outcomes can even be more effective and can ultimately improve the adult health status of the individuals receiving the intervention as well as the health of their future children [50]. Therefore, integrated approaches of both education and health sectors are helpful and may be even necessary to diminish health inequalities [37, 52]. 


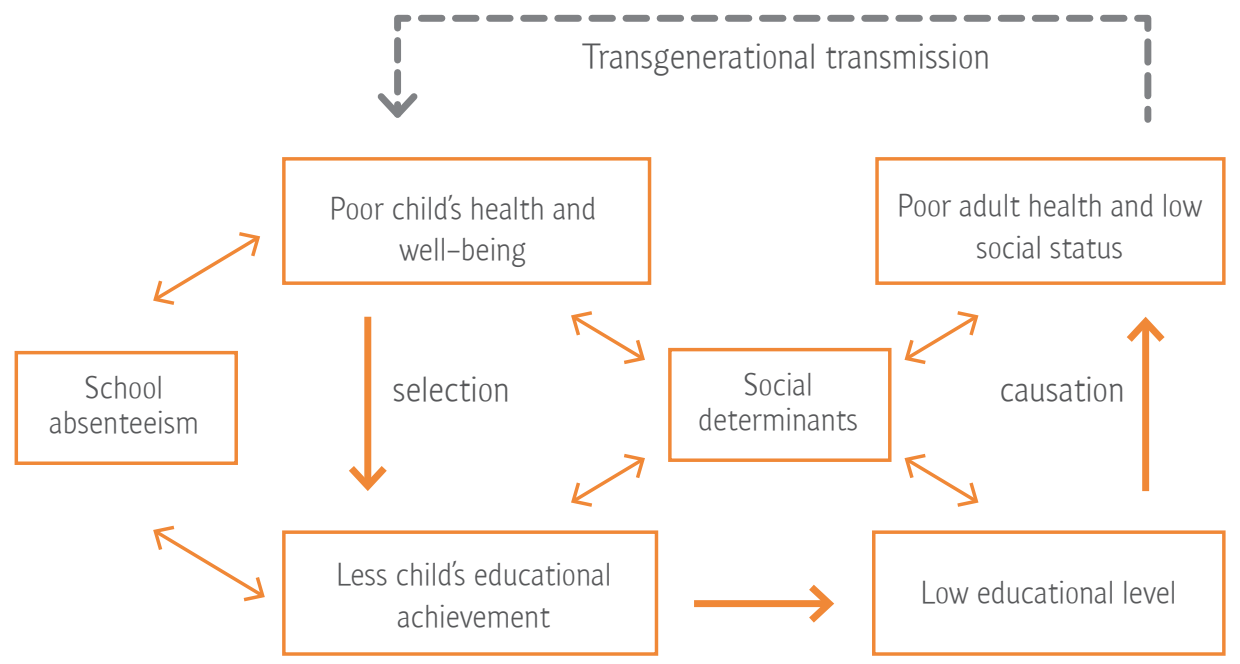

Figure 4: Visualisation of school absenteeism as a public health problem: the causation and selection process, and the transgenerational transmission of a low socioeconomic (health) status in a life-time perspective, coupled with the interrelationship between education, health, and social determinants on the one hand, and between education, health and school absenteeism on the other hand. Source: Adapted from Allensworth (2010) [50] and Murray et al. (2006) [51].

\subsection{School absenteeism due to sickness reporting, so-called medical absenteeism}

It is to be expected that the interrelationship between school absenteeism and health seems to be all the more reflected in school absenteeism due to sickness reporting, so-called medical absenteeism.

A distinction is frequently made between unexcused and excused school absenteeism. Unexcused absenteeism means not attending school without permission, i.e. truancy. Excused absence suggests not attending lessons with permission because of familial or personal reasons, or because of sickness reporting. The latter is referred to as medical absenteeism and is in the Netherlands by far the most common reason for excused absence [53]. Prevalence rates on school absenteeism as reported in literature are not directly comparable internationally, due to inconsistent use of parameters for school absenteeism. Nowadays, when the figures are compared at the national level of other European countries, medical absenteeism occurs about twice as often as truancy [54-56]. In the Netherlands in 2002 medical absenteeism was more prevalent in pre-vocational secondary education than in the other two tracks in secondary education (higher general secondary education and pre-university education): $4 \%$ v. $3.7 \%$ and $3.4 \%$ [53]. There are no recent valid figures on medical absenteeism available. Because of the strict enforcement of measures against truancy during the last years and on the basis of the recent international figures, it is conceivable that also in the Netherlands, meanwhile, the medical absence rate has increased in relation to truancy. 
Contrary to research on school dropout and truancy, until now research on medical absenteeism has been scarce. There are some studies on factors associated with medical absenteeism that show that it is related to both biological and psychosocial factors: there is an association with chronic somatic and mental diseases, physical complaints $[11,57-59]$, unhealthy lifestyle $[54,60]$, and psychological, family, and social problems [11]. Chronic diseases do not necessarily cause a higher than average absence from school [11]. Research was performed in how optimizing treatment can reduce absenteeism following severe organic diseases such as asthma, and psychiatric disorders such as school refusal behaviour [11]. An initial study shows that medical absenteeism in adolescence appears to be predictive of medical absenteeism in adulthood [61].

\subsection{Youth Health Care (YHC)}

Preventive $\mathrm{YHC}$ is an important field of application within public health. Like in other industrialised countries, the goal of the Dutch preventive YHC is to foster an optimal trajectory for growth and development in children and to provide anticipatory guidance to prevent a negative health outcome later in life. To achieve this goal, the Public Health Act (In Dutch: Wet Publieke Gezondheid, WPG) determines a basic task package (In Dutch: Basispakket JCZ) in which YHC focuses on health and developmental issues, as well as psychosocial problems, including behavioural problems and emotional difficulties, and learning disabilities. For its implementation, all children living in the Netherlands receive free preventive medical assessments, from birth to adolescence. YHC works not only by reacting to a demand for care, but also pro-actively by reaching out to youth at risk in health, growth and/or development. To be able to do so, attention is paid to early detection of vulnerable and high risk groups and individuals. YHC works in close cooperation with schools to reach these groups. Research also shows that children who are growing up in problem families and adolescents are not reached well by YHC services $[62,63]$. This is at least partly due to the fact that in the Netherlands it is not obligatory to participate in $\mathrm{YHC}$ services. Nowadays YHC services are challenged more than ever to a better reach of adolescents because of the unmet need for treatment of (mental) health problems that is a major issue, especially during adolescence [64]. This may be partly due to the fact that most young people do not visit a physician when experiencing physical complaints or psychosocial problems [65].

Several diagnostic and prognostic tools make preventive action possible and useful and therefore underpin the periodic examinations of children in a life-span perspective: for example, the prediction, to some extent, of diseases and developmental disorders with a strong genetic basis [66], the possibility to predict adverse adult outcomes in cases of adolescent psychiatric disorders $[67,68]$, and the detection of the presence of chronic diseases at an early stage [69]. The latter is based on the 'growing into deficit'-theory (Figure 5) $[66,70]$ that is the theory of the progression of the disease: chronic diseases usually develop slowly over a long period of time, and take time to evolve. This theory also supposes that biological and psychosocial conditions have an influence on the development of diseases. In other words, diseases develop as a consequence of inherited susceptibilities and environmental exposure. Over time, pathology increases and reversibility decreases, causing increasing burden for the patients, their families, and the healthcare system. By predicting, early detecting and intervening the progression of the disease could considerably be slowed down and the disease burden be reduced. 


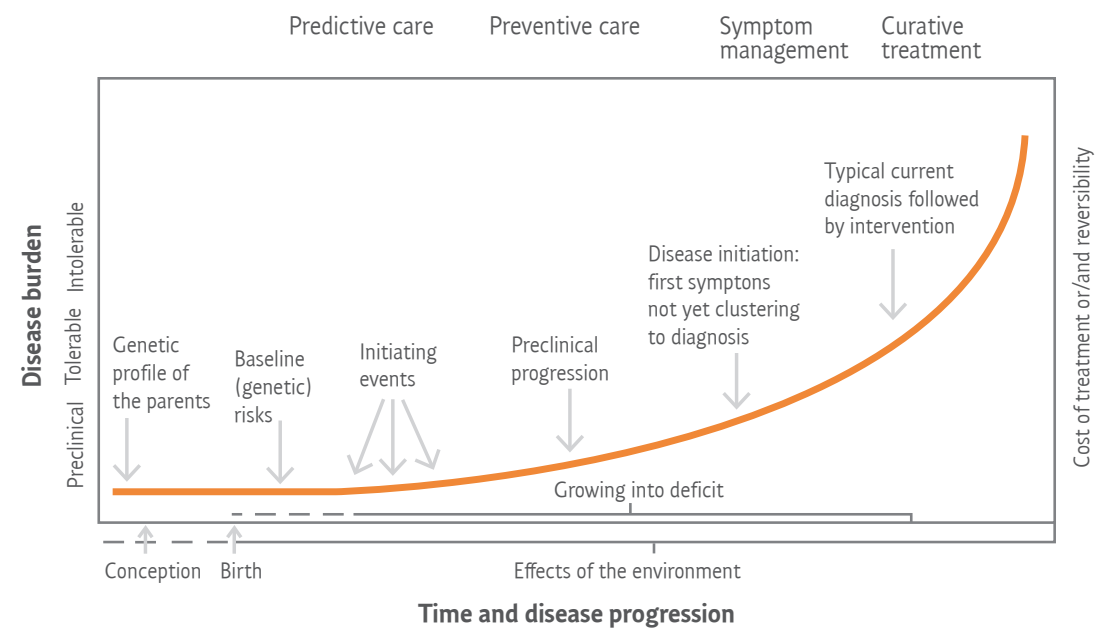

Figure 5: Disease progression is shown from baseline risk to irreversibility, and health care from predictive care to curative treatment (Syurina, 2013) [66]. Adapted from Snyderman's curve representing growing into deficit and developing common complex diseases [70].

The 'growing into deficit'-theory underpins the use of a biopsychosocial perspective in which youth health care physicians (YHCPs) pay attention to the interaction between children, society and environment and to the interconnection with multiple risk factors and protective factors, long latency and multistep pathogenesis of diseases. The biopsychosocial model is a theoretical framework that posits that biological, psychological and social factors all play a significant role in human disease or illness and health, rather than biology alone. The biopsychosocial perspective assumes that the origin, maintenance and recovery of a complaint or disease result from an interaction of biological, psychological and social factors $[71,72]$. The biopsychosocial perspective therefore is part of the MASS intervention, because medical absenteeism is related to a great diversity of health-related factors.

YHCPs are in a key position to act on medical absenteeism for three main reasons. First, because YHCPs deal with symptom management and diagnosis of existing physical complaints and psychosocial problems signalized by the child or parents (Figure 5) $[66,70,73]$. In cases of physical complaints and psychosocial problems with no clear medical diagnosis, the YHCP can make diagnostic considerations. As chronic diseases have a pre-clinical phase and first symptoms [70], these physical complaints and psychosocial problems may be related to a disease not yet diagnosed. It is also known that most mental diseases emerge just during adolescence and early adulthood $[74,75]$. The median age of onset of all mental diseases is approximately 14 years [76]. Secondly, because of their use of a biopsychosocial perspective on physical complaints, psychosocial problems and diseases. YHCPs can pay attention to family-related and schoolrelated factors, as well as health risk behaviours and lifestyle aspects that contribute to the physical complaints or psychosocial problems. Also in case the child is suffering from a (chronic) disease attention should be paid to psychosocial factors that influence the disease burden and the adherence to treatment. Of all Dutch children, $14 \%$ has a chronic diagnosed disease [77, 78]. It is well known that having a chronic disease can be stressful for children, their parents, and their environment [78]. And many psychiatric symptoms do not cluster in a diagnosis but do cause dysfunction. Thirdly, YHCPs are the gateway to curative medicine. If there is a specific 
medical or psychiatric diagnosis, they can optimise the treatment or refer to other specialist support. Fourthly, YHC and schools work closely together. YHCPs participate in the support and care network of the school and in the health care network. In this way YHCPs can bridge the gap between support at school and care outside school $[50,79]$.

\subsection{School absenteeism and school dropout: the vulnerability of pre-vocational secondary students}

Our study primarily focuses on pre-vocational secondary students as, compared to other secondary students, these students are especially vulnerable when it comes to school absenteeism because it more often results in school dropout. This is caused to some extent by the structure of the Dutch education system, in which pre-vocational secondary education is the lowest form of secondary education. Moreover, their vulnerability is also impacted by student characteristics. The Dutch general educational system is structured as follows (following the International Standard Classification of Education ISCED) [80]: at the age of twelve, after primary education, students can choose between three tracks of education, each aiming at a different educational level in secondary school. They can go to pre-vocational secondary education (VMBO: ISCED 2), which takes four years and prepares for intermediate vocational education (MBO: ISCED ${ }_{3} C$ ). The second track in Dutch secondary education is higher general secondary education (HAVO), which takes five years and prepares for higher vocational education (HBO). The third track is pre-university education (VWO), which takes six years and prepares for studies at university level (academic bachelors and masters). The Dutch educational system is visualized in Figure 6. Students can arrange their educational pathways in many ways, by going up or down levels. The levels relate to the degree of complexity of the content of the programme. As pre-vocational secondary education is the lowest level, these students cannot fall back on a lower level of education. In addition to general education, in the Netherlands there is also 'special needs education', in which the content of the educational programmes designed can be adapted to students'specific needs.

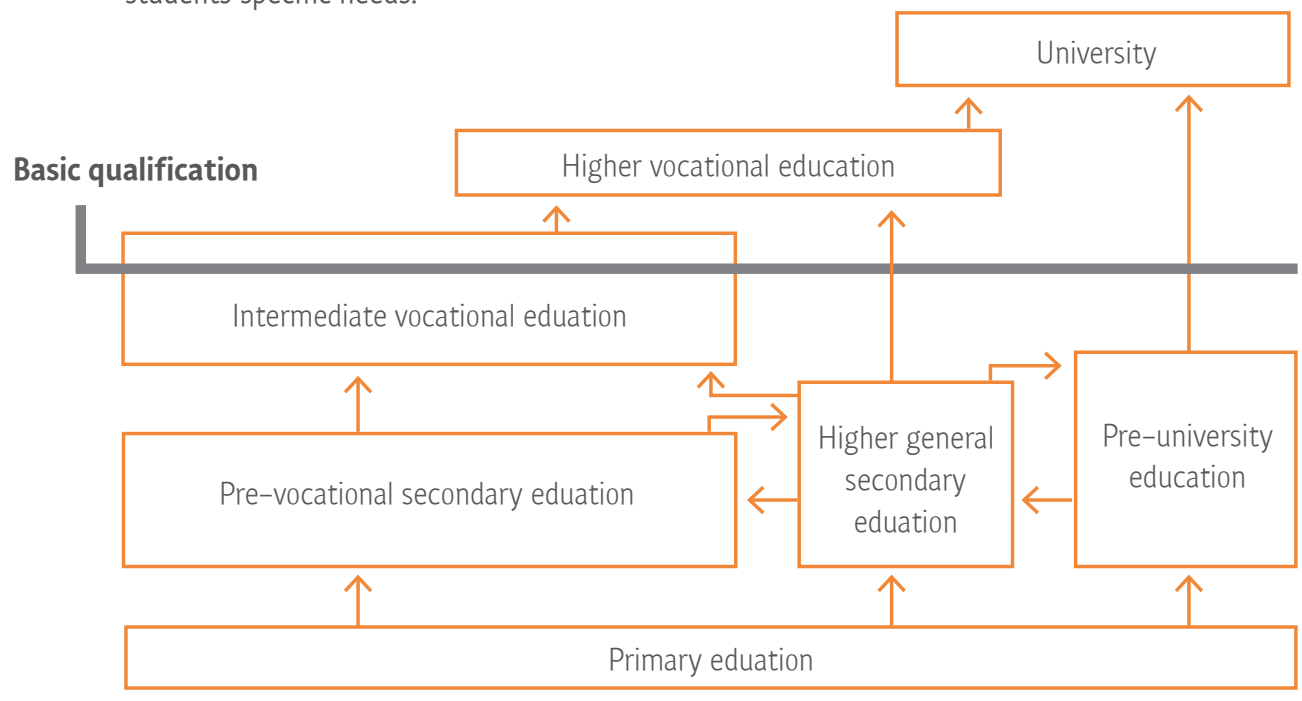

Figure 6: The Dutch general educational system. 
In the Netherlands, school absenteeism is most prevalent in pre-vocational secondary education $(8 \%)$, in comparison to higher general secondary education $(7.4 \%)$ and pre-university education (6.8\%) [53]. However, the main problem in pre-vocational secondary schools is early school dropout: on average three quarters of new early school dropouts registered each year come from pre-vocational secondary education [81]. School dropout occurs more frequently at this educational level because pre-vocational secondary students often have learning difficulties and demonstrate problems with planning, which prevent their catching up when falling behind $[82,83]$ as a result of missing education in case of (substantial) school absenteeism. As they cannot fall back on a lower level of education, school absenteeism has serious consequences for them because it will more often lead to school dropout. Early interventions for students with substantial school absenteeism is necessary, before learning delays occur. These interventions could contribute to prevention of early school dropout.

\subsection{The MASS intervention}

The MASS intervention has been developed in reaction to schools' concerns about the growing problem of students' absences from school, especially those absences resulting from sick reports. Schools encountered problems in approaching these students and in managing their absence. There were no suitable interventions nor agencies for addressing medical absenteeism among students.

\section{Challenges prior to the development of the intervention}

Addressing medical absenteeism came with some major challenges. These were considered prior to the development of the intervention. First of all, there is no national policy on school absenteeism due to sickness reports. Medical absence is considered to be authorized absence and therefore not an area of responsibility of compulsory education. The school attendance officer has no legal duty to enforce the law in case of excused absenteeism and lacks medical expertise to interpret medical absenteeism correctly. Medical absenteeism from secondary school results solely from parental sickness reporting and it is the school's authority to decide how to deal with it. Secondly, in practice schools often have problems discussing medical absenteeism with students and parents. This is because of the school's relationship of trust with the parents, and the lack of medical expertise. Thirdly, there is no school policy regarding counselling in case of student's medical absenteeism. In some countries schools decide that sick reports must always be verified by an appropriately licensed medical professional in order to be accepted, regardless of the length of absence. However, in the Netherlands, general practitioners and medical specialists are not allowed to make statements about medical conditions or learning abilities in a school setting. And there are no agreements between school and YHCPs on consultation with the YHCP and on their advising on the opportunities for participation in class and the necessary educational adjustments. Therefore, although YHCPs are available, their medical expertise is only utilised to a limited extent. Fourthly, there are no existing standards for an absence rate which should be acted upon. In 2006, Kearney used the term 'severe' absenteeism for an absence rate over 11 school days [84]. 'Frequent' school absenteeism has been defined as absence for more than $20 \%$ of the school year over three consecutive school terms [57] and is assumed to be problematic for a child's development. The term 'persistent absence' describes absence for more than $15 \%$ of the year. Hawkrigg and Payne [31] recommend that health professionals intervene as soon there is a pattern of 'sustained' school absence. As there are no standards for such criteria, criteria for 
inclusion of a student in the MASS trajectory for referral to the YHCP also have been defined within this study.

\section{The basic principles of the MASS intervention}

The MASS intervention consists of an integrated approach in a public health setting. MASS provides a clear framework in which schools, in direct collaboration with YHCPs, are able to reach students and their parents, discuss aspects of the student's medical absence, and design and monitor a management plan that aims to optimize students' health and maximize students' participation in school activities. A systematic routine is followed (Figure 7).

Step 1: School's policy and absence registration

\section{MASS-criteria}

Step 2: Referral of the student to the YHCP by school

Step 3: Consultation of student and parents with the YHCP and designing the management plan

Step 4: Monitoring the management plan by school and YHCP

Figure 7: Stages of the MASS-intervention

Step 1 School's policy: the school communicates with students and parents about the new policy in case of absenteeism because of medical reasons.

Step 2 Referral to the YHCP: students with extensive medical absence are identified by school by using well-defined threshold criteria: reported sick four times in 12 school weeks or more than six consecutive school days (MASS-criteria). Meeting the criteria always leads to a referral to the YHCP for student and parents.

Step 3 Consultation of student and parents with the YHCP: during the interview and medical assessment YHCPs look for biological, psychological and social factors that contribute to the students' medical absenteeism. The YHCP identifies whether there is a specific somatic or psychiatric diagnosis to account for the absence. If the diagnosis is clear the focus will be 
on optimising the (adherence to) treatment. In cases of frequent physical complaints and psychosocial problems with no clear organic diagnosis, the YHCP considers diagnostics, and looks for family-related and school-related factors, as well as health risk behaviours and lifestyle aspects that contribute to the physical complaints and psychosocial problems. If needed, the $\mathrm{YHCP}$ refers to a medical specialist or a psychosocial support network. A management plan is then designed together with student, parents and school, and with curative professionals, if applicable. This plan includes agreements on cure, care and attendance.

Step 4 Monitoring the management plan: school and YHCP monitor the execution of the management plan.

In summary, MASS aims to limit medical absenteeism by arranging appropriate care, educational adjustments and adequate support for students. The expectation is that through an approach like this the risk of dropout is reduced [31], thus improving the adult educational and health status and ultimately increasing the chances of healthier future generations too. By addressing medical absenteeism, YHCPs can contribute positively to the health, well-being and educational opportunities of young people and can break the downward spiral.

\subsection{The developmental process of MASS, accompanied by a practice- driven intervention study}

The development of the MASS-intervention started in December 2006 at the request of a pre-vocational secondary school in West Brabant. In a number of sessions headed by a project leader, the special education needs coordinator, and the school attendance officer and YHP who were linked to the school, discussed the most important issues that had to be dealt with (see paragraph 1.6). Based on this practice-based knowledge and their defined needs, the first version of the intervention was designed. In the school year $2007 / 2008$, a pilot study was carried out (chapter 2). In December 2009, the Regional Health Service West Brabant was awarded first prize for the intervention by the professional association youth health care because of its innovative character. In December 2010, the intervention was recognized as theoretically wellfounded and was included in the intervention database of the National Institute for Public Health and the Environment, RIVM [85]. Subsequently, the Dropout Committee West Brabant Region 34 offered to subsidize the implementation of the intervention in secondary schools, if schools were willing to co-finance with their own means. In the spring of 2010, ten general secondary schools registered. In school year 2010/2011, the refined version of the MASS intervention (as described in 1.6) was implemented. The refinements were based on the study outcomes and recommendations of the pilot study. This version was the basis for a request for funding of a practice-driven intervention study on a large scale. ZonMw, the Dutch Organization for Health Research and Development, provided funding for an intervention research over a period of two years. The study was limited to pre-vocational secondary schools because the intervention was described for this specific target group in the database. In school year 2011-2012, the implementation of MASS in seven pre-vocational secondary schools was accompanied by research on the health condition of pre-vocational secondary students with medical absence above threshold criteria, the MASS-criteria (chapter 3 ) and the effectiveness of the intervention (chapter 4).To study various implementation and dissemination aspects a variation on the MASS intervention was presented, as will be described in chapter 5 . Ten general secondary schools in the 
region West Brabant that had already indicated their interest in implementing the intervention, were asked to work with this variant. In addition at the request of ZonMw exploratory research into aspects of medical absenteeism in primary education and intermediate vocational education focused on adjusting the intervention to these new target groups. Three primary schools showed an interest in the study and were willing to cooperate. The inventory of their needs for addressing medical absenteeism was accompanied by a study on factors associated with extensive medical absenteeism in primary school children. This study is described in chapter 6. Meanwhile, at the request of all regional intermediate vocational schools and again with funding by the Dropout Committee West Brabant Region 34, the MASS intervention was developed and piloted for this level of education, after which a handbook was written. Subsequently, the adjusted MASS intervention was recognized as theoretically well-founded and was included in the intervention database of the National Institute for Public Health and the Environment, RIVM, in September 2013 [86]. Then, an explorative qualitative study among intermediate vocational students was performed as described in chapter 7 .

A practice-driven intervention study was performed to evaluate MASS. MASS was developed as a participative bottom-up approach and has been implemented in real-life conditions from the onset. Studies that accompany this kind of intervention development are referred to as practicedriven intervention study. Rots-de Vries et al. [87] already showed that when developing an intervention in this way, the understanding of the implementation process and the assurance that the intervention matches the needs of professionals are just as important as the assessment of outcomes. Moreover, as MASS is a public health intervention, it is also of great importance to look closely into motives for its adoption and into preconditions for implementation and dissemination in an early stage because the impact of a public health intervention is determined not only by its effectiveness but also by its dissemination, allowing for widespread adoption and implementation beyond the region of origin [88-90]. Our research on the MASS intervention covers all stages of a practice-driven intervention study from a first idea for an innovative approach in order to address a public health problem to maintenance of an intervention with indications of effectiveness throughout the system.

\subsection{General outline and aims of this thesis}

The chapters of this thesis deal with two main topics, namely, the development and evaluation of the MASS intervention in pre-vocational secondary education, on the one hand (part I, chapter $2,3,4$ ), and the research on factors related to successful implementation and dissemination as well as the potential of the MASS intervention for other target populations such as primary school children and intermediate vocational students, on the other (part II chapter 5, 6, 7).

\section{Part I. The development and evaluation of the MASS intervention in pre-vocational education}

In Chapter 2 the evaluation of the pilot study is presented. The first version of the intervention in one pre-vocational secondary school was tested in a pilot. A problem definition, population at risk, and underlying programme theory were designed. Moreover, evaluation outcomes were defined, based on practice-based knowledge and an inventory of practical needs, combined with sciencebased knowledge from a concise literature research. The research was based on a descriptive study at one school with one comparison school. Semi-structured interviews and questionnaires 
delivered information about the intervention's acceptability, feasibility and practicability both from professionals' and students' and parents' perspectives.

The objective of the study presented in Chapter 3 was to examine the health condition and characteristics of pre-vocational secondary students with extensive medical absenteeism who participated in the effectiveness study, from the biopsychosocial perspective of youth health care. Data were obtained from school files, medical assessments and Strengths and Difficulties Questionnaires (SDQs).

Chapter 4 reports on the results on the effectiveness of the intervention. A quantitative study was designed to evaluate the effectiveness of the intervention on the scale of medical absence at individual students' level, comparing with 'care as usual': is there a decline in the students' level of medical absenteeism following systematic identification and consistent referral to the YHCP of students with extensive medical absenteeism, compared to a situation in which this does not happen? The study had a quasi-experimental design, with 7 intervention schools that had applied the MASS intervention, and 7 control schools that had not applied the MASS intervention.

\section{Part II. Implementation and dissemination aspects of the MASS intervention, and adjustment to other target groups}

In Chapter 5, the barriers and facilitators experienced by schools in the implementation, dissemination and sustainability of the MASS intervention, were studied. A qualitative study was carried out in nine secondary schools by questioning school staff members who put the intervention into practice, using semi-structured interviews. The central questions were: what are the reasons that motivate school staff to pay attention to extensive medical absenteeism, what are their experiences in applying MASS, and what are facilitators and barriers when implementing MASS, including considerations of sustainability?

Chapter 6 deals with an explorative study on determinants that indicate an increased risk of medical absenteeism in primary school, ultimately aiming at adjusting and tailoring the intervention to suit this new target group. Files of primary school children with extensive medical absenteeism were studied in an explorative practice-based matched case-control study, to find answers to the question: What are the factors that indicate an increased risk of medical absenteeism in primary school?

Chapter 7 describes an explorative study on reasons for medical absenteeism by students visiting intermediate vocational schools. A qualitative study of students' perceptions of medical absenteeism was performed, using semi-structured interviews. The ultimate objective was to find leads for addressing medical absenteeism at this educational level. The following research questions were leading the interviews: what, according to the students, are their reasons for medical absence, and what factors, according to the students, influence their sickness reporting?

Chapter 8, the general discussion, reflects on the findings of the studies thematically, including implications for practice and suggestions for future research. Subsequently, the strengths and limitations of the study are presented and discussed. Followed by general reflections on the study findings in the light of the current policy climate. 


\section{References}

1. Wieske RCN, Nijhuis MC, Carmiggelt BC, Wagenaar-Fischer MM, Boere-Boonekamp MM. Preventive youth health care in 11 European countries: an exploratory analysis. Int I Public Health. 2012;57(3):637-641. doi:10.1007/ s00038-011-0305-1

2. Kuo AA, Inkelas M, Lotstein DS, Samson KM, Schoret EL, Halfon N. Rethinking Well-Child Care in the United States: An International Comparison. Pediatrics. 2006;118(4):1692-702. doi:10.1542/peds.2006-0620

3. Weitzman M, Klerman LV, Lamb G, Menary J, Alpert J. School Absence: a problem for the paediatrician. Pediatrics. $1982 ; 69: 739-64$.

4. Klerman LV. School absence - a health perspective. Pediatr Clin N Am. 1988;35:1253-69

5. Rumberger RW. Dropping out of middle school: A multilevel analysis of students and schools. Am Educ Res ). 1995:32(3):583-625.

6. Michaud P, Piot-Delbos I, Narring FMD. Silent Dropouts in Health Surveys: Are Nonrespondent Absent teenagers Different From Those Who Participate in School-Based Health Surveys? J Adolescent Health. 1998;22:326-33.

7. Eckstein Z, Wolpin KI. Why Youths Drop Out of High School: the Impact of Preferences, Opportunities, and Abilities. Econ Soc. 1999;67(6):125-1339. doi:10.1111/1468-0262.00081

8. Battin-Pearson S. Predictors of Early High School Dropout: A Test of Five Theories. I Educ Psychol. 2000 ;9(3):568-82. http://dx.doi.org/10.1037/0022-0663.92.3.568

9. Christenson SL, Thrulow ML. School Dropouts: Prevention Considerations, Interventions, and Challenges. Curr Dir Psychol Sci. 2004;13:36-39. doi:10.1111/j.0963-7214.2004.01301010.x

10. Kearney CA. Bridging the Gap Among Professionals Who Address Youths With School Absenteeism: Overview and Suggestions for Consensus. Prof Psychol-Res Pr. 2003:34(1):57-65. doi:10.1037/0735-7028.34.1.57

11. Kearney CA. School absenteeism and school refusal behavior in youth: A contemporary review. Clin Psychol Rev. 2008;28:451-471. doi:10.1016/j.cpr.2007.07.012

12. Rumberger RW. Why Students Drop Out of School and What Can be Done. Dropouts in America: How Severe is the Problem? What Do We Know about Intervention and Prevention? Harvard University. 2001;1-45. http:// civilrightsproject.ucla.edu/research/k-12-education/school-dropouts/why-students-drop-out-of-school-andwhat-can-be-done/rumberger-why-students-dropout-2001.pdf.

13. Rumberger RW. High School Dropouts: A Review of Issues and Evidence. Rev Educ Res. 1987;57(2):101-121. doi:10.3102/00346543057002101

14. Belfield C, Levin HM. The Price We Pay: Economic and Social Consequences of Inadequate Education. Book; Brookings Institution. 2007. http://www.brookings.edu/research/books/2007/pricewepay.

15. Nevala A-M, Hawley J, Stokes D, Slater K, Souto Otero M, Santos R, Duchemin C, Manoudi A. Reducing early school leaving in the EU. Brussels, (C) European Parliament, department of Education and Culture, Policy Department B: Structural and Cohesion Policies. 2011. https://www.spd.dcu.ie/site/edc/documents/ ESLfinalpublishedstudy-execsum.pdf.

16. The cost of exclusion. Counting the cost of youth disadvantage in the UK. London: Prince's Trust. 2002. http://www.princes-trust.org.uk/pdf/COE full report.pdf.

17. Coles B, Godfrey C, Keung A, Parrott S, Brädshaw J. Estimating the life-time cost of NEET: 16-18 year olds not in Education, Employment or Training. York: University of York. 2010. https://www.york.ac.uk/media/spsw/documents/research-and-publications/NEET Final Report July 2010 York.pdf.

18. Dale R. Network of Experts in Social Sciences of Education and training. Report on: Early School Leaving: Lessons from Research for Policy Makers. An independent expert report submitted to the European Commission. 2010. http://www.nesse.fr/nesse/activities/reports/activities/reports/early-school-leaving-report.

19. The approach to school drop-out. Policy in the Netherlands and the provisional figures of the 2009-2010 performance agreements. Ministry of Education, Culture and Science: The Hague, the Netherlands. 2011. http:// www.aanvalopschooluitval.nl/userfiles/file/2011029_OCW VSV_Cijferbijlage_UK_Internet.pdf.

20. Beckers ITT, Traag T. Met een startkwalificatie betere kansēn op ${ }^{-}$de arbeidsmarkt. Sociaaleconomische trends [Better opportunities in the labour market with a basic qualification. Socioeconomic Trends.]. The Hague: Statistics, the Netherlands. 2005;23-28. http://www.cbs.nl/NR/rdonlyres/31B62F76-21E2-40C8-86AB230589D4F9EA/o/2007k3v4p23art.pdf.

21. Dahlgren G, Whitehead M. European strategies for tackling social inequities in health: Levelling up part 2. World Health Organization Regional Office for Europe. 2006. http://www.euro.who.int/ data/assets/pdf file/o018/103824/E89384.pdf.

22. Mackenbach JP. Health Inequalities: Europe in Profile. Tackling Health Inequalities: Governing for Health. Rotterdam: European Commission. 2006. http://www.who.int/social_determinants/resources/european_inequalities.pdf.

23. Thrane C. Explaining educational-related inequalities in health: Mediation and moderator models. Soc Sci Med. 2006;62(2):467-78. doi:10.1016/j.socscimed.2005.06.010 
24. Basch CE. Healthier students are better learners: A missing link in school reforms to close the achievement gap. I Sch Health. 2011;81:593-598. doi:10.1111/j.1746-1561.2011.00632.x

25. Higgins CT, Lavin T, Metcalfe O. Health Impacts of Education: a review. The Institute of Public Health in Ireland. 2008. http://www.publichealth.ie/files/file/Health\%2olmpacts\%200\%20Education.pdf.

26. O'toole L, Kropf D. Learning for well-being. Changing paradigms, sharing our hearts, beginning a dialogue. Universal Education Foundation. 2012. http://www.eiesp.org/hosting/a/admin/files/L4WB\%20Booklet\%20V2-02\%20SMALL. pdf.

27. Suhrcke M, Paz Nievesk C de. The impact of health and health behaviours on educational outcomes in highincome countries: a review of the evidence. 2011. Copenhagen, WHO Regional Office for Europe. http://www.eurowho.int/en/publications/abstracts/impact-of-health-and-health-behaviours-on-educationaloutcomes-in-high-income-countries-the-a-review-of-the-evidence.

28. Woolf SH, Johnson RE, Phillips Ir RL, Philipsen M. Giving Everyone the Health of the Educated: An Examination Whether Social Change Would Save More Lives Than Medical Advances. I Public Health. 2007;97(4):679-83. doi:10.2105/AJPH.2005.084848

29. Freudenberg N, Ruglis ). Reframing school dropout as a public health issue. Prev Chronic Dis. 2007;4(4):1-11. http://www.cdc.gov/pcd/issues/2007/oct/07 0063.htm.

30. WHO World Health Organisation. Health for the world's adolescents. 2014. http://www.who.int/maternal_child adolescent/topics/adolescence/second-decade/en.

31. Hawkrigg S, Payne DN. Prolonged school non-attendance in adolescence: a practical approach. Arch Dis Child. 2014:99:954-957. doi:10.1136/archdischild-2013-304595

32. Ross CE, Wu C (1995) The links between education and health. Am Sociol Rev 60:719-745. doi:10.2307/2096319

33. Heesch MMJ van, Bosma H, Traag T, Otten F. Hospital admissions and school dropout: a retrospective cohort study of the 'selection hypothesis'. Eur | Public Health. 2011;22(4):550-555. doi:10.1093/eurpub/ckr129

34. Case A, Fertig A, Paxson C. The lasting impact of childhood health and circumstance. I Health Econ. 2005;24(2):365-389. doi:10.1016/j.jhealec0.2004.09.008

35. Mheen HD van de, Stronks K, Mackenbach JP. A Lifecourse Perspective on Socio-economic Inequalities in Health: The Influence of Childhood Socio-economic Conditions and Selection Processes. Sociol Health IIIn. 1998;20(5): 754-777. doi:10.1111/1467-9566.00128

36. Smyth E, McCoy S. Investing in Education: Combating Educational Disadvantage. The economic and social research institute Dublin: Dublin, Ireland. 2009. http://www.drugsandalcohol.ie/12326/.

37. Iton A. Tackling the root causes of health disparities through community capacity building. In Hofreichter R. (Ed.). Tackling health inequities through public health practice: A handbook for action (Chapter 7: pp. 115-136). Washington, DC and Lansing, Michigan: The national association of county \& city health officials. The Ingham county health department. 2006. http://www.naccho.org/pubs/product1.cfm?Product ID=11.

38. Haas SA. Health Selection and the Process of Social Stratification: The Effect of Childhood Health on Socioeconomic Attainment. J Health and Social Behavior 2006;47(4):339-54 doi:10.1177/002214650604700403

39. Droomers M, Schrijvers CTM, Mheen H van de, Mackenbach JP. Educational differences in leisure-time physical inactivity: a descriptive and explanatory study. Soc Sci Med. 1998;47(11):1665-76. doi:10.1016/ So277-9536(98)00272-X

40. Droomers M, Schrijvers CTM, Stronks K, Mheen D van de, Mackenbach JP. Educational differences in excessive alcohol consumption: the role of psychosocial and material stressors. Prev Med. 1999;29(1):1-10. doi:10.1006/ pmed.1999.0496

41. Cutler DM, Lleras-Muney A. Education and Health: Evaluating Theories and Evidence, National Poverty Center Working Paper Series Paper no. 12352. 2006. http://www.chrp.org/pdf/Cutler_Lieras-Muney_Education_ and Health.pdf.

42. Lundborg P. The Health Returns to Education: What Can We Learn from Twins? J Popul Econ. 2013;26(2):673701. doi:10.1007/s00148-012-0429-5

43. Kulhánová I, Hoffmann R, Eikemo TA, Menvielle G, Mackenbach JP. Educational inequalities in mortality by cause of death: first national data for the Netherlands. Int | Public Health. 2014;59(5):687-96. doi:10.1007/so0o38$014-0576-4$

44. Junger-Tas J. Diploma's en goed gedrag II: Preventie van antisociaal gedrag in het onderwijs. [Diplomas and good behaviour II: Prevention of antisocial behavior in education.]. The Hague: Dutch Ministry of Justice. 2002. http:// members.multimania.nl/veiligeschool/Preventie\%20van\%20antisociaa\%2ogedrag.pdf.

45. Traag T, Marie O, Velden R van de. Risicofactoren voor voortijdig schoolverlaten en jeugdcriminaliteit. [Risk factors for school dropout and juvenile delinquency.]. 2010;55-60. http://www.cbs.nl/NR/rdonlyres/131FADA3-2E22-4E519A91-6BB53E1E0895/o/2010k2b15P55art.pdf. 
46. Traag T, Valk J van der, Velden R van der, Vries R de, Wolbers M. Leren Loont! De overgang van school naar werk voor leerlingen van het VOCL '8g. [Is it worth learning! The transition from school to work for students of the secondary education cohort students '89.]. ROA-R-2004/6, Maastricht: ROA + CBS. 2004. http://pub.maastrichtuniversity.nl/6oca8861-763a-44C5-8650-33281bd46bfb.

47. Steeg M van der, Webbink D. Voortijdig schoolverlaten in Nederland: omvang, beleid en resultaten. [Dropping out from school in the Netherlands; magnitude, policy and results.]. CPB, Economic Policy Analysis: The Hague. 2006. http://www.cpb.nl/en/publication/dropping-out-school-netherlands-magnitude-policy-and-results.

48. Allen JMC. Voortijdig schoolverlaters: aanleiding en gevolg. [School dropouts: Causes and consequences.]. Research Centre for Education and the Labor Market (ROA), Maastricht University. Research report No. ROA-R-2010/9. 2010. http://roa.sbe.maastrichtuniversity.nl/roanew/.

49. Eimers T, Bekhuis H. Vroeg is nog niet voortijdig. [Early is not yet premature.]. Kenniscentrum Beroepsonderwijs Arbeidsmarkt (KBA). 2006. http://www.aanvalopschooluitval.nl/userfiles/file/Vroeg\%2ois\%2onog\%2oniet\%20 voortijdig.pdf.

50. Allensworth DD. Addressing the social determinants of health of children and youth: a role for SOPHE members. Health Educ Behav. 2011;38(4):331-8. doi:10.1177/1090198111417709

51. Murray NL, Franzini L, Marko D, Lupo P, Garza I, Linder S. (2006). Education and health: A review and assessment. Appendix E. In Task Force on Access to Health Care in Texas (Eds.), Code red: The critical condition of health in Texas. http://www.coderedtexas.org/files/Appendix E.pdf

52. Schrijvers C, Storm I. Naar een integrale aanpak van Cezondheidsachterstanden. Een beschrijving van beleidsmaatregelen binnen en buiten de volksgezondheidssector. [Towards an integrated approach for tackling health inequalities. A description of policy measures inside and outside the public health sector.]. The Netherlands: Bilthoven; RIVM (National Institute for Public Health and the Environment) rapport 270171001. 2009. http:// www.rivm.nl/bibliotheek/rapporten/270171001.pdf.

53. NIPO het marktonderzoeksinstituut. Rapport: Schoolverzuim in het Voortgezet Onderwijs. [Report on school absenteeism in secondary school.]. Amsterdam. 2002. http://www.tns-nipo.com/pages/persvannipo/pdf/ schoolverzuimo3.pdf.

54. Eaton DK, Brener N, Kann LK. Associations of health risk behaviors with school absenteeism. Does having permission for the absence make a difference? I Sch Health. 2008;78(4):223-9. doi:10.1111/j.1746-1561.2008.00290.x

55. Scottish Executive National Statistics. Results of pupil attendance and absence for session 2006/7. Edinburgh: The Scottish Government, Statistics. 2007. http://www.scotland.gov.uk/Publications/2013/12/4199/17.

56. Lenzen C FG, Jentzsch A, Kaess M, Parzer P, Carli V, Wasserman D, et al. Schulabsentismus in Deutschland - die Prävalenz von entschuldigten und unentschuldigten Fehlzeiten und ihre Korrelation mit emotionalen und Verhaltensauffälligkeiten. [School absenteeism in Germany: prevalence of excused and unexcused absenteeism and its correlation with emotional and behavioural problems.]. Prax Kinderpsychol K. 2013;62 (8):570-82. doi:http://www.vr-elibrary.de/doi/abs/10.13109/prkk.2013.62.8.570

57. Iones R, Hoare P, Elton R, Dunhille Z, Scharpe M. Frequent medical absences in secondary school students: survey and case-control study. Arch Dis Child. 2009;94:763-67. doi:10.1136/adc.2008.140962

58. Pan L, Sherry B, Park S, Blanck HM. The Association of Obesity and School Absenteeism Attributed to Illness or Injury Among Adolescents in the United States, 2009. I Adolesc Health. 2013;52(1):64-9. doi:http://dx.doi. org/10.1016/j.jadohealth.2012.04.003

59. Rappaport EB, Daskalakis C, Andrel J. Obesity and other predictors of absenteeism in Philadelphia school children. I Sch Health. 2011;81(6):341-4. doi:10.1111/j.1746-1561.2011.00599.x

6o. Vaughn, 2013, Baxter SD, Royer JA, Hardin JW, Guinn CH, Devlin CM. The relationship of school absenteeism with body mass index, academic achievement, and socioeconomic status among fourth-grade children. J Sch Health. 2011;81(7):417-23. doi:10.1111/j.1746-1561.2011.00610.x

61. Mittendorfer-Rutz E, Hensing G, Westerlund H, Backheden M, Hammarström A. Determinants in adolescence for adult sickness absence in women and men: a 26 -year follow-up of a prospective population based cohort (Northern Swedish cohort). BMC Public Health. 2013;13(1):75. doi:10.1186/1471-2458-13-75

62. De leugdgezondheidszorg beter in positie. [Youth health care in better position.]. Utrecht: Inspectie voor de Gezondheidszorg [Healthcare Inspectorate], 2014. http://www.rijksoverheid.nl/documenten-en-publicaties/ rapporten/2014/11/06/de-jeugdgezondheidszorg-beter-in-positie.html.

63. Samenwerkend Toezicht Jeugd. Vormgeving zorg en ondersteuning aan gezinnen met geringe sociale redzaamheid. [Cooperating inspection youth. Shaping care and support to families with little social resilience.]. Ministerie OCW. [Ministry of Education, Culture and Science.]. The Hague, the Netherlands. 2014. http://www.rijksoverheid. nl/documenten-en-publicaties/rapporten/2014/05/15/vormgeving-zorg-en-ondersteuning-aan-gezinnen-metgeringe-sociale-redzaamheid.html.

64. Demyttenaere K, Bruffaerts R, Posada-Villa J, et al. Prevalence, severity, and unmet need for treatment of mental disorders in the World. Health Organization World Mental Health Surveys. The WHO World Mental Health Survey Consortium. Jama. 2004;291:2581-90. doi:10.1001/jama.291.21.2581

65. Theil A, Verkerk PH, Buiting E. Snel terug naar school. [Quickly back to school.]. Medisch Contact. 2007:62:31-32.

66. Syurina EV, Hens K, Feron FJM. Literature Review: Use of Family History for Primary Paediatric Care as the Next 
Step Towards use of Cenomics in Healthcare. Curr Pediatric Rev. 2013;9(4): 353-372. doi:10.2174/1573396309 04131223112559

67. Vander Stoep A, Weiss NS, McKnight B, Beresford SAA, Cohen P. Which measure of adolescent psychiatric disorder - diagnosis, number of symptoms, or adaptive functioning - best predicts adverse young adult outcomes? | Epidemiol Commun H. 2002;56:56-65. doi:10.1136/jech.56.1.56

68. Heetman I, Bosma H, Kuiper G, Feron F. Preventive healthcare surveillance can detect emerging behavioural problems that are related to later school dropouts. Acta Paedr. 2015;104(1):e27-31. doi:10.1111/apa.12839

69. Mould D. Models for disease progression: new approaches and uses. Clin Pharmacol Ther. 2012;92(1):125-131. doi:10.1038/clpt.2012.53

70. Snyderman R, Langheier J. Prospective health care: the second transformation of medicine. Genome Biol. 2006;7:104. doi:10.1186/gb-2006-7-2-104

71. Engel GL. The need for a new medical model: a challenge for biomedicine. Science. 1977;196(4286):129-36. doi:10.1126/science.847460

72. Engel GL. The need for a new medical model: A challenge for biomedicine. Fam Syst Med. 1992;10(3):317-331 doi:http://dx.doi.org/10.1037/hoo8g26o

73. Burns CE, et al. Pediatric primary care. Book. 2012. Saunders (5th edition).

74. Caspi A, Moffitt TE, Newman DL, et al. Behavioral Observations at Age 3 Years Predict Adult Psychiatric Disorders: Longitudinal Evidence From a Birth Cohort. Arch Gen Psychiat. 1996;53(11):1033-1042. doi:10.1001/ archpsyc.1996.01830110071009

75. Hofstra MB, Ende I van der, Verhulst FC. Adolescents' self-reported problems as predictors of psychopathology in adulthood: 10-year follow-up study. Br | Psychiatry. 2001;179:203-9.

76. Kessler R, Amminger GP, Aguilar-Gaxiola S, Alonso I, Lee S, Ustin TB. Age of onset of mental disorders: a review of recent literature. Curr Opin Psychiatr. 2007;20(4):359-64. doi:10.1097/YCO.obo13e32816ebc8c

77. Mokkink LB, Lee JH van der, Grootenhuis MA, Offringa M, Praag BMS van, Heymans HSA. Omvang en gevolgen van chronische aandoeningen bij kinderen. [Scale and impact of chronic diseases in children.]. Tijdschrift Kindergeneeskunde. 2007:75:154-58. doi:10.1007/BFo3061684

78. Eiser C. Growing up with a chronic disease: the impact on children and their families. London: Jessica Kingsley Publishers. 1993.

79. Daponte A, Bernal M, Bolívar I, Mateo I, Salmi L-R, Barsanti S, et al. Criteria for implementing interventions to reduce health inequalities in primary care settings in European regions. Eur J Pub Health. 2014;24(6):979-89. doi:10.1093/eurpub/ckuo44

80. UNESCO Institute for Statistics, Canada. ISCED Fields of Education and Training 2013 (ISCED-F 2013). United Nations International Family of Economic and Social Classifications. Manual on the International Standard Classification of Education (ISCED). Re-edition. (C)UNESCO-UIS Montreal, Canada. 2014. http://www.uis.unesco. org/Education/Pages/international-standard-classification-of-education.aspx. doi:http://dx.doi.org/10.15220/97892-9189-150-4-en

81. Nieuwe voortijdig schoolverlaters. Convenantjaar 2011-2012. Voorlopige cijfers. Bijlage vsv-brief 2010. [New early school leavers. Covenant year 2011-2012. Provisional figures. Appendix ESL-letter 2010.] Dutch Ministry of Education, Culture and Science. Dropout Explorer. National perspective of school dropouts. The Hague, the Netherlands. 2013. http://www.rijksoverheid.nl/documenten-en-publicaties/kamerstukken/2010/02/17/bijlagevsv-cijfers-2010.html.

82. Groeneveld MJ, Steensel KM van, Herben B, et al. Kenmerkend vmbo: een vergelijkend onderzoek naar de kenmerken van vmbo-leerlingen en de 'generatie Einstein'. [Characteristics pre-vocational secondary education: a comparative study of the characteristics of pre-vocational secondary students and the 'Einstein generation'.]. Hilversum: Hiteq, 2008. http://www.hiteq.org/Hiteq/Downloads/Publicaties\%2ogeheel/Kenmerkend\%20vmbo\%2ombo\%20havo\%20 en\%2ovwo.pdf.

83. Havas J, Bosma H, Spreeuwenberg C, Feron FJ. Mental health problems of Dutch adolescents: the association with adolescents' and their parents' educational level. Eur I Public Health. 2009;20(3):258-64. doi:10.1093/eurpub/ ckp172

84. Kearney CA, Bensaheb A. School Absenteeism and School Refusal Behavior: A Review and Suggestions for SchoolBased Health Professionals. I Sch Health. 2006;76(1):3-7. doi:10.1111/j.1746-1561.2006.0006o.x

85. Vanneste YTM. Interventie M@ZL op het VMBO: Erkenning als 'theoretisch goed onderbouwd'. [MASS intervention in pre-vocational secondary education: Qualification recognised as 'scientific rigour at the core of theory'.]. 2010. National Institute for Public Health and the Environment, RIVM. http://www.nji.nl/nl/Databanken/DatabankEffectieve-Jeugdinterventies/MZL-Medische-Advisering-Ziek-gemelde-Leerling.

86. Vanneste YTM. Interventie M@ZL op het MBO: Erkenning als 'theoretisch goed onderbouwd'. [MASS intervention in intermediate vocational education: Qualification recognised as 'scientific rigour at the core of theory'.]. 2013. National Institute for Public Health and the Environment, RIVM. http://www.loketgezondleven.nl/i-database/ interventies $/ \mathrm{m} / 1402355 /$.

87. Rots-de Vries MC, Garretsen HFL, Stronks K, Goor LAM van de. Rich evidence for poor families. Exploring the potential of practice-driven intervention research in Preventive Child Healthcare. Thesis. 2010. 
88. Nutbeam D. Evaluating health promotion: progress, problems and solutions. Health Promot Int. 1998;13(1):27-44. doi:10.1093/heapro/13.1.27

89. Clasgow RE, Vogt TM, Boles SM. Evaluating the public health impact of health promotion interventions: the RE-AIM framework. Am / Public Health. 1999;89(g):1322-1327. doi:10.2105/AJPH.89.9.1322

90. Rogers EM. Diffusion of Innovations. 2003. http://teddykw2.files.wordpress.com/2012/o7/everett-m-rogersdiffusion-of-innovations.pdf. 



\section{Chapter 2}

\section{Chapter 2: Medical Advice for Sick-reported Students (MASS) in secondary school by the youth health care physician: development of an intervention}

\section{YTM Vanneste, MC Rots-de Vries, LAM van de Goor, FJM Feron.}

\section{Abstract}

Objective: Socioeconomic health differences can be reduced by decreasing health risks and increasing educational opportunities. In the latter substantial school absenteeism is a crucial risk factor. By addressing school absenteeism due to sickness reporting, so-called medical absenteeism, youth health care makes a positive contribution to health, welfare and educational opportunities for young people and thereby to reduction of socioeconomic health differences. The Regional Public Health Service (RPHS) West Brabant has developed the MASS intervention (abbreviation for: Medical Advice for Sick-reported Students) to address school medical absenteeism among secondary school students. The aims of the study were to evaluate the intervention, and gather information about the intervention's acceptability, feasibility and practicability both from professionals', students' and parents' perspectives.

Method: A pilot study using a descriptive and non-experimental design with an intervention and control school, and semi-structured interviews and questionnaires.

Results: A description of MASS and data from the pilot study are presented. Almost all students $(98 \%)$ that missed a substantial number of schooldays due to sickness reporting had been reached by the youth health care physician or school attendance officer. Half of the latter group showed physical symptoms; for many students psychosocial problems appeared to be the main cause for health-related absenteeism. The size of medical absence decreased in $63 \%$ of the students receiving counselling, while on the school level the absence rate was reduced with 1.1 school days per student per year.

Conclusion: It is concluded that MASS is a promising intervention for reducing medical absenteeism in secondary school; leads for further development are therefore given.

Key words: regional public health service, youth health care, youth health care physician, medical absenteeism in secondary school, drop out, school absenteeism.

Published: TSG. 2012;90(7):412-19. 


\section{Introduction}

School absenteeism is subdivided into excused and unexcused absence. The most common form of excused absenteeism is absence due to sickness reporting. Research has shown that the total school absenteeism percentage amounts to $7.9 \%$ (when 'checking in class', $7.9 \%$ of the students is absent at the moment of taking attendance). Sickness is the reported cause of absence for almost half $(49 \%)$ of these students [1].

Since 1990, (inter)national attention has been paid to reducing the numbers of early school dropouts (leaving school without a diploma) and to the relation between early dropping out and school absenteeism. Extensive school absenteeism can cause a student's (learning) development to stagnate, which may cause discharging into a lower level of education or dropping out before receiving a diploma. Determinants of early dropping out are school absenteeism and poor school performance [2-10]. Recognition of absenteeism leads to early detection of children at risk of dropping out of school prematurely [2].

A (high) school diploma provides a better starting point in society: a better chance at finding a permanent skilled job and one's place in society, with a smaller chance at social exclusion and development of criminality [11]. Additionally, education is a good predictor of health [12-14], and a lower level of education is strongly associated with higher mortality rates, increased risk behaviour (smoking, obesity, lack of exercise) and a higher prevalence of chronic health issues and common mental problems [15]. Literature suggests that investing in improvement of level of education can save more lives than medical progress [16]. Moreover, a causal relation can be found between health and education: health and well-being influence school performance [17] and early dropping out. Therefore, optimizing education opportunities for all youths is a socially relevant responsibility of public health care.

Literature indicates both the individual as well as social and economic significance of pursuing good education $[18,19]$. The EU countries entered into agreements on reducing the amount of early school dropouts in Lisbon, 2000. In the Netherlands, this has led to the introduction of the start qualification (a higher general secondary education or pre-university secondary education diploma or an intermediate vocational education diploma starting at level 2) and the 'Attack on dropout': a set of additional measures to fight school dropouts actively. The measures mainly concern 'keeping youths focused' by inspection of illegitimate school absenteeism. Until now, there has not been paid much attention for school absenteeism reported as sickness from politics. It is true that many students may be sick sometimes and unable to come to school. However, if the absenteeism is substantial and development threatens to stagnate, then there is a request for help and thus a task for the social medical sector.

\section{Difficulties with regard to addressing medical absenteeism at school}

Extensive medical absenteeism at school often remains unnoticed by schools because the amount of attention paid to adequate data aggregation on student level is insufficient. This obstructs 
the possibility to communicate with student and parents early on when extensive or frequent absenteeism after report of sickness occurs. In practice, it becomes apparent that schools often have problems discussing medical absenteeism with the student and parents. This is because of the school's relationship of trust with the parents and the lack of medical insight and possibilities for consultation with practitioners. Although the youth health care physician (YHCP) has medical expertise, this is only utilized up to a limited extent. On the one hand, this is the case because visiting the youth health care $(\mathrm{YHC})$ is without obligations and because of this certain students remain out of reach. On the other hand it is caused by the fact that there have not been made any agreements between the YHC, the schools and the student/parents on advising about possibilities for class participation and desired adjustments and the mutual collaboration of the school in this. This is of great importance for efficient absence counselling. The school attendance officer has no legal duty to enforce the law in case of excused absenteeism and lacks medical expertise to interpret medical absenteeism correctly.

The approach of medical absenteeism has been a priority for the YHC departments of the Regional Public Health Service (RPHS). The West-Brabant RPHS has developed an intervention to signal and reach students with substantial medical absence. The intervention has been the subject of a pilot study.

In the school year 2007/2008, a pilot study was carried out with the MASS intervention at two school locations of a pre-vocational secondary education school: the main location (759 students) and the care location ( 283 students). The evaluation of the pilot study was aimed at the reach, the execution, the client satisfaction and the intended effects of the intervention. In the process evaluation, the progress of the execution and the extent of the intervention have been researched. In the impact assessment, the decrease of the extent of medical absenteeism at school level and student level has been studied.

\section{Research questions}

The main issues of the pilot study were:

- With regard to the extent and the (reached) target group:

o What is the extent of the intervention and what are the characteristics of the target group in reach?

0 What are the YHCP's findings and actions?

o What are the school attendance officer's actions?

- With regard to the execution of the intervention:

0 How do the four executing parties value the MASS intervention?

o What difficulties are being experienced in the execution of M@ZL?

- With regard to the client satisfaction:

0 How satisfied are students and their parents with the attention paid to medical absenteeism and the consultations with the YHCP?

- With regard to the effects:

0 Has medical absenteeism decreased at school level?

o Has medical absenteeism decreased at individual level? 


\section{Description of the MASS intervention}

In 2007 and 2008, MASS (Medical Advice for Sick-reported Students) was developed by RPHS West-Brabant, the municipal school attendance service for compulsory education in West Brabant and a regional pre-vocational secondary school. MASS represents an integral medical absenteeism school policy. This policy incorporates a clear positioning of the three parties involved, embedment of medical absenteeism counselling in the school's care structure and criteria for involvement of the YHCP.

MASS aims to reduce medical absenteeism and, in extension to that, early dropping out of school. This is firstly realized through early detection of above average medical absenteeism among students. In addition, these students are brought into contact with the YHCP on time. Intervention can only be realized correctly by determining the reasons for a sick report. This way, accurate care can be provided and assistance can be employed, which will limit the medical absenteeism. This is where the added value of the YHCP becomes apparent.

The school includes in its regulations that the YHCP acts as medical advisor in case of substantial medical absenteeism. The school registers the sickness reports and aggregates the present sickness reports on student level. Criteria for referring a student to the YHCP are medical absenteeism for more than six consecutive school days or more than 16 hours per four school weeks, in somewhat isolated periods (MASS-criteria). The YHCP can judge health complaints and consult with fellow practitioners in primary and secondary health care. In addition, as general specialist of the child, the YHCP pays attention to the interaction between the child and its environment. In cooperation with parents and student, the YHCP constructs a problem analysis of the reasons for absence, pronounces on'the possibility to either partly or completely participate in classes' from the first consultation on, and draws up a reintegration advice if necessary. Intended counselling or actions from within the school can be part of this advice. This is to be agreed upon with the school. The advice will, if desired, be discussed in the school's Care Advice Team (CAT) and be considered in the school counselling. If necessary, the YHCP will arrange (para) medical care or external counselling for the student.

If parents and student do not want to provide information, collaborate on solving or reducing absenteeism, or if they do not show up at YHCP's consultation hour, the school is advised to change the 'excused' medical absenteeism into 'possibly illegitimate absence' and to sign up the student with the school attendance officer. Subsequently the school attendance officer is authorized to enforce the principles of compulsory education.

In addition, the RPHS provides the school attendance officer with the opportunity to consult an independent - not employed at the school in question - YHCP. This way, the YHCP at the concerning school can avoid a role conflict.

The school, the YHCP and the school attendance officer each have their own distinguished responsibilities and tasks regarding the execution (see figure 1). The school is the pivot: it identifies students with extensive medical absenteeism and refers these students to the YHCP or the school attendance officer. Subsequently, after entering the absenteeism course the student is monitored with regard to the extent of the medical absence. The school attendance officer enforces the procedure for medical absenteeism which is reported as 'possibly illegitimate' by the 
school. Binding agreements will be made between both the RPHS and the local authorities and the school.

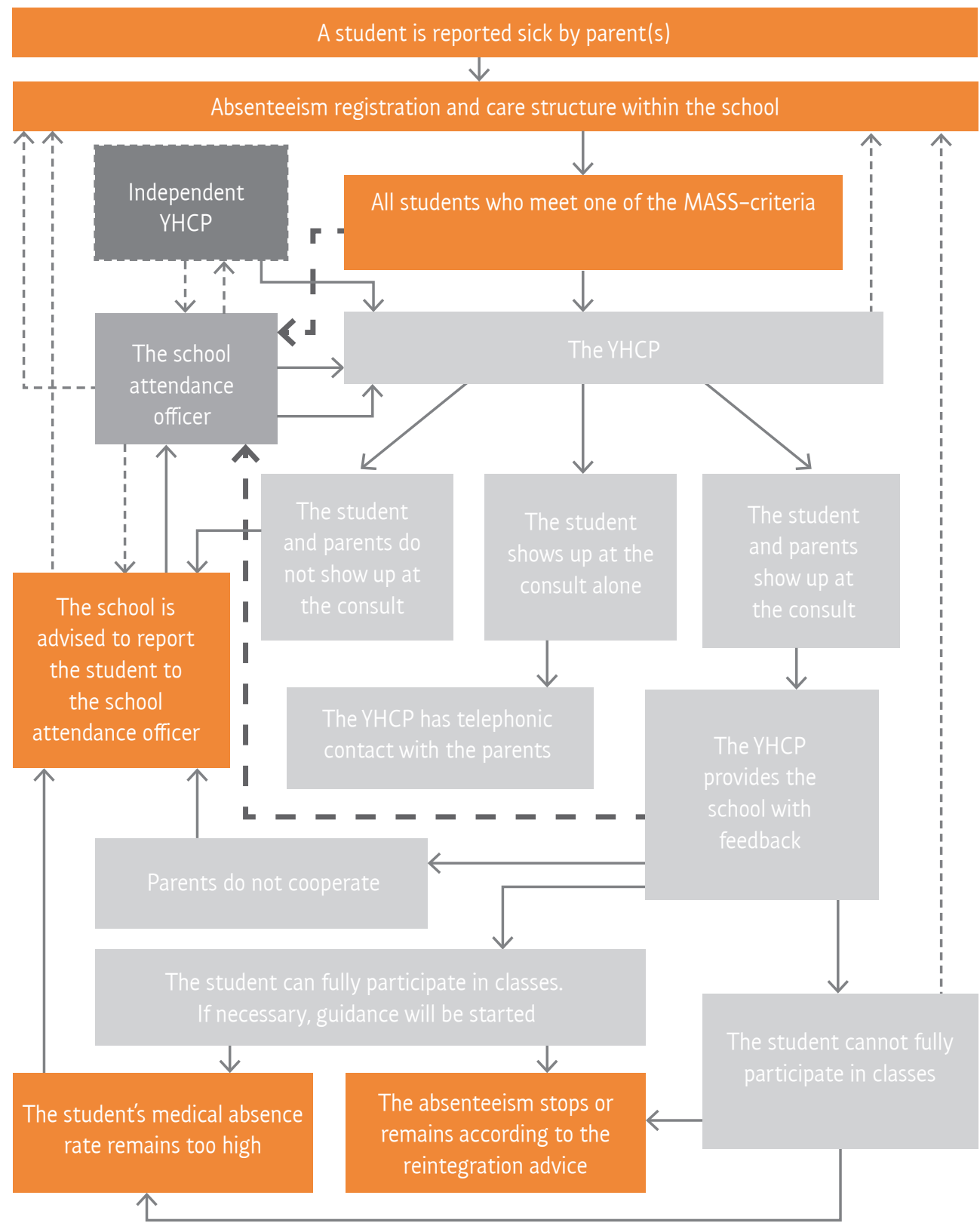

Legend $\quad$ Report to/result $\longrightarrow$ Feedback $----\rightarrow$ In copy to $\quad \longrightarrow \rightarrow$ 


\section{Research plan}

Several research methods have been utilized (see Table 1). To gain insight into the process of the intervention, semi-structured interviews have been conducted with the $\mathrm{YHCP}$, the school contact person, and the school attendance officer [20]. Additionally, the YHCP has filled out a registration form on each reached student. Afterwards, data (student characteristics and undertaken actions) from the students in question were inquired of the school and the school attendance officer. A questionnaire in which parents and students were asked to respond to some propositions concerning the intervention was developed to gain an impression of the degree of client satisfaction. In order to determine the extent of medical absenteeism at school level, data on the number of periods of sick reports of all students were collected both at the intervention school and the control school (a pre-vocational secondary school in the same region that was not applying MASS) afterwards. Data were collected from the school year of 2006-2007 (the school year prior to the introduction, the baseline) and the school year of 2008-2009 (the school year following the start of the intervention).

To examine if and to what extent medical absenteeism had been reduced regarding individual students receiving medical absenteeism counselling, the percentage of students meeting with one of the criteria for medical absenteeism counselling according to the MASS intervention at two months and four months after the start of the course was taken into account.

Table 1. Research methods

\begin{tabular}{|c|c|c|}
\hline Collected data & Research group & Method of data collection \\
\hline Process evaluation & $\begin{array}{l}\text { School contact person, YHCP, } \\
\text { school attendance officer and } \\
\text { independent YHCP }\end{array}$ & Semi-structured interviews \\
\hline Reach & Students & $\begin{array}{l}\text { YHC dossier, student tracking } \\
\text { system school, registration } \\
\text { school attendance officer and } \\
\text { registration form research }\end{array}$ \\
\hline Client satisfaction & Parents and students & Questionnaire \\
\hline $\begin{array}{l}\text { Effects measurement extent } \\
\text { absenteeism student level }\end{array}$ & Students & $\begin{array}{l}\text { Absence registration school } \\
\text { and registration form research }\end{array}$ \\
\hline $\begin{array}{l}\text { Effects measurement extent } \\
\text { absenteeism school level }\end{array}$ & $\begin{array}{l}\text { Intervention and control } \\
\text { school }\end{array}$ & Absence registration schools \\
\hline
\end{tabular}




\section{Research results}

\section{Reach and characteristics reached target group}

Of the total school population ( $n=1042), 66$ students $(6.3 \%)$, whereof $52(79 \%)$ female and 14 $(21 \%)$ male students, entered the course for medical absenteeism counselling in a year's time. The total school population existed of $55 \%$ male and $45 \%$ female students. The third year had a significantly higher percentage of students enrolled for the course than year 1, 2 and 4. Out of 66 students, 52 students were reached by the YHCP, and 12 students were reached only by the school attendance officer. Two students were not reached. Four of the students reached by the YHCP were enrolled by the school twice. This resulted in a total of 56 consultations concerning 52 students.

\section{Findings and actions of the YHCP}

Half of the students indicated that physical complaints caused the medical absenteeism. A large part of all of the students reached by the YHCP turned out to have multiple psychosocial issues at the moment of consultation, in which the report of absence was considered to be rooted. The top 4 of most commonly occurring issues is: physical health issues $(50 \%)$, issues in the domestic situation $(41 \%)$, internalizing behaviour issues $(30 \%)$ and parents' attitude towards dealing with complaints in relation to medical absenteeism, which resulted in a low absenteeism threshold (23\%) (See Table 2).

Table 2. Nature of the issues observed by the YHCP during the consult as percentage of the number of consults $(n=56)$

\begin{tabular}{|l|c|}
\hline Nature of the issues & $\begin{array}{c}\text { Observed by YHCP as percentage } \\
\text { of the number of consults }\end{array}$ \\
\hline Physical health problem & $50 \%$ \\
\hline Issues concerning the home situation & $41 \%$ \\
\hline Internalising behavioural problem & $30 \%$ \\
\hline Attitude parents & $23 \%$ \\
\hline Issues related to lifestyle & $18 \%$ \\
\hline Issue concerning major event & $14 \%$ \\
\hline Externalising behavioural problem & $11 \%$ \\
\hline Issue concerning contact with students & $11 \%$ \\
\hline Other issues & $9 \%$ \\
\hline No enjoyment & $4 \%$ \\
\hline Issue concerning contact with teachers & $0 \%$ \\
\hline
\end{tabular}


After issue analysis, the YHCP judged the possibility of class participation from the moment of consultation on, despite complaints or issues. 43 students were considered able to attend classes regularly. The other 9 students did have reasons which (partially) disabled them to attend classes regularly. In these cases, the $\mathrm{YHCP}$, if possible in consultation with the practitioner, constructed a reintegration advice. The reintegration advice consisted of agreements on the build-up of class participation until full reintegration was completed. After consultations, the YHCP had follow-up consultations with 10 students; regarding 8 students, the YHCP advised the school to deal with the school related issues.

\section{The actions of the school attendance officer}

The school attendance officer was in contact with 41 of the 66 students. Out of these 41 students, 12 students were registered with the school attendance officer by the school after failing to show up for the consult with the YHCP. The other 19 students were signed up by the school because they continued to skip (too many) classes after the advice of the YHCP. The school attendance officer gave warnings 23 times, requested independent medical advice 9 times and drew up a fine for refusal of collaboration by parents and student 9 times.

\section{Client satisfaction}

Out of the 66 students and their parents invited to a consult with the YHCP, 40 students $(61 \%)$ and $23(35 \%)$ parents filled out a client satisfaction questionnaire. 32 students and 17 parents of them had been present at the consult; these students and parents only could judge the consult. $84 \%$ of all respondents, $(n=63)$, indicated to consider it important that the school pays attention to medical absenteeism counselling. According to almost half of them, the YHCP has to play an important role in this process (see Table 3).

Table 3. Results of the client satisfaction measurement of all respondents: students and their parents $(n=63)$

\begin{tabular}{|c|c|c|c|}
\hline & $\begin{array}{l}\text { (Strongly) } \\
\text { disagree }\end{array}$ & Neutral & $\begin{array}{l}\text { (Strongly) } \\
\text { agree }\end{array}$ \\
\hline \multicolumn{4}{|l|}{ Value medical absenteeism counselling: } \\
\hline It is important for my child to go to school daily. & ०\% & $3 \%$ & $97 \%$ \\
\hline $\begin{array}{l}\text { It is important for the school to pay attention to } \\
\text { medical absenteeism counselling }\end{array}$ & $3 \%$ & $13 \%$ & $84 \%$ \\
\hline $\begin{array}{l}\text { It is important for the school to have a talk with } \\
\text { me about the medical absenteeism }\end{array}$ & $16 \%$ & $45 \%$ & $39 \%$ \\
\hline \multicolumn{4}{|l|}{ Cooperation: } \\
\hline $\begin{array}{l}\text { Good cooperation between the YHCP and the } \\
\text { school is important }\end{array}$ & $3 \%$ & $13 \%$ & $67 \%$ \\
\hline $\begin{array}{l}\text { Good cooperation between the YHCP and GP } \\
\text { and own specialist is important }\end{array}$ & $10 \%$ & $40 \%$ & $50 \%$ \\
\hline $\begin{array}{l}\text { Good cooperation between the YHCP and the } \\
\text { school attendance officer is important }\end{array}$ & $5 \%$ & $39 \%$ & $56 \%$ \\
\hline
\end{tabular}


Of those who were present at the consult with the YHCP, $(n=49)$, the majority was satisfied with the consult, and $33 \%$ acknowledged that medical absenteeism counselling benefits from the contact with the YHCP (see Table 4).

Table 4. Results of the client satisfaction measurement of all respondents present at the YHCP's consult $(n=49)$

\begin{tabular}{|c|c|c|c|}
\hline & $\begin{array}{l}\text { (Strongly) } \\
\text { disagree }\end{array}$ & Neutral & $\begin{array}{l}\text { (Strongly) } \\
\text { agree }\end{array}$ \\
\hline \multicolumn{4}{|l|}{ Approach of the YHCP: } \\
\hline $\begin{array}{l}\text { Satisfied with the way the YHCP } \\
\text { treated me }\end{array}$ & $19 \%$ & $23 \%$ & $58 \%$ \\
\hline $\begin{array}{l}\text { Personal opinion was taken into } \\
\text { account }\end{array}$ & $22 \%$ & $29 \%$ & $49 \%$ \\
\hline $\begin{array}{l}\text { The opportunities for asking questions } \\
\text { were sufficient }\end{array}$ & $4 \%$ & $21 \%$ & $75 \%$ \\
\hline \multicolumn{4}{|l|}{ Value medical absenteeism counselling: } \\
\hline $\begin{array}{l}\text { The contact with the YHCP was } \\
\text { rewarding }\end{array}$ & $27 \%$ & $40 \%$ & $33 \%$ \\
\hline \multicolumn{4}{|l|}{ Information: } \\
\hline $\begin{array}{l}\text { Have been well attended to by the } \\
\text { YHCP }\end{array}$ & $27 \%$ & $38 \%$ & $35 \%$ \\
\hline Have taken the YHCP's advice & $15 \%$ & $43 \%$ & $43 \%$ \\
\hline \multicolumn{4}{|l|}{ Cooperation: } \\
\hline $\begin{array}{l}\text { I was able to discuss my questions } \\
\text { and/or concerns about health with } \\
\text { the YHCP }\end{array}$ & $15 \%$ & $34 \%$ & $51 \%$ \\
\hline
\end{tabular}

\section{Impact assessment school level and student level}

At school level a decrease in medical absenteeism of 1.1 sickness days per student per school year (from 8.4 to 7.3 sickness days) was measured. At the control school, no decrease was detected (from 8.0 to 8.1 sickness days). Four months after the course had started, for $63 \%$ of the 66 identified students the extent of the medical absenteeism did not meet with the MASS-criteria anymore.

\section{Appreciation and difficulties of the MASS intervention}

The four interviews showed that the MASS intervention was valued by all four actors. The feedback by the YHCP provided the school with clarity regarding the possible class participation and required counselling, and gave insight into 'possibly illegitimate' medical absenteeism. The possibility to request independent medical advice enabled the school's YHCP to avoid a role 
conflict and provided the school attendance officer with access to medical expertise.Subsequently, the school attendance officer was able to enforce the principles of compulsory education. The school still needed to pay special attention to the registering, aggregating and subsequently consistently processing the enrolment criteria.

\section{Discussion}

It is prominent that in this pilot more female and third-year students are registered with the YHCP. Studies have shown that female students more often than male students experience stress-related complaints, which results in more sicknesses and sleeping disorders [21]. Possibly, a relation can be found between these findings. The identified target group is reached sufficiently, partly due to the integrated approach. The school attendance officer is of importance when the student does not attend the consult with the YHCP and when the student remains absent (too often) after advice from the YHCP. The approach enables the school attendance officer to also enforce the principles of compulsory education in cases of 'possibly illegitimate' medical absenteeism.

Half of the students with substantial medical absenteeism suffer from physical health issues. Absenteeism due to physical complaints requires physical examination and judgment of the indication for further (psycho) diagnosis [22]. Studies show a strong association between medical absenteeism and psychiatric syndromes [23]. Only a minority of youths suffering from psychiatric issues receive treatment [24-26]. Literature also shows that youths suffering from ununderstood physical or mental complaints often do not consult the general practitioner [2127]. MASS offers the possibility to reach these youths and, if necessary, to arrange further diagnosis and treatment.

If a student already is under treatment, it is the responsibility of the YHCP to consult with practitioner in question, and to raise attention for the medical absenteeism and the functioning at school. Literature shows that in general, practitioners do not pay much attention to the patient's functioning at school [27]. By optimising the treatment and paying attention to advice targeted at achievement, school absenteeism can be decreased and functioning at school can be improved. The pilot study results show that report of absence is often rooted in multiple (psychosocial) issues. Discussing physical complaints often turns out to lead towards underlying psychosocial issues. Long term absence from school is often partially caused by the presence of underlying psycho social issues. This is also the case for youths suffering from somatic diseases. Having a disease is rarely a sufficient reason for long term absence $[3,23,28]$. Interaction between psyche and somatoform disorder is known with adolescents [10, 13, 29-35]. A connection can be found between 'not being up for school' and a troubled home situation on the one hand, and psychosomatic complaints such as headaches and stomach aches on the other hand [3, $23,24,36-38]$. Psychosomatic complaints can lead to dysfunction and school absenteeism [5, 21, 37-39]. If psychosomatic complaints are caused by school or home situation factors, the $\mathrm{YHCP}$ can interpret and clear up the mutual relationship between an adolescent and its parents. Additionally, help can be provided in finding an adequate solution or counselling. The YHCP is not only of importance in finding an adequate solution or counselling, but also in the guidance process of a student's return back to school. Furthermore, medical absence is often a sign of risk behaviour [40]. In that case, the YHCP provides insight, counsel and limitation. 
Despite the limitations of the research we can conclude that substantial medical absenteeism is a signal of dysfunction and that medical absenteeism guidance of secondary school students by a YHCP can contribute to early on recognition of health and psychosocial issues. Early on detection enables prevention in a stage prior to diagnosis $[39,41]$. Detection of the causes of medical absence offers the possibility to provide students, parents and school with some support for guidance.

The research data suggest that it is often still unclear which role the YHCP can play for students and parents with regard to medical absenteeism. This may have caused the failure to appear at the YHCP's consults. The procedure is appreciated because it provides the possibility to make use of the YHCP's expertise. A decrease in medical absenteeism has been observed, at school as well as at individual level.

This study has a number of limitations. To start with, the pilot study was executed at merely one pre-vocational secondary school. The quality of the absence registration has not been tested, and it has not been examined whether all students meeting up to one of the criteria have actually been enrolled. The evaluation was mainly observational and has not been tested quantitatively based on indicators. There are indications of decrease of the extent of medical absenteeism at both school and student level; however, due to the small size of the group, no conclusions can be drawn on the significance of the differences found. It remains unclear whether the decrease of the medical absenteeism can be attributed directly to MASS.

\section{Conclusion and recommendations}

Based on the pilot results, we can conclude that the MASS intervention is very promising for reducing school medical absenteeism. In dealing with medical absenteeism lies an important task for the YHCP. It is recommended to call the attention of the target group to the role which the YHCP could play in cases of substantial medical absenteeism. This could improve the attendance rate of the consult, and consequently the school attendance officer's role in the approach could become less prominent. Adaptations of the school's absenteeism registration system have to support the school in aggregating absenteeism figures on student level, which will facilitate the signalling of students with substantial medical absenteeism.

Up until now, no (quasi) experimental effectiveness research has been carried out on interventions which decrease school absenteeism in the Netherlands [42,43]. These pilot results offer starting points for further development of this intervention. Currently, the West-Brabant RPHS carries out a practice-driven intervention study in which MASS will be substantiated through fine tuning and larger-scaled repetition of the intervention, in which it will be accompanied with an effectiveness research. This is necessary in order to implement the programme on larger scale later on, if the positive findings will be confirmed [44]. 
1. NIPO het marktonderzoeksinstituut. Rapport: Schoolverzuim in het Voortgezet Onderwijs. [Report on school absenteeism in secondary school.]. Amsterdam. 2002. http://www.tns-nipo.com/pages/persvannipo/pdf/ schoolverzuimo3.pdf.

2. Weitzman M, Klerman LV, Lamb G, Menary I, Alpert II. School Absence: a problem for the paediatrician. Pediatrics. 1982;69:739-64.

3. Klerman LV. School absence - a health perspective. Pediatr Clin N Am. 1988;35:1253-69.

4. Rumberger RW. Dropping out of middle school: A multilevel analysis of students and schools. Am Educ Res I. 1995:32(3):583-625.

5. Michaud P, Piot-Delbos I, Narring FMD. Silent Dropouts in Health Surveys: Are Nonrespondent Absent teenagers Different From Those Who Participate in School-Based Health Surveys? I Adolescent Health. 1998;22:326-33.

6. Eckstein Z, Wolpin KI. Why Youths Drop Out of High School: the Impact of Preferences, Opportunities, and Abilities. Econ Soc. 1999;67(6):125-1339. doi:10.1111/1468-0262.00081

7. Battin-Pearson S. Predictors of Early High School Dropout: A Test of Five Theories. I Educ Psychol. 2000;9(3):56882. http://dx.doi.org/10.1037/0022-0663.92.3.568

8. Christenson SL, Thrulow ML. School Dropouts: Prevention Considerations, Interventions, and Challenges. Am Psychol Society. 2004;13(1):36-39.

9. Kearney CA. Bridging the Gap Among Professionals Who Address Youths With School Absenteeism: Overview and Suggestions for Consensus. Prof Psychol-Res Pr. 2003:34(1):57-65. doi:10.1037/0735-7028.34.1.57

10. Kearney CA. School absenteeism and school refusal behavior in youth: A contemporary review. Clin Psychol Rev. 2008;28:451-471. doi:10.1016/j.cpr.2007.07.012

11. Thrane C. Explaining educational-related inequalities in health: Mediation and moderator models. Soc Sci Med. 2006;62(2):467-78. doi:10.1016/j.socscimed.2005.06.010

12. Cutler DM, Lleras-Muney A. Education and Health: Evaluating Theories and Evidence, National Poverty Center Working Paper Series Paper no. 12352. 2006. http://www.chrp.org/pdf/Cutler_Lieras-Muney_Education_ and Health.pdf.

13. Freüdenberg N, Ruglis ). Reframing school dropout as a public health issue. Prev Chronic Dis. 2007:4(4):1-11. http://www.cdc.gov/pcd/issues/2007/oct/07_0063.htm.

14. Lundborg P. The Health Returns to Education: What Can We Learn from Twins? J Popul Econ. 2013;26(2):673-701. doi:10.1007/s00148-012-0429-5

15. Mackenbach JP. Health Inequalities: Europe in Profile. Tackling Health Inequalities: Governing for Health. Rotterdam: European Commission. 2006. http://www.who.int/social determinants/resources/european inequalities.pdf.

16. Woolf SH, Johnson RE, Phillips Jr RL, Philipsen M. Giving Everyone the Health of the Educated: An Examination Whether Social Change Would Save More Lives Than Medical Advances. I Public Health. 2007;97(4):679-83. doi:10.2105/AJPH.2005.084848

17. Duckett P, Kagan C, Sixsmith I. Consultation and Participation with Children in Healthy Schools: Choice, Conflict and Context. Am / Community Psychol. 2010;46(1-2):167-78. doi:10.1007/s10464-010-9327-8

18. Rumberger RW. Why Students Drop Out of School and What Can be Done. Dropouts in America: How Severe is the Problem? What Do We Know about Intervention and Prevention? Harvard University. 2001;1-45. http://civilrightsproject.ucla.edu/research/k-12-education/school-dropouts/why-students-drop-out-of-schooland-what-can-be-done/rumberger-why-students-dropout-2001.pdf.

19. Dutch Central Statistics Office. Jaarrapport 2009. Landelijke Jeugdmonitor 2009, Jeugd en Cezin. [Annual Report 2009. National Youth Monitor 2009, Youth and Family.]. The Hague, the Netherlands. http://www.cbs.nl/nl-NL/ menu/themas/bevolking/publicaties/publicaties/archief/2009/2009-g93-pub.htm.

20. Kolkman S, Boere-Bonekamp M, Klok PJ. Begeleiding van leerlingen met langdurig ziekteverzuim in het voortgezet onderwijs door de jeugdarts of jeugdverpleegkundige. [Guidance for students with long-term absenteeism in secondary education by the youth health care physician or nurse.]. Twente University: Twente. 2009. http://www.utwente.nl/bms/htsr/education/completed\%2oassignments/Kolkman.pdf.

21. Beker M, Maas CI, Boelhouwer J, Hoff SIM. Sociaal en Cultureel Planbureau. Rijswijk, the Netherlands. Rapportage jeugd. [Reporting Youth.]. 1997;148.

22. Collin C, Hockaday IM, Waters WE. Headache and school absence. Arch Dis Child. 1985;60:245-247. doi: $10.1177 / 000992289203100503$

23. Jones R, Hoare P, Elton R, Dunhille Z, Scharpe M. Frequent medical absences in secondary school students: survey and case-control study. Arch Dis Child. 2009;94:763-67. doi:10.1136/adc.2008.140962

24. Mitchell S, Shepherd M. Reluctance to go to school. In: Out of school - Modern perspectives in Truancy and School Refusal. Hersov LA, Berg I, editors. John Wiley \& Sons Inc; 1st Ed. Edition. 1980. pp.7-24.

25. Kataoka SH, Zhang L, Wells KB. Unmet need for mental health care among U.S. children: variation by ethnicity and insurance status. Am | Psychiatry. 2002;159(g):1548-55. http://dx.doi.org/10.1176/appi.ajp.159.9.1548 
26. Kessler RC, Berglund P, Demler O, Jin R, Merikangas KR, Walters EE. Lifetime prevalence and age-ofonset distributions of DSM-IV disorders in the national comorbidity survey replication. Arch Cen Psychiat. 2005;62 (6):593-602. doi:10.1001/archpsyc.62.6.593

27. Theil A, Verkerk PH, Buiting E. Snel terug naar school. [Quickly back to school.]. Medisch Contact. 2007;62:31-32.

28. Anderson HR, Bailey PA, Cooper JS, Palmer JC, West S. Morbidity and school absence caused by asthma and wheezing sickness. Arch Dis Child. 1983;58(10):777-784.

29. Hackauf H, Winzen G. Information and communication network concerning health-related prevention projects for young people in the European Union. Final Report. German Youth Institute, Munich, March 2004. http://www. nuigalway.ie/hbsc/documents/yip_europe.pdf.

30. Michaud P-A. Prevention and Health Promotion in School and Community Settings: A Commentary on the International Perspective. I Adolescent Health. 2003;33:219-225.

31. Jackson S, Coossens L. Handbook of adolescent development. Health-related behaviour: Current situation, trends, and prevention. pp 284-300. New York: Psychology Press, 2006.

32. Millstein S, Petersen A, Nightingale E. Promoting the health of adolescents: new directions for the twenty-first century. Oxford: Oxford University in Press. 1993.

33. Löwe MD, Spitzer RL, Williams JWB, Mussell M, Schellberg D, Kroenke K. Depression, anxiety and somatization in primary care: syndrome overlap and functional impairment. Gen Hosp Psychiat. 2008; 30:191-9. doi:10.1016/j. genhosppsych.2008.01.001

34. Merikangas Kr, Ames M, Cui L, et al. The impact of comorbidity of mental and physical conditions on role disability in the us adult household population. Arch Gen Psychiat. 2007;64(10):1180-1188.

35. Allen LA, Gara MA, Escobar II, et al. Somatisation: a debilitating syndrome in primary care. Psychosom 2001;42:63-7.

36. Michaud P, Narring FMD, Piot-Delbos I. Is school absenteeism really linked with health problems? I Adolescent Health. 1994;18(2):154.

37. Breuner CC, Smith MS, Womack WM. Factors Related to School Absenteeism in Adolescents With Recurrent Headache. Headache 2004;44:217-22.

38. Besculides M, Hefferman R, Mostashari F, Weiss D. Evaluation of school absenteeism data for early outbreak detection, New York City. BMC Public Health. 2005:5:105.

39. Vander Stoep A, Weiss NS, McKnight B, Beresford SAA, Cohen P. Which measure of adolescent psychiatric disorder - diagnosis, number of symptoms, or adaptive functioning - best predicts adverse young adult outcomes? I Epidemiol Commun H. 2002;56:56-65. doi:10.1136/jech.56.1.56

40. Eaton DK, Brener N, Kann LK. Associations of health risk behaviors with school absenteeism. Does having permission for the absence make a difference? I Sch Health. 2008;78(4):223-9. doi:10.1111/j.1746-1561.2008.00290.x

41. Committee on Psychosocial Aspects of Child and Family Health and Task Force on Mental health. The future of Pediatrics: Mental Health Competencies for Pediatric Primary Care. Pediatrics. 2009;124:410-21.

42. Steeg M van der, Webbink D. Voortijdig schoolverlaten in Nederland: omvang, beleid en resultaten. [Dropping out from school in the Netherlands; magnitude, policy and results.]. CPB, Economic Policy Analysis: The Hague. 2006 http://www.cpb.nl/en/publication/dropping-out-school-netherlands-magnitude-policy-and-results.

43. Baat MD. Wat werkt bij het voorkomen en verminderen van schoolverzuim? [What works in preventing and reducing truancy?]. Utrecht: Nederlands Jeugd Instituut, 2009.

44. Nutbeam D. Evaluating health promotion: progress, problems and solutions. Health Promot Int. 1998;13(1):27-44. doi:10.1093/heapro/13.1.27 


\section{Case histories}

\section{Fleur}

Fleur (class 4 Higher Ceneral Secondary Education, 16 years old) is regularly reported sick with headaches by her mother. In a conversation between the mentor Fleur and her mother, the truth came out. Fleur often goes to bed far too late because she has too much homework to do. In the morning she has a problem getting up and frequently oversleeps. On those occasions Fleur asks her mother to report her sick. Often mother agrees because she knows how hard Fleur works and feels sorry for her. The mentor offers his support in planning her homework and giving support lessons to Fleur. Mother and daughter leave school relieved.

\section{Olivier}

Olivier is 17 years old and is often reported sick at the beginning of the week, without any reason. When the mentor asks Olivier and his mother what is going on, Olivier relates that he goes out every weekend. He drinks a lot then. Olivier is in his final year and his mentor explains that he will have to work really hard to pass his exams. Olivier understands that he really ought to make school his top priority for now. When the mentor says that he will be happy to help Olivier, on condition that the absenteeism stops, Olivier agrees to go out less and drink less alcohol. 



\section{Chapter 3}

\section{Chapter 3: Extensive medical absenteeism among secondary school students: an observational study on their health condition from a biopsychosocial perspective}

YTM Vanneste, JJP Mathijssen, LAM van de Goor, MC Rots-de Vries, FJM Feron.

\section{Abstract}

Objective: An adequate approach to reduce school absenteeism should focus on medical absenteeism as this is the most prevalent form of school absenteeism. The objective of this study is to explore the health condition of pre-vocational secondary students with extensive medical absenteeism form a biopsychosocial perspective.

Methods: Data were obtained from medical assessments and Strengths and Difficulties Questionnaires (SDQs) of students with medical absence above threshold criteria (i.e. reported sick four times in 12 school weeks or more than six consecutive school days) who were referred to a youth health care physician.

Results: The results showed that the students had a mean absence rate of $14 \%$ in 12 school weeks. Of all students, $43.5 \%$ had a diagnosed disease and $81.5 \%$ had problems such as physical complaints not yet diagnosed, psychosocial problems, lifestyle problems and sleeping difficulties. Four groups could be distinguished: $13.4 \%$ with a diagnosed disease and no problem, $30.1 \%$ with a diagnosed disease and a problem, $51.5 \%$ with a problem and no diagnosed disease and $5.1 \%$ without a diagnosed disease or problem. Significantly higher scores of the Total difficulties-scale on the SDQ were found (mean 10.5; SD 5.8) in the study group, compared to a reference group (mean 9.1; SD 4.9).

Conclusions: This study shows that when using the aforementioned criteria for extensive medical absenteeism to intervene with the absence, students with a mean absence rate of $14 \%$ in 12 school weeks are identified. If there was a diagnosed disease, it was accompanied by problems about twice as often. More than half of the students' absence was caused by problems rather than a disease. The great diversity of these problems calls for a personalized approach. A broad perspective, including medical expertise, is needed to distinguish between emerging mental and physical diseases, psychosocial and lifestyle problems.

Key words: adolescent health, preventive pediatric primary care, school absenteeism, public health, psychosocial problems.

Published: Open J Prev Med. 2015;5:111-121.

http://dx.doi.org/10.4236/ojpm.2015.53013 


\section{Introduction}

School absenteeism can lead to a lower level of education or even to school dropout [1-4]. Low educational level and school dropout are both strongly associated with extensive risk behaviour (e.g. smoking, obesity, lack of exercise) [5, 6], a higher prevalence of mental problems and chronic health issues [7-10], and higher mortality rates [11-16]. Health outcomes, therefore, can be improved by optimizing educational opportunities [17]. Recently, Hawkrigg and Payne [18] proposed an approach to tackle prolonged school absenteeism. As they pointed out, the risk of associated long-term adverse health outcomes can be lowered by diagnosis and management of specific physical and mental health problems and facilitation of school attendance.

Often, a distinction is made between unexcused (truancy) and excused school absenteeism. The latter is mainly due to sickness reporting, so-called medical absenteeism, and may be related to chronic somatic and psychiatric diseases. When these diseases are present, absenteeism appears to be commonly due to physical complaints and stress. It may also be caused by a low threshold for reporting sick, or by more complex causes such as psychological, family or social problems [4]. Moreover, medical absenteeism is associated with risk behaviours [19]. An absence rate of $>20 \%$ of the school year is strongly associated with psychiatric diseases, especially depression and anxiety [20]. Considering these research outcomes, a broad perspective on medical absence is needed.

In the Netherlands, the approach to reducing school absences centers primarily on truancy. Although at least half of school absenteeism is related to medical absenteeism [21], an approach for addressing medical absenteeism is not yet available. Medical absenteeism is not an area of responsibility of Compulsory Education. The attendance officer has no legal duty to enforce the law in case of excused absenteeism and lacks medical expertise to interpret medical absenteeism correctly. It is the school's authority to decide how to deal with it. In some countries schools decide that sick reports must be verified by an appropriately licensed medical professional in order to be accepted, regardless of the length of absence. However, in the Netherlands, medical professionals are not allowed to make statements about medical conditions or learning abilities. Medical absenteeism from school thus results solely from parental sickness reporting. Therefore, the youth health care department $[22,23]$ of the Regional Public Health Service West Brabant has developed the MASS intervention (Medical Advice for Sick-reported Students [24]; see Box), in collaboration with secondary schools and the municipal school attendance service for compulsory education in West Brabant. Schools actively identify students with medical absence above threshold criteria: reported sick four times in 12 school weeks or more than six consecutive school days (the MASS-criteria). As there are no standards for such criteria, these criteria are based on the results of a preliminary study [24] and expert agreement. After referral, youth health care physicians (YHCPs; the Dutch specialism for preventive paediatric primary care) look for factors that contribute to the students' medical absenteeism, using a biopsychosocial perspective $[25,26]$. The biopsychosocial perspective is a conceptual model that assumes that 
psychological and social factors must also be included along with the biologic in understanding a person's physical complaints, medical illness or disorder. A management plan is then designed together with student, parents and school, and with curative professionals, if applicable, aimed to optimize students' health and maximize students' participation in school activities.

Box: Description of the Dutch intervention 'Medical Advice for Sick-reported Students', abbreviated as MASS.

The MASS intervention consists of an integrated approach in a public health setting. MASS provides a clear framework in which schools, in direct collaboration with YHCPs, are able to reach students and their parents, discuss aspects of the student's medical absence, and design and monitor a management plan that aims to optimize students' health and maximize students' participation in school activities. In summary, the aim of the MASS intervention is to limit the absenteeism by arranging appropriate care, educational adjustments and adequate support for students and parents. A systematic routine is followed.

\section{Step 1 School's policy}

The school communicates with students and parents about the new policy in case of absenteeism because of medical reasons.

\section{Step 2 Referral to the YHCP}

Students with extensive medical absence are identified by school by using well-defined threshold criteria: reported sick four times in 12 school weeks or more than six consecutive school days (MASS-criteria). Meeting the criteria always leads to a referral to the YHCP for student and parents.

\section{Step 3 Consultation of student and parents with the YHC}

During the interview and medical assessment YHCPs look for biological, psychological and social factors that contribute to the students' medical absenteeism. The YHCP identifies whether there is a specific somatic or psychiatric diagnosis to account for the absence. If the diagnosis is clear the focus will be on optimising the (adherence to) treatment. In cases of frequent physical complaints and psychosocial problems with no clear medical diagnosis, the YHCP considers diagnostics, and looks for family-related and schoolrelated, as well as health risk behaviours and lifestyle aspects that contribute to the physical complaints and psychosocial problems. If needed, the YHCP refers to a medical specialist or a psychosocial support network. A management plan is then designed together with student, parents and school, and with curative professionals, if applicable. This plan includes agreements on cure, care and school attendance.

\section{Step 4 Monitoring the management plan}

School and YHCP monitor the execution of the management plan. 
Implementation of MASS started at pre-vocational secondary schools, for two reasons. First, in the Netherlands, medical absenteeism is more prevalent at this educational level [21]. Secondly, school dropout occurs more frequently at this educational level because pre-vocational secondary students cannot fall back on a lower level of education. As they often demonstrate behavioural problems [27] and problems with planning [28], which prevent their catching up when fallen behind, school absenteeism therefore has serious consequences for them. The objective of this study is to explore the health condition and socio-demographic characteristics of those students who met the MASS-criteria, from the biopsychosocial perspective of youth health care.

\section{Methods}

\section{Setting}

Since 2010, MASS has been implemented in Dutch general secondary schools in the region West Brabant, in the Netherlands. This study is part of the research project on the MASS intervention.

\section{Study group}

The students were selected from 7 pre-vocational secondary schools which had applied the MASS intervention and consisted of 493 students who met the MASS-criteria and had been referred to the YHCP over the course of school year 2011-2012. If any student received two or more separate referrals over the data collection period, only data associated with the first referral were included. Of all students referred to the YHCPs 336 gave permission to use the information about their health condition and 256 students filled in the Strengths and Difficulties Questionnaire (SDQ).

\section{Data collection procedure}

Data were obtained from the medical assessments. The YHCPs filled out a registration form about the student's health condition. At the end of the consultation written informed consent was obtained from students and parents to participate in the study. Additionally, students were asked to complete the Strengths and Difficulties Questionnaire [29, 30] (SDQ) at home. Data from YHCP files and school files were used to identify socio-demographic characteristics and to determine the absence rate.

\section{Description of the measurements}

Health condition: by means of diagnostic interview and medical examination, the YHCPs identified and registered all determinants of medical absenteeism, both diseases and problems. Based on this procedure, a student could receive more than one classification in the domain of diseases and/or problems. Diseases were registered in open fields and categorized by expert agreement afterwards. Physical complaints, sleeping difficulties, lifestyle problems, and psychosocial problems, all categorized by protocol in child-related, family-related or school-related problems, were registered by checking the boxes on the registration form. The YHCPs were trained in using the registration form. Peer evaluation took place monthly to standardize the scoring method. The categorization and description of the health condition are presented in Table 1. 
Table 1: Categorization and description of the health condition from a biopsychosocial perspective.

\begin{tabular}{|c|c|}
\hline Health condition & Description \\
\hline \multicolumn{2}{|l|}{ Diseases: } \\
\hline 1. Chronic physical disease & $\begin{array}{l}\text { Including migraine, cervicogenic headache, asthma, allergies, } \\
\text { eczema, urticarial, Osgood Schlatter, low blood pressure, } \\
\text { hypermobility syndrome, mastocytosis, Diabetes Mellitus, } \\
\text { obesity, thyroid problems, benign skin tumour, Irritable Bowel } \\
\text { Syndrome, lactose intolerance, hearing problems, congenital } \\
\text { abnormality. }\end{array}$ \\
\hline 2.Temporary physical disease & $\begin{array}{l}\text { Including Pfeiffer, pneumonia, urinary tract infections, } \\
\text { appendicitis, anaemia, upper respiratory infection, acute otitis, } \\
\text { sinusitis, abscess, inflamed lymph node, laryngitis, cystitis, } \\
\text { flu(-like illness), chickenpox, whooping cough, shingles. }\end{array}$ \\
\hline 3. Injury & $\begin{array}{l}\text { Including concussion, elbow fracture, tendon rupture, ankle } \\
\text { injury, spinal fracture. }\end{array}$ \\
\hline 4. Mental disease & $\begin{array}{l}\text { Including Obsessive Compulsive Disorder (OCD), Attention } \\
\text { Deficit (Hyperactivity) Disorder (AD(H)D), Pervasive } \\
\text { Developmental Disorder - Not Otherwise Specified (PDD- } \\
\text { NOS), anxiety, depression, dysthymia, mood disorders, conduct } \\
\text { disorder, sexual abuse, addiction, eating disorder. }\end{array}$ \\
\hline \multicolumn{2}{|l|}{ Problems: } \\
\hline $\begin{array}{l}\text { 5. Physical complaints (not } \\
\text { related to the present disease) }\end{array}$ & $\begin{array}{l}\text { Including constipation, tired, headache, abdominal pain, } \\
\text { musculoskeletal complaints, menstrual problems, pregnancy, } \\
\text { and unexplained physical complaints. }\end{array}$ \\
\hline 6. Sleeping difficulties & $\begin{array}{l}\text { Including problems with falling asleep or sleeping through the } \\
\text { night. }\end{array}$ \\
\hline 7. Lifestyle problems & $\begin{array}{l}\text { Including poor diet, going to bed too late, much computing, } \\
\text { poor personal care, lack of exercise or relaxation, substance } \\
\text { use. }\end{array}$ \\
\hline $\begin{array}{l}\text { 8. Child-related psychosocial } \\
\text { problem* }\end{array}$ & $\begin{array}{l}\text { Including past experiences or traumas (such as the death of } \\
\text { a loved one, the child or a relative have been sick or have had } \\
\text { an accident), personality (such as less strength of character, } \\
\text { anxiety). }\end{array}$ \\
\hline $\begin{array}{l}\text { 9. Family-related psychosocial } \\
\text { problem* }\end{array}$ & $\begin{array}{l}\text { Including (threatening) divorce, poverty, unemployment, } \\
\text { addiction, serious and/or chronic illness of a relative, substance } \\
\text { abuse, neglect, or child kept at home to take care of a relative. }\end{array}$ \\
\hline $\begin{array}{l}\text { 10. School-related } \\
\text { psychosocial problem* }\end{array}$ & $\begin{array}{l}\text { Including bullying, learning or motivation problems, } \\
\text { troublesome relationship with a teacher or fellow-students }\end{array}$ \\
\hline
\end{tabular}

* Emotional and behavioural problems. The categorization followed the origin of the problem, as indicated by the YHCP. 
Psychosocial problems were also identified using the student's version of the SDQ. The SDQ is a standardized measure covering the most important domains of psychopathology in children and adolescents (4-16 year old), and is used as a valid instrument for early identification of psychosocial problems [31-33]. The questionnaire is divided in five subscales ( 5 items per scale): emotional problems, conduct problems, hyperactivity-inattention, peer problems and prosocial behaviour. On the basis of the four problem scales a total difficulty score can be calculated.

Socio-demographic characteristics: students' ethnicity was determined and categorized on the basis of the country of birth of both parents and student. The level of social deprivation in the neighbourhood was assessed by postal code, using the classification in seven groups by the Dutch Institute for Social Research [34], 1 indicating highest level of deprivation and 7 the lowest. Three categories were used: high deprivation (1 through 3), medium deprivation (4) and low deprivation (5 through 7).

Medical absenteeism: medical absenteeism was calculated as the total number of absence days per 12 school weeks, which is equivalent to 60 school days, prior to consultation date. For this purpose, routinely collected school attendance data were used.

\section{Ethical approval}

The research protocol was approved by the Medical Ethics Committee of the University Hospital Maastricht and Maastricht University (Dossier number 11-4-070.6/ivb).

\section{Statistical analysis}

Descriptive statistics were used to analyse the health condition and socio-demographic characteristics of the students. Pearson's chi-squared tests and Student's t-test were used to study the difference in SDQ scores between the study group and a reference population.

\section{Results}

\section{Socio-demographic characteristics and absence rate}

The school population consisted of 4,159 students, 2,078 (50\%) of those male students and $2,080(50 \%)$ female students. The number of students was evenly distributed over the four school years. Nearly $12 \%$ (493 students) of the school population participated in the study. The study group consisted of $218(44.2 \%)$ male and $275(55.8 \%)$ female students. Of the study group, $152(31.2 \%)$ students were in the second school year, $124(25.3 \%)$ were non-Western immigrants, and $89(18.3 \%)$ students lived in a highly deprived neighbourhood. The mean age of the students was 15.05 years (SD1.26). The mean number of absence days was 8.4 (SD6.60; range $1-45)$, which is equivalent to a rate of $14 \%$. The results are presented in Table 2 . 
Table 2: Socio-demographic characteristics and size of medical absenteeism.

\begin{tabular}{|c|c|c|}
\hline Characteristic & & $\begin{array}{c}\text { Students }^{1} \\
\mathrm{n}=493\end{array}$ \\
\hline \multirow[t]{2}{*}{ Gender, n (\%) } & Male & $218(44.2)$ \\
\hline & Female & $275^{*}(55.8)$ \\
\hline \multirow[t]{4}{*}{ School year, n (\%) } & First & $103(21.1)$ \\
\hline & Second & $152^{*}(31.2)$ \\
\hline & Third & $113(23.2)$ \\
\hline & Fourth & $119(24.4)$ \\
\hline \multirow[t]{3}{*}{ Ethnicity, n (\%) } & Native & $334(68.2)$ \\
\hline & Western & $32(6.5)$ \\
\hline & Non-Western & $124(25.3)$ \\
\hline \multirow[t]{3}{*}{ Status score, n (\%) } & Low & $89(18.3)$ \\
\hline & Medium & $339(69.6)$ \\
\hline & High & $59(12.1)$ \\
\hline $\begin{array}{l}\text { Age, mean (SD), } \\
\text { range }\end{array}$ & In years & $\begin{array}{c}15.05(1.26) \\
12.3-18.5\end{array}$ \\
\hline $\begin{array}{l}\text { Medical absenteeism, } \\
\text { mean (SD), } \\
\text { range }\end{array}$ & In total number of days & $\begin{array}{c}8.4(6.60) \\
1-45\end{array}$ \\
\hline
\end{tabular}

${ }^{1}$ The numbers do not always add up to 493 because of missing data from YHC files and registration forms.

* Over-represented in the study group, compared to the school population.

\section{The health condition}

Diseases and problems: of all students referred to the YHCPs 336 gave permission to use the information about their health condition. The YHCPs indicated that $146(43.5 \%)$ of these students had one or more diagnosed diseases, and 274 (81.5\%) had one of more problems. Table 3 shows how often the YHCPs noted diseases and problems. The percentages do not add to $43.5 \%$ (for disease) and $81.5 \%$ (for problem) since several diseases or problems may relate to the same student. 
Table 3: Results of the health condition.

\begin{tabular}{|l|c|}
\hline Health condition & $\begin{array}{c}\text { Students } \\
\mathbf{n}=336\end{array}$ \\
\hline Disease, $\mathbf{n}(\%):$ & $146(43.5)$ \\
\hline 1. Chronic physical disease & $92(24.0)$ \\
\hline 2. Temporary physical disease & $50(13.0)$ \\
\hline 3. Injury & $15(3.9)$ \\
\hline 4. Mental disease & $32(8.3)$ \\
\hline Problem, $\mathbf{n}(\%):$ & $274(81.5)$ \\
\hline 5. Child-related psychosocial problem & $134(34.9)$ \\
\hline 6. Family-related psychosocial problem & $130(33.9)$ \\
\hline 7. School-related psychosocial problem & $72(18.8)$ \\
\hline 8. Physical complaint & $228(40.4)$ \\
\hline 9. Sleeping difficulty & $28(7.3)$ \\
\hline 10. Lifestyle problem & $93(16.5)$ \\
\hline
\end{tabular}

According to whether or not the student had a disease and/or problem, four groups could be distinguished: $13.4 \%$ of the students had a disease and no problem, $30.1 \%$ had a disease and a problem, $51.5 \%$ had a problem and no disease and $5.1 \%$ had neither a disease nor a problem. The various groups are shown in Figure 1.

\section{The study sample divided onto four groups}

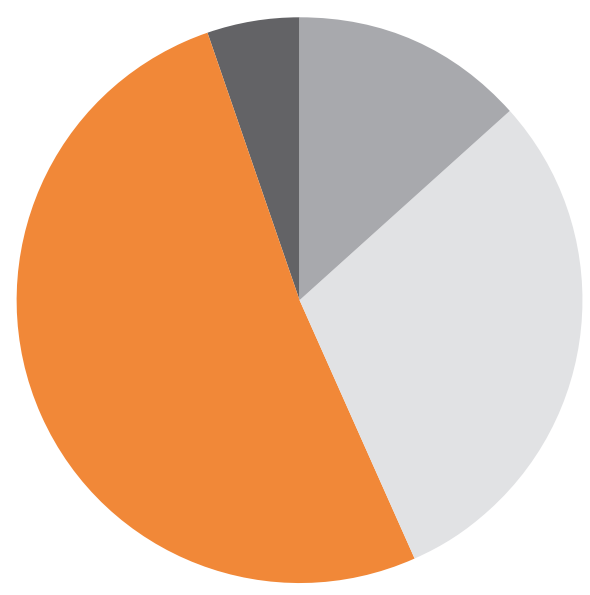

Students having a disease and no problem: $13 \cdot 4 \%$

Students having a disease and a problem: $30.1 \%$

Students having a problem and no disease: $51.5 \%$

Students having neither a disease nor a problem: $5.1 \%$

Figure 1: Visual presentation, according to whether or not having a disease or problem. 
Psychosocial problems as measured by the Strengths and Difficulties Questionnaire (SDQ): of all students referred to the YHCPs 256 students filled in the Strengths and Difficulties Questionnaire (SDQ). The results of the SDQ are presented in Table 4. For the SDQ, there is no gold standard for the Dutch adolescent population yet. Therefore, the findings were compared to those of the Dutch National Youth Monitor in the region of West Brabant [35]. Student's t-tests revealed significant differences between the study group and the reference population, with higher means for the students with medical absenteeism on total difficulties, and on two subscales, emotional symptoms and prosocial behaviour. In relation to peer problems, significant difference appears only with the female students. With reference to the SDQ-scale Total difficulties, the results of the Chi-square tests (Male: $\chi^{2}=6.78, \mathrm{df}=2, \mathrm{p} \leq 0.05$; female: $\chi^{2}=48.4, \mathrm{df}=2, \mathrm{p} \leq 0.01$ ) show that there are significant differences between the study group and the reference population, indicating that the study group more often has a border range $(10.5 \%$ versus $8.0 \%)$ and an elevated score $(9.8 \%$ versus $2.9 \%)$.

Table 4: Means and reference means of the SDQ, referred to norms of SDQ-scale Total difficulties.

\begin{tabular}{|c|c|c|c|c|c|c|}
\hline & \multicolumn{3}{|c|}{$\begin{array}{c}\text { Study group } \\
n=256 \\
\text { Mean age: } 15.05(1.26)\end{array}$} & \multicolumn{3}{|c|}{$\begin{array}{l}\text { Dutch Youth Monitor } \\
\text { West Brabant } 2011 \\
\qquad n=1,821 \\
\text { Mean age: } 13.97(1.34)\end{array}$} \\
\hline & $\begin{array}{c}\text { Total } \\
(n=256)\end{array}$ & $\begin{array}{c}\text { Male } \\
(n=119)\end{array}$ & $\begin{array}{l}\text { Female } \\
(n=137)\end{array}$ & $\begin{array}{c}\text { Total } \\
(n=1821)\end{array}$ & $\begin{array}{c}\text { Male } \\
(n=826)\end{array}$ & $\begin{array}{c}\text { Female } \\
(n=995)\end{array}$ \\
\hline SDQ scores scales & $\begin{array}{l}\text { Mean } \\
\text { (SD) }\end{array}$ & $\begin{array}{l}\text { Mean } \\
\text { (SD) }\end{array}$ & $\begin{array}{l}\text { Mean } \\
\text { (SD) }\end{array}$ & $\begin{array}{l}\text { Mean } \\
\text { (SD) }\end{array}$ & $\begin{array}{l}\text { Mean } \\
\text { (SD) }\end{array}$ & $\begin{array}{l}\text { Mean } \\
\text { (SD) }\end{array}$ \\
\hline Total difficulties & $\begin{array}{l}10.5^{* *} \\
(5.8)\end{array}$ & $\begin{array}{c}10.0^{* *} \\
(5.5)\end{array}$ & $\begin{array}{c}11.0^{* *} \\
(5.9)\end{array}$ & $\begin{array}{c}9.1 \\
(4.9)\end{array}$ & $\begin{array}{c}8.5 \\
(4.8)\end{array}$ & $\begin{array}{c}9.6 \\
(4.9)\end{array}$ \\
\hline Emotional symptoms & $\begin{array}{l}3 \cdot 4^{* \star} \\
(2.5)\end{array}$ & $\begin{array}{l}2.9^{\star \star} \\
(2.2)\end{array}$ & $\begin{array}{l}3 \cdot 73^{* *} \\
(2.6)\end{array}$ & $\begin{array}{c}2.2 \\
(2.1)\end{array}$ & $\begin{array}{c}1.5 \\
(1.6)\end{array}$ & $\begin{array}{c}2.7 \\
(2.2)\end{array}$ \\
\hline Conduct problems & $\begin{array}{c}1.6 \\
(1.4)\end{array}$ & $\begin{array}{c}1.6 \\
(1.4)\end{array}$ & $\begin{array}{c}1.6 \\
(1.5)\end{array}$ & $\begin{array}{c}1.5 \\
(1.3)\end{array}$ & $\begin{array}{c}1.6 \\
(1.4)\end{array}$ & $\begin{array}{c}1.4 \\
(1.2)\end{array}$ \\
\hline $\begin{array}{l}\text { Hyperactivity- } \\
\text { inattention }\end{array}$ & $\begin{array}{c}4.1 \\
(2.7)\end{array}$ & $\begin{array}{c}4.1 \\
(2.7)\end{array}$ & $\begin{array}{c}4.1 \\
(2.7)\end{array}$ & $\begin{array}{c}4.1 \\
(2.5)\end{array}$ & $\begin{array}{c}4.2 \\
(2.5)\end{array}$ & $\begin{array}{c}4.1 \\
(2.5)\end{array}$ \\
\hline Peer problems & $\begin{array}{c}1.4 \\
(1,5)\end{array}$ & $\begin{array}{c}1.3 \\
(1.5)\end{array}$ & $\begin{array}{l}1.6^{*} \\
1.5)\end{array}$ & $\begin{array}{c}1.3 \\
(1.5)\end{array}$ & $\begin{array}{c}1.3 \\
(1.5)\end{array}$ & $\begin{array}{c}1.3 \\
(1.5)\end{array}$ \\
\hline Prosocial behaviour & $\begin{array}{l}8.6^{\star *} \\
(1.4)\end{array}$ & $\begin{array}{l}8.3^{* *} \\
(1.4)\end{array}$ & $\begin{array}{l}8.8^{* *} \\
(1.4)\end{array}$ & $\begin{array}{l}8.0 \\
(1.7)\end{array}$ & $\begin{array}{c}7.6 \\
(1.8)\end{array}$ & $\begin{array}{c}8.3 \\
(1.5)\end{array}$ \\
\hline
\end{tabular}




\begin{tabular}{|c|c|c|c|c|c|c|}
\hline $\begin{array}{l}\text { SDQ-scale Total } \\
\text { difficulties*** }\end{array}$ & $\begin{array}{l}N \\
(\%)\end{array}$ & $\begin{array}{l}N \\
(\%)\end{array}$ & $\begin{array}{l}N \\
(\%)\end{array}$ & $\begin{array}{l}N \\
(\%)\end{array}$ & $\begin{array}{l}N \\
(\%)\end{array}$ & $\begin{array}{l}N \\
(\%)\end{array}$ \\
\hline Normal rating & $\begin{array}{l}204^{* \star} \\
(79.7)\end{array}$ & $\begin{array}{l}102^{* *} \\
(85.7)\end{array}$ & $\begin{array}{l}102^{* *} \\
(74 \cdot 5)\end{array}$ & $\begin{array}{l}1,623 \\
(89.2)\end{array}$ & $\begin{array}{c}754 \\
(91.3)\end{array}$ & $\begin{array}{c}870 \\
(87.4)\end{array}$ \\
\hline Border range & $\begin{array}{l}27^{* *} \\
(10.5)\end{array}$ & $\begin{array}{l}10^{\star \star} \\
(8.4)\end{array}$ & $\begin{array}{l}17^{\star *} \\
(12.4)\end{array}$ & $\begin{array}{l}145 \\
(8.0)\end{array}$ & $\begin{array}{c}51 \\
(6.2)\end{array}$ & $\begin{array}{c}94 \\
(9.4)\end{array}$ \\
\hline Elevated score & $\begin{array}{l}25^{\star *} \\
(9.8)\end{array}$ & $\begin{array}{l}7^{\star \star} \\
(5.9)\end{array}$ & $\begin{array}{l}18^{* *} \\
(13.1)\end{array}$ & $\begin{array}{c}53 \\
(2.9)\end{array}$ & $\begin{array}{c}21 \\
(2.5)\end{array}$ & $\begin{array}{c}31 \\
(3.1)\end{array}$ \\
\hline
\end{tabular}

${ }^{*} \mathrm{p} \leq 0.05 ;{ }^{* *} \mathrm{p} \leq 0.01 ;{ }^{* * *}$ Cut-off values: normal rating $=0-15$, border range $=16-19$, elevated score $=20-40$ points.

\section{Discussion}

This study explores the health condition, from a biopsychosocial perspective, and the sociodemographic characteristics of Dutch pre-vocational secondary students who were referred to a youth health care physician (YHCP) because of extensive medical absenteeism: reported sick four times in 12 school weeks or more than six consecutive school days.

Regarding health condition, the study showed that $43.5 \%$ of the students had a disease, and $81.5 \%$ had problems such as physical complaints not yet diagnosed, psychosocial problems, lifestyle problems and sleeping difficulties that caused clinically significant functional impairment as they resulted in absenteeism.

Of all students in our study group, about a third $24 \%$ chronic physical and $8.3 \%$ mental diseases) suffered a chronic disease. Since our study group was comprised of $12 \%$ of the school population, this means that about $4 \%$ of the school population had a chronic disease and met the MASS-criteria. Given that in the Netherlands, in general education about $12 \%$ of all children has a chronic disease $[36,37]$, it can be assumed that most of the students with a chronic disease did not meet our criteria of extensive absence. This suggests that having a chronic disease does not mean that you are absent from school that much necessarily. Maybe they do receive optimal care, and therefore they are able to participate in school .It is known from research that having a chronic disease does not mean that it is necessarily to be absent from school more than average [4].

However, $40.4 \%$ of the students in our study had physical complaints, and $34.9 \%$ of the students had child-related, $33.9 \%$ family-related and 18.8\% school-related psychosocial problems. Physical complaints and psychosocial problems may be related to a disease not yet diagnosed, the preclinical stage [38]. It often takes some time to break through ('growing into deficit'). Given that most of mental diseases emerge during adolescence and early adulthood and the median age of onset of all mental diseases is approximately 14 years [39], it is likely that some of our students go through psychological problems that do not yet cluster into a psychiatric diagnosis. Unmet need for treatment of mental problems is a major issue [40], possibly because most 
adolescents do not visit a physician when experiencing complaints or psychosocial problems [41]. In a previous study, Jones found that $45 \%$ of the students with an absence rate of more than $20 \%$ over three consecutive school terms had psychiatric disorders [20]. In our study, students with a mean absence rate of $14 \%$ over one school term were included. When using the MASS-criteria for intervening in medical absence, at least some of these students can be identified in an early stage, which may prevent severe mental disease later.

Four groups could be distinguished according to whether or not the student had a disease and/or problem. In case of extensive medical absence, a disease will primarily be put forward as a cause. Therefore the groups are presented in the following order:

The first group (13.4\%) consisted of students who had a diagnosed disease without problems. In cases of chronic diseases, school absenteeism may indicate that the disease is not being managed appropriately $[4,18]$. More proper treatment and care can contribute to reducing medical absenteeism [4]. In cases of an injury or a temporary disease such as flu, absenteeism may be inevitable.

The second group of students $(30.1 \%)$ had a diagnosed disease and problems. Kearney already found that in cases of having a disease, medical absenteeism is often due to psychological, family or social problems [4]. Having a chronic disease can be stressful for children, their parents, and their environment [42]. Issues such as experiencing the disease, feeling different from their school friends, lacking confidence to deal with their complaints at school and lagging behind in school work, may put up barriers for going to school.

In the third group (51.5\%) the YHCPs indicated that medical absenteeism was most often caused by problems rather than diseases. The presence of psychosocial problems was confirmed by the significantly higher mean scores of SDQ total difficulties scales in the study group. Lenzen already demonstrated that medical absenteeism is positively associated with emotional and behavioural problems [43]. The nature of the problems appears to be diverse, when looked at from a biopsychosocial perspective: psychosocial problems, physical complaints, sleeping difficulties and lifestyle problems can be the underlying reasons for medical absenteeism. Medical expertise is needed in order to make diagnostic considerations for the early detection of developing physical and mental diseases as they usually progress over a period of time and have a pre-clinical phase and first symptoms [38]. This specific medical expertise is the additional value of $\mathrm{YHC}$, because it is not available directly at Dutch schools.

The fourth group $(5.1 \%)$ consisted of students who according to the YHCPs suffered neither disease nor problem. A conflict between student and parents sometimes precedes reporting sick. Moreover, the medical absenteeism may be due to a low threshold for reporting sick, although this may occur in all four groups [4].

Regarding socio-demographic characteristics, students visiting the second school year and female students were over-represented in the study group. In the Netherlands, medical absenteeism is the highest in the lowest school years [21]. It is known from research that there is a higher prevalence of medical absenteeism among female students [19]. 
Regarding the size of the absence, this study showed that the students had a mean absence rate of 8.4 days in 12 school weeks, which is equivalent to $14 \%$. Jones et al. [20] stated that a school absence rate of over $20 \%$ cumulatively over several school terms is problematic for a child's development. The criteria chosen beforehand in our study seem to identify students with a 'not-yet-problematic' absence rate. The MASS intervention offers potential to approach them more adequately at this early stage and thereby possibly prevent future problematic medical absenteeism. Future research is recommended to further study whether even better criteria can be developed and whether for these students, problematic medical absenteeism may be predicted or prevented.

This study knows some limitations. First, inclusion in this study was linked to the application of an intervention. This requires serious commitment of school personnel who is involved in identifying and referral of the students who meet the criteria. It is therefore quite conceivable that not all students have been identified, and that referral to the YHCP may be influenced by the personal vision of the school personnel. Second, the study took place in Dutch schools for pre-vocational secondary education in West Brabant, the Netherlands. Consequently, the findings may not be fully generalizable. Third, since only the results of YHCPs' first consultations are included, there may be underreporting of more personal factors contributing to the absence. Practice has taught that, in particular, issues of lifestyle and family are not easy to address in one consultation.

In conclusion, this study shows that when using the MASS-criteria to intervene with medical absence, students with a mean absence rate of $14 \%$ in 12 school weeks are identified. Looking at their health condition from a biopsychosocial perspective, it shows that in $43.5 \%$ of the cases there is a diagnosed disease, and if this is the case, two-third of the students also experienced additional problems. In $81.5 \%$ of the cases, the medical absenteeism presents students with problems. The largest group consists of students who have problems without a diagnosed disease. The great diversity of problems calls for a personalized approach from a biopsychosocial perspective, including medical expertise. This will allow emerging mental and physical diseases, social and lifestyle problems to be distinguished.

Acknowledgements: The authors would like to thank all students and youth health care physicians who participated in this study, and Ike Kroesbergen and Monique de Beer who supported the analysis of this study.

Funding: ZonMw, the Dutch Organization for Health Research and Development.

Competing interests: None.

Ethics approval: Medical Ethics Committee of the University Hospital Maastricht and Maastricht University (Dossier number 11-4-070.6/ivb).

\section{What is already known on this topic?}

- School absence due to sickness reports, so-called medical absenteeism, is related to diseases, psychosocial problems, risk behaviour and a low threshold for reporting sick.

- A'problematic' medical absence rate of $>20 \%$ of the school year is frequently associated with psychiatric illness, especially depression and anxiety. 


\section{What this study adds?}

- In this group of pre-vocational secondary students with a mean medical absence rate of $14 \%$ in $12 \mathrm{school}$ weeks, $43.5 \%$ of them has a disease and $81.5 \%$ has problems such as physical complaints not yet diagnosed, psychosocial problems, lifestyle problems and sleeping difficulties.

- If a diagnosed disease was found, two-third of the students in the study group also experienced additional problems.

- In cases of problems, a broad perspective including medical expertise should be applied to distinguish between emerging mental and physical diseases, psychosocial and lifestyle problems. 
1. Eckstein Z, Wolpin KI. Why Youths Drop Out of High School: the Impact of Preferences, Opportunities, and Abilities. Econ Soc. 1999;67(6):125-1339. doi:10.1111/1468-0262.00081

2. Rumberger RW. Why Students Drop Out of School and What Can be Done. Dropouts in America: How Severe is the Problem? What Do We Know about Intervention and Prevention? Harvard University. 2001;1-45. http://civilrightsproject.ucla.edu/research/k-12-education/school-dropouts/why-students-drop-out-of-schooland-what-can-be-done/rumberger-why-students-dropout-2001.pdf.

3. Christenson SL, Thrulow ML. School Dropouts: Prevention Considerations, Interventions, and Challenges. Curr Dir Psychol Sci. 2004;13:36-39. doi:10.1111/j.0963-7214.2004.01301010.x

4. Kearney CA. School absenteeism and school refusal behavior in youth: A contemporary review. Clin Psychol Rev. 2008;28:451-71. doi:10.1016/j.cpr.2007.07.012

5. Droomers M, Schrijvers CTM, Mheen Dvd, Mackenbach JP. Educational differences in leisure-time physical inactivity: a descriptive and explanatory study. Soc Sci Med. 1998;47(11):1665-76. doi:10.1016/So2779536/g8)00272-X

6. Droomers M, Schrijvers CTM, Stronks K, Mheen Dvd, Mackenbach JP. Educational differences in excessive alcohol consumption: the role of psychosocial and material stressors. Prev Med. 1999;29(1):1-10. doi:10.1006/ pmed.1999.0496

7. Havas I, Bosma H, Spreeuwenberg C, Feron FI. Mental health problems of Dutch adolescents: the association with adolescents' and their parents' educational level. Eur | Public Health. 2009;20(3):258-64. doi:10.1093/eurpub/ ckp172

8. Dahlgren G, Whitehead M. European strategies for tackling social inequities in health: Levelling up part 2. World Health Organization Regional Office for Europe. 2006. http://www.euro.who.int/_data/assets/pdf file/o018/103824/E89384.pdf.

9. Mackenbach JP. Health Inequalities: Europe in Profile. Tackling Health Inequalities: Governing for Health. Rotterdam: European Commission. 2006. http://www.who.int/social_determinants/resources/european_inequalities.pdf.

10. Thrane C. Explaining educational-related inequalities in h̄ealth: Mediation and moderator models. Soc Sci Med. 2006;62(2):467-78. doi:10.1016/j.socscimed.2005.06.010

11. Bosma H, Mheen DH vd, Borsboom GJJM, Mackenbach JP. Neighborhood Socioeconomic Status and All-Cause Mortality. Am J Epidemiol. 2001;153(4):363-71. doi:10.1093/aje/153.4.363

12. Huisman M, Kunst AE, Bopp M, Borgan JK, Borrell C, Costa C, Deboosere P, Gadeyne S, Glickman M, Marinacci C, Minder C, Regidor E, Valkonen T, Mackenbach JP. Educational inequalities in cause-specific mortality in middleaged and older men and women in eight western European populations. Lancet. 2005;365(9458):493-500. doi:10.1016/So140-6736/05)17867-2

13. Mackenbach JP, Stirbu I, Roskam AJ, Schapp M, Menvielle G, Leinsalu M, et al. Socioeconomic inequalities in health in 22 European countries. N Engl | Med. 2008;358(23):2468-81. doi:10.1056/NE/Msa0707519

14. Lager AC), Torssander J. Causal effect of education on mortality in a quasi-experiment on 1.2 million Swedes. Proc Natl Acad Sci USA. 2012;109(22):8461-67. doi:10.1073/pnas.1105839109

15. Gathmann C, Jürges H, Reinhold S. Compulsory schooling reforms, education and mortality in twentieth century Europe. Soc Sci Med. 2015;127:74-82. doi:10.1016/j.socscimed.2014.01.037

16. Kulhánová I, Hoffmann R, Eikemo TA, Menvielle G, Mackenbach JP. Educational inequalities in mortality by cause of death: first national data for the Netherlands. Int I Public Health. 2014;59(5):687-96. doi:10.1007/s00038$014-0576-4$

17. WHO World Health Organisation. Health for the world's adolescents. 2014. http://www.who.int/maternal_child adolescent/topics/adolescence/second-decade/en.

18. Hawkrigg S, Payne DN. Prolonged school non-attendance in adolescence: a practical approach. Arch Dis Child. 2014;99:954-957. doi:10.1136/archdischild-2013-304595

19. Eaton DK, Brener N, Kann LK. Associations of health risk behaviors with school absenteeism. Does having permission for the absence make a difference? / Sch Health. 2008;78(4):223-9. doi:10.1111/j.1746-1561.2008.00290.x

20. Jones R, Hoare P, Elton R, Dunhille Z, Scharpe M. Frequent medical absences in secondary school students: survey and case-control study. Arch Dis Child. 2009;94:763-67. doi:10.1136/adc.2008.140962

21. NIPO het marktonderzoeksinstituut. Rapport: Schoolverzuim in het Voortgezet Onderwijs. [Report on school absenteeism in secondary school.]. Amsterdam. 2002. http://www.tns-nipo.com/pages/persvannipo/pdf/ schoolverzuimo3.pdf.

22. Wieske RCN, Nijhuis MG, Carmiggelt BC, Wagenaar-Fischer MM, Boere-Boonekamp MM. Preventive youth health care in 11 European countries: an exploratory analysis. Int I Public Health. 2012;57(3):637-641. doi:10.1007/ s00038-011-0305-1 
23. Kuo AA, Inkelas M, Lotstein DS, Samson KM, Schoret EL, Halfon N. Rethinking Well-Child Care in the United States: An International Comparison. Pediatrics. 2006;118(4):1692-702. doi:10.1542/peds.2006-0620

24. Vanneste YTM, Rots-de Vries MC, Goor LAM van de, Feron FJM. Medische Advisering Ziekgemelde leerling door de jeugdarts (M@ZL); ontwikkeling van een interventie. [Medical Advice for Sick- reported Students in secondary school by the youth health care physician (MASS); development of an intervention.]. TSG. 2012;90(7):412-19. www.tsg.bsl.nl.

25. Engel GL. The need for a new medical model: a challenge for biomedicine. Science. 1977;196(4286):129-36. doi:10.1126/science.847460

26. Engel GL. The need for a new medical model: A challenge for biomedicine. Fam Syst Med. 1992;10(3):317-331. doi: http://dx.doi.org/10.1037/hoo8926o

27. Groeneveld MI, Steensel KM van, Herben B, et al. Kenmerkend vmbo: een vergelijkend onderzoek naar de kenmerken van vmbo-leerlingen en de 'generatie Einstein'. [Characteristics pre-vocational secondary education: a comparative study of the characteristics of pre-vocational secondary students and the 'Einstein generation'.]. Hilversum: Hiteq, 2008. http://www.hiteq.org/Hiteq/Downloads/Publicaties\%2ogeheel/Kenmerkend\%20vmbo\%2ombo\%20havo\%20 en\%2ovwo.pdf.

28. Neut I van de, Teurlings C, Kools Q. Inspelen op leergedrag van vmbo-leerlingen. [Responding to learning behaviour of pre-vocational secondary students.]. Tilburg: IVA., 2005. http://www.aanvalopschooluitval.nl/userfiles/file/ CPB rapport.pdf.

29. Goodman R, Ford T, Simmon, H, Gatward R, Meltzer H. Using the Strengths and Difficulties Questionnaire (SDQ) to screen for child psychiatric disorders in a community sample. Brit / Psychiat. 2002;177:534-539. doi: 10.1192/ bjp.177.6.534

30. Goodman R. The Strengths and Difficulties Questionnaire: A Research Note. / Child Psychol Psych. 2006;38(5):581-86. doi: 10.1111/j.1469-7610.1997.tbo1545.x

31. Muris P, Meesters C, Berg F van den. The Strengths and Difficulties Questionnaire (SDQ) - Further evidence for its reliability and validity in a community sample of Dutch children and adolescents. Eur Child Adoles Psy. 2003;12:1-8. doi: $10.1007 /$ s00787-003-0298-2

32. Widenfelt BM van, Goedhart AW, Treffers PDA, Goodman R. Dutch version of the Strengths and Difficulties Questionnaire (SDQ). Eur Child Adoles Psy. 2003;12:281-89. DOI 10.1007/s00787-003-0341-3

33. Vogels ACM, Hoekstra F, Reijneveld SA. Drie vragenlijsten voor het opsporen van psychosociale problemen bij kinderen van zeven tot twaalf jaar. [Three questionnaires for the detection of psychosocial problems in children from seven to twelve years.]. Leiden: TNO Quality of life. The Netherlands. 2005. http://www.ggdkennisnet.nl/? file=211 4\&m=1310999371\&action=file.download.

34. SCP Dutch Institute for Social Research. http://www.scp.nl/.

35. Central Statistics Office, Dutch National Youth Monitor. (2012). The Hague, the Netherlands. www.jeugdmonitor.cbs.nl/.

36. Mokkink LB, Lee JH van der, Grootenhuis MA, Offringa M, Praag BMS van, Heymans HSA. Omvang en gevolgen van chronische aandoeningen bij kinderen. [Scale and impact of chronic diseases in children.]. Tijds Kindergeneeskunde. 2007:75:154-58. doi:10.1007/BF03061684

37. Dutch ministry of education. Speciaal onderwijs. [Disability-specific special schools.]. 2012. http://www.rijksoverheid.nl/ministeries/ocw.

38. Snyderman R, Langheier J. Prospective health care: the second transformation of medicine. Cenome Biol. 2006;7:104. doi:10.1186/gb-2006-7-2-104

39. Kessler R, Amminger GP, Aguilar-Gaxiola S, Alonso J, Lee S, Ustin TB. Age of onset of mental disorders: a review of recent literature. Curr Opin Psychiatr. 2007;20(4):359-64. doi:10.1097/YCO.obo13e32816ebc8c

40. Demyttenaere K, Bruffaerts R, Posada-Villa J, et al. Prevalence, severity, and unmet need for treatment of mental disorders in the World. Health Organization World Mental Health Surveys. The WHO World Mental Health Survey Consortium. Jama. 2004;291:2581-90. doi:10.1001/jama.291.21.2581

41. Theil A, Verkerk PH, Buiting E. Snel terug naar school. [Quickly back to school.]. Medisch Contact. 2007;62:31-32.

42. Eiser C. Growing up with a chronic disease: the impact on children and their families. London: Jessica Kingsley Publishers. 1993.

43. Lenzen C FG, Jentzsch A, Kaess M, Parzer P, Carli V, Wasserman D, et al. Schulabsentismus in Deutschland - die Prävalenz von entschuldigten und unentschuldigten Fehlzeiten und ihre Korrelation mit emotionalen und Verhaltensauffälligkeiten. [School absenteeism in Germany: prevalence of excused and unexcused absenteeism and its correlation with emotional and behavioural problems.]. Prax Kinderpsychol K. 2013;62 (8):570-82. doi:http:// www.vr-elibrary.de/doi/abs/10.13109/prkk.2013.62.8.570 


\section{Case histories}

\section{Roos}

Roos is a new student in the first class of secondary school. She leaves for home two to three times a week with complaints of nausea and stomach aches. Once she is home her complaints quickly disappear. Roos has no idea what causes her complaints and is fed up with the situation herself. In the meeting with the mentor Roos' parents indicate they don't know what to do. Roos says she quite enjoys school. However, she is intimidated by the maths teacher. She is in a very noisy class and several times already the maths teacher has sent children out. Once they discuss it, the parents notice that she is often nauseous on the days she has maths class. The mentor arranges a meeting between himself, the maths teacher and Roos. Roos is quite relieved to find out that the maths teacher is quite a nice person. Her sickness reporting stops.

\section{Younes}

Younes (13 years old, second class) regularly has problems with teachers. He is restless in class and often has not done his homework. Lately his mother has reported him sick a few times. The mentor invites them to come and discuss this with him. That is when his mother tells that Younes suffers from ADHD (Attention Deficit Hyperactivity Disorder) and is on medication, which he regularly forgets to take. He is also not a good sleeper. Younes prefers the teachers not to know this. His mentor explains that it might help if the teachers know, because they will be better able to understand his behaviour in class. Younes then admits that he dislikes the fact that teachers are always nagging and finding fault with him. It even gives him stomach aches. They jointly agree that the mentor can inform the teachers. And Younes receives special support from school.

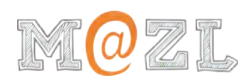




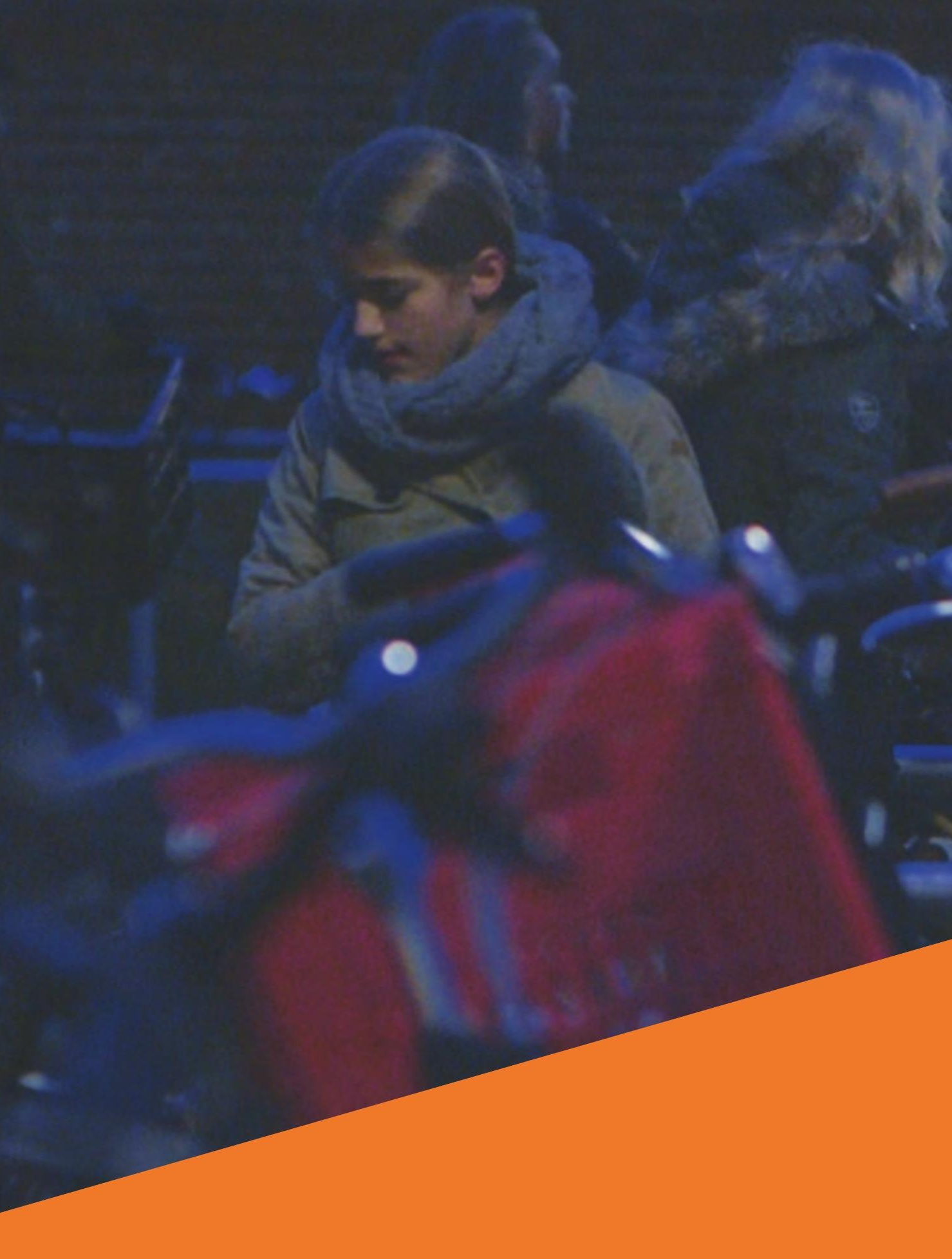





\section{Chapter 4}

\section{Chapter 4: Addressing medical absenteeism in pre-vocational secondary students: effectiveness of a public health intervention, using a quasi- experimental design}

YTM Vanneste, JJP Mathijssen, LAM van de Goor, MC Rots-de Vries, FJM Feron.

\section{Abstract}

Objective: Students' health and school absenteeism affect educational level, with adverse effects on health prospects. This interdependence is definitely reflected in medical absenteeism. In the Netherlands, a public health intervention has been developed to address medical absenteeism in pre-vocational secondary education. This study aims to investigate the effectiveness of this intervention on students' medical absenteeism.

Method: A quasi-experimental design with an intervention group and a control group was applied. Multilevel analysis was used to study differences in the development of the level of a student's medical absence over time (after 3 and 12 months).

Results: In the intervention group, the level of absenteeism decreased from 8.5 days reported sick in 12 school weeks to 5.7 days after 3 months, and to 4.9 days after 12 months. The number of absence periods fell from 3.9 in 12 school weeks to 2.5 after 3 months, and to 2.2 after 12 months. In the control group, the absence days initially decreased from 10.4 to 9 in 12 school weeks, after which an increase to 9.3 was measured. The number of absence periods initially decreased from 4.4 to 3.4 , after which an increase to 3.7 was measured. The number of absence days per period remained about the same in both groups.

Conclusion: The intervention appears to be effective for Dutch pre-vocational secondary students with increased absence rates, and therefore seems to be a promising approach for addressing medical absenteeism. Personalized management of medical absenteeism by systematic identification of students with extensive medical absenteeism, and consistent referral to youth health care physicians, is more effective than 'care-as-usual'. The difference between aspects of medical absenteeism in number of absence periods and days per period is important for understanding that the effectiveness of the intervention is shown primarily by a decrease in the number of periods reported sick.

Key words: school absenteeism, medical absenteeism, preventive youth health care, intervention research, health inequalities, pre-vocational secondary education.

Under review: BMC Public Health 


\section{Background}

School absenteeism induces socioeconomic health inequalities because it may lead to a lower level of education or even to school dropout [1-4]. Low educational level and school dropout are both strongly associated with an increased risk of social failure and delinquency [5-9], increased risk behaviour (e.g. smoking, obesity, lack of exercise) [10,11], a higher prevalence of mental problems and chronic health issues [12-15], and higher mortality rates [16-21].

Literature frequently distinguishes between unexcused and excused school absenteeism. Unexcused absenteeism is truancy, not attending school without permission. Excused absence means not attending lessons with permission because of familial or personal reasons, with sickness reporting, so-called medical absenteeism, as a major reason. Prevalence rates on school absenteeism as reported in literature are not directly comparable internationally, due to inconsistent use of parameters for school absenteeism. Nowadays, figures at the national level show that medical absenteeism occurs approximately twice as often as truancy [22-24]. In the Netherlands in 2002 medical absenteeism was more prevalent in pre-vocational secondary education than in the other two tracks in secondary education (higher general secondary education and pre-university education): $4 \%$ v. $3.7 \%$ and $3.4 \%$ [25]. No more recent valid figures on absenteeism are available. Because of the strict enforcement of measures against truancy in recent years and on the basis of current international figures, it is conceivable that in the Netherlands also, the medical absence rate has increased meanwhile compared to truancy.

Research on medical absenteeism shows that it is caused not only by medical problems or psychiatric disorders $[2,26]$, but also by a low threshold for reporting sick, by risk behaviour, or stress-related physical complaints $[2,22]$. The latter may have more complex causes such as psychological, family, or social problems related to medical absenteeism [2]. Students attending Dutch pre-vocational secondary education are less positive about their health, have a poorer lifestyle and more psychosomatic complaints [27,28], and more often demonstrate behavioural problems [29], which may explain their higher medical absenteeism. Moreover, these students have difficulties planning their studies [30]. Consequently, they experience problems in catching up after once having fallen behind. When dropping out, these students cannot fall back on a lower level of education. This explains why dropout rates are the highest in pre-vocational secondary education. On average three quarters of the new early school-leavers that are registered each year come from pre-vocational secondary education [31].

Until now, the only programmes for reducing absenteeism developed and applied relate to unexcused absence and school refusal behaviour [2]. It would be recommendable to develop interventions for addressing medical absenteeism, especially for pre-vocational secondary students, because of its increased prevalence and risk of dropout. Taking into account the aforementioned causes of medical absenteeism, school absenteeism in cases of sickness reporting was assumed to be reduced by providing personalized care, support, and guidance addressing these multiple causes. In the Netherlands a standardized approach for addressing 
medical absenteeism is not yet available. Medical absenteeism is not an area of responsibility of Compulsory Education. The authority to decide how to deal with the absence lies with the schools. In some countries schools decide that sick reports must be verified by an appropriately licensed medical professional in order to be accepted, regardless of the length of absence. As Dutch medical professionals are not allowed to make statements about medical conditions or learning abilities, medical absenteeism from school depends solely on parental sickness reporting. Therefore, the youth health care department of the Regional Public Health Service West Brabant (a region in the southwest of the Netherlands with a population density of 375 people per square kilometre) developed the MASS intervention [32] (see Box) in collaboration with the educational sector and the municipal school attendance service for compulsory education in West Brabant. Students with increased medical absence rates (i.e. four periods in 12 school weeks, or more than six consecutive school days) are identified by the school, and are then referred to youth health care physicians (YHCPs) who look, in a broad and bio-psychosocial perspective, for factors that contribute to the student's medical absence. In addition, the physician, together with student, parents and school, prepares a management plan based on guidelines for care, counselling, and educational adaptation. This plan describes what is needed to improve the student's health and well-being and to maximize the participation in school activities, thus protecting the student against underachievement and dropout from education. Recently, Hawkrigg and Payne presented a more or less similar practical approach to prolonged school non-attendance [33]. The MASS intervention was included in a survey on European real-life interventions that aim to reduce socioeconomic health inequalities [34].

Box: Description of the Dutch intervention 'Medical Advice for Sick-reported Students', abbreviated as MASS.

The MASS intervention consists of an integrated approach in a public health setting. MASS provides a clear framework in which schools, in direct collaboration with youth health care physicians (YHCPs), are able to reach students and their parents, discuss aspects of the student's medical absence, and design and monitor a management plan that aims to optimize students' health and maximize students' participation in school activities. In summary, the aim of the MASS intervention is to limit the absenteeism by arranging appropriate care, educational adjustments and adequate support for students and parents. A systematic routine is followed.

\section{Step 1 School's policy}

The school communicates with students and parents about the new policy in case of absenteeism because of medical reasons.

\section{Step 2 Referral to the YHCP}

Students with extensive medical absence are identified by school by using well-defined threshold criteria: reported sick four times in 12 school weeks or more than six consecutive school days (MASS-criteria). Meeting the criteria always leads to a referral to the YHCP for student and parents. 


\section{Step 3 Consultation of student and parents with the YHCP}

During the interview and medical assessment YHCPs look for biological, psychological and social factors that contribute to the students' medical absenteeism. The YHCP identifies whether there is a specific somatic or psychiatric diagnosis to account for the absence. If the diagnosis is clear the focus will be on optimising the (adherence to) treatment. In cases of frequent physical complaints and psychosocial problems with no clear medical diagnosis, the YHCP considers diagnostics, and looks for family and school related factors, as well as health risk behaviours and lifestyle aspects that contribute to the physical complaints and psychosocial problems. If needed, the YHCP refers to a medical specialist or a psychosocial support network. A management plan is then designed together with student, parents and school, and with curative professionals, if applicable. This plan includes agreements on cure, care and school attendance.

\section{Step 4 Monitoring the management plan}

School and YHCP monitor the execution of the management plan.

To the best of our knowledge, the effectiveness of an intervention for addressing extensive medical absenteeism has not been investigated before. The objective of the current study is to evaluate the effects of the MASS intervention in pre-vocational secondary education: is there a decline in students' level of medical absenteeism following systematic identification and consistent referral to the YHCP of students with extensive medical absenteeism, compared to a situation in which this is not offered?

\section{Methods}

\section{Setting}

The study was conducted in the Netherlands, West-Brabant region. In school year 2011-2012, the MASS intervention had been applied by seven schools for pre-vocational secondary education.

\section{Study design and population}

The study had a quasi-experimental design, with 7 intervention schools that had applied the MASS intervention, and 7 control schools that had not applied the MASS intervention. These pre-vocational secondary schools were all located in the West-Brabant region. The intervention group consisted of students who were attending one of the intervention schools, had been identified by the school as having extensive medical absence (according to the MASS-criteria, i.e. four periods in 12 school weeks, or more than six consecutive school days), and had been referred to the YHCP during school year 2011-2012. The control group consisted of the absence data from students who were attending one of the control schools. In 2014, these control schools were asked to participate in the study retrospectively by providing the anonymised absence data of their students. The students were selected by determining the medical absence rate at two points in time (December 1 and February 1 ). When the level of absence met one of the MASScriteria, the student was included. The characteristics of the schools are described in Table 1. 
Table 1: The characteristics of the intervention and control schools.

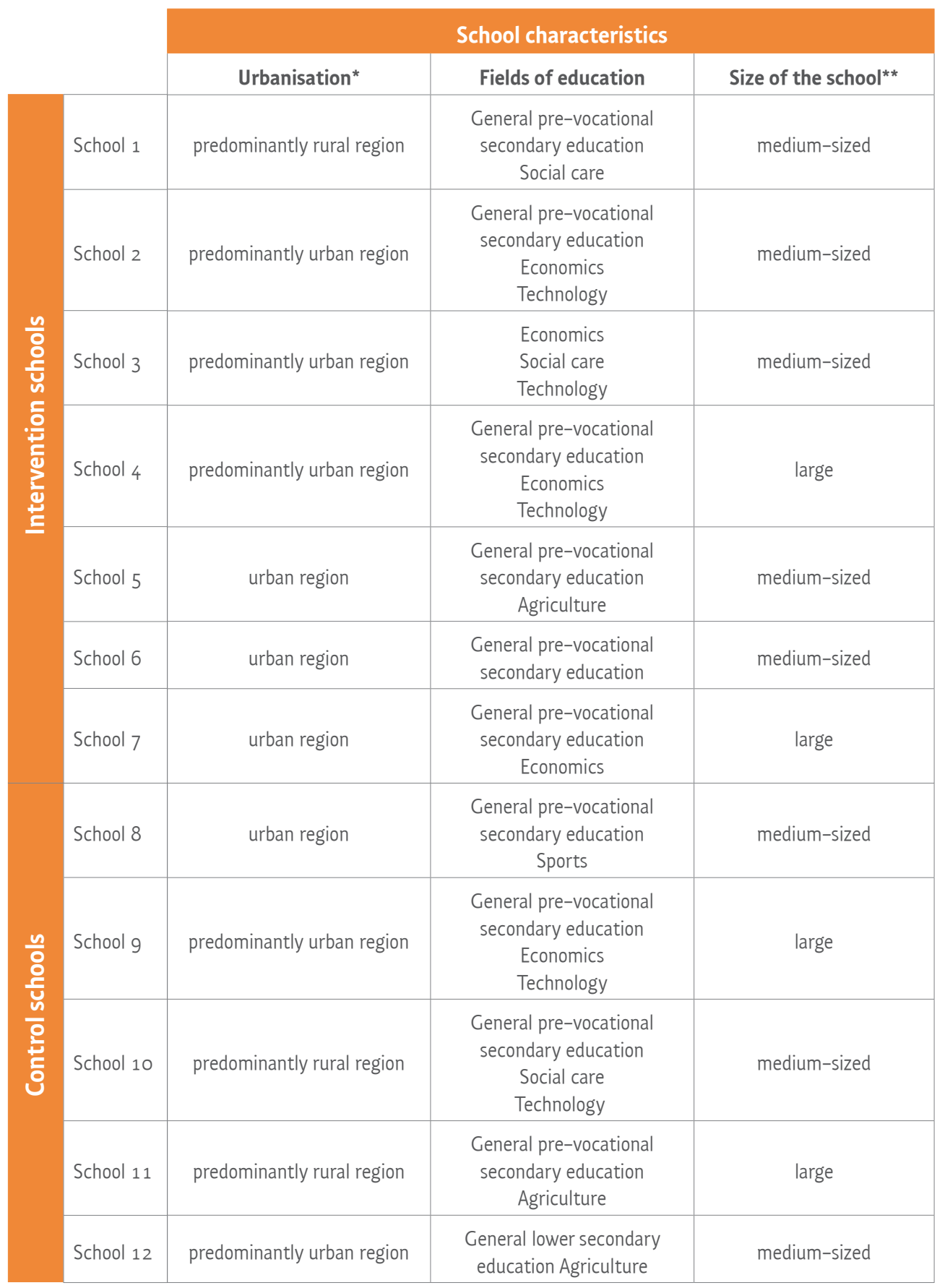




\begin{tabular}{|c|c|c|c|}
\hline School 13 & predominantly urban region & $\begin{array}{c}\text { Ceneral lower secondary } \\
\text { education Economics } \\
\text { Social care } \\
\text { Technology }\end{array}$ & small \\
\hline School 14 & rural region & $\begin{array}{l}\text { Economics } \\
\text { Social care } \\
\text { Technology }\end{array}$ & medium-sized \\
\hline
\end{tabular}

*Urbanisation: rural (<200 inhabitants per square kilometre), predominantly rural region (200-500 inhabitants per square kilometre), predominantly urban region (500-1000 inhabitants per square kilometre) and urban (>1000 inhabitants per square kilometre) ${ }^{* *}$ Size of the school: small ( $<250$ students), medium-sized ( $250-750$ students) and large ( $>750$ students).

\section{Data collection procedure and outcome measurements}

In order to determine the level of medical absence, the school absence registration over the school years 2011-2012 and 2012-2013 was used. The level of medical absence was measured at three points in time. For the intervention group, the first time (To) was when the student was invited to the YHCP. At the end of the consultation written informed consent was obtained from students and parents to participate in the study. For the control group, the first time (To) was on December 1 or February 1. After 3 months $\left(T_{1}\right)$ and 12 months $\left(T_{2}\right)$ the measurement was repeated. In accordance with the Dutch public health act [35], collection of data to perform anonymous group comparisons does not require prior informed consent.

The level of a student's medical absence was measured as the number of absence periods and absence days reporting sick during the 12 school weeks prior to the three measurement points. Partial absences such as going home during the day because of sickness were counted as full-day absences. When still reported sick after autumn, spring, and Christmas breaks absences counted for new sickness reporting. Due to the shifting of summer holidays, the irregular school hours during the first school week and the examination weeks at the end of the school year, the level of medical absence was calculated only between September 1 and June 1. When the measurement period was (partly) outside this period, the absence rate was recorded as 'missing'.

\section{Ethical approval}

The research protocol was approved by the Medical Ethics Committee of the University Hospital Maastricht and Maastricht University (Dossier number 11-4-070.6/ivb).

\section{Statistical analysis}

Pearson's chi-squared tests (for categorical variables) and Student's t-test (for continuous variables) were used to determine differences in socio-demographic variables between the intervention group and the control group.

Due to the hierarchical structure of the data, with the students (first level) nested within schools (second level), we applied repeated measurements within multilevel analysis (linear mixed models in SPSS, version 19.0) for studying differences between the intervention group and the control group in the development of the level of medical absence over time. 


\section{Results}

The total study group, including both intervention and control groups, consisted of 938 students, of whom $40.2 \%$ were male and $59.8 \%$ female. As shown in Table 2 , there is a significant difference between the two groups in gender, age, absence rate in periods, and absence rate in days. The intervention group had a higher proportion of males, a somewhat higher average age, and a lower absence rate in terms of both periods and days (initial values). There was no statistically significant difference in the number of days per period between the groups.

Table 2: The selected demographic characteristics and the initial values of medical absenteeism of the intervention and control groups.

\begin{tabular}{|l|c|c|c|}
\hline & $\begin{array}{c}\text { Intervention group } \\
(493)\end{array}$ & $\begin{array}{c}\text { Control group } \\
(445)\end{array}$ & Statistical values \\
\hline Gender, \% male & $44.2^{*}$ & 35.7 & $\chi^{2}=7.01^{* *}, \mathrm{df}=1$ \\
\hline Age in years, mean (SD) & $14.54(1.32)$ & $14.32(1.28)$ & $\mathrm{t}=2.49^{*}$ \\
\hline $\begin{array}{l}\text { Absence rate in periods } \\
\text { per 12 school weeks, } \\
\text { mean (SD) }\end{array}$ & $3.91(1.62)^{* *}$ & $4.50(1.16)$ & $\mathrm{t}=-6.20^{* *}$ \\
\hline $\begin{array}{l}\text { Absence rate in days } \\
\text { per 12 school weeks, } \\
\text { mean (SD) }\end{array}$ & $8.40(5.39)^{*}$ & $9.92(5.39)$ & $\mathrm{t}=-4.27^{* *}$ \\
\hline $\begin{array}{l}\text { Number of days per } \\
\text { period }\end{array}$ & $2.29(1.53)$ & $2.39(1.67)$ & $\mathrm{t}=-0.95$ \\
\hline
\end{tabular}

${ }^{*} \mathrm{p} \leq 0.05 ;{ }^{* *} \mathrm{p} \leq 0.01$

Multilevel analysis showed a significant effect over time on the absence rate in periods ( $F=215.63$; $p \leq 0.01)$, and a significant interaction effect $(F=28.25 ; p \leq 0.01)$ in favour of the intervention group. Figure 1 shows that in the intervention group the number of absence periods decreased over time: from $3.9(95 \% \mathrm{Cl}: 3.6-4.2)$ to $2.5(95 \% \mathrm{Cl}: 2.2-2.8)$ and finally to 2.2 (95\% Cl:1.9-2.5) times reported sick in 12 school weeks. In the control group, the number of absence periods initially decreased from $4.4(95 \% \mathrm{Cl}: 4.2-4.7)$ to $3.4(95 \% \mathrm{Cl}: 3.1-3.7)$, after which an increase to 3.7 (95\% $\mathrm{Cl}: 3.4-4.0)$ was measured.
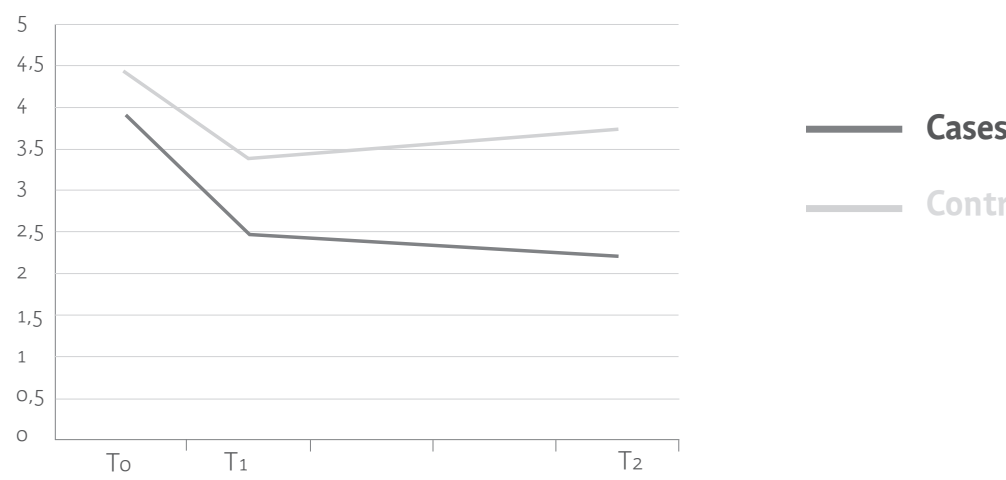

Figure 1: The progress of the absenteeism in number of periods. 
With respect to the absence rate in total number of days, there was a significant effect over time ( $F=60.99 ; p \leq 0.01)$ and a significant interaction effect $(F=14.68 ; p \leq 0.01)$. Again the intervention group scored better than the control group. Figure 2 shows that in the intervention group the total number of absence days in the 12 week period decreased over time: from 8.5 (95\% $\mathrm{Cl}: 7.1-9.8)$ to $5.7(95 \% \mathrm{Cl}: 4.4-7.1)$ to $4.9(95 \% \mathrm{Cl}: 3.5-6.2)$ days reported sick. In the control group, the number of absence days initially decreased from 10.4 (95\% $\mathrm{Cl}: 9.1-11.8)$ to 9 $(95 \% \mathrm{Cl}: 7.6-10.3)$ days, after which an increase to $9.3(95 \% \mathrm{Cl}: 7.9-10.7)$ was measured.

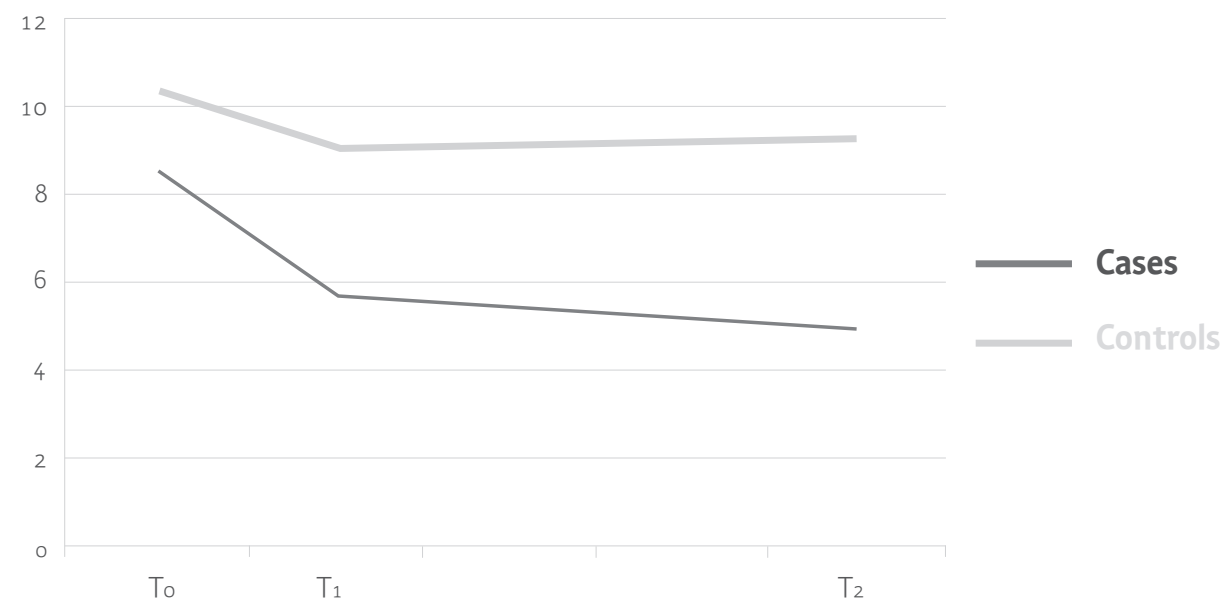

Figure 2: The progress of the absenteeism in number of days. Because of the application of a multilevel model for this part of the analysis, the initial value of 8.5 days differs from the initial value in Table 1.

With respect to the number of days per period, there was no significant effect over time ( $F=1.09$; $p>0.05)$ and no significant interaction effect $(F=0.60 ; p>0.05)$. Figure 3 shows that in the intervention group the number of days per period initially remained the same over time: from 2.3 (95\% $\mathrm{Cl}: 1.7-2.9)$ to $2.3(95 \% \mathrm{Cl}: 1.7-2.9)$, after which it decreased slightly to 2.2 (95\% $\mathrm{Cl}: 1.6-$ 2.9). In the control group, the number of days per period increased initially from 2.7 ( $95 \% \mathrm{Cl}: 2.1-$ $3.3)$ to $3.0(95 \% \mathrm{Cl}: 2.4-3.6)$ days, after which a decrease to $2.8(95 \% \mathrm{Cl}: 2.2-3.4)$ was measured.

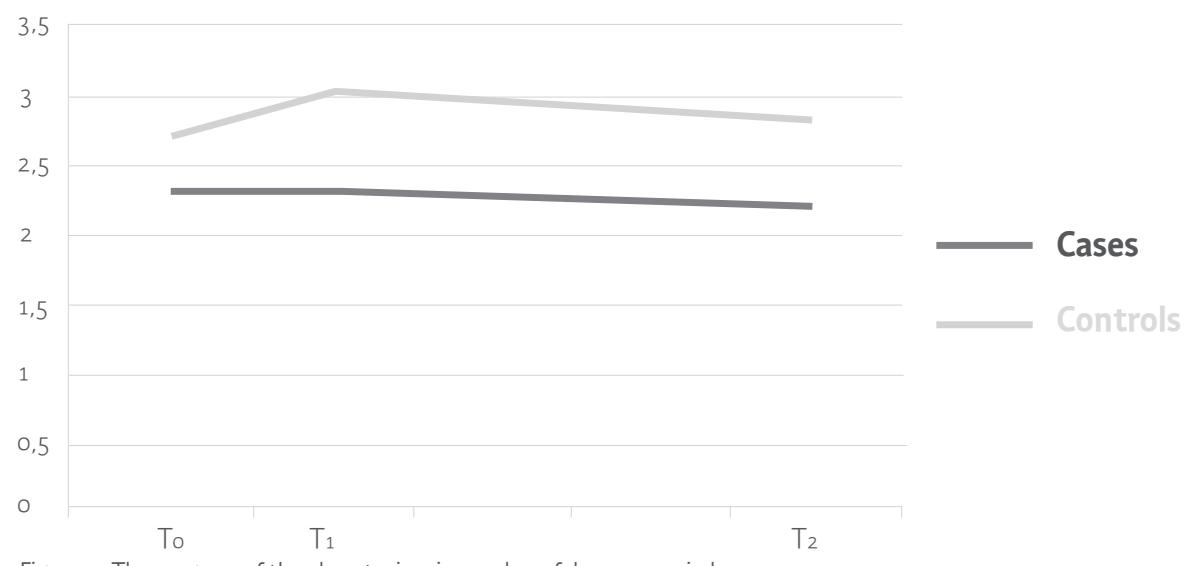

Figure 3: The progress of the absenteeism in number of days per period. 
No gender effect was found on the absence rate in periods $(F=0.01 ; p>0.05)$ and total number of days $(F=0.03 ; p>0.05)$. This also applies to age, according to the absence rate in periods $(F=0.07 ; p>0.05)$ and total number of days $(F=1.29 ; p>0.05)$.

\section{Discussion}

To the best of our knowledge, this was the first study on the effectiveness of an intervention for addressing medical absenteeism in which a Regional Public Health Service and schools collaborated intensively. The objective of this quasi-experimental study was to investigate the effects of this intervention on medical absenteeism in Dutch pre-vocational secondary education, compared to a situation in which this intervention is not offered.

The study showed a decrease in the number of absence periods and days in the intervention group and the control group. The effects, however, were significantly stronger in the intervention group. Since only students with the highest rates of absenteeism were included in this study, 'regression-to-the-mean' could (partly) explain the initial decrease. However, the effect measured in the control group is much less strong. This supports the hypothesis that the rapid decline of absenteeism after three months is also due to the attention generated by the MASS intervention. We know for certain that the schools had paid attention to all students in the intervention group, including referrals to the YHCP.This probably did not happen with all students in the control group. The effect after 12 months might be explained by the multimodal approach: the underlying reasons for the absenteeism had been analysed from a broad and biopsychosocial perspective, based upon which appropriate care and support could be arranged by schools and YHCPs. With respect to the number of days per period, no significant effects were found. This means that the students were reported sick less often on average after referral to the YHCP, but the average number of days per sickness period remained unaltered. It suggests that a two days absence could be experienced as a natural minimal period for one sick report. The significant decrease in total number of days of medical absence therefore appears to be explained by a significant decrease in frequency of sickness periods in the 12 school week period.

In literature various parameters are used as a measure of absenteeism, including number of days per month or per year, and percentages of students that are absent at a given time. Sometimes students are questioned about the frequency of their absence, or alternatively the level is derived from the absence registration of the school or from the absence reporting systems of agencies for compulsory education [2]. In this study it was decided to use the 'number of periods' and 'number of days' reported sick over a period of 12 school weeks to measure medical absenteeism. Practice shows that the study outcomes of students are adversely affected not only by the length, but also by the frequency of (short-term) absences, and that therefore both present similar risks. The measurement period, i.e. 12 school weeks, was chosen not only because of the MASS-criteria for referral to the YHCP, but also because the period is long enough to diminish seasonal influences and short enough to make the measurement as accurate as possible. Accurate measurement was also possible because periods of irregular school hours were excluded.

Medical absence rate was chosen as the central outcome measurement in this study because it is a prime reason for school absenteeism which in turn is related to a lower level of education or even school dropout. Our research shows that, after systematic identification of students with 
extensive medical absenteeism and consistent referral to the YHCP, as was done in the MASS intervention, students' medical absenteeism decreased in comparison to students who received 'care-as-usual'. However, this study provides no definite answers to the question which specific factor is responsible for this decrease. It is known from literature that medical absence can be due to a low threshold for reporting sick [2]. A combination of systematic, and thereby improved, identification of students with extensive medical absenteeism, resulting in the school paying more attention to students' medical absenteeism, and referral to the YHCP, makes students feel that they and their absenteeism are not ignored but taken seriously. This can result in a raised threshold for reporting sick in future. As mentioned earlier, medical absenteeism is associated with various psychosocial and health-related problems. The decrease in medical absenteeism can be attributed to the intervention of the YHCP, resulting in more personalized and adequate care or support. As a consequence, students possibly experience fewer (health-related) problems and/or find better ways to deal with their problems. It is recommended to further investigate the effects of the intervention on the care and support initiated by school and health care, on the satisfaction of students and parents with care and support, and on students' well-being and mental and/or physical health.

It is likely that the results can be generalized at national level. If the MASS intervention is properly implemented in pre-vocational secondary schools in other Dutch regions, similar effects are to be expected. The control schools were generally situated in rural areas. It is unknown in which way this affected the counselling of students with extensive medical absenteeism. That the schools were not yet applying the intervention may be due to the fact that they were more hesitant and reserved about implementing a new approach, or because they assumed their'care-as-usual'was already working well. This study refutes to some extent the second assumption regarding the effectiveness of their care for students with extensive medical absenteeism. However, the effects that can be expected at other educational levels still remain uncertain. In addition it also remains unclear to what extent these results can be generalized internationally, since both public health care and school systems differ substantially across countries. At the same time, it can be stated that, in general, medical absenteeism has a wide variety of causes, and personal attention to individual students is necessary to create an effect on medical absenteeism.

In the total study population, more female $(59.8 \%)$ than male $(40.2 \%)$ students met the criteria for extensive medical absenteeism. The gender ratio of $60: 40$ is confirmed in literature $[2,26]$. Between the two study groups, there was a significant difference in gender and age, meaning that males and older students had been referred to the YHCP more often. This could be caused by the inclusion procedure in both study groups. In the intervention group, despite the fact that schools had been instructed to consistently refer to the YHCP all students who met one of the criteria, schools seemed less inclined to report female and younger students. In the control group, only two points in time were used to include students, and therefore it is not known how many students overall met the criteria. The development of medical absenteeism over time appeared not to depend on gender or age.

Initially there was also a significant difference in absence rate between the two groups in terms of total number of absence periods and days. Students of the intervention group had been referred to the YHCP at the time their absenteeism met one of the criteria, resulting in a To that was close to that moment. However, for the students of the control group who met one of the 
criteria at an early moment during the selected period of 12 weeks, the To was delayed to a later time. This resulted in a significantly higher initial absence rate. Presumably the absence in the intervention group had already decreased owing to the notification of the student by the school or to the invitation for an appointment with the YHCP. Consequently it could be concluded that if the students had been referred to the YHCP as happened in the intervention group, the mean initial absence rate of the control group would have been lower than measured, meaning that the effect of the intervention may have been even greater than measured.

\section{Conclusions}

The MASS intervention seems to be effective: personalized management of medical absenteeism by systematic identification of students with extensive medical absenteeism, and consistent referral to the YHCP, as in the MASS intervention, is more effective than 'care-as-usual'. The difference between medical absenteeism in number of absence periods and in days per period is important for understanding that the effectiveness of the intervention is demonstrated primarily by a decrease in the number of periods reported sick. MASS seems to be a promising tool in the public health setting for addressing medical absenteeism among students, and could potentially be an effective way of taking action against health inequalities.

Competing interests: The authors declare that they have no competing interests.

Authors' contributions: All authors contributed to the study design. YV participated in data collection and coordinated the study. JM supported the analysis of this study. All authors contributed to the interpretation of the data. YV drafted the manuscript, the coauthors critically revised the manuscript. All authors have read and approved the final version of this manuscript.

Acknowledgements: The authors would like to thank all students and youth health care physicians who participated in this study, and to Winke Swinkels who participated in the data collection.

Funding: This study was funded by ZonMw, the Dutch Organization for Health Research and Development.

Availability of Supporting Data: The study data is stored by the Faculty of Social and Behavioural Sciences, Tranzo, Tilburg University in the Netherlands following the Institution's data management policies. Data can be released by researchers in research collaboration based on permission from the steering committee of the study. 
1. Eckstein Z, Wolpin KI. Why Youths Drop Out of High School: the Impact of Preferences, Opportunities, and Abilities. Econ Soc. 1999;67(6):125-1339. doi:10.1111/1468-0262.00081

2. Kearney CA. School absenteeism and school refusal behavior in youth: A contemporary review. Clin Psychol Rev. 2008;28:451-71. doi:10.1016/j.cpr.2007.07.012

3. Christenson SL, Thrulow ML. School Dropouts: Prevention Considerations, Interventions, and Challenges. Curr Dir Psychol Sci. 2004;13:36-39. doi:10.1111/j.0963-7214.2004.01301010.x

4. Rumberger RW. Why Students Drop Out of School and What Can be Done. Dropouts in America: How Severe is the Problem? What Do We Know about Intervention and Prevention? Harvard University. 2001;1-45. http:// civilrightsproject.ucla.edu/research/k-12-education/school-dropouts/why-students-drop-out-of-schooland-what-can-be-done/rumberger-why-students-dropout-2001.pdf.

5. Traag T, Marie O, Velden R van de. Risicofactoren voor voortijdig schoolverlaten en jeugdcriminaliteit. [Risk factors for school dropout and juvenile delinquency.]. 2010;55-60. http://www.cbs.nl/NR/rdonlyres/131FADA3-2E22-4E519A91-6BB53E1E0895/0/2010k2b15P55art.pdf.

6. Beckers ITT, Traag T. Met een startkwalificatie betere kansen op de arbeidsmarkt. Sociaaleconomische trends. [Better opportunities in the labour market with a basic qualification. Socioeconomic Trends.]. The Hague: Statistics, the Netherlands, 2005:23-28. http://www.cbs.nl/NR/rdonlyres/31B62F76-21E2-40C8-86AB230589D4FgEA/o/2007k3v4p23art.pdf.

7. Junger-Tas J. Diploma's en goed gedrag II: Preventie van antisociaal gedrag in het onderwijs. [Diplomas and good behaviour II: Prevention of antisocial behavior in education.]. The Hague: Dutch Ministry of Justice. 2002. http:// members.multimania.nl/veiligeschool/Preventie\%20van\%20antisociaa\%2ogedrag.pdf.

8. Ross CE, Wu C-L. The Links between Education and Health. Am Sociol Rev. 1995;60(5):719. doi:10.2307/2096319

9. Galobardes B, Lynch J, Smith CD. Measuring socioeconomic position in health research. Br Med Bull. 2007;8182:21-37. doi:10.1093/bmb/ldmoo1

10. Droomers M, Schrijvers CTM, Mheen Dvd, Mackenbach JP. Educational differences in leisure-time physical inactivity: a descriptive and explanatory study. Soc Sci Med. 1998;47(11):1665-76. doi:10.1016/So2779536/g8)00272-X

11. Droomers M, Schrijvers CTM, Stronks K, Mheen Dvd, Mackenbach JP. Educational differences in excessive alcohol consumption: the role of psychosocial and material stressors. Prev Med. 1999;29(1):1-10. doi:10.1006/ pmed.1999.0496

12. Thrane C. Explaining educational-related inequalities in health: Mediation and moderator models. Soc Sci Med. 2006;62(2):467-78. doi:10.1016/j.socscimed.2005.06.010

13. Dahlgren $G$, Whitehead M. European strategies for tackling social inequities in health: Levelling up part 2. World Health Organization Regional Office for Europe. 2006. http://www.eurowho.int/ data/assets/pdf file/o018/103824/E89384.pdf.

14. Mackenbach JP. Health Inequalities: Europe in Profile. Tackling Health Inequalities: Governing for Health. Rotterdam: European Commission. 2006. http://www.who.int/social determinants/resources/european inequalities.pdf.

15. Havas J, Bosma H, Spreeuwenberg C, Feron F). Mental health problems of Dutch adolescents: the association with adolescents' and their parents' educational level. Eur | Public Health. 2009;20(3):258-64. doi:10.1093/eurpub/ ckp172

16. Kulhánová I, Hoffmann R, Eikemo TA, Menvielle G, Mackenbach JP. Educational inequalities in mortality by cause of death: first national data for the Netherlands. Int I Public Health. 2014;59(5):687-96. doi: 10.1007/s00038$014-0576-4$

17. Bosma H, Mheen DH vd, Borsboom GJJM, Mackenbach JP. Neighborhood Socioeconomic Status and All-Cause Mortality. Am J Epidemiol. 2001;153(4):363-71. doi:10.1093/aje/153.4.363

18. Huisman M, Kunst AE, Bopp M, Borgan JK, Borrell C, Costa C, et al. Educational inequalities in causespecific mortality in middle-aged and older men and women in eight western European populations. Lancet. 2005:365(9458):493-500. doi:10.1016/So140-6736/05)17867-2

19. Gathmann C, Jürges H, Reinhold S. Compulsory schooling reforms, education and mortality in twentieth century Europe. Soc Sci Med. 2015;127:74-82. doi:10.1016/j.socscimed.2014.01.037

20. Lager AC), Torssander J. Causal effect of education on mortality in a quasi-experiment on 1.2 million Swedes. Proc Natl Acad Sci USA. 2012;109(22):8461-67. doi:10.1073/pnas.1105839109

21. Mackenbach JP, Stirbu I, Roskam AJ, Schapp M, Menvielle G, Leinsalu M, et al. Socioeconomic inequalities in health in 22 European countries. N Engl | Med. 2008;358(23):2468-81. doi:10.1056/NE/Msa0707519

22. Eaton DK, Brener N, Kann LK. Associations of health risk behaviors with school absenteeism. Does having permission for the absence make a difference? I Sch Health. 2008;78(4):223-9. doi:10.1111/j.1746-1561.2008.00290.x

23. Scottish Executive National Statistics. Results of pupil attendance and absence for session 2006/7. Edinburgh: The Scottish Government, Statistics. 2007. http://www.scotland.gov.uk/Publications/2013/12/4199/17. 
24. Lenzen C FG, Jentzsch A, Kaess M, Parzer P, Carli V, Wasserman D, et al. Schulabsentismus in Deutschland - die Prävalenz von entschuldigten und unentschuldigten Fehlzeiten und ihre Korrelation mit emotionalen und Verhaltensauffälligkeiten. [School absenteeism in Germany: prevalence of excused and unexcused absenteeism and its correlation with emotional and behavioural problems.]. Prax Kinderpsychol K. 2013;62 (8):570-82. doi:http:// www.vr-elibrary.de/doi/abs/10.13109/prkk.2013.62.8.570

25. NIPO het marktonderzoeksinstituut. Rapport: Schoolverzuim in het Voortgezet Onderwijs. [Report on school absenteeism in secondary school.]. Amsterdam. 2002. http://www.tns-nipo.com/pages/persvannipo/pdf/ schoolverzuimo3.pdf.

26. Jones R, Hoare P, Elton R, Dunhille Z, Scharpe M. Frequent medical absences in secondary school students: survey and case-control study. Arch Dis Child. 2009;94:763-67. doi:10.1136/adc.2008.140962

27. Looze Md, Dorsselaer Sv, Roos Sd, Verdurmen J, Stevens G, Gommans R, et al. Gezondheid, welzijn en opvoeding van jongeren in Nederland. [Health, well-being and upbringing of young people in the Netherlands.]. Utrecht: Trimbos Instituut, 2014. http://www.trimbos.nl/ /media/files/gratis\%20downloads/af1327\%20hbsc\%202013.ashx: HBSC.

28. Schrijvers C, Schoemaker CC. Spelen met gezondheid: leefstijl en psychische gezondheid van de Nederlandse jeugd. [Playing with health: lifestyle and mental health of the Dutch youth.]. Bilthoven: RIVM, 2008. http://www.rivm.nl/ bibliotheek/rapporten/270232001.pdf.

29. Groeneveld MI, Steensel KM van, Herben B, et al. Kenmerkend vmbo: een vergelijkend onderzoek naar de kenmerken van vmbo-leerlingen en de 'generatie Einstein'. [Characteristics pre-vocational secondary education: a comparative study of the characteristics of pre-vocational secondary students and the 'Einstein generation'.]. Hilversum: Hiteq, 2008. http://www.hiteq.org/Hiteq/Downloads/Publicaties\%2ogeheel/Kenmerkend\%20vmbo\%2ombo\%20havo\%20 en\%2ovwo.pdf.

30. Neut I van de, Teurlings C, Kools Q. Inspelen op leergedrag van vmbo-leerlingen. [Responding to learning behaviour of pre-vocational secondary students.]. http://www.aanvalopschooluitval.nl/userfiles/file/CPB rapport.pdf. Tilburg: IVA., 2005.

31. Traag T, Velden RKW van de. Early school-leaving in the Netherlands. The role of student-, family- and school factors for early school-leaving in lower secondary education. Research Centre for Education and the Labour Market. 2008/3. http://arnop.unimaas.nl/show.cgi? fid=10250.

32. Vanneste YTM, Rots-de Vries MC, Goor LAM van de, Feron FJM. Medische Advisering Ziekgemelde leerling door de jeugdarts (M@ZL); ontwikkeling van een interventie. [Medical Advice for Sick- reported Students in secondary school by the youth health care physician (MASS); development of an intervention.]. TSC. 2012;90(7):412-19. www.tsg.bsl.nl.

33. Hawkrigg S, Payne DN. Prolonged school non-attendance in adolescence: a practical approach. Arch Dis Child. 2014:99:954-957. doi:10.1136/archdischild-2013-304595

34. Daponte A, Bernal M, Bolívar I, Mateo I, Salmi L-R, Barsanti S, et al. Criteria for implementing interventions to reduce health inequalities in primary care settings in European regions. Eur f Pub Health. 2014;24(6):979-89. doi:10.1093/eurpub/ckuo 44

35. Dutch public health law. http://www.wetten.overheid.nl. 


\section{Case histories}

\section{Joost}

When 15-year old Joost is in the third class of pre-vocational secondary education, he is suddenly absent quite often with headache complaints. Joost is the eldest of four children and last year his youngest sibling Wouter was diagnosed with a benign brain tumour. Wouter has been operated on and fortunately he is doing quite well now. Joost's parents take his headache complaints really serious. He is examined by the general practitioner. Everyone is relieved, for loost turns out to be completely healthy. But since the sickness absence continues, the mentor suggests to Joost and his parents to call in the YHCP. Joost is reluctant, but the mentor insists. The regular absenteeism caused him to fall behind with homework already and Joost is unhappy about it. He likes going to school. In the meeting with the YHCP Joost and his mother acknowledge that things are not well at home. Joost's father is unemployed and has a problem with alcohol. The children have already been placed in care once and mother is afraid this will happen again. There are many social service providers in the home, but they pay little attention to Joost's absenteeism; there are much 'bigger' issues to handle and mother really doesn't know how to deal with it. When the YHCP talks to loost alone for a while, he says he is afraid that his father wil 'knock the daylights' out of his mother and sisters while he is at school; that is why he stays home. He wants to protect them. Sometimes his headaches are genuine, because he has so much to worry about. The YHCP invites all the social workers to the school and in the presence of the parents and Joost they discuss this serious situation. In this meeting it is arranged that first of all loost will be supported by a coach from school.

\section{Kiki}

The mother of Kiki ( 15 years old) indicates in a conversation with the mentor that Kiki is not doing well. She hurts herself (self-mutilation), is very depressed and thinks about suicide. Kiki refuses any form of help and does not want to go to schoo anymore. The mentor suggests to consult a YHCP. Mother discusses this with Kiki. At first Kiki refuses, but when mother says that she can talk to the YHCP on her own, she gives in. Kiki understands that she cannot go on like this. Something has to happen! The YHCP manages to create a bond with Kiki. By supporting Kiki and her parents, also in the direction of specialised psychiatric care, Kiki receives the treatment that she needs. Meanwhile she has fallen back considerably and has no idea how to catch up. Schedules are drawn up by the mentor and support lessons are started by school. Eventually Kiki is doing much better and she comes to school increasingly regular. 


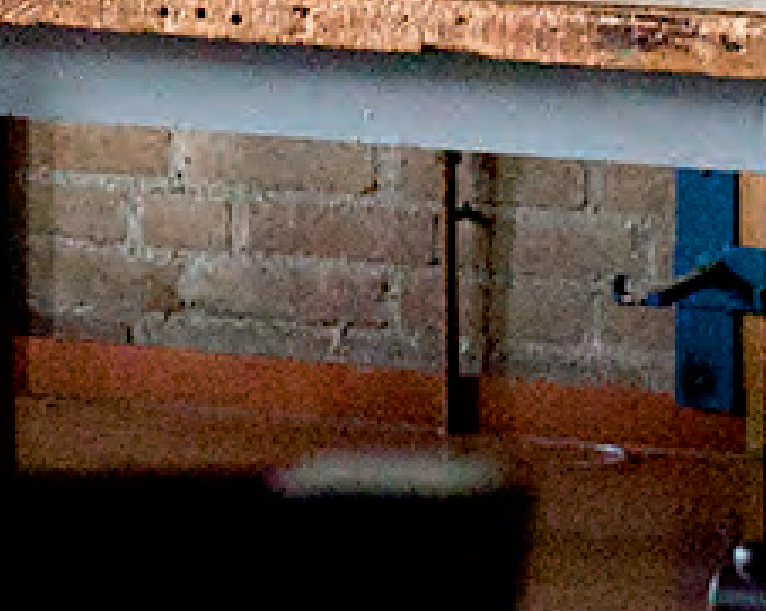

$6^{2}: 9$
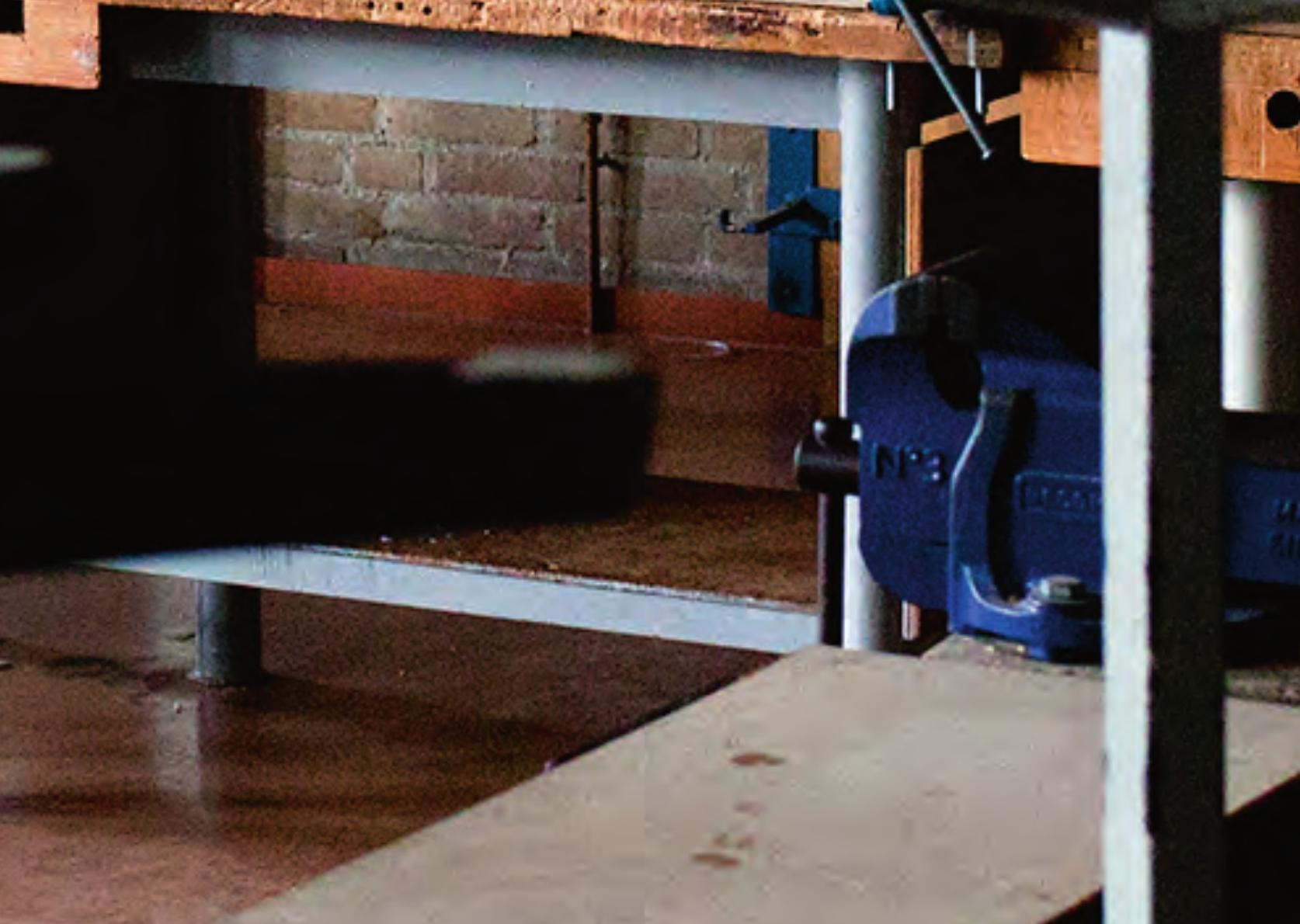


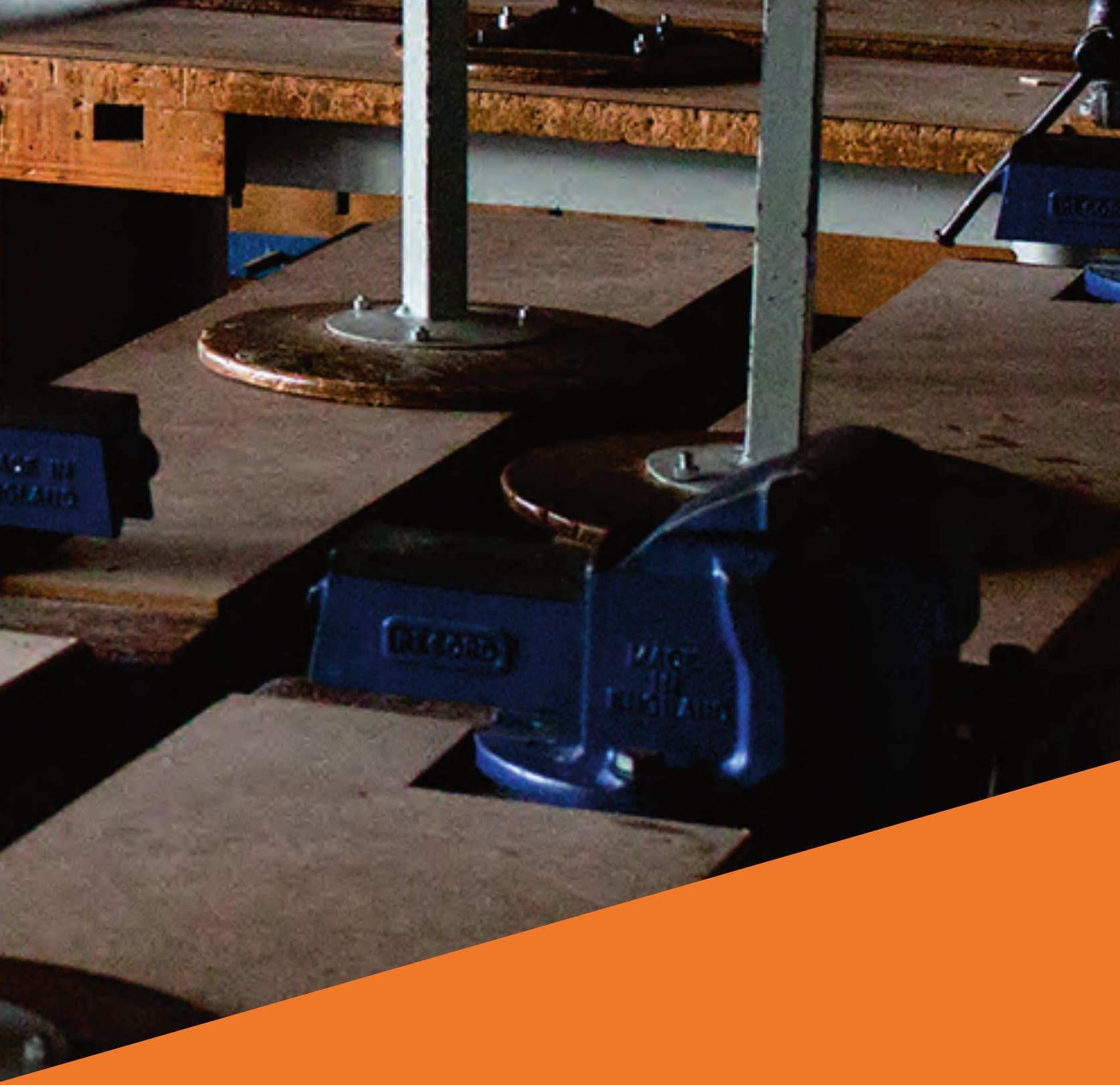

Chapter 5: Attitudes towards addressing medical absenteeism in secondary school 


\section{Chapter 5}

\section{Chapter 5: Attitudes towards addressing medical absenteeism in secondary school}

YTM Vanneste, MHA van de Loo, FJM Feron, MC Rots-de Vries, LAM van de Goor.

\section{Abstract}

Objective: Reducing school absenteeism is of great benefit to the health and educational opportunities of young people, resulting in a reduction of socioeconomic health inequalities. The Dutch intervention Medical Advice for Sick-reported Students (abbreviated as MASS) has been developed to address school absenteeism reported as sickness, so-called medical absenteeism. This study is part of a research project on the effectiveness of MASS and explores factors that influence the implementation and dissemination of the intervention, from schools' perspectives.

Method: A qualitative research method was used. Semi-structured in-depth interviews were held with nine principals and eight special education needs coordinators, working at nine secondary schools that apply MASS. Inductive content analysis was carried out.

Findings: According to the participants, the main reasons for schools to address medical absenteeism are their concerns about students' well-being and future prospects, the wish to share these concerns with students' parents, and the wish to raise the threshold for reporting sick. Moreover, schools believe that reducing medical absenteeism improves educational outcomes. MASS responds to schools' needs by solving 'role conflicts', their main problem when handling medical absenteeism, satisfactorily by providing a clear approach and socio-medical expertise. Schools experience having a constructive dialogue about medical absence with students and their parents as the most difficult part of the implementation. The participants are convinced that MASS also improves parental involvement in school and the quality of care for students, and supports schools in achieving their goal of increasing the number of students that graduate. Schools recognize that these factors can put the subject of addressing medical absenteeism on schools' agendas, thereby supporting adoption and securing sustainable implementation and dissemination of MASS.

Conclusions: Schools' initial reasons for implementing MASS relate to the well-being of individual students. Schools recognize that MASS also ensures the improvement of parental involvement in school, better quality of care for students, and an increased number of students that graduate. These factors can put the subject of addressing medical absenteeism on schools' agendas, thereby supporting adoption and securing sustainable implementation and dissemination of MASS. Adequate communication about the purpose of the intervention and the training of teachers are preconditions for successful implementation. Intersectoral policy seems to be needed.

Key words: preventive pediatric primary care, youth health care, public health, education, medical absenteeism, parental involvement in school, school absenteeism, students, dropout.

Under review: PlosOne 


\section{Introduction}

Whereas education optimizes children's growth and development, and is an indicator for better health and chances of full participation in society [1-6], health also affects educational outcomes $[3,7-10]$. This interdependence calls for collaboration between health care and education [11]. Collaboration can be realized within the approach to medical absenteeism. Substantial absenteeism in secondary school is associated with reduced school performance and school dropout [12-19]. In the Netherlands, half of school absenteeism is related to sick reports, socalled medical absenteeism [20]. Schools are confronted daily with students' medical absence and, as we know from everyday practice, this is not adequately addressed. For this reason the intervention Medical Advice for Sick-reported Students (abbreviated as MASS; see Box 1) has been developed by the preventive youth health care department (YHC) [21, 22] of the Dutch Regional Public Health Service West Brabant, in collaboration with secondary schools and the municipal school attendance service for compulsory education in West Brabant. Since 2010, MASS has been applied at sixteen secondary schools in the West Brabant region. After piloting [23], all these schools are currently involved in a study to collect data on the intervention's effectiveness. For the purpose of this study, two different routes of the MASS intervention were implemented.

Box: Description of the Dutch intervention 'Medical Advice for Sick-reported Students', abbreviated as MASS.

The MASS intervention consists of an integrated approach in a public health setting. MASS provides a clear framework in which schools, in direct collaboration with youth health care physicians (YHCPs), are able to reach students and their parents, discuss aspects of the student's medical absence, and design and monitor a management plan that aims to optimize students' health and maximize students' participation in school activities. In summary, the aim of the MASS intervention is to limit the absenteeism by arranging appropriate care, educational adjustments and adequate support for students and parents. A systematic routine is followed.

\section{Step 1 School's policy}

The school communicates with students and parents about the new policy in case of absenteeism because of medical reasons.

\section{Step 2 Referral to the YHCP}

Schools actively identify students with extensive medical absence, and can choose between two different routes. The first route has well-defined threshold criteria for referring to the YHCP: four times reported sick in 12 school weeks or more than six consecutive school days (MASS-criteria). Meeting the criteria always leads to a referral to the YHCP for student and parents. In the second route, the school decides if and when to confront students and their parents in cases of absence reported as sickness. This dialogue may 
lead to consultation with the YHCP. In both routes the consultation is compulsory. If the appointment is missed, the medical absence is registered as 'not excused' and is reported to the school attendance officer, who will undertake further action.

\section{Step 3 Consultation of student and parents with the YHCP}

During the interview and medical assessment YHCPs look for biological, psychological and social factors that contribute to the students' medical absenteeism. The YHCP identifies whether there is a specific somatic or psychiatric diagnosis to account for the absence. If the diagnosis is clear the focus will be on optimising the (adherence to) treatment. In cases of frequent physical complaints and psychosocial problems with no clear medical diagnosis, the YHCP considers diagnostics, and looks for familyrelated and school-related factors, as well as health risk behaviours and lifestyle aspects that contribute to the physical complaints and psychosocial problems. If needed, the YHCP refers to a medical specialist or a psychosocial support network. A management plan is then designed together with student, parents and school, and with curative professionals, if applicable. This plan includes agreements on cure, care and school attendance.

\section{Step 4 Monitoring the management plan}

School and YHCP monitor the execution of the management plan.

The impact of a public health intervention is determined not only by its effectiveness but also by its dissemination, allowing widespread adoption and implementation beyond the region of origin [24-27]. The effectiveness and dissemination of an intervention can be improved by providing insights into motives for its adoption and into preconditions for implementation, and by ensuring that the intervention matches the needs [28-31]. Schools and preventive youth health care services are both key adopters and users of MASS. It is obvious that youth health care physicians (YHCPs) are motivated to carry out MASS. When students with substantial medical absence are actively identified and referred to YHCPs, these professionals are able to promote, protect, and monitor the health and development of these young people, which is their objective. In contrast, school staff are not legally obliged to address medical absenteeism, because the absence is authorized; and paying attention to medical absenteeism is at best a tool for helping students towards graduation. Consequently, this study focused on the attitudes of school staff towards addressing medical absenteeism. To gain insight into implementation aspects it is clearly necessary to consult school staffs who are already using MASS. By asking principals, who are key players regarding school policy and decision making, and special education needs coordinators (SENCO; see Box 2) who are key players regarding the actual implementation, you gain insight into different and complementary views on adopting and implementing an intervention [25]. 
Box 2: Description of the special education needs coordinator (SENCO).

In the Netherlands, special education needs coordinators (SENCOs) are responsible, in contact with external experts, for arranging the care of students with special needs, both within and outside the school. They coordinate the care policy of the school, and advice and coach colleagues how to act in the best interests of students that need extra care. In school, they are responsible for the implementation of policy changes that are related to the care of students.

The research questions that guided the study included: (1) what reasons motivate school staff to pay attention to extensive medical absenteeism? (2) What are their experiences in applying MASS? (3) What are facilitators and obstacles when implementing MASS, including considerations of sustainability? The first question provides insight into how the intervention should be brought to the attention of schools so as to promote adoption. The second question provides insight into how the intervention matches the needs, and into preconditions for improving implementation. The third question provides insight into the need for sustainable implementation and widespread use.

\section{Methods}

\section{Setting}

This qualitative study is part of a practice-driven intervention study, which aims to evaluate the MASS intervention in pre-vocational secondary schools: by investigating the health condition of pre-vocational secondary students with extensive medical absence, the effectiveness of the intervention, and implementation and dissemination issues.

\section{Study participants}

Participants were principals and SENCOs of schools applying the MASS intervention. The schools varied in educational level, school size, the period of time from when they were implementing MASS and in using the first or second route (see Box 1 for an explanation of the routes). They were recruited using purposive sampling. All those invited agreed to be interviewed. Participants were added until data saturation was reached. The participants and school's characteristics are presented in Table 1. 
Table 1: Overview of participants and school's characteristics

\begin{tabular}{|c|c|c|c|c|}
\hline \multirow[b]{2}{*}{ Participants* } & \multicolumn{4}{|c|}{ School characteristics } \\
\hline & Educational levels & School size $e^{\star *}$ & MASS*** & Route \\
\hline$P_{1}$ and $S_{1}$ & Pre-vocational secondary education & Medium-sized & $>1$ year & First \\
\hline $\mathrm{P}_{2}$ and $\mathrm{S}_{2}$ & Pre-vocational secondary education & Medium-sized & $>1$ year & First \\
\hline $\mathrm{P}_{3}$ and $\mathrm{S}_{3}$ & Pre-vocational secondary education & Large & $>1$ year & First \\
\hline $\mathrm{P}_{4}$ and $\mathrm{S}_{4}$ & $\begin{array}{l}\text { Pre-vocational secondary education, } \\
\text { higher general secondary education } \\
\text { and pre-university education }\end{array}$ & Large & $<1$ year & First \\
\hline $\mathrm{P}_{5}$ and $\mathrm{S}_{5}$ & Pre-vocational secondary education & Small & $<1$ year & First \\
\hline $\mathrm{P}_{6}$ and $\mathrm{S}_{6}$ & $\begin{array}{l}\text { Pre-vocational secondary education, } \\
\text { higher general secondary education } \\
\text { and pre-university education }\end{array}$ & Large & $<1$ year & Second \\
\hline $\mathrm{P}_{7}$ and $\mathrm{S}_{7}$ & Pre-vocational secondary education & Medium-sized & $<1$ year & Second \\
\hline$P_{8}$ & Pre-vocational secondary education & Small & $<1$ year & Second \\
\hline $\mathrm{P}_{9}$ and $\mathrm{S}_{9}$ & Pre-vocational secondary education & Small & $>1$ year & Second \\
\hline
\end{tabular}

* $\mathrm{P}=$ Principal, $\mathrm{S}=\mathrm{SENCO}$, number refers to school. ${ }^{* *}$ Size of the school: small ( $<250$ students), medium-sized ( $250-$ 750 students) and large (>750 students). ${ }^{* *}$ Period of time from when MASS has been implemented.

\section{Data collection}

In order to gain insight into schools' beliefs and perceptions, in-depth interviews were carried out. Semi-structured interviews were conducted face-to-face by two researchers. The interview started with a description of the purpose of the research, the anonymously processed data analysis, and the use of the information received. The topic guide originated from earlier experiences of the investigators [23] and from theoretical grounds derived from the literature [25]. The questions were broad, open-ended, and non-directive. This led to a detailed exploration of participants' views and experiences with regard to the intervention. Topics put forward were reasons for paying attention to medical absenteeism, possible explanations for medical absenteeism, the possible added value of a YHCP in this intervention, opinions about and experiences with the intervention, and factors influencing the implementation of the intervention. The audio-recorded interviews lasted 45 to 90 minutes and were transcribed verbatim for analysis. Field notes taken during the interviews, for example about the atmosphere and body language, were added to the transcripts. After the first seven interviews there was an intermediate analysis to check whether all topics had been covered. Additional schools were selected until no new concepts were identified and the point of data saturation [32] was occurred. Finally, from December 2011 to February 2012, 9 principals and 8 senco's were interviewed, in five of the eight schools implementing the first route and in four of the eight schools implementing the second route of the intervention (see Box 1 for an explanation of the routes). 


\section{Data Analysis}

Initially, an inductive content analysis was carried out [33]. The two researchers together read and open-coded the first seven transcripts and created categories, based on text fragments and the topic guide being used, resulting in a code-book. Next, categories were created within the bounds of Rogers' theoretical frameworks, leading to a deductive content analysis. All transcripts were coded again by one of the researchers, using MAXQDA 10 software [34], with the other researcher reading and assessing the classified codes. Different interpretations of codes were discussed and refined until inter-coder agreement was reached. All data (transcripts, coding tree, and findings) were available for inspection by the coauthors during the research, and are still available to other interested parties. In addition, the participants were asked if the findings matched their experience, and a multidisciplinary research team was asked whether they considered the findings to be clear, understandable, and logical.

\section{Findings}

The findings are described in the order in which the research questions were posed.

\section{Reasons for paying attention to extensive medical absenteeism}

The reasons most often mentioned for paying attention to medical absenteeism are those related to the negative impact of absenteeism on the students. First, the participants express concerns about students' educational achievements. Students miss course material and, as a result, their school performance can decrease, which increases the risk for drifting to a lower educational level and dropout. Moreover, since they have fallen behind, these students need to catch up. Participants observe that students with extensive medical absence often already have problems with structuring their school work and keeping motivated for school. Therefore, these students cannot be left with full responsibility for catching up on missed lessons and assignments. This causes a lot of extra work for teachers. The participants also have concerns about a student's wellbeing, because absence means a lack of the social contacts, structure, and regularity, normally provided by school attendance. Consequently, students can go astray, which not only decreases school performance but also affects their socio-emotional development.

"Students who are often sick miss out on subject matter. Their performance declines. They also
lose out on social aspects and miss a lot of things that happen in class." $\mathrm{S}_{4}$

"Some of our students already struggle to keep up and to structure their school work, and if they are often sick, it becomes even more difficult." $S_{2}$

"Teachers have to deal with that. Therefore, absence always has significant consequences for both students and their teachers." S2

"School is an important part of children's required daily routine. If they are at school, there is structure and routine." $P_{3}$

"If children end up staying at home they will look for entertainment outdoors. But'setting the fox to watch the geese' is asking for trouble." P7 
Secondly, participants mention the wish to share their concerns with students' parents. They are convinced that a child's education and well-being should be more the collective concern and responsibility of both parents and school than is experienced currently. This applies particularly to medical absence, because they presume that only some of the students really are sick.

\section{"Well, it is the parents who report their child sick, in any case. I consider it important to share care with the parents when a child is not doing well." $\mathrm{S}_{4}$ \\ "If students drop out because they start making bad choices and going astray, then it is a problem for the students and their parents, and not only for the school." $\mathrm{P}_{4}$}

The participants assume that there is a wide range of 'hidden' reasons for reporting sick. They spontaneously mention domestic problems first. Problems they mention are: lack of stability, needed at home, and a disturbed relationship between parents and children. They suppose that nowadays there is an increase in domestic problems and broken families, and a lack of structure, safety, and control.

"Frequent medical absenteeism has everything to do with the situation a student finds himself in. I feel that the home situation is a dominant factor here." P8

When probed further, they mention problems at school such as bullying, a study pressure that is too high, a boring school system, difficulties with learning, problems with a teacher. Then child-related problems are mentioned: lifestyle problems such as going out in the weekend, busy with social media and going to bed too late, psychological problems, and social pressure. The participants note that they have gone too far in supporting students, and that parental involvement in school matters is generally too low.

"The student can feel bothered, be bullied." P2

"We also have a lot of trouble with students who are consistently sick on Monday morning; These are students who go out at weekends and party so hard that they are in no state

to come to school."S7

"In our society, parents are increasingly pushing the responsibility for the students' development onto school, and that is a completely wrong development. It is our ambition to increasingly support parents and involve them in the school. Parents are, logically, inextricably bound up with the development of their children, and the school can support that, but the school has different responsibilities." P1

The third reason is the wish to raise the threshold for reporting sick, which arises from the participants' assumption that students are reported sick too easily and, with the collusion of the parents, stay home for the least excuse. They note that it is an obligation not only of the school but also of both parents and children to ensure school attendance. Some participants even mention that reporting sick too easily can result in negative future work ethics. 
"Students are very quick to say they do not 'feel well', and then stay home. It is a slippery slope; when they realize they can easily report themselves sick, next time it will be a smaller step." 44

"It contributes to the changing attitude to standards throughout society; that it matters, that you have rights and duties, and that if you are still of school age you have to go to school." P1

Moreover, the presumption of unjustified sickness reporting can also result in the teachers developing a negative image of the child. They mention that feeling responsible and not being able to share (with parents), in combination with all the extra work involved in helping students to catch up and in supporting them to prevent dropout, causes a lot of frustration for teachers.

"At any moment we interpret students' behaviour; and we draw our conclusions. And these conclusions, this image, will only become stronger. Because we mostly see what we want to see - that fits the picture we have previously built up. You can call it 'tunnel vision'. And, once an image has been formed that a student is 'faking it', it will be hard to break it."S6

\section{Experiences in applying MASS}

At the beginning of the interviews the participants were asked to describe the problems they experienced with medical absenteeism before MASS was implemented. For understanding, it is important to realize that in the Netherlands it is not possible to get sick reports verified by an appropriately licensed medical professional. When trying to reach parents and students to discuss medical absence, the following problems were experienced: to begin with, for each individual teacher there were different considerations that influenced their decision on whether or not to contact parents and students in response to sickness reporting. A shared and objective approach was lacking. And anyway, confronting students and parents was often experienced as unpleasant and difficult. This was caused by doubts about the right tone and content of the dialogue, and was related to the personality, social skills, and frame of reference of the teacher. They feared damage to their relationship with the parents.

"Yes, one teacher might be 'bolder' or 'more forward' than another. And that is the case for all duties one has of course. It is like that at every work place; one person takes his duties very seriously and gets right down to it." P6

"I doubt whether those conversations would be held properly. Because you can have a conversation in many different ways, and one person will deal with it more easily than another."S6

"I think that some teachers are scared at that moment, like 'now I have to have a horrible conversation, because you as a parent report your child as sick too easily, or at least we feel that way'. So I think that some teachers then show avoidance behaviour themselves (laughs)."S1

\section{"I'd better not deal with this now'.'I will just let it slip, and not go into it too much, that way the conversation will not become too difficult." $\mathrm{S}_{3}$}

They also feared that they might overlook something important because of their limited medical knowledge and emphasized that these fears often causes a delay in entering into conversation with students and their parents about the medical absence. 
“I do not want to step into the physician's shoes. Perhaps, with my limited medical knowledge, I would overlook something which a physician would not." $S_{3}$

When confronted, a number of parents thought that it was none of the schools' business. Parents did not want to share their personal affairs. And when parents were willing to share information, the information was often perceived as subjective and unreliable, and when parents did refer the schools to their GP, the information received was often not relevant.

"People are so quick to go on the defensive, even when no attack is intended." P8 "Information via the parents is often very biased and rather unreliable."S2

"I assume the parents think that their personal affairs are being interfered with, and that they are being accused of incompetence, as it were." $P_{1}$

"Well, if I call the GP, I never receive an answer. And that is how it ought to be, I think. But that is not for us to do, as a school."S7

"We are seldom any wiser after speaking to a GP, if we get any information at all." S2

The participants mention that the prime advantage of MASS is the approach in general. The approach provides a framework for talking about medical absence by providing clear criteria and the emphasis on the dialogue being conducted for reasons of concern and not from a wish to enforce compulsory education. This lowers the threshold for entering into dialogue by simplifying the contact with parents, because teachers can say: 'This is just how MASS works.'When choosing the first route, that is, the use of fixed criteria for referral to the YHCP, it is not necessary to argue aspects or judge reasons for medical absenteeism. It is easy to explain to parents that all students that meet the criteria will be invited to see a YHCP. When choosing the second route, that is, teachers themselves confronting students and parents about medical absence initially, participants mention that having the dialogue can strengthen the relationship between school and parents.

"It is now very easy for me to explain to parents 'this applies to everyone', 'everyone just has to do this and we are not doctors." $\mathrm{S}_{5}$

"If parents were to go to the YHCP straightaway, they would miss the connection with the school, that the school cares." 44

"It is a conversation based on concerns. Other matters will arise from it. Because the student can feel bothered, be bullied, a student can eh..., and if these matters turn out to be the cause of the absenteeism, teachers can take them up themselves." P8

"If the communication with parents is very clear from the beginning, they will see it as an extra aid, and not as an evil means of control." Pg

Moreover, some issues brought up by students and parents can be taken up immediately by the school itself, for example bullying or a problematic relationship with teachers. The approach 
also provides the possibility of identifying children at risk at an early stage and arranging care. This early identification is needed because participants are convinced that the stress on the student caused by having to catch up can lead to further medical complaints and absence, and prolonged absence can, in turn, become a deterrent to school attendance. Both situations can lead to a vicious circle of increased school absence, making it increasingly difficult to support the student adequately.

"I am convinced that a student in a family situation where parents are getting divorced or where one of the parents has passed away can suffer from the situation and develop symptoms that we can identify with MASS at an early stage." Pg

"Whenever the student went to school, there would be ten teachers grabbing him to tell him to 'catch up with this and hand in that', and the student wouldn't be able to figure out how to manage everything. The stress might then become too much, resulting in more absence." 33

Secondly, the collaboration with YHCPs (as against GPs) is experienced as an advantage. The participants describe YHCPs as being objective medical experts who act independently and have a holistic view of students, who also check whether there are other important issues that influence the absence. Parents (because of the professional contacts of the YHCPs within the health care sector): experience their involvement as 'formal' and feel that complaints are taken seriously; are discouraged from distorting the facts; are given insight into symptoms that make it necessary for students to stay at home; and, if necessary, are given more directive and confrontational support. In addition to this, YHCPs can give medical advice. Participants observe that teachers find clear feedback from YHCPs (such as guidelines on participation, hints on supporting students in school, confirmation of support that has already been started, and possible agreements on coping with the students' problems) to be really useful.

"If an independent third party, a qualified doctor, with a certain status in the eyes of the parents', gives his opinion, this is received differently from when an educational institution does so." $P_{5}$

"And because of MASS we shall be able to refer a student for more care, ensuring that the student will not end up in mental distress. School can provide this student with support, but not the medical support he might need." $P_{3}$

"It is just the fact that somebody with a medical background confirms that what is happening

is correct. That is essential. But it also helps when somebody with a medical background ascertains that a student has been kept home for a long time unjustly and asks the parents:

'Why did you keep him home that long?' It is not even about blame, but it is a matter of making people aware of the situation." $S_{3}$

"A YHCP discusses these subjects differently from a CP."S5

"The feedback received from the YHCP gives you something to get hold of."Sg

"Since MASS, the connections are short and are really being made.

That is a substantial difference with how it used to be." S9 
Finally, another advantage is the acquisition of a better understanding of what influences a student's well-being and what a certain disease or circumstance means for a student's functioning. A majority of the participants find that these insights help them to react properly to problems and causes, and increases the engagement with students, which leads to better support and school progress.

"Firstly, I think there could be much more understanding, not just at an emotional level, but literal understanding, about situations. Knowledge about what goes on in students' lives and what reasons there can be for not attending school. Students and teachers can learn how to deal with absenteeism more satisfactorily and, eventually, it decreases." P6

"Absenteeism, home situation, and school situation are all aspects of a school career. By monitoring medical absenteeism, giving good feedback, also to parents, I think you gain a better perspective of the well-being of a student, at school as well as at home, from which study results and definitely school development subsequently benefit." P2

\section{Facilitators and obstacles when implementing MASS, including consideration of sustainability}

Questions about facilitators and obstacles show up the challenges to a successful implementation. Participants who are implementing the second route unanimously mention that the main challenge is the questioning by teachers of students and their parents about the context of medical absence. Participants agree that this dialogue is the trickiest and most difficult part of the intervention, as the course of the dialogue is of vital importance for the results of the intervention. Some suggest a need for training in asking the right questions and how to interpret the answers.

"If the communication with parents is very clear from the beginning, and they see it as an extra aid and not as an evil means of control, you avoid angry phone calls from parents saying 'What are you doing with my child?." P3

“Discussing medical absence often provokes resistance from parents. That makes it hard." P6

"It is a very sensitive subject, you quickly use the wrong words." $S_{3}$

Secondly, follow-up to the feedback from the YHCP is experienced as most difficult when implementing the first route, especially in cases of persistent absenteeism without appropriate reasons. In those cases, enforcement and reporting to the school attendance officer is needed. This also requires correct registration, which is a third challenge, as mentioned by the participants

"The downside of the first route would be that our school would not develop its own expertise and learn to handle contacts about absenteeism. I see that teachers find it difficult to discuss and perform the advice of the YHCP." $P_{3}$

"The registration has to be accurate. If we produce figures that are not correct, there is no opening for a dialogue about care."Sg

"Absenteeism registration has to be accurate, throughout the time at school. Otherwise, if the 
student is referred to the school attendance officer and the case goes to court, a judge can say 'Get lost, do your homework first and then we shall see.' If you can't refute the contention that a student has attended school, some students and parents will feel victorious." P7

Finally, it is a challenge to achieve the full support of all involved. Commitment is required at all organizational levels within school. And all professionals need to collaborate appropriately on matters that are mostly delicate and confidential.

"Parents are playing us off against each other. Those are matters we have to deal with together." 7

"It is not acceptable that one mentor discusses the absenteeism and the other does not." $P_{3}$

"All teachers need to pick up on the feedback." $\mathrm{P}_{2}$

When questioning factors that can influence the sustainability of MASS, principals note that observable positive effects will stimulate all those involved to invest the time needed. In response to questions about observable effects, participants unanimously mention an increase in awareness in school of the level of medical absenteeism, which is often more extensive than expected. Parents are also made aware: some of them do not even realize that absence is this high; others do not appreciate the consequences of reporting sick or do not realize that children need to be stimulated to go to school. A noticeable decrease in medical absence as a result of greater attention, control, and guidance is mentioned repeatedly.

"We have to feel that it brings results." P7

"The number of sick reports we receive has been mapped by MASS, and that has opened our eyes. We had been blind before, because the number was huge! We were so alarmed by it that we now treat it with greater emphasis." S1 $_{1}$

"The effect of it might be in the fact that the parents now also become aware of the frequency with which they report their children sick." 55

"I am convinced that absenteeism has decreased since the application of MASS." P3

Exaggerated expectations of intervention outcomes that are then not realized in the short-term can be an obstacle to the sustainability of MASS. Expected long-term effects are the saving of time and investment resulting from decreased absenteeism, which leaves more time for their 'core-business', a change in attitude towards reporting sick among students and parents, and a decrease of school dropout. Participants also note that, realistically, school dropout cannot be solved with only this intervention. They note that MASS can be seen as an investment in that specific vulnerable group of students, where many risk factors play a role.

"Because when it comes to premature dropping out, there are so many factors of influence. Perhaps MASS contributes greatly to decreasing dropouts, or less sickness reports at work, but you will find out only in a couple of years' time." P7 
Furthermore, participants raise that addressing medical absenteeism is not an issue on schools' agendas, which is needed to secure sustainability. However, their experience is that MASS can be a tool for improving parental involvement in school and collaboration between all involved, and that MASS enables preventive action. This can result in better quality of care for students. They note that all these advantages contribute positively to achieving their own direct goal of helping as many students as possible to graduate.

"Eventually, we are judged on graduation rates." $P_{5}$

"Paying attention to medical absenteeism is not on our agenda. However, now that I think about it, increasing parental involvement in school is on schools' agendas and has a high priority. And I see that MASS can help us to achieve this." P8

Finally, funding is also required to finance the assessments and consultations by YHCPs. If the dialogues with students and parents are allocated to school employees, time and energy need to be invested in creating a strategy and in carrying out these dialogues. MASS operates on the border between school and health care. Many participants therefore see difficulties in the structural financing of this intervention.

\section{Discussion}

This study highlights schools' attitudes towards addressing medical absenteeism, in particular with respect to the use of MASS, with the aim of optimizing its effectiveness and dissemination. Principals and senco's were interviewed from nine schools where the intervention was implemented.

The findings from the first research question show that schools' reasons for paying attention to medical absenteeism are their concerns about the perceived negative consequences of school absence for students and their wish to increase the threshold for reporting sick. Ultimately they want to support students adequately. However, feeling responsible and not being able to share their concerns and the responsibility for the consequences with parents, causes frustration. The latter may be an important underlying incentive. The presumption that the threshold for reporting sick is often too low, underlines the need for schools themselves to address and reduce medical absenteeism collectively, for example by reviewing the reporting procedure. It is known that interventions are more effective when carried out at different levels, both individual and collective, at the same time $[35,36]$.

The findings from the second research question show that the intervention is compatible with the needs of schools wanting to address medical absenteeism. 'Role conflicts' are the core problem for schools in addressing medical absenteeism. Teachers do not find it comfortable and easy to talk to students and their parents about extensive medical absence, particularly if they suspect domestic problems or unjustified reporting of school absence. They fear damage to their relationship with students and parents, and fear the overlook of medical problems. The objective approach in general and the support by YHCPs make it possible to reach parents and students, to discuss the subject, to share concerns and responsibility, to provide medical expertise and care, and to gain insights into a child's functioning and situation. Better understanding prevents 
teachers from developing a negative image of a child, and helps them to provide adequate support. Furthermore, MASS makes it possible to identify students at risk of dropout, proactively. A vicious circle of increased absence can then be prevented. It is known from the literature that many cases of sickness can be prevented by changing underlying behaviour or by supporting the psychosocial support system, and that not all illnesses make it necessary to stay at home [37].

The findings from the third research question show that the main challenges to teachers for successful implementation are the dialogue with the parents about the context of medical absence, and the follow-up to the feedback from the YHCP. When applying the first route, there is no need for teachers to confront students and parents. However, the follow-up is experienced as difficult. In contrast, the second route makes it easier to follow-up to the feedback because, from the start, teachers are more actively involved in contacting students and parents regarding the medical absence. It is conceivable that, when it is clear that the purpose of the approach is the promotion of a student's well-being and educational chances, resistance to discussing a student's medical absence is reduced. And if it is a schools' general policy, parents and students will get used to it. You can then expect that the dialogue will become easier and less troublesome. In addition, teachers can be trained. This seems to be a prerequisite when implementing the second route. This study also highlights the fact that, despite motivations and feelings of frustration among teachers, medical absenteeism is not an issue on schools' agendas. However, MASS can optimize educational outcomes and prevent school dropout, not only through improving the quality of care for students but also through improving parental involvement in school. Improving parental involvement in school is on schools' agenda, because it strongly impacts on students' achievements and learning $[38,39]$, and therefore helps students to graduate. Furthermore, MASS helps schools to get a grip on medical absenteeism. A decrease of absenteeism will reduce the extra work for teachers in helping students to catch up. As a consequence, they can focus on their main goal, teaching students. By improving the quality of care for students and parental involvement in school, and decreasing the level of medical absenteeism, MASS contributes to schools' primary objectives. This should be considered when bringing MASS to schools' attention and in motivating them to adopt it. Getting the full support of all those involved may be the greatest challenge at organizational level [29]. For this, adequate communication about the purpose of the intervention and the results to be expected, is needed [24, 25].The short term effects are not only increased awareness of medical absenteeism and increased parental involvement in school, as noticed by the participants, but also better understanding and less frustration. Visible effects could be a decrease in medical absenteeism, as shown in the preliminary results of the pilot study [23], and better school performance. The ongoing study of effects will provide conclusive evidence in this respect. Finally, prioritizing is needed to ensure good records, and a professional approach to the dialogue. Prioritization can be achieved when the addressing of medical absenteeism is put on schools' agendas. Intersectoral health policy is needed for achieving overall agenda-setting, including overall dissemination and sustainability $[30,40]$.

Children's development can benefit greatly from the reduction of medical absenteeism. Teachers play a pivotal role in addressing medical absenteeism, and YHCPs can support this. When considering using MASS to address medical absenteeism, it should be realized that, although MASS is a well-defined intervention, it is difficult to implement. This is typical when focusing on a group at risk, and also when effectuation and funding involve multiple sectors $[26,41$, 42]. Exaggerated expectations can discourage people. Therefore, a long-term view of program 
dissemination and a simultaneous focus on short-term outcomes are needed to maintain motivation when implementing MASS $[25,29]$.

Some limitations must be considered. MASS has been developed within the boundaries of Dutch legislation and policy on school absenteeism, and public and school health care. To some extent this affects the general applicability of this study. However, dealing with sick reports and medical absence is a universal problem. To the best of our knowledge, this study is the first to explore schools' attitudes towards the addressing of medical absenteeism, which adds to its value. Strengths of the study also include a design that ensures broad, complete, and detailed information, and the minimization of socially desirable answers through the interviewing of individuals rather than groups. In a drive for high internal validity, a topic guide was used to channel the interviews for collecting the required data, and the interviewer was always accompanied by a second researcher. To counter the pro-innovation bias, the findings were presented to the participants and a multidisciplinary research team, and their comments were incorporated.

\section{Conclusions}

The main reason for school staff to address medical absenteeism is the wish to provide timely and adequate care and support to students who are in need, in collaboration with parents and from a shared sense of responsibility. MASS appears to improve parental involvement in school and the quality of care for students, thus supporting schools in maximizing the number of students graduating. These are important additional reasons for adopting it. The main problems that schools experience when wanting to handle medical absenteeism can be summarized as 'role conflicts'. The MASS intervention solves these problems satisfactorily by providing a clear approach and socio-medical expertise. In addressing medical absenteeism, the collaboration with YHCPs is experienced as of great benefit. When implementing MASS, the importance of adequate communication about the purpose of the intervention and good functioning registration should be emphasized. And especially when choosing the second route, teachers should be offered training in having the dialogue with students and parents about the context of the medical absence. To secure widespread dissemination of MASS, there is a need for intersectoral health policy to put the subject on every school agenda, thus contributing to prioritization, adoption, and sustainability.

Acknowledgements: The authors wish to thank the school principals and special education needs coordinators of the participating schools for their contribution to the research.

Ethical approval: The research protocol was approved by the Medical Ethics Committee of the University Hospital Maastricht and Maastricht University (Dossier number 11-4-070.6/ivb).

Role of funding: Funding for this study was provided by a ZonMw, the Dutch Organization for Health Research and Development. The funding sources had no direct input into any of the processes.

Competing interests: None declared. 
1. Dahlgren G, Whitehead M. European strategies for tackling social inequities in health: Levelling up part 2. World Health Organization Regional Office for Europe. 2006. http://www.euro.who.int/_data/assets/pdf file/0018/103824/E89384.pdf.

2. Mackenbach JP. Health Inequalities: Europe in Profile. Tackling Health Inequalities: Governing for Health. Rotterdam: European Commission. 2006. http://www.who.int/social_determinants/resources/european_inequalities.pdf.

3. Thrane C. Explaining educational-related inequalities in health: Mediation and moderator models. Soc Sci Med. 2006;62(2):467-78. doi:10.1016/j.socscimed.2005.06.010

4. Kulhánová I, Hoffmann R, Eikemo TA, Menvielle G, Mackenbach JP. Educational inequalities in mortality by cause of death: first national data for the Netherlands. Int | Public Health. 2014;59(5):687-96. doi:10.1007/s00038$014-0576-4$

5. Higgins CT, Lavin T, Metcalfe O. Health Impacts of Education: a review. The Institute of Public Health in Ireland. 2008. http://www.publichealth.ie/files/file/Health\%20Impacts\%200\%20Education.pdf.

6. O'toole L, Fropf D. Learning for well-being. Changing paradigms, sharing our hearts, beginning a dialogue. Universal Education Foundation. 2012. http://www.eiesp.org/hosting/a/admin/files/L4WB\%20Booklet\%20V2-02\%20SMALL. pdf.

7. Basch CE. Healthier students are better learners: A missing link in school reforms to close the achievement gap.| School Health. 2011;81:593-598. doi:10.1111/j.1746-1561.2011.00632.x

8. Suhrcke M, Paz Nievesk C de. The impact of health and health behaviours on educational outcomes in high-income countries: a review of the evidence. 2011. Copenhagen, WHO Regional Office for Europe.

http://www.euro.who.int/en/publications/abstracts/impact-of-health-and-health-behaviours-on-educationaloutcomes-in-high-income-countries-the-a-review-of-the-evidence.

9. Woolf SH, Johnson RE, Phillips Jr RL, Philipsen M. Giving Everyone the Health of the Educated: An Examination Whether Social Change Would Save More Lives Than Medical Advances. I Public Health. 2007;97(4):679-83. doi:10.2105/AJPH.2005.084848

10. Heesch MMJ van, Bosma H, Traag T, Otten F. Hospital admissions and school dropout: a retrospective cohort study of the 'selection hypothesis'. Eur | Public Health. 2011;22(4):550-555. doi:10.1093/eurpub/ckr129

11. Tang KC, Nutbeam D, Aldinger C, Leger L, Bundy D, Hoffmann AM, et al. Schools for health, education and development: a call for action. Health Promotion Int. 2009;24(1):68-77. doi: 10.1093/heapro/dan037.

12. Weitzman M, Klerman LV, Lamb G, Menary I, Alpert II. School Absence: a problem for the paediatrician. Pediatrics. 1982;69:739-64.

13. Klerman LV. School absence - a health perspective. Pediatr Clin N Am. 1988;35:1253-69.

14. Rumberger RW. Dropping out of middle school: A multilevel analysis of students and schools. Am Educ Res I. $1995 ; 32(3): 583-625$.

15. Michaud P, Piot-Delbos I, Narring FMD. Silent Dropouts in Health Surveys: Are Nonrespondent Absent teenagers Different From Those Who Participate in School-Based Health Surveys? I Adolescent Health. 1998;22:326-33.

16. Eckstein Z, Wolpin KI. Why Youths Drop Out of High School: the Impact of Preferences, Opportunities, and Abilities. Econ Soc. 1999;67(6):125-1339. doi:10.1111/1468-0262.00081

17. Battin-Pearson S. Predictors of Early High School Dropout: A Test of Five Theories. I Educ Psychol. 2000;9(3):56882. http://dx.doi.org/10.1037/0022-0663.92.3.568

18. Christenson SL, Thrulow ML. School Dropouts: Prevention Considerations, Interventions, and Challenges. Curr Dir Psychol Sci. 2004;13:36-39. doi:10.1111/j.0963-7214.2004.01301010.x

19. Kearney CA. Bridging the Gap Among Professionals Who Address Youths With School Absenteeism: Overview and Suggestions for Consensus. Prof Psychol-Res Pr. 2003;34(1):57-65. doi:10.1037/0735-7028.34.1.57

20. NIPO het marktonderzoeksinstituut. Rapport: Schoolverzuim in het Voortgezet Onderwijs. [Report on school absenteeism in secondary school.]. Amsterdam. 2002. http://www.tns-nipo.com/pages/persvannipo/pdf/ schoolverzuimo3.pdf.

21. Wieske RCN, Nijhuis MG, Carmiggelt BC, Wagenaar-Fischer MM, Boere-Boonekamp MM. Preventive youth health care in 11 European countries: an exploratory analysis. Int I Public Health. 2012;57(3):637-641. doi:10.1007/ s00038-011-0305-1

22. Kuo AA, Inkelas M, Lotstein DS, Samson KM, Schoret EL, Halfon N. Rethinking Well-Child Care in the United States: An International Comparison. Pediatrics. 2006;118(4):1692-702. doi:10.1542/peds.2006-0620

23. Vanneste YTM, Rots-de Vries MC, Goor LAM van de, Feron FJM. Medische Advisering Ziekgemelde leerling door de jeugdarts (M@ZL); ontwikkeling van een interventie. [Medical Advice for Sick- reported Students in secondary school by the youth health care physician (MASS); development of an intervention.]. TSC. 2012;90(7):412-19. www.tsg.bsl.nl.

24. Glasgow RE, Vogt TM, Boles SM. Evaluating the public health impact of health promotion interventions: the RE-AIM framework. Am | Public Health. 1999;8g(g):1322-1327. doi:10.2105/AJPH.89.9.1322 
25. Rogers EM. Diffusion of Innovations. 2003. http://teddykw2.files.wordpress.com/2012/o7/everett-m-rogersdiffusion-of-innovations.pdf.

26. Nutbeam D. Evaluating health promotion: progress, problems and solutions. Health Promot Int. 1998;13(1):27-44. doi:10.1093/heapro/13.1.27

27. Bartholomew LK, Parcel CS, Kok G. Intervention mapping: a process for developing theory- and evidence-based health education programs. Health Educ Behav. 1998;25(5):545-63. doi:10.1177/109019819802500502

28. Schoenwald SK. Effectiveness, Transportability, and Dissemination of Interventions: What Matters When? Psychiatr Serv. 2001;52(g):1190-1197.

29. Fixsen DL, Blasé KA. Creating new realities: program development and dissemination. J Appl Behav Anal. 1993;26(4):597-615.

30. Oddrun S, Louise R. Theoretical and empirical base for implementation components of health-promoting schools. Health Educ. 2011;111(5):367-390.

31. Kingdon JW. Agendas, alternatives, and public policies. New York: Longman. 2010. http://www.amazon.com/ Alternatives-Policies-Epilogue-Classics-Political/dp/020500086X.

32. Claser BG, Strauss LA. The discovery of grounded theory: strategies for qualitative research. Chicago: Aldine Publishing Company. 2012. http://www.amazon.com/The-Discovery-Grounded-Theory-Qualitative/ dp/020230260.

33. Elo S, Kyngäs H. The qualitative content analysis process. I Adv Nurs. 2008;62(1):107-15 doi: $10.1111 / j .1365-2648.2007 .04569 . x$

34. Maxqda. Maxqda10 The Art of Text Analysis. Marburg: Verbi Software. 95. http://maxqda1o.com.

35. Saan H, Haes W de. Cezond effect bevorderen. Het organiseren van effectieve gezondheidsbevordering. Het Nationaal Instituut voor Gezondheidsbevordering en Ziektepreventie. [Promote healthy effect. Organizing effective health promotion. The Dutch Centre for Ethics and Health (CEG).]. Woerden: 2005. http:// www.nigz.nl.

36. Yperen TA van, Steege M van der, Addink A, Boendermaker L. Algemeen en specifiek werkzame factoren in de jeugdzorg. Stand van de discussie. [Common and specific factors in child and youth care. State of the debate.] Utrecht: Nederlands Jeugdinstituut, 2010.

37. Beker M, Maas C. Rapportage jeugd 1997. Sociaal en Cultureel Planbureau. [Reporting youth 1997. The Dutch Institute for Social research.]. http://www.scp.nl/Publicaties/Alle_publicaties/Publicaties_1998/Rapportage jeugd_1997.

38. Avvisăti F, Besbas B and Guyon N. Parental Involvement in School: A Literature Review. Rev d'écon Polit. 2010;120(5):759-778.

39. Shute VI, Hansen EG, Underwood IS and Razzouk R. A Review of the Relationship between Parental Involvement and Secondary School Students' Academic Achievement. Educ Res Int. 2011; Open acces article. Volume 2011 , Article ID 915326, 10 pages. doi:10.1155/2011/915326

40. Deschesnes M. Comprehensive approaches to school health promotion: how to achieve broader implementation? Health Promotion Int. 2003;18(4):387-396. doi: 10.1093/heapro/dag410

41. Rots-De Vries C. Rich evidence for poor families. Exploring the potential of practice-driven interaction research in Preventive Child Healthcare. Thesis. 2010. http://www.researchgate.net.

42. Rychetnik L, Nutbeam D, Hawe P. Lessons from a review of publications in three health promotion journals from 1989 to 1994. Health Educ Res. 1997;12(4):491-504. 


\section{Case histories}

\section{Cecile}

Cecile (14 years) is in the second class in pre-vocational secondary education. She suffers from asthma, which the school knows. Her sick reports are continually blamed on her asthma. Cecile and her parents tell the mentor nothing can be done about it. However, when the mentor refers her to the YHCP for consultation, the YHCP notices that Cecile does not use medication at all. Her last visit to the paediatrician was already two years ago. Moreover, Cecile does not join sports classes because she is afraid of getting short of breath. The YHCP explains to Cecile and her parents that Cecile's asthma can benefit a lot from medical treatment and a better physica condition. The YHCP refers Cecile to the general practitioner and a physiotherapist. Two months later, Cecile is feeling much better. She takes her medication. Physical therapy is terminated and Cecile has joined the football club. There are no more sick reports.

\section{Halina}

Halina (17 years old, pre-vocational secondary education) is referred to the YHCP by school after extensive absenteeism with all kinds of vague physical complaints. When the mentor wants to discuss this absenteeism, Halina and her parents fail to respond. Communication between school, Halina and her parents has been difficult for a long time. The mentor refers to the YHCP for consultation, and Halina and her parents comply reluctantly. The YHCP expresses her concern about the frequent absenteeism, informs after the complaints and examines Halina, who has not yet been to see her general practitioner. The YHCP is able to reassure Halina and her parents, but then mother starts to tell how difficult it is to get Halina to school. Halina is the boss at home. She just does not feel like school and 'forces' her mother to report her sick. Mother is ashamed of this. The YHCP explains to Halima what will be the consequences of her absenteeism with a view to school attendance regulations. And her mother is only allowed to report Halina sick when she has a temperature over 38,5C. Upon inquiry at school, the sickness absenteeism turns out to have stopped immediately in the month after the conversation. 




\section{Chapter 6}

\section{Chapter 6: Family-related problems associated with extensive medical absenteeism in primary school children}

YTM Vanneste, MF Dautzenberg, AI Groffen, LAM van de Goor, FJM Feron.

\section{Abstract}

Objective: It is well established that extensive school absenteeism in secondary school has a deleterious effect on academic achievement, and induces socioeconomic health inequalities. Therefore, school absenteeism is not only an educational problem, but also a serious public health problem. Since attendance patterns manifest themselves at an early stage in primary school, it is vitally important to seek to minimise school absenteeism in primary school. The aim of this study is to explore factors associated with extensive school absenteeism in Dutch general primary schools reported as sickness, ultimately aiming to find clues to measures for addressing it.

Method: An exploratory retrospective study from medical records and school files. In order to determine factors leading to extensive medical absenteeism of a primary school child, a matched case-control study was performed, using conditional logistic regression analysis.

Results: About $13 \%$ of the primary school children in our sample met the extensive medical absence criteria (i.e. more than four periods or more than nine days per school year). Familyrelated factors that were associated with higher rates of extensive medical absenteeism of the child are incompleteness of the family, an unemployed or poorly educated mother, and a suboptimal upbringing situation for the child, including financial problems. Low school motivation was found to be the only child-related factor associated with extensive medical absenteeism. The involvement of child welfare authorities and an incomplete participation in the youth health care (the Dutch equivalent of preventive paediatric primary care) programme were also associated with medical absenteeism during primary school.

Conclusion: This exploratory study shows that, in Dutch general primary schools, extensive medical absenteeism concerns a group of children growing up in (economically) disadvantaged families. Effectively addressing medical absenteeism requires a broad and integrated approach, focusing not only on biomedical and health aspects, but also on the psychosocial context and home environment of the child.

Key words: youth health care, preventive paediatric primary care, public health, school absenteeism, medical absenteeism, children, education.

Submitted: Global Journal of Medical Research Interdisciplinary 


\section{Introduction}

School absenteeism has a negative impact on learning and social development, and is significantly associated with lower school performance and dropping out of school [1-9]. Dropping out adversely affects health and participation in society [10-18], thus contributing to socioeconomic health inequalities [19-21]. Within this context, school absenteeism is not only an educational problem, but also important from the perspective of public health [22]. To increase educational and health outcomes, school absenteeism should be minimized, and dropout should be prevented.

Contrary to research on school absenteeism in secondary school, until now research on school absenteeism in primary school has been scarce. Literature review shows that school absenteeism in general is linked to myriad physical and psychiatric conditions [2, 23-25]. In conjunction with these diseases and disorders, the somatic complaints related to school absenteeism are often trivial and low-grade, and usually due to stress rather than the disease or disorder itself [2]. In addition, school absenteeism has been linked to risky health behaviour $[2,26]$ and environmental factors. Environmental factors include school-related factors such as low school binding and poor parental involvement in school, and family-related factors. There are indications that extensive absenteeism is more common among children from low-income families, low parental socioeconomic status, or single parent (mother) families [2, 3, 25-27], and from families in which parents have a low educational level $[2,28]$ or have been treated for mental health problems or alcoholism $[2,28,29]$.

School absenteeism can be unexcused or excused. Medical absenteeism is excused absenteeism for reasons reported as medical. Medical absenteeism in secondary school is as common as, or perhaps even more prevalent than, unexcused absence [26, 28-30]. To the best of our knowledge, there are no studies on the prevalence of medical absenteeism in primary schools. There is also a lack of studies on the factors contributing to extensive medical absenteeism in primary schools.

The Dutch youth health care department (YHC; the Dutch equivalent of preventive paediatric primary care) $[31,32]$ has developed the intervention MASS (Medical Advice for Sick-reported Students) [33] to address medical absenteeism in secondary schools. Since attendance patterns manifest themselves at an early stage in primary school $[16,26,27]$, there is also felt to be a need to address medical absenteeism in primary school. This study explores factors that indicate an increased risk of medical absenteeism in Dutch primary schools, aiming to ultimately find clues to measures for addressing medical absenteeism in primary school children.

\section{Methods}

\section{Study population}

Three general primary schools that indicated the need for research on medical absenteeism were included in this practice-based exploratory case-control study. All these schools were located in Breda, which is a large city in the southwest of the Netherlands with approximately 180,000 
inhabitants. In the whole study population of 1,193 primary school children, $611(51.2 \%)$ were male, and the mean age in years was 8.3 (range $4-13$; SD 2.4). The mean number of absence days per primary school child was 3.6 days per year (range 0-47; SD 4.8), and the mean frequency of absence periods was 2.0 times per year (range 0-20; SD 2.2).

The total study sample of the case-control study consisted of 312 primary school children, 156 cases and 156 controls, matched on sex and school class. Cases were those primary school children whose accumulated medical absenteeism exceeded defined thresholds (i.e. more than four periods or more than nine days per school year). Controls were primary school children with the lowest absence rate.

\section{Data collection procedure}

Data was collected from January to June 2012. Initially, the school principals and special education needs coordinators of the three participating schools were interviewed in order to explore their views on a definition of, and potential factors for, extensive medical absenteeism. Subsequently, medical records and school files of the study population were examined to define extensive medical absenteeism and to identify factors. Indistinctness in the school file was presented to the special education needs coordinator. In cases of ambiguity in the medical records, and for categorizing the data collected, expert diagnostic agreement was sought. Neither researchers nor special education needs coordinators knew whether the child was a case or a control.

In the Netherlands, routine preventive health examinations and assessments are provided to all children by YHC services. Data collection and epidemiological analyses relate an official statutory task of Regional Public Health Service, based on the Public Health Act [34, 35]. As such, special ethical approval was not required and in this respect the Code of Conduct for the Use of Data in Health Research of the Dutch Federation of Biomedical Scientific Societies was adhered.

\section{Description of research criteria}

Extensive medical absenteeism

Since there is no standard definition of extensive medical absenteeism in the literature, for the purposes of this study it was decided to define extensive medical absenteeism as 'more than four periods or more than nine days per school year'. The interviews revealed that currently only those primary school children with large-scale medical absence, such as an unbroken period of three weeks, are known to school personnel. The interviewees indicated that there is no concrete picture of primary school children with short term absenteeism. Therefore, a measurement of frequency in terms of periods per year was included in the definition of extensive medical absenteeism. On the basis of routinely collected school attendance data in the school year 20102011, the threshold was defined as more than one standard deviation from the mean for both measures: frequency in periods and length in accumulated days of absence.

\section{Potential factors}

Potential factors (Table 1) were first of all selected on the basis of literature review. As psychiatric conditions were often noted as 'suspected' in the medical records, these conditions were indicated as externalizing and internalizing behavioural problems as observed at school.School performance 
was included rather than learning disabilities, because of underreporting in the medical records and school files. The list of factors was complemented by interviewing the school principals and special education needs coordinators of the participating schools. The interviewees assumed that family-related factors, such as a large or incomplete family, sickness or unemployment of one of the parents, low educational level of the parents, and a suboptimal upbringing situation (e.g. due to financial problems or alcoholism), are the main causes of extensive medical absenteeism. With regard to child-related factors, the interviewees presumed that not only medical symptoms and diagnoses, but also behavioural problems and low school motivation or performance, might be linked to extensive medical absenteeism. Additional factors added were 'involvement of child welfare authorities', 'YHC incomplete file', and 'not participating fully in YHC services'. These latter factors were added from an evaluative perspective, to investigate whether children with extensive medical absenteeism have been reached adequately by YHC services.

Table 1: Description of the potential factors.

\begin{tabular}{|c|c|}
\hline Potential risk factor & Description \\
\hline \multicolumn{2}{|l|}{ Family-related factors } \\
\hline Large family & A family with more than 3 children. \\
\hline Incomplete family & Parents are separated or divorced, or one parent is deceased. \\
\hline Medical diagnosis of parent & $\begin{array}{l}\text { Known medical diagnoses of parents are registered, including } \\
\text { need for psychiatric treatment. }\end{array}$ \\
\hline Having no paid job & Including unemployment and being at home in the day. \\
\hline Educational level of the parents & The educational level is divided into three categories: \\
\hline low & Primary or secondary school. \\
\hline medium & Intermediate vocational school. \\
\hline high & University or higher vocational school. \\
\hline Suboptimal upbringing situation & $\begin{array}{l}\text { Suboptimal upbringing situation is divided into six categories, } \\
\text { as presented below. }\end{array}$ \\
\hline 1. Primary care group problems & $\begin{array}{l}\text { Problematic parent-child relationship, (signs of) child abuse, } \\
\text { siblings with medical or behavioural problems, young mother } \\
\text { (age below } 20 \text { years), demanding parents, parents who are } \\
\text { often not at home because of their work, and troubled home } \\
\text { environment. }\end{array}$ \\
\hline 2. Social support problems & $\begin{array}{l}\text { Limited social network, or living in a disadvantaged } \\
\text { neighbourhood. }\end{array}$ \\
\hline 3. Housing problems & $\begin{array}{l}\text { Frequent moving, living in with grandparents or grandparents } \\
\text { living in, roaming parent, and immigration. }\end{array}$ \\
\hline 4. Financial problems & Having financial debts or receiving unemployment benefits. \\
\hline 5. Legal problems & $\begin{array}{l}\text { Parents involved in lawsuit or guardianship cases, and } \\
\text { parents who are asylum seekers. }\end{array}$ \\
\hline
\end{tabular}




\begin{tabular}{|c|c|}
\hline 6. Other problems & $\begin{array}{l}\text { Detention of a parent, the child witnessing domestic } \\
\text { violence, staying in shelter for battered women, etc. }\end{array}$ \\
\hline \multicolumn{2}{|l|}{ Care-related factors } \\
\hline $\begin{array}{l}\text { Involvement of child welfare } \\
\text { authorities }\end{array}$ & $\begin{array}{l}\text { Child welfare authorities include: social work, youth welfare } \\
\text { agency, and agency for reporting child abuse. } \\
\text { Involvement is noted in the school file or in the medical } \\
\text { records. It does not matter whether the family had accepted } \\
\text { the voluntary assistance or not, nor whether this assistance } \\
\text { was still there at the study moment. }\end{array}$ \\
\hline Not participating fully in $\mathrm{YHC}$ services & $\begin{array}{l}\text { Missing one or more medical examinations during the first } \\
\text { four years of life. }\end{array}$ \\
\hline YHC service file (part) missing & $\begin{array}{l}\text { Medical reports are (partly) missing, because a child was } \\
\text { born abroad, relocated within the Netherlands, or the file is } \\
\text { missing for unknown reasons. }\end{array}$ \\
\hline \multicolumn{2}{|l|}{ Child-related factors } \\
\hline Medical symptoms and diagnoses & $\begin{array}{l}\text { Significant health issues reported in the medical records of } \\
\text { the child, from birth until the last visit to the YHC service. } \\
\text { The most common symptoms and diseases included are: } \\
\text { weight and growth problems, persistent ear, nose, and throat } \\
\text { related problems, asthma, noticeable fatigue, abdominal pain, } \\
\text { and headache. Common infant diseases such as chickenpox, } \\
\text { respiratory infections, and seasonal flu are not included in } \\
\text { this category. }\end{array}$ \\
\hline Behavioural problems $(\geq 1)$ & $\begin{array}{l}\text { These problems are observed at school and divided in two } \\
\text { categories. }\end{array}$ \\
\hline Internalizing & $\begin{array}{l}\text { Insecurity, shyness, weak social skills and defensibility, } \\
\text { perfectionism, and having separation anxiety. }\end{array}$ \\
\hline Externalizing & $\begin{array}{l}\text { Lying, stealing, having abnormally frequent conflicts with } \\
\text { classmates or teachers, fighting, bullying, tantrums, showing } \\
\text { clownish or noisy behaviour, and demanding attention from } \\
\text { teachers during the class. }\end{array}$ \\
\hline School motivation problem & $\begin{array}{l}\text { This has been observed at school or reported by the parents } \\
\text { and recorded in the school file or medical file. }\end{array}$ \\
\hline School performance & This risk factor consists of two elements: \\
\hline Repeating school year & A school year is repeated once or more. \\
\hline Test results Cito & $\begin{array}{l}\text { In the Netherlands, primary school performance is mapped } \\
\text { and monitored by the Cito test that consists of multiple- } \\
\text { choice questions in the areas of language, mathematics, } \\
\text { and study skills, and uses standardized test scores. The test } \\
\text { results are from A (best) to E (worst). }\end{array}$ \\
\hline
\end{tabular}




\section{Statistical analyses}

Demographic variables and selected factors were compared between cases and controls using Student's t-test for continuous variables and Pearson's chi-squared test for categorical variables. Next, conditional logistic regression models were used to calculate Odds Ratios (ORs) and 95\% confidence intervals (Cls). All analyses were performed using SPSS, version 19.0.

\section{Results}

Selected demographic characteristics of the cases and controls are presented in Table 2. Of the 156 cases, 50\% were male (78), and the mean age in years was 7.8 (range 4-13; SD 2.3). The mean number of absence days per case was 13.2 days per year (range 6-47; SD 7.2), and the mean number of absence periods was 6.3 times per year (range 1-20; SD 2.8). For controls, the mean number of absence days was 1.4 (range $0-11$; SD 2.2) and the mean number of absence periods was 0.8 (range $0-5$; SD 1.1).

Table 2: Selected demographic characteristics of 156 cases and their matched controls

\begin{tabular}{|l|c|c|c|}
\hline & Case & Control & P-value \\
\hline $\begin{array}{l}\text { School class, mean } \\
\text { (range, SD) }\end{array}$ & $\begin{array}{c}3.67 \\
(0-8,2.13)\end{array}$ & $\begin{array}{c}3.71 \\
(0-8,2.09)\end{array}$ & 0.872 \\
\hline $\begin{array}{l}\text { Age in years, mean } \\
\text { (range, SD) }\end{array}$ & $\begin{array}{c}7.78 \\
(4-13,2.31)\end{array}$ & $\begin{array}{c}7.71 \\
(4-12,7.71)\end{array}$ & 0.801 \\
\hline Male sex n, \% male & $78,50.0$ & $79,50.6$ & 0.910 \\
\hline $\begin{array}{l}\text { Absence rate in days/year, mean } \\
\text { (range; SD) }\end{array}$ & $\begin{array}{c}13.2 \\
(6-47 ; 7.2)\end{array}$ & $\begin{array}{c}1.4 \\
(0-11 ; 2.2)\end{array}$ & $<0.001$ \\
\hline $\begin{array}{l}\text { Absence rate in periods/year, } \\
\text { mean (range; SD) }\end{array}$ & $\begin{array}{c}6.3 \\
(1-20 ; 2.8)\end{array}$ & $\begin{array}{c}0.8 \\
(0-5 ; 1.1)\end{array}$ & $<0.001$ \\
\hline
\end{tabular}

Table 3 presents the results of the Chi-square tests and conditional logistic regression analyses. Several family-related factors were associated with extensive absenteeism, including an incomplete family (OR 2.22; $95 \% \mathrm{Cl} 1.27-3.88$ ) and the mother having no paid job (OR 2.44; $95 \% \mathrm{Cl} 1.36-4.36)$. Whereas the educational level of the mother was associated with absenteeism in children (OR 2.08; 95\% Cl 0.87-4.98), the educational level of the father was not. Reporting more than one problem in the category 'suboptimal upbringing situation' was also positively associated with extensive medical absenteeism (OR 2.44; 95\% Cl 1.27-4.96). After categorizing, problems in the primary care group (OR 1.92; 95\% $\mathrm{Cl} 1.18-3.11$ ) and financial problems (OR $2.58 ; 95 \% \mathrm{Cl} 1.33-5.03$ ) appeared to be related. The factors 'large family' and 'medical diagnosis for one of the parents' were not found to be associated with medical absenteeism in children.

With regard to the role of child care and welfare institutions, the involvement of child welfare authorities (OR 4.67; 95\% Cl 2.27-9.60), and not participating fully in the YHC programme below the age of four ( $\mathrm{OR} 2.14 ; 95 \% \mathrm{Cl} 1.28-3.60$ ) were both positively associated with medical absenteeism during primary school. No association was found between a (partly) missing YHC service file and extensive medical absenteeism in children. 
With respect to child-related factors, only a school motivation problem was significantly associated with extensive medical absenteeism (OR 2.24; 95\% Cl 1.26-3.96). Other factors, including medical symptoms and diagnoses, behavioural problems, and school performance, were not associated with medical absenteeism.

Table 3: Estimated risk of extensive medical absenteeism with selected factors

\begin{tabular}{|c|c|c|c|}
\hline Risk factor & Cases (\%) & Controls (\%) & $\begin{array}{l}\text { Conditional logistic } \\
\text { regression } \\
\text { OR } 95 \% \mathrm{Cl}\end{array}$ \\
\hline \multicolumn{4}{|l|}{ Family-related factors } \\
\hline Large family & 13.5 & 11.5 & $1.20(0.61-2.38)$ \\
\hline Incomplete family & 34.6 & 20.5 & $2.22(1.27-3.88)$ \\
\hline Medical diagnosis of parent & 24.4 & 16.7 & $1.55(0.90-2.64)$ \\
\hline Father having no paid job & 13.5 & 7.17 & $2.00(0.86-4.67)$ \\
\hline \multicolumn{4}{|l|}{ Educational level of father } \\
\hline low & $45 \cdot 5$ & 42.3 & $1.66(0.98-2.82)$ \\
\hline medium/high & 28.2 & 44.9 & ref \\
\hline Mother having no paid job & 42.9 & $24 \cdot 4$ & $2.44(1.36-4.36)$ \\
\hline \multicolumn{4}{|l|}{ Educational level of mother } \\
\hline Low & 60.9 & 48.1 & $2.08(0.87-4.98)$ \\
\hline medium/high & 29.5 & $45 \cdot 5$ & ref \\
\hline \multicolumn{4}{|l|}{$\begin{array}{l}\text { Suboptimal upbringing } \\
\text { situation }\end{array}$} \\
\hline no problems & 41.0 & 52.6 & ref \\
\hline 1 problem & 32.7 & 32.7 & $1.23(0.72-2.12)$ \\
\hline$>1$ problem & 26.3 & 14.7 & $2.44(1.27-4.69)$ \\
\hline $\begin{array}{l}\text { 1. Primary care group } \\
\text { problems }\end{array}$ & 46.8 & 32.1 & $1.92(1.18-3.11)$ \\
\hline 2. Social support problems & 5.1 & 6.4 & $0.80(0.32-2.03)$ \\
\hline 3. Housing problems & 11.5 & 11.5 & $1.00(0.52-1.92)$ \\
\hline 4. Financial problems & 25.6 & $13 \cdot 5$ & $2.58(1.33-5.03)$ \\
\hline 5. Legal problems & 2.6 & 5.1 & $0.50\left(0.15^{-1.66)}\right.$ \\
\hline 6. Other problems & 4.5 & 2.6 & $2.00(0.50-8.00)$ \\
\hline \multicolumn{4}{|l|}{ Care-related factors } \\
\hline $\begin{array}{l}\text { Involvement of child welfare } \\
\text { authorities }\end{array}$ & 30.1 & 9.0 & $4.67(2.27-9.60)$ \\
\hline
\end{tabular}




\begin{tabular}{|c|c|c|c|}
\hline $\begin{array}{l}\text { Not participating fully in YHC } \\
\text { services }\end{array}$ & 38.5 & 23.1 & $2.14(1.28-3.60)$ \\
\hline $\begin{array}{l}\text { YHC service file (partial) } \\
\text { missing }\end{array}$ & 14.1 & 12.8 & $1.11(0.59-2.06)$ \\
\hline \multicolumn{4}{|l|}{ Child-related factors } \\
\hline $\begin{array}{l}\text { Medical symptoms and } \\
\text { diagnoses }\end{array}$ & 59.6 & 53.8 & $1.27(0.81-1.98)$ \\
\hline Behavioural problems $(\geq 1)$ & 48.7 & 39.1 & $1.52(0.95-2.43)$ \\
\hline Internalizing & 23.7 & 19.2 & $1.76(0.92-3.37)$ \\
\hline Externalizing & 22.4 & 16.7 & $0.94(0.25-3.58)$ \\
\hline Both & 2.6 & 3.2 & $1.49(0.85-2.60)$ \\
\hline Neither & 51.3 & 60.9 & ref \\
\hline School motivation problems & 34.0 & 20.5 & $2.24(1.26-3.96)$ \\
\hline \multicolumn{4}{|l|}{ School performance } \\
\hline Repeating school year & 25.0 & 19.7 & $1.58(0.90-2.77)$ \\
\hline \multicolumn{4}{|l|}{ Test results Cito } \\
\hline$A-B$ & 37.8 & 41.0 & ref \\
\hline $\mathrm{C}$ & 30.8 & 29.5 & $1.17(0.65-2.10)$ \\
\hline D-E & 18.6 & $17 \cdot 3$ & $1.13(0.56-2.30)$ \\
\hline
\end{tabular}

1 Results in bold indicate significant difference based on Chi-square tests. 2 Results in bold and italic indicate significant association between risk factor and extensive medical absenteeism. 3 Ref: category of reference in the analyses. The most favourable condition was used as a reference.

\section{Discussion}

This matched case-control study explored the factors associated with extensive medical absenteeism in Dutch general primary schools, with the aim of finding clues to measures for addressing absenteeism.

In the present study population, on average, a primary school child misses 3.6 days of education annually, spread over 2 absence periods. While this overall absence rate does not seem alarming, extensive medical absenteeism (i.e. more than nine days or more than four times per year) occurs in about $13 \%$ of the primary school children.

Extensive medical absenteeism of the primary school child appears to be associated particularly with factors from the home environment. Incomplete families, families where the mother has no paid job or a low educational level, and families with more than one problem in the upbringing situation (including financial problems and problems in the primary care group), are positively related to extensive medical absence. These findings are in line with previous research outcomes. 
Many underlying mechanisms are described for the interrelationship between poverty, health, education, and children's cognitive, socio-emotional, and physical well-being [36-38]. In 2010, Zhang showed an association between school absenteeism in London primary schools and child poverty [27]. Because an incomplete family, a low educational level, and unemployment can affect the financial situation, this may explain why all these factors are positively associated. Our additional analysis, in which the variables 'financial problems' and 'having no paid job' for both mother and father were adjusted for each other, indicated that these variables may also have independent effects. The relationship between extensive medical absenteeism and a mother who does not have a paid job may be explained by other factors, for example, the fact that, when the mother is at home in the day, it may be easier to keep the child at home in the case of physical complaints or sickness. The fact that there is no association found with a father who has no paid job is probably due to the fact that this information was often missing in the case of an incomplete family. The association with a low educational level is found only for the mother, and is not found for the father. Future research is needed to investigate the effect of low parental educational level on medical absenteeism in children.

With regard to the child-related factors, behavioural problems and medical symptoms and diagnoses have not been found to be associated. This outcome may be influenced by the fact that, in the Netherlands, children with a severe medical disorder or learning disability, attend disability-specific special schools and are therefore not included. In our study, a child with a school motivation problem has an increased risk of extensive medical absence. In the literature, an adverse relationship between motivation to attend school, health, and academic achievement has been described in secondary school $[36,39,40]$. It is quite conceivable that this relationship also applies to primary school children. The causal pathways may be interrelated. On the one hand, absenteeism can bring up a barrier to school attendance, which in turn leads to less school motivation. On the other hand, children who are less motivated feel less connected to school and less inclined to attend school. They can have or even fake physical complaints, resulting in medical absenteeism. Moreover, underlying school issues such as learning disabilities and bullying can cause reduced school motivation and increased stress, which in turn can cause sleeping difficulties, and physical and psychological complaints, resulting in medical absenteeism.

This study shows no association between performance in the regular primary school tests and extensive medical absenteeism. This may be explained by the small size of primary school settings, resulting in optimal support. As known from the literature, extensive medical absenteeism in primary school is a predictor of extensive medical absenteeism in secondary school $[16,26,27]$, which has a deleterious effect on academic performance. This suggests that a start should be made in primary school to paying attention to medical absenteeism, even though the consequences for educational achievement do not seem as severe as those at later stages. It could be a tool for preventing later decline in performance. More detailed longitudinal research is recommended.

Interestingly, not participating fully in YHC services and the involvement of child welfare authorities are both positively associated with extensive medical absenteeism. The aim of YHC services is to promote children's health and development, to optimise their upbringing situation, and to prevent them becoming involved with child welfare authorities. In the Netherlands it is not obligatory to participate in $\mathrm{YHC}$ services. It is known from research that these services do not reach all children equally well, in particular those growing up in problem families [41- 
43]. Children's educational outcomes and development can be optimized by improving their upbringing situation through a better reach and guidance of these families by preventive youth health care services. No association has been found with sickness of one of the parents. This may be due to the fact that this is not always inquired after and therefore not known to YHC professionals or school personnel.

Some limitations must be considered. First, because of the explorative character of the study, the data of children with the highest absence rate were compared with the data of children with the lowest absence rate. Therefore, the factors found associated are indicative. Second, as this study was based on retrospective data from medical reports and school files, information about the child and its family that could be of interest to this study, may not have been asked for. Moreover, data might be wrongly interpreted. Third, of the 312 medical reports, 42 reports were incomplete or missing, which may have led to an underestimate of the factors. However, no significant differences (in terms of age, sex, and extensive medical absence) were found between the children with a complete medical report and those with an incomplete medical report. Fourth, the number of absence days and periods may also have been underestimated, because we had to rely on the school absence registration which might not always be accurate [20]. Fifth, during the study period, 17 children (10 cases and 7 controls) changed school. However, no significant difference was found between the number of absence days and number of absence periods $(p=0.99)$ of these children and the data of the total group. Therefore, these 17 children were not excluded. Finally, because of the small study population, a type-Il error may have occurred for some factors, including the medical symptoms and the problems of the child. However, a posthoc power analysis carried out after the study showed, on average, $80 \%$ power with the present sample size, allowing significant results. Additional studies are recommended that give insight into children's, parents', teachers', and YHC professionals' findings at the time that extensive medical absenteeism occurs.

Our study findings give first leads for addressing medical absenteeism in primary school, concerning both schools and YHC professionals. As previously stated by Basch, school personnel cannot tackle these complex problems without help [36]. There is an additional role here for $\mathrm{YHC}$ professionals regarding the approach to medical absenteeism $[44,45,46]$. In cases of medical absence school personnel can pay attention to the child's school motivation. By supporting children on school issues, by increasing their school connectedness, and by eliminating barriers to school attendance, their educational progress can be secured. Furthermore, school personnel can discuss the context of the medical absenteeism with the parents, and pay particular attention to the upbringing situation. In addition, $\mathrm{YHC}$ professionals can provide their socio-medical expertise, and can identify bio-medical and socio-emotional problems that count for the absence. These professionals can bridge the gap between education, curative health care, and welfare services by strengthening the collaboration between all involved in the cure and care (including parents, school personnel, and colleagues). Furthermore, it is up to YHC services to link their medical records with school data. Especially in cases of medical absenteeism, they owe it to these children to make every effort to reach and support their families, ultimately aiming to ensure the physical, mental, and social health of children. 


\section{Conclusions}

This exploratory study shows that family-related problems in the upbringing situation including financial problems, and a school motivation problem, may be associated with an increased risk of extensive medical absenteeism in children attending Dutch general primary schools. Medical absenteeism does not seem to be associated with medical diagnoses or disorders of the child. Our study findings give first leads for addressing medical absenteeism in primary school and should be considered when developing an approach to addressing medical absenteeism. In cases of extensive medical absenteeism, attention should be paid to the child's school motivation and the social conditions of its upbringing situation. A broad and integrated approach is needed, through a joint effort of school personnel and youth health care professionals, in order to optimize educational and health outcomes of primary school children, eventually leading to a reduction of socioeconomic health inequalities.

Acknowledgements: The authors wish to thank the school principals and special education needs coordinators of the participating schools for their contribution to the research.

Funding: None declared.

Ethical approval: The Code of Conduct for the Use of Data in Health Research of the Dutch Federation of Biomedical Scientific Societies was adhered.

Competing interests: None declared. 
1. Weitzman M, Klerman LV, Lamb G, Menary I, Alpert II. School Absence: a problem for the paediatrician. Pediatrics. 1982;69:739-64.

2. Kearney CA. School absenteeism and school refusal behavior in youth: A contemporary review. Clin Psychol Rev. 2008;28:451-471. doi:10.1016/j.cpr.2007.07.012

3. Klerman LV. School absence - a health perspective. Pediatr Clin N Am. 1988;35:1253-69.

4. Rumberger RW. Dropping out of middle school: A multilevel analysis of students and schools. Am Educ Res ). 1995:32(3):583-625.

5. Michaud P, Piot-Delbos I, Narring FMD. Silent Dropouts in Health Surveys: Are Nonrespondent Absent teenagers Different From Those Who Participate in School-Based Health Surveys? | Adolescent Health. 1998;22:326-33.

6. Eckstein Z, Wolpin KI. Why Youths Drop Out of High School: the Impact of Preferences, Opportunities, and Abilities. Econ Soc. 1999;67(6):125-1339. doi:10.1111/1468-0262.00081

7. Battin-Pearson S. Predictors of Early High School Dropout: A Test of Five Theories. I Educ Psychol. 2000;9(3):56882. http://dx.doi.org/10.1037/0022-0663.92.3.568

8. Christenson SL, Thrulow ML. School Dropouts: Prevention Considerations, Interventions, and Challenges. Curr Dir Psychol Sci. 2004;13:36-39.

9. Kearney CA. Bridging the Gap Among Professionals Who Address Youths With School Absenteeism: Overview and Suggestions for Consensus. Prof Psychol-Res Pr. 2003;34(1):57-65. doi:10.1037/0735-7028.34.1.57

10. Droomers M, Schrijvers CTM, Mheen H van de, Mackenbach JP. Educational differences in leisure-time physical inactivity: a descriptive and explanatory study. Soc Sci Med. 1998;47(11):1665-76. doi:10.1016/So2779536)(g8)00272-X

11. Droomers M, Schrijvers CTM, Stronks K, Mheen D van de, Mackenbach JP. Educational differences in excessive alcohol consumption: the role of psychosocial and material stressors. Prev Med. 1999;29(1):1-10. doi:10.1006/ pmed.1999.0496

12. Beckers ITT, Traag T. Met een startkwalificatie betere kansen op de arbeidsmarkt. Sociaaleconomische trends [Better opportunities in the labour market with a basic qualification. Socioeconomic Trends.]. The Hague: Statistics, the Netherlands. 2005;23-28. http://www.cbs.nl/NR/rdonlyres/31B62F76-21E2-40C8-86AB230589D4FgEA/o/2007k3v4p23art.pdf.

13. Lundborg P. The Health Returns to Education: What Can We Learn from Twins? I Popul Econ. 2013;26(2):673-701. doi:10.1007/s00148-012-0429-5

14. Kulhánová I, Hoffmann R, Eikemo TA, Menvielle G, Mackenbach JP. Educational inequalities in mortality by cause of death: first national data for the Netherlands. Int I Public Health. 2014;59(5):687-96. doi:10.1007/s00038$014-0576-4$

15. Junger-Tas J. Diploma's en goed gedrag II: Preventie van antisociaal gedrag in het onderwijs. [Diplomas and good behaviour II: Prevention of antisocial behavior in education.]. The Hague: Dutch Ministry of Justice. 2002. http:// members.multimania.nl/veiligeschool/Preventie\%2ovan\%2oantisociaal\%2ogedrag.pdf.

16. Traag T, Marie $\mathrm{O}$, Velden $\mathrm{R}$ van de. Risicofactoren voor voortijdig schoolverlaten en jeugdcriminaliteit. [Risk factors for school dropout and juvenile delinquency.]. 2010;55-6o. http://www.cbs.nl/NR/rdonlyres/131FADA3-2E22-4E519A91-6BB53E1E0895/o/2010k2b15P55art.pdf.

17. Ross CE, Wu C (1995) The links between education and health. Am Sociol Rev 60:719-745. doi:10.2307/2096319

18. Higgins CT, Lavin T, Metcalfe O. Health Impacts of Education: a review. The Institute of Public Health in Ireland. 2008. http://www.publichealth.ie/files/file/Health\%20Impacts\%200\%20Education.pdf.

19. Dahlgren $G$, Whitehead M. European strategies for tackling social inequities in health: Levelling up part 2. World Health Organization Regional Office for Europe. 2006. http://www.euro.who.int/ data/assets/pdf file/0018/103824/E89384.pdf.

20. Mackenbach JP. Health Inequalities: Europe in Profile. Tackling Health Inequalities: Governing for Health. Rotterdam: European Commission. 2006. http://www.who.int/social_determinants/resources/european inequalities.pdf.

21. Thrane C. Explaining educational-related inequalities in health: Mediation and moderator models. Soc Sci Med. 2006;62(2):467-78. doi:10.1016/j.socscimed.2005.06.010

22. Freudenberg N, Ruglis ). Reframing school dropout as a public health issue. Prev Chronic Dis. 2007;4(4):1-11. http://www.cdc.gov/pcd/issues/2007/oct/07_0063.htm.

23. Jones R, Hoare P, Elton R, Dunhille Z, Scharpe $\bar{M}$. Frequent medical absences in secondary school students: survey and case-control study. Arch Dis Child. 2009;94:763-67. doi:10.1136/adc.2008.140962

24. Pan L, Sherry B, Park S, Blanck HM. The Association of Obesity and School Absenteeism Attributed to Illness or Injury Among Adolescents in the United States, 2009. I Adolesc Health. 2013;52(1):64-9. doi:http://dx.doi. org/10.1016/j.jadohealth.2012.04.003

25. Rappaport EB, Daskalakis C, Andrel J. Obesity and other predictors of absenteeism in Philadelphia school children. Sch Health. 2011;81(6):341-4. doi:10.1111/j.1746-1561.2011.00599.x 
26. Eaton DK, Brener N, Kann LK. Associations of health risk behaviors with school absenteeism. Does having permission for the absence make a difference? I Sch Health. 2008;78(4):223-9. doi:10.1111/j.1746-1561.2008.00290.x

27. Zhang M. Links Between School Absenteeism and Child Poverty, Pastoral Care in Education: An Int I Personal, Socia and Emotional Development. 2003;21(1):10-17. http://dx.doi.org/10.1111/1468-0122.00249

28. NIPO het marktonderzoeksinstituut. Rapport: Schoolverzuim in het Voortgezet Onderwijs. [Report on school absenteeism in secondary school.]. Amsterdam. 2002. http://www.tns-nipo.com/pages/persvannipo/pdf/ schoolverzuimo3.pdf.

29. Scottish Executive National Statistics. Results of pupil attendance and absence for session 2006/7. Edinburgh: The Scottish Government, Statistics. 2007. http://www.scotland.gov.uk/Publications/2013/12/4199/17.

30. Lenzen C FC, Jentzsch A, Kaess M, Parzer P, Carli V, Wasserman D, et al. Schulabsentismus in Deutschland - die Prävalenz von entschuldigten und unentschuldigten Fehlzeiten und ihre Korrelation mit emotionalen und Verhaltensauffälligkeiten. [School absenteeism in Germany: prevalence of excused and unexcused absenteeism and its correlation with emotional and behavioural problems.]. Prax Kinderpsychol K. 2013;62 (8):570-82. doi:http:// www.vr-elibrary.de/doi/abs/10.13109/prkk.2013.62.8.570

31. Kuo AA, Inkelas M, Lotstein DS, Samson KM, Schoret EL, Halfon N. Rethinking Well-Child Care in the United States: An International Comparison. Pediatrics. 2006;118(4):1692-702. doi:10.1542/peds.2006-0620

32. Wieske RCN, Nijhuis MC, Carmiggelt BC, Wagenaar-Fischer MM, Boere-Boonekamp MM. Preventive youth health care in 11 European countries: an exploratory analysis. Int | Public Health. 2012;57(3):637-641. doi:10.1007/ s00038-011-0305-1

33. Vanneste YTM, Rots-de Vries MC, Goor LAM van de, Feron FIM. Medische Advisering Ziekgemelde leerling door de jeugdarts (M@ZL); ontwikkeling van een interventie. [Medical Advice for Sick- reported Students in secondary school by the youth health care physician (MASS); development of an intervention.]. TSC. 2012;90(7):412-19. www.tsg.bsl.nl.

34. Dutch Public Health Law. 2007. http://www.wetten.overheid.nl.

35. The Code of Conduct for the Use of Data in Health Research; Dutch federation of Biomedical Scientific Societies. 2004. http://www.federa.org.

36. Basch CE. Healthier students are better learners: A missing link in school reforms to close the achievement gap. I School Health. 2011;81:593-598. doi:10.1111/j.1746-1561.2011.00632.x

37. Evans CW, Gonnella C, Marcynyszyn LA, Gentile L, Salpekar N. The Role of Chaos in Poverty and Children's Socioemotional Adjustment. Psychol Sci. 2005;16(7):560-5.

38. Evans CW, Kim P. Childhood Poverty and Health: Cumulative Risk Exposure and Stress Dysregulation. Psychol Sci. 2007:18(11):953-7.

39. Bonny AE, Britto MT, Klostermann BK, Hornung RW, Slap GB. School disconnectedness: identifying adolescents at risk. Pediatrics. 2000;106(5):1017-21.

40. Palloni A. Reproducing Inequalities: Luck, Wallets, and the Enduring Effects of Childhood Health. Demography. 2006;43(4):587-616. DOl:10.1353/dem.2006.0036

41. Dunnink C. Standpunt bereik van de jeugdgezondheidszorg. [The effective coverage of the youth health services.]. 2010. RIVM. http://rivm.nl.

42. De leugdgezondheidszorg beter in positie. [Youth health care in better position.]. Utrecht: Inspectie voor de Gezondheidszorg [Healthcare Inspectorate], 2014. http://www.rijksoverheid.nl/documenten-en-publicaties/ rapporten/2014/11/06/de-jeugdgezondheidszorg-beter-in-positie.html.

43. Samenwerkend Toezicht leugd. Vormgeving zorg en ondersteuning aan gezinnen met geringe sociale redzaamheid. [Cooperating inspection youth. Shaping care and support to families with little social resilience.]. Ministerie OCW. [Ministry of Education, Culture and Science.]. The Hague, the Netherlands. 2014. http://www.rijksoverheid. $\mathrm{nl} /$ documenten-en-publicaties/rapporten/2014/05/15/vormgeving-zorg-en-ondersteuning-aan-gezinnen-metgeringe-sociale-redzaamheid.html.

44. Hawkrigg S, Payne DN. Prolonged school non-attendance in adolescence: a practical approach. Arch Dis Child. 2014:99:954-957. doi:10.1136/archdischild-2013-304595

45. Allensworth DD. Addressing the social determinants of health of children and youth: a role for SOPHE members. Health Educ Behav. 2011;38(4):331-8. doi:10.1177/1090198111417709

46. Taras H, Potts-Datema W. Chronic Health Conditions and Student Performance at School. J Sch Health. 2005;75(7):255-266. DOI: 10.1111/j.1746-1561.2005.00034.X 


\section{Case histories}

\section{Audrey}

Audrey is 10 years old and in group 6 of primary school. She is regularly reported sick with a variety of health complaints. The teacher of group 6 is familiar with the multiple problems at home: mother is seriously ill, brother is in prison and following the divorce there is no contact with father. She understands that the situation is not easy for mother, but at the same time she knows that Audrey will continue to fall back at school if things go on like this. Not only does she miss a lot of teaching, she also misses her peers. She watches Audrey become increasingly sad. But mother avoids the discussion with the group teacher and ignores the situation. During a parent-teacher meeting the group teacher suggests that Audrey visits a YHCP for an examination. Audrey turns out to be perfectly healthy. When the YHCP discusses the possibilities of supervision, mother admits she is afraid that the children will be taken away from her by the Youth Welfare Agency. The YHCP indicates to mother that staying away from school sick is not an option. She understands that Audrey may sometimes have a stomach ache or a headache due to all the worries, but school will provide a distraction and will help her to develop. School arranges additional didactic supervision for Audrey. Mother is open to this. And Audrey is looked after in school when she is not feeling well. Mother promises not to report her sick anymore and is pleased with the understanding and the support.

Richie

Richie ( 6 years old) is in group 3 of primary school and is the youngest in a family of four children. Mother is at home and father says he is in the building trade. He is currently unemployed. The family has to make do with social benefits. Richie's brothers and sister are in 'special needs education'. Richie is often reported sick without any reason. The group teacher has a good contact with mother, but when she wants to discuss Richie's absenteeism, mother brushes aside her worries. Richie just catches colds easily. But the group teacher is persistent, also because Richie can be unruly at school and not always seems to understand the assignments. Mother admits that Richie is not always nice at home either. Mother also says that she stopped going to the YHC service because he always 'tore the place down' there too. After a report from the YHC service they have now been receiving care at home from the Youth and Family centre for quite some time already. Mother does want Richie to get help at school. The group teacher is allowed to contact her care worker at the Youth and Family centre. She refers Richie and mother to the YHCP for his frequent colds and his probable lag in development. 


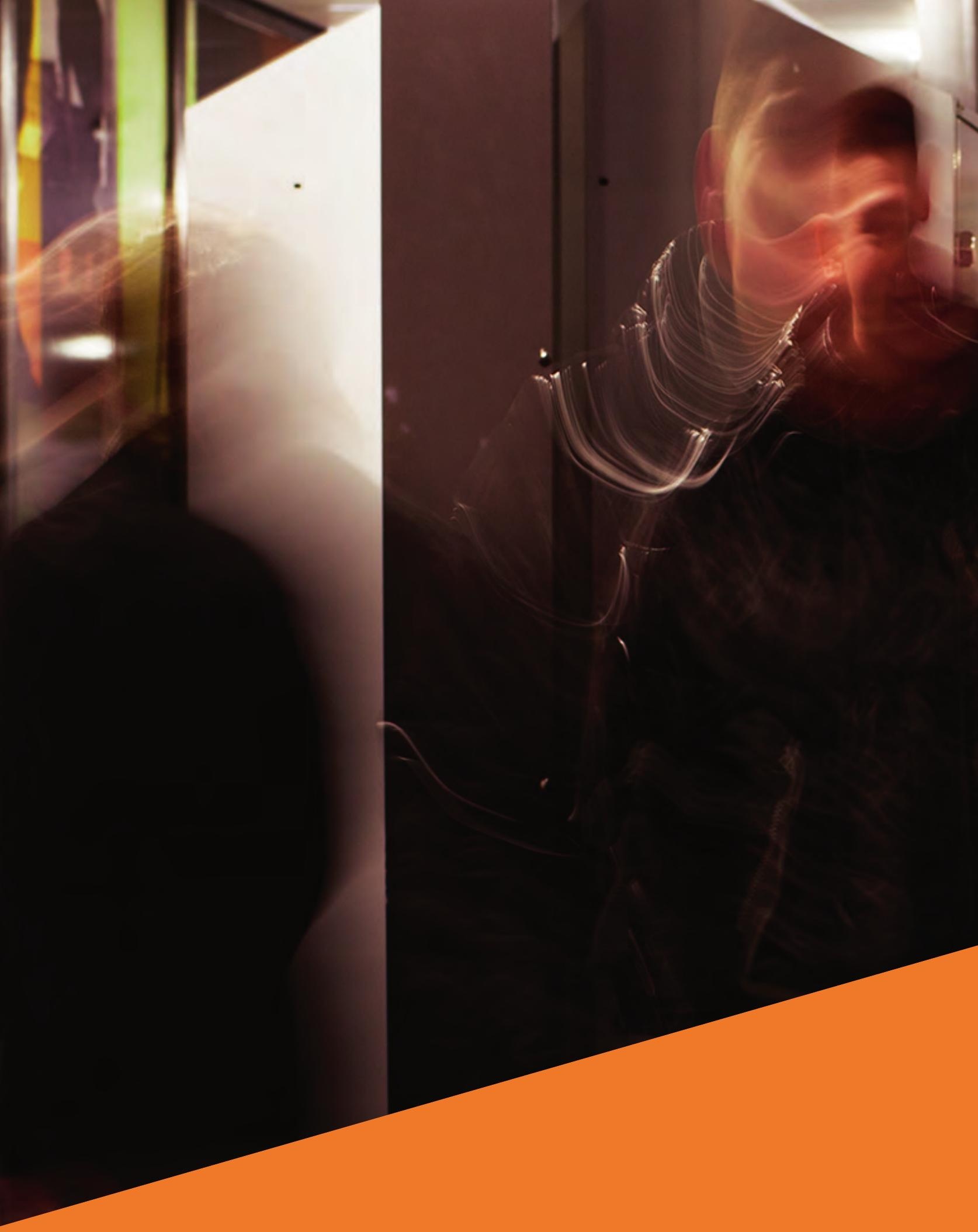





\section{Chapter 7}

\section{Chapter 7: Towards a better understanding of medical absenteeism in adolescence: a qualitative study among Dutch intermediate vocational students}

\section{YTM Vanneste, MAW van Mook, A de Rijk, FJM Feron.}

\section{Abstract}

Objective: An adequate approach to reduce the medical absenteeism of students can make a substantial contribution to the reduction of school dropout. This exploratory study investigates the reasons for and the factors that influence sickness reporting, from student's perspective, and to what extent Veerman's model, a decisional model for workplace medical absence, applies to the medical absence of intermediate vocational students. The ultimate objective of the study is to find starting points for addressing medical absenteeism in adolescence.

Methods: A qualitative research method was used. Semi-structured interviews were held with sixteen students, attending Dutch intermediate vocational education at the highest level.

Findings: Three types of medical absenteeism could be distinguished: students view their medical absence as necessity, as asking for understanding, or as pardonable. Their views on their absence related to medical legitimacy, feeling able to taking their own responsibility, feeling being taken seriously at school and the degree to which the sickness reporting procedure at school is viewed as anonymous and easy. Reporting sick seems more a reaction to a necessity or opportunity, than the result of a conscious decision-making process, which is what is assumed in Veerman's decision model.

Conclusions: Intermediate vocational students have different views on their medical absence. Feelings of self-responsibility and how the school context is perceived can also play a role in the medical absence, besides medical reasons. This variety in backgrounds and the sometimes impulsive character of reporting sick, call for more diversity in the guidance of intermediate vocational students who report sick. In determining the guidance needed, one should take student's own view on the absence as a starting point. Veerman's model does not seem to apply to the medical absence of intermediate vocational students.

Key words: intermediate vocational education, school dropout, career guidance, medical absence theory, decision model, medical absenteeism.

Submitted: PlosOne. 


\section{Introduction}

School absenteeism is a major problem, both for the individual and for society. It may lead to a lower level of education or even school dropout [1-4]. Low educational level and school dropout are both strongly associated with increased risk behaviour $[5,6]$, a higher prevalence of chronic health issues and common mental problems [7-10], and higher mortality rates [1116], and an increased risk of social failure and delinquency [17-21]. In the Netherlands, school dropout mainly occurs in intermediate vocational education. In the school year 2011-2012, $71.5 \%(29.671)$ of all school dropouts left from schools of intermediate vocational education [22]. In particular, those dropouts with (mental) health problems appear to be subsequently less successful in their individual career development and lives [23, 24].

School absenteeism in compulsory education up to the age of 18 appears to be associated with unhealthy lifestyle [25-27], psychological, family, and social problems, diseases and physical complaints $[2,26,28-31]$, and school-related factors such as parental involvement in school and student's school engagement $[27,32-35]$. School absenteeism and school disengagement appear to be interrelated. School absenteeism can be a result of school disengagement. In addition, students are often sanctioned as response to absenteeism, contributing to further negative perceptions about investing in school and leading to increased school disengagement $[32,36]$ and school absence.

Often a distinction is made between excused and unexcused school absenteeism. The first includes mainly sickness reporting, so-called medical absenteeism. Medical absenteeism is as common as truancy, or even more prevalent [26, 37-39]. In primary and secondary school, students are reported sick by their parents. In the Netherlands, students attending intermediate vocational education report themselves sick. Derriks studied the reporting of absenteeism by these students [40]. Almost $40 \%$ of the students stated that they do not report their absence, $20 \%$ stated that, if reporting their absence, they do not tell the real reason for their absence, and $45 \%$ of the students said that it is rather easy to be absent from school unnoticed. To the best of our knowledge, no international studies of school absenteeism in intermediate vocational education from student's perspective have been conducted.

In the Netherlands, contrary to the treatment of occupational absenteeism due to sickness, there are no interventions and agencies for addressing medical absenteeism among students. In tackling medical absenteeism in intermediate vocational education, there are two important reasons for learning from occupational health services. First, during work placements these students will also be expected to function as employees. Second, given their age, one should be able to appeal to their autonomy. As mentioned earlier, school absenteeism is associated with health-related, personal and school-related factors. Veerman's model [41] has been used to develop an intervention for addressing medical absenteeism in intermediate vocational education [42] acknowledging these related factors. This is one of the many models for occupational absenteeism due to sickness [43]. The Veerman model is a decisional model [43]. This model (Fig. 1) distinguishes different 
aspects of the individual and workplace situation that are taken into account before reporting sick, and explains that 'absence necessity' (that is, feeling sick or being ill) is moderated by a 'medical absence threshold'. This threshold is influenced by 'absence opportunities' and 'need for absence' (affected inversely by need to be present).'Absence opportunities' refer to organizational factors and legislation that allow for absence.'Need for absence' refers to the subjective values of the job, and how much an employee wants to report sick due to the job. This model represents a two-stage process: first there must be an absence necessity, after that a weighing process (a process of weighing pros and cons) starts.

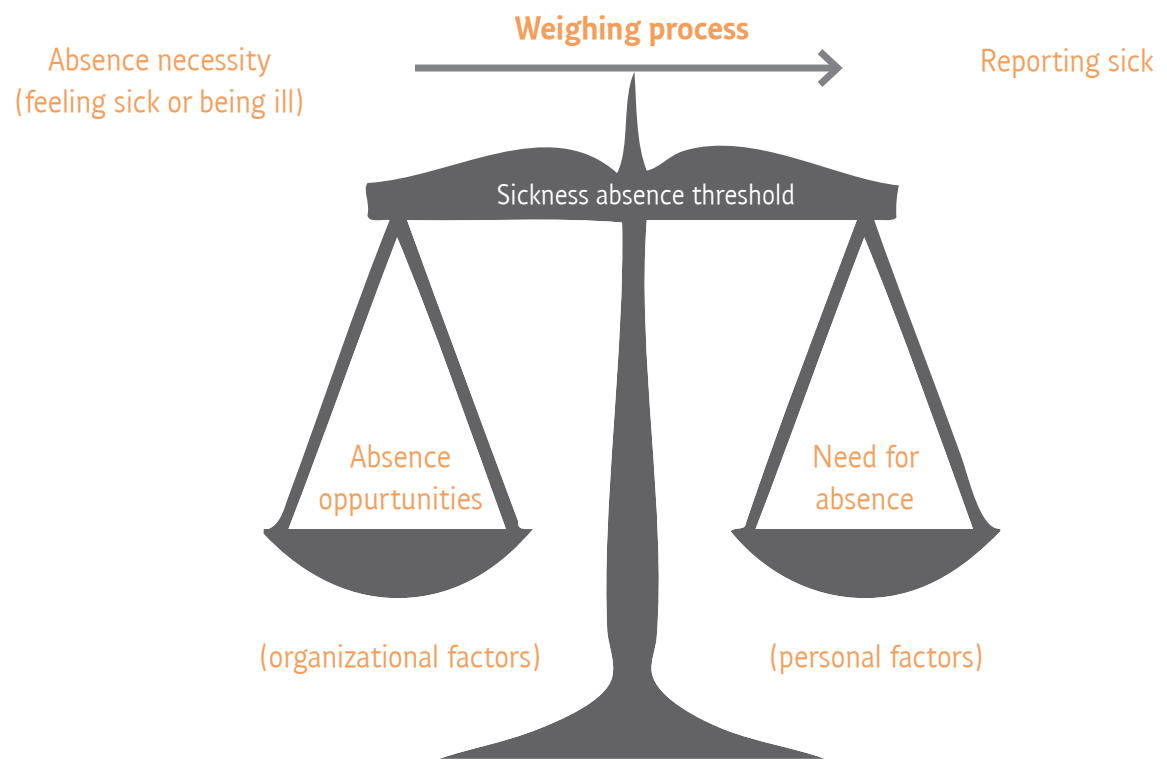

Figure 1: A model with aspects of the individual and workplace situation that are taken into account before reporting sick. Adapted from the decision model (Veerman, 1993].

Despite its seeming validity for the case of students, the validity of the Veerman model for absence among students in intermediate vocational education needs to be examined. Elements for consideration are the difference in age between these students and employees, and the different interrelationship between on the one hand school and student, and on the other hand employer and employee.

To a better insight in the specific dynamics of absenteeism in an intermediate vocational education setting, students' perceptions ought to be considered. The research questions for this study are: (1) what, according to the students, are their reasons for sickness absence? (2) What factors, according to the students, influence their sickness reporting? (3) To what extent does Veerman's model apply to the medical absence of students in intermediate vocational education? 


\section{Methods}

Qualitative research methods are useful when exploring stakeholders' perceptions [44, 45]. To find answers to our research questions and to obtain proper insight into the experiences and perceptions of the students, in-depth individual semi-structured interviewing was selected as the best method of data gathering [44-46]. Data were collected between February and June 2014 in the North Brabant region in the southwest of the Netherlands. In order to obtain as many different views as possible, purposive sampling and snowball sampling were used [44, 47], and participants were added until data saturation had been reached.

\section{Study participants}

To be included, students had to be attending intermediate vocational education and had to have experienced medical absence. At the start, students were asked to participate in the study by a special education needs coordinator of the school. It appeared to be difficult to recruit students this way: only 4 students were willing to be interviewed. Then, by using the 'chain-referral sampling' method [48], the next 12 students could be recruited. Because of the fact that, in the beginning, only students who were receiving education at level 4 were willing to participate in the study, participationwas eventuallylimited to thislevel.Toobtainasmanydifferentviewsas possible,students with different background characteristics were searched for.Student characteristics are presented in Table 1.

Table 1: Overview of students' characteristics.

\begin{tabular}{|c|c|c|c|c|c|c|c|}
\hline & Gender & Age & $\begin{array}{c}\text { Living at } \\
\text { home }\end{array}$ & Ethnicity & School & $\begin{array}{c}\text { Sick reporting } \\
\text { system }\end{array}$ & $\begin{array}{c}\text { Subject of } \\
\text { education }\end{array}$ \\
\hline N. & Male & 20 & Yes & Native & 1 & Digital & Architecture \\
\hline H. & Male & 24 & No & Immigrant ${ }^{1}$ & 1 & Digital & Architecture \\
\hline D. & Female & 20 & Yes & Native & 2 & By phone & Legal services \\
\hline D. & Female & 19 & Yes & Native & 2 & By phone & Legal services \\
\hline R. & Male & 18 & Yes & Native & 3 & By phone & Entrepreneurship \\
\hline M. & Female & 17 & Yes & Native & 2 & By phone & Legal services \\
\hline J. & Male & 19 & Yes & Native & 1 & Digital & Architecture \\
\hline F. & Male & 18 & Yes & Native & 1 & Digital & Architecture \\
\hline L. & Female & 17 & Yes & Native & 2 & By phone & Legal services \\
\hline T. & Male & 19 & Yes & Native & 3 & By phone & Entrepreneurship \\
\hline L. & Female & 19 & Yes & Native & 4 & By phone & Teaching assistant \\
\hline I. & Male & 21 & Yes & Native & 5 & By phone & Leisure \\
\hline M. & Female & 19 & Yes & Native & 4 & By phone & Social care \\
\hline T. & Male & 23 & Yes & Native & 5 & By phone & Branch manager \\
\hline W. & Female & 19 & Yes & Native & 6 & By phone & Veterinary assistant \\
\hline I. & Male & 22 & Yes & Native & 7 & Digital & Sports \\
\hline
\end{tabular}

${ }^{1}$ Second generation immigrant. 


\section{Ethical considerations}

According to the guidelines of the Maastricht University committee for the application of the law on Medical Research Involving Human Subjects, the study was not subject to this law. Students were informed by letter of the purpose of the research, the anonymously processed data-analysis, and the use of the information received, in which confidentiality was guaranteed. They were made aware that they were free to refuse to participate at any time before, during, and after the interview. They were given a 3 day reflection period before an appointment was made. The interview was not started until written consent had been received.

\section{Interview procedure}

The questions were broad, open-ended, and non-directive. The interview topic list was inspired by Veerman's model, the experience of youth health care physicians, and interviews with sick employees. It included questions such as: (a) why the student reported sick from school (from their perspective), followed by questions such as: (b) what is the sickness reporting procedure in your school, (c) when and how do you report sick, (d) what happens after that, (e) who was involved in your sickness reporting, (f) how do your classmates deal with sickness reporting, and (g) from whom do you expect support after reporting sick? At the end of the interview the student was offered a conversation with the teacher or the youth health care physician. None of the respondents actually made use of this offer. The audio-recorded interviews lasted around 45 minutes, and were transcribed verbatim for further analysis.

\section{Analysis}

Initially, two researchers independently from each other carried out an inductive thematic analysis $[44,46]$ by structuring data, initial coding, categorizing experiences and perceptions, and identifying themes and their interrelations. Then, in the research team, different interpretations were discussed and refined until agreement was reached. Several intermediate analyses were applied to check whether all topics had been covered. Students to be interviewed were added until no additional new concepts were identified; saturation occurred after fourteen interviews, and was confirmed through two final interviews. All data (transcripts, coding tree, and findings) was available for inspection by the coauthors during the research. In addition, a three-hour group meeting took place, in which a multidisciplinary team of teachers, youth health care physicians, and school attendance officers was asked whether they considered the findings to be clear, understandable, and logical. On the basis of this meeting the analysis was refined.

\section{Availability of Supporting Data}

The study data is stored by the Faculty of Social and Behavioural Sciences, Tranzo, Tilburg University in The Netherlands following the Institution's data management policies. Data can be released by researchers in research collaboration based on permission from the steering committee of the study. 


\section{Findings}

To begin with, three ways are found in which students view their absent periods: they regard their absence as necessity, as asking for understanding or as pardonable. These three views can be understood by varied background experiences: the degree to which they feel able to take responsibility for themselves, the degree to which the sick reporting procedure at school is experienced as anonymous and (too) easy, and the degree to which they feel themselves to be taken seriously by the school.

\section{How students regard their absence}

When asking for the reason for medical absence, all the students spontaneously gave a sort of 'retrospective justification' for their medical absence. Three views can be distinguished here.

First, absence as necessity was distinguished. The students find their medical absence necessary and legitimate. These students indicated that they report sick because they are sick or have physical complaints.

"I was sick two years ago. A problem with my nerves. And I missed eight months". N., 20 y.

"I had flu and a temperature. Yes, I did try, but it wasn't on. So then I just went home". D., 20 y.

Second, absence as asking for understanding was distinguished. The students excuse themselves and ask for understanding for their medical absence, because they are at a loss or are confused and upset. They expect that reporting sick will help them to feel better. These students reported that psychological complaints, problems at home or at school made them report sick.

"I was much too occupied with myself, so then what's the point of being at school? ....And I explained that. I think I can expect allowance to be made for this". D., $19 \mathrm{y}$.

"If I need to calm down I report sick". H., 24 y.

"There is still a rather unpleasant atmosphere in the class.... it puts very many students off, and then they sometimes simply report sick". T., $19 \mathrm{y}$.

Third, absence as pardonable was distinguished. The students regard their reporting sick as pardonable and believe that school should not constrain them. Some of them blamed others for their sickness reporting and said that they occasionally reported sick because of reasons such as: other students were also going home, free periods during the day, and the non-inspiring method of teaching.

"I think that many students think that a little bit of absence during school time is not really a problem". F., $18 \mathrm{y}$.

"If coming to school is just a waste of time, then you can expect people to think up an excuse for not having to come any more. Anyone would do that if they didn't find a lesson interesting".T., $19 \mathrm{y}$

You know, some more interesting and active lessons, those are more appealing". W., 19 y. 
Others indicated that students report sick because of excuses such as: too tired after the weekend, (no longer) feel like going to school, being too lazy to get out of bed, or having something else to do.

"Some are not really motivated, and they go out in the evening or find football more interesting. Others might prefer going for a joint". R., $18 \mathrm{y}$.

The above-mentioned views are categorized on a conceptual level. On the student's level a mix of views is possible.

\section{"If I need to calm down I report sick, or if I'm really sick, or if I've got too much going on in my head". H., $24 \mathrm{y}$.}

These three views can be understood as variations on taking responsibility, valuing the school sick reporting procedure and feeling treated seriously, which is explained next.

\section{The degree to which they feel able to take responsibility}

Some students said they were quite able to take responsibility. Other students indicated that they are still learning to take responsibility, because they are still maturing into adulthood.

"...I live alone and take responsibility for everything myself". H., 24 y.

"I think that those who are older should be able to imagine what it's like to be young. That things can be quite difficult for us. Or how to cope, because sometimes I simply have no idea. We have to learn it all". D., 19 y.

Students said that their parents could help them in this. Some students indicated that their parents had little involvement in school, while other students said that their parents do involve themselves in school matters.

“Even if I were 18 I would still get my parents to report me sick. So I couldn't misuse it ... Yes, I also prefer them to know what's going on". M., $17 \mathrm{y}$.

“My parents were always on my back. If they hadn't done that it would have been much worse, I think". W., $19 \mathrm{y}$.

"My parents have left me free to do what I want". T., 23 y.

Some students said that they spoke openly at home about their medical absence, while others kept it from their parents.

“I'm honest with my mother, but she says it's your own affair as long as you get through". I., $22 \mathrm{y}$.

"I didn't say that I went home sick. I was afraid that they would keep on at me if I told them, and I don't want that. If I were honest about it they wouldn't support me, and I suppose that's 
Students also indicated that the school could help by teaching them to take responsibility more than it does at present according to them. School can help by showing understanding of the fact that the students are not yet able to take full responsibility, and by presenting clear consequences to medical absence.

"I think, so help us with it, but that's not how I see things here at school". D., $19 \mathrm{y}$.

"They don't necessarily have to do anything specific, but I hope that the school can at least show some understanding". L., 19 y.

"There would be a lot fewer students absent if the school took more action against excessive absence". W., 19 y.

The students related that they feel a greater obligation to turn up when on work placement.

"I don't make plans to meet up during work placement time, because I find that a bit more serious than school, because then you're actually in a company and it's not really on to say each week that you've got something else to do. And the companies also quickly get fed up with it and you have to look for another company. It's not easy to skip work placement, and I wouldn't recommend it to anyone". F., $18 \mathrm{y}$.

\section{The degree to which the sick reporting procedure at school is perceived as anonymous and too easy}

The students explained how you can call in sick, and whether parents are involved or not. Most of the students who had to report sick digitally indicated that this was too easy, meaning that they were ready to call in sick more easily.

"I think that people are quick to report sick when they can report sick online... (so easy)...". .., 22 y.

The students also indicated that they miss a personal way of reporting sick, for example to the career counsellor. They said that the person at the other end of the line can also contribute. Then they could get the story off their chest, and know straight away what the other person thinks about it.

“... While you're on the phone you have to talk to someone and tell them what the problem is.

They may well come to the opinion that you are not really sick ...

But the main thing is that you can tell about what's really the matter. Then at least you hear their voice. At present you have no idea what they think about your medical absence... I would prefer a more personal way of reporting sick". F., $18 \mathrm{y}$.

At the same time, the students indicated that they have no idea what use a career counsellor is to them, and whether they can rely on them. They said that the talks they have with their career 
counsellor could be more strongly focused on personal guidance.

“... So I don't know whether I can count on the career counsellor if there is something wrong at home, I really couldn't say...". F., 18 y.

"... I now have a career counsellor, and last year he really said something wrong. He told me, you must keep school and private life separate. Well sorry, I find that really stupid. There is a reason for having a career counsellor, isn't there? You simply have a talk, and then they ask how things are going. Are you getting good marks? Okay, good, send in the next one. Surely it's not only about your marks? Isn't it also about your development as a person?". D., 19 y.

Other students indicated that they didn't feel their relationship with their career counsellor was good enough for them to wish to discuss their problems with him or her.

"That Mrs $X$ is very pleasant but she really gives the impression that she thinks you're stupid. Everyone says that you've got someone you can go to and that's Mrs X. Yeah, yeah, it's not going to be her, that's the last person I would go to with my problems". T., $19 \mathrm{y}$.

\section{The degree to which they feel themselves to be taken seriously by the school}

Although the students explained that they cannot be expected to take all responsibility themselves, it does not mean that they do not want to be taken seriously by the school. The students said that schools react in many different ways to a sick report. Some students said that the reaction took a long time and sometimes never even took place. They would like the school to inquire about the reason for medical absence.

“.....No, they didn't ask about it.... a classmate was genuinely sick, but they didn't really ask after her. They never asked how she was. So I think, that's pretty bad...". M., 19 y.

"If you really report sick frequently then I would expect them to want to talk to you about it: why do you report sick so often, and how can I help you? Do you enjoy school or not? What don't you like, and what is it that you do like? Is the course right for you? Is something else the problem, are there problems at home? You look into the background of your students, so that you, as career counsellor, can watch out for things or give guidance". L., 19 y.

One of the students claimed to experience too much checking up after reporting sick.

"So they really checked up to see whether we were really sick ... Just as if they were always suspicious that you are pretending to be sick, or playing truant, or that sort of thing". I., $21 \mathrm{y}$.

According to the students themselves, if they were taken seriously they would also make more effort to avoid absence.

"There are really quite a few who are away a lot. I have the idea that it's really badly handled.

Now and again they're called to account, but that's it... If the system were different, then I would be better myself and would put more effort into acting differently. When it's so easy, you 
The students noted that the ease with which they can stay away from school hinders them in taking their own responsibility for reporting sick.

\section{Discussion}

The purpose of this exploratory study was to gain insight into how medical absence is perceived by students themselves, and to answer the questions: which factors, in their opinion, influence their medical absence, and to what extent does the decision model from occupational medicine apply to the medical absence of students in intermediate vocational education? For this study, 16 students at the highest level of intermediate vocational education in the Netherlands were interviewed.

Although the students were not explicitly asked about this during their interviews, they all spontaneously gave a 'retrospective justification' for their medical absence. Three perceptions of their medical absence could be distinguished: as necessity, as asking for understanding or as pardonable. These views can be understood by the following background experiences: the degree to which they feel able to take their own responsibility, the degree to which the sickness reporting procedure at school is perceived as anonymous and easy, and the degree to which they feel themselves to be taken seriously at school. Fig. 2 presents a conceptual model schematically illustrating the relationship between the students' view on medical absence and the aforementioned factors.

\begin{tabular}{|c|c|}
\hline the degree of medical legitimacy & $\begin{array}{l}\text { the degree to which they feel able to take } \\
\text { their own responsibility }\end{array}$ \\
\hline \multicolumn{2}{|c|}{$\begin{array}{l}\text { absence as necessity, as asking for understanding or } \\
\qquad \text { as pardonable }\end{array}$} \\
\hline $\begin{array}{l}\text { the degree to which they feel themselves } \\
\text { to be taken seriously at school }\end{array}$ & $\begin{array}{c}\text { the degree to which the sickness reporting } \\
\text { procedure at school is perceived as anonymous } \\
\text { and easy }\end{array}$ \\
\hline
\end{tabular}

Figure 2. Schematic representation of the relationship between the way students perceive their medical absence and the background experiences involved, according to the students.

\section{Relevance of the decision model}

The decision model of Veerman [41] assumes an absence necessity as a motive for the absence, after which an assessment is made that is influenced by personal factors that indicate the need for absence and organizational factors that indicate the opportunity for absence, followed by the decision to report absence or not. There seems to be no question of a weighing process in the case of the students in intermediate vocational education. Even though there is an absence necessity 
(for example, a health problem), the sick report still appears to be more an ad hoc decision than the result of a well-considered decision-making process. If it all gets too much for students, they call in sick without feeling able to oversee the consequences. And this occurs, according to the students, more easily if the opportunity presents itself as a consequence of the sickness reporting procedure being impersonal and too easy. This 'retrospective justification' implies that the consequences hardly play a role in their reporting sick. For students in intermediate vocational education, sickness reporting seems to be rather a comprehensive process in which many factors can play a part. Reporting sick is a reaction to a need, a desire, or an opportunity rather than a process of consideration in the case of an absence necessity. They might not yet be able to, due to their state of development. When considering something, one needs to be able to form a view of long-term consequences of decisions. At the age of these students in intermediate vocational education this is frequently not the case, taking into consideration the degree of maturation of the prefrontal cortex, showing great individual variation $[49,50]$.

\section{Discussion of the findings}

The reasons for absence given by the students themselves varied from 'really too ill to go to school' to 'got something else to do', indicating that the degree of medical legitimacy differs. Not only sickness, but also mental health problems caused by the home or class situation, together with the behaviour of peers, the timetable, and the content of the lessons, were all reasons for medical absence among students in intermediate vocational education. These findings match the results of previous research on school absenteeism referred to in the introduction. Reasons as 'too tired or lazy' given by students to explain away their absence, may be linked to school disengagement. This disengagement may be strengthened by the feeling of not being taken seriously by school and by anonymous sick reporting procedures.

The degree to which, in their own opinion, students feel up to taking responsibility, differed per student. Some students stated explicitly that they are still learning to be responsible. This is consistent with differences in maturity of the prefrontal cortex, as previously mentioned. The prefrontal cortex is involved in the development of executive functions such as planning and decision-making $[49,50]$. Both are required for the recognition of consequences, and thus the ability to take responsibility for one's actions.

Although the students suggest that their parents could help them in learning how to take responsibility, the interviews show that this cannot be realized to the same extent with every student. Parents' involvement in school, and the effectiveness of this involvement according to the student, differed largely between students. While one student spoke about his medical absence at home, another concealed it, out of fear of causing trouble and stress. Research indeed showed that the withholding of information by students, especially in cases of questionable acts, was primarily due to concerns about parental disapproval $[51,52]$. Precisely at this age young people are trying to establish their independence from home $[53,54]$, and parental interference is not always appropriate. This can explain the differences and ambiguity concerning the help wanted. Whereas for students the goal of adolescence is to gain independence and establish an identity, the challenge for parents is to correctly assess the degree to which their child needs guidance in this process [55]. 
The students in this study do have concrete ideas on how the school can help them learn to take responsibility. In the first place the students asked the school to show some understanding for the fact that they are 'learning'. They consider that linking consequences to medical absence and clear communication about these may help them to (learn to) take responsibility. Reporting sick in a personal way, for example to the career counsellor, could help in learning to take responsibility because student then get the chance to explain their situation. Students wish to know an adult's opinion about it. They would like to see that someone shares their thoughts about the necessity and consequences of the absence. This will help them to make a proper judgement. At the same time the students indicate that they do not have a clear picture of the benefits of a career counsellor, and that a good relationship is important. The formal position of career counsellor was introduced into the educational system in the Netherlands in 2008. During the career conversations, attention is paid primarily to study progress [56]. Preferably the personal development of the student should form the central theme and the conversations should be reflective dialogues [57]. This study demonstrates the importance of discussing sick reports as part of this, for the medical absenteeism of students of intermediate vocational education is not limited to medical backgrounds.

The students also indicate that if the school enters into discussion with them following a sick report they feel that they are being taken serious. However this must be done out of interest rather than for reasons of checking up. This is also found in literature: students are often sanctioned by school staff in response to school absenteeism and, unfortunately, this contributes to further negative perceptions about investing in school, thus leading to school dropout $[32,36]$.

The students indicate that their experience with reporting sick on previous occasions plays a role in case of a new occurrence. Factoring in this is not only how easy it was to do, but also the anonymity of the sickness reporting and the absence of reaction to the sick report by the school. Some students even state that they would feel better if they were not absent without good reason.

\section{Implications}

The findings provide points of departure for reducing medical absenteeism in intermediate vocational education. First it is important to personalize the sick reporting procedures as much as possible as backgrounds and experiences are very diverse. That will cause students to feel taken seriously and it gives an opening to address the underlying reasons. Moreover, it might enable schools to help adolescents in learning to take their own responsibility regarding the sickness reporting. When discussing the medical absence, demonstrating interest rather than control, the students' own views on their medical absence should be taken as a starting point. This allows the interlocutor to connect with students' own experiences on the sick reporting procedure and to organise adequate care and guidance. Real connection with the student might prevent student's disengagement with school. Medical absenteeism might also be reduced by promoting a good atmosphere in the class, and well-scheduled lessons matching the capabilities and interests of students. Students indicating that they report sick because they 'have something else to do' may not have the right attitude towards school. In such cases it will probably be important to link clear consequences to (too much) medical absence. However, a wrong choice of study might also cause 'not feeling like school any more'. And 'too tired or lazy' could hide a lifestyle problem (addiction, lack of exercise, poor diet, etc.). Discussing student's medical absence interlinks with successful 
and effective career guidance and should be included in the career conversations that career counsellors have with their students. Regarding further research, for a more comprehensive understanding of medical absenteeism in intermediate vocational education, it is recommended to also study the issue from the school's perspective.

Acknowledgements: The authors would like to thank all students who participated in this study.

Authors' contributions: All authors contributed to the conception and design of the study. YV coordinated the study. MM and YV participated in data collection. AR and FF supported the analysis of the study. All authors contributed to the interpretation of the data. YV drafted the manuscript, the coauthors critically revised the manuscript. All authors are accountable for all aspects of the work and have read and approved the final version of the manuscript. 
1. Eckstein Z, Wolpin KI. Why Youths Drop Out of High School: The Impact of Preferences, Opportunities, and Abilities. Econometrica. 1999;67(6):1295-1339. doi:10.1111/1468-0262.00081

2. Kearney CA. School absenteeism and school refusal behavior in youth: A contemporary review. Clin Psychol Rev. 2008;28:451-471. doi:10.1016/j.cpr.2007.07.012

3. Christenson SL, Thrulow ML. School Dropouts: Prevention Considerations, Interventions, and Challenges. Am Psychol Soc. 2004;13(1):36-39. doi:10.1111/j.0963-7214.2004.01301010.x

4. Rumberger RW. Why Students Drop Out of School and What Can be Done, in Dropouts in Amerca: How Severe is the Problem? What Do We Know about Intervention and Prevention? Harvard University. 2001;1-45. http://civilrightsproject.ucla.edu/research/k-12-education/school-dropouts/why-students-drop-out-of-schooland-what-can-be-done/rumberger-why-students-dropout-2001.pdf.

5. Droomers M, Schrijvers CTM, Mheen $\mathrm{H}$ van de, Mackenbach JP. Educational differences in leisure-time physica inactivity: a descriptive and explanatory study. Soc Sci Med. 1998;47(11):1665-1676. doi:10.1016/So2779536/98)00272-X

6. Droomers M, Schrijvers CTM, Stronks K, Mheen D van de, Mackenbach JP. Educational differences in excessive alcohol consumption: the role of psychosocial and material stressors. Prev Med. 1999;29(1):1-10. doi:10.1006/ pmed.1999.0496

7. Thrane C. Explaining educational-related inequalities in health: Mediation and moderator models. Soc Sci Med. 2006;62(2):467-78. doi:10.1016/j.socscimed.2005.06.010

8. Dahlgren $\mathrm{C}$, Whitehead M. European strategies for tackling social inequities in health: Levelling up part 2. WHO Regional Office for Europe. World Health Organization Regional Office for Europe. 2006. ttp://www.euro.who. int/ data/assets/pdf file/0018/103824/E89384.pdf?ua=1.

9. Mackenbach JP. Health Inequalities: Europe in Profile, in Tackling Health Inequalities: Governing for Health. European Commission: Rotterdam, Erasmus University. 2006. http://www.who.int/social_determinants/resources/european_ inequalities.pdf.

10. Havas J, Bosma H, Spreeuwenberg C, Feron F). Mental health problems of Dutch adolescents: the association with adolescents' and their parents' educational level. Eur / Pub Health. 2010;20(3):258-264. doi:10.1093/eurpub/ ckp172

11. Kulhánová I, Hoffmann R, Eikemo TA, Menvielle G, Mackenbach JP. Educational inequalities in mortality by cause of death: first national data for the Netherlands. Int J Public Health. 2014;59(5):687-96. doi: 10.1007/s00038$014-0576-4$

12. Bosma H, Mheen D van de, Borsboom GJJM, Mackenbach JP. Neighborhood Socioeconomic Status and All-Cause Mortality. Am J Epidemiol. 2001;153(4):363-371.

13. Huisman M, Kunst AE, Bopp M, Borgan JK, Borrell C, Costa G, Deboosere P, Gadeyne S, Glickman M, Marinacci C, Minder C, Regidor E, Valkonen T, Mackenbach JP. Educational inequalities in cause-specific mortality in middle-aged and older men and women in eight western European populations. Lancet. 2005;365(9458):5-11. dx.doi.org/10.1016/So140-6736/05)17867-2, hdl.handle.net/1765/58767

14. Gathmann C, Jürges H, Reinhold S. Compulsory schooling reforms, education and mortality in twentieth century Europe. Soc Sci Med. 2015;127:74-82. doi:10.1016/j.socscimed.2014.01.037

15. Lager AC), Torssander J. Causal effect of education on mortality in a quasi-experiment on 1.2 million Swedes. Proc Natl Acad Sci USA. 2012;109(22):8461-8466. doi:10.1073/pnas.1105839109

16. Mackenbach JP, Stirbu I, Roskam AJR, Schaap MM, Menvielle G, Leinsalu M, Kunst AE. Socioeconomic inequalities in health in 22 European countries. N Eng I Med. 2008;358(23): 2468-81. DOI:10.1056/NEJMsa0707519

17. Traag T, Marie O, Velden Rvd. Risicofactoren voor voortijdig schoolverlaten en jeugdcriminaliteit. [Risk factors for dropping out of school and juvenile delinquency: relationship school dropout and juvenile delinquency.]. 2010; 556o. http://www.cbs.nl/NR/rdonlyres/131FADA3-2E22-4E51-gA91-6BB53E1E0895/o/2010k2b15P55art.pdf.

18. Beckers I, Traag T. Met een startkwalificatie betere kansen op de arbeidsmarkt. [With a basic qualification better opportunities in the labor market.]. Sociaal-economische Statistics Netherlands: The Hague. Trends, 4, 23-28. 2005. http://www.cbs.nl/nl-NL/menu/themas/arbeid-sociale-zekerheid/publicaties/artikelen/archief/2005/20051816-wm.htm.

19. Junger-Tas J. Diploma's en goed gedrag II: Preventie van antisociaal gedrag in het onderwijs. [Diplomas and good behavior II: Prevention of antisocial behavior in education.] The Hague, the Netherlands. Ministry of Justice. 2002. http://members.multimania.nl/veiligeschool/Preventie\%2ovan\%20antisociaal\%2ogedrag.pdf.

20. Ross CE, Wu C-L. The Links between Education and Health. Am Sociol Rev. 1995;6o(5):719. doi:10.2307/2096319

21. Galobardes B, Lynch J, Smith CD. Measuring socioeconomic position in health research. Br Med Bull. 2007;8182:21-37. doi:10.1093/bmb/ldmoo1 
22. Nieuwe voortijdig schoolverlaters. Convenantjaar 2011-2012. Voorlopige cijfers. Bijlage vsv-brief 2010. [New early school leavers. Covenant year 2011-2012. Provisional figures. Appendix ESL-letter 2010.] Dutch Ministry of Education, Culture and Science. Dropout Explorer. National perspective of school dropouts. The Hague, the Netherlands. 2013. http://www.rijksoverheid.nl/documenten-en-publicaties/kamerstukken/2010/02/17/bijlagevsv-cijfers-2010.html.

23. Allen J, Meng C. Voortijdig schoolverlaters: aanleiding en gevolg. [School dropouts: Causes and consequences.] Research report No. ROA-R-2010/9. Research Centre for Education and the Labor Market (ROA): Maastricht. Maastricht University. 2010. http://roa.sbe.maastrichtuniversity.nl/roanew.

24. Eimers T, Bekhuis H. Vroeg is nog niet voortijdig. [Early is not yet premature.]. Kenniscentrum Beroepsonderwijs Arbeidsmarkt (KBA). 2006. http://www.aanvalopschooluitval.nl/userfiles/file/Vroeg\%20is\%2onog\%2oniet\%20 voortijdig.pdf.

25. Baxter SD, Royer JA, Hardin JW, Guinn CH, Devlin CM. The relationship of school absenteeism with body mass index, academic achievement, and socioeconomic status among fourth-grade children. I Sch Health. 2011;81:417423. doi:10.1111/j.1746-1561.2011.00610.x

26. Eaton DK, Brener N, Kann LK. Associations of health risk behaviors with school absenteeism. Does having permission for the absence make a difference? I Sch Health. 2008;78(4):223-9. doi:10.1111/j.1746-1561.2008.00290.x

27. Vaughn MC, Maynard BR, Salas-Wright CP, Perron BE, Abdon A. Prevalence and correlates of truancy in the US: results from a national sample. I Adolesc. 2013;36(4):767-76. doi:10.1016/j.adolescence.2013.03.015

28. Jones R, Hoare P, Elton R, Dunhill Z, Sharpe M. Frequent medical absences in secondary school students: survey and case-control study. Arch Dis Child. 2009;94:763-767. doi:10.1136/adc.2008.140962

29. Pan LP, Sherry B, Park S, Blanck HM. The Association of Obesity and School Absenteeism Attributed to IIIness or Injury Among Adolescents in the United States, 2009. I Adolesc Health. 2013:52(1):64-69. doi:10.1016/j. jadohealth.2012.04.003

30. Rappaport EB, Daskalakis C, Andrel J. Obesity and other predictors of absenteeism in Philadelphia school children. I Sch Health. 2011;81(6):341-4. doi:10.1111/j.1746-1561.2011.00599.x

31. Vanneste YTM, Rots-de Vries MC, Goor LAM van de, Feron F.J.N. Medische Advisering Ziekgemelde leerling door de jeugdarts (M@ZL); ontwikkeling van een interventie. [Medical Advice for Sick-reported Students (MASS); Development of an intervention.]. TSC. 2012;90(7):412-19. www.tsg.bsl.nl.

32. Archambault I, Janosz M, Fallu JS, Pagani LS. Student engagement and its relationship with early high school dropout. | Adolesc. 2009;32:651-670. doi:10.1016/j.adolescence.2008.06.007

33. Duckett P, Kagan C, Sixsmith I. Consultation and Participation with Children in Healthy Schools: Choice, Conflict and Context. Am J Community Psychol. 2010;46:167-178. doi:10.1007/s10464-010-9327-8

34. Shute VI, Hansen EG, Underwood JS, Razzouk R. A Review of the Relationship between Parental Involvement and Secondary School Students' Academic Achievement. Educ Res Int. 2011; Open access article. Article ID 915326, 10 pages. doi:10.1155/2011/915326

35. Vander Stoep A, Weiss NS, McKnight B, Beresford SAA, Cohen P. Which measure of adolescent psychiatric disorder - diagnosis, number of symptoms, or adaptive functioning - best predicts adverse young adult outcomes? | Epidemiol Commun H. 2002;56:56-65. doi:10.1136/jech.56.1.56

36. Finn JD. Withdrawing From School. Rev Educ Res. 1989;59(2):117-142. doi:10.3102/00346543059002117

37. Scottish Executive National Statistics. Results of pupil attendance and absence for session $2006 / 7$. The Scottish Government, Edinburgh. 2007. http://www.scotland.gov.uk/Publications/2013/12/4199/17.

38. Lenzen C FG, Jentzsch A, Kaess M, Parzer P, Carli V, Wasserman D, et al. Schulabsentismus in Deutschland - die Prävalenz von entschuldigten und unentschuldigten Fehlzeiten und ihre Korrelation mit emotionalen und Verhaltensauffälligkeiten. [School absenteeism in Germany: prevalence of excused and unexcused absenteeism and its correlation with emotional and behavioural problems.]. Prax Kinderpsychol K. 2013;62 (8):570-82. doi:http://www.vr-elibrary.de/doi/abs/10.13109/prkk.2013.62.8.570

39. NIPO het marktonderzoeksinstituut. Rapport: Schoolverzuim in het Voortgezet Onderwijs. [Report on school absenteeism in secondary school.] Amsterdam, the Netherlands. 2002. http://www.tns-nipo.com/pages/ persvannipo/pdf/schoolverzuimo3.pdf.

40. Derriks M, Kat Ed, Voncken E. ledereen bij de les! Externe evaluaties pilots $100 \%$ actie terugdringen VSV. [Everyone attending school! External evaluation pilots $100 \%$ action to reduce ESL.]. Research Report No. 799. FMG: Research Institute Child Development and Education (CDE). SCO-Kohnstamm Instituut. 2008. http:// www.kohnstamminstituut.uva.nl/.

41. Veerman T). Theoriën over ziekteverzuim. [Sickness absence theories.]. In: Smulders PCW, Veerman T], editors. Handboek ziekteverzuim. Gids voor de bedrijfspraktijk. [Handbook Sickness Absence. Guide for the organisational practice.]. The Hague, the Netherlands: Delwel; 1993.

42. Vanneste YTM. Handboek voor een integrale aanpak van ziekteverzuim volgens M@ZL op het MBO. [Manual for application of the MASS intervention in intermediate vocational education.]. National Institute for Public Health and the Environment, RIVM. 2013. http://www.loketgezondleven.nl/idatabase/bijlagen/Interventie1402355/ Erkenning/18087_IDBEffBijlage_2417_Beschrijving\%20M@ZL\%20op\%2ohet\%20MBO.pdf. 
43. Rijk A de. Appendix Work Disability Theories: A Taxonomy for Researchers. In: Loisel P, Anema JR, editors. Handbook of Work Disability: Prevention and Management. (C) Springer Science+Business Media New York. 2013.

doi:10.1007/978-1-4614-6214-9

44. Baxter P, Jack S. Qualitative Case Study Methodology: Study Design and Implementation for Novice Researchers. The Qualitative Report. 2008;13(4):544-559. http://nsuworks.nova.edu/tar/vol13/iss4/2.

45. Given LM. The SACE Encyclopedia of Qualitative Research Methods. 2008. Sage Publications.

46. Boeije HR. Analyseren in kwalitatief onderzoek. [Analysis in qualitative research.]. Londen: Sage. 2010.

47. Boeije HR. Analyseren in kwalitatief onderzoek: Denken en doen. [Analysis in qualitative research: Thinking and doing.]. The Hague, the Netherlands. Boom/Lemma uitgevers. 2014.

48. Biernacki P, Waldorf D. Snowball Sampling: Problems and Techniques of Chain Referral Sampling. Sociol Method Res. 1981;10:141-163. doi: 10.1177/004912418101000205

49. Anderson VA, Anderson P, Northam E, Jacobs R, Catroppa C. Development of executive functions through late childhood and adolescence in an Australian sample. Dev Neuropsychol. 2001;20(1):385-406. DOl:10.1207/ $\mathrm{S}_{15326942 \mathrm{DN} 20015}$

50. Roberts AC, Robbins TW, Weiskrantz L. The Prefrontal Cortex: Executive and Cognitive Functions. 2002; New York, NY, US: Oxford University Press. (1998). viii 248 pp.

51. Smetana JC, Metzger A, Gettman DC, Campione-Barr N. Disclosure and Secrecy in Adolescent-Parent Relationships. Child Dev. 2006;77(1):201-217. doi:10.1111/j.1467-8624.2006.00865.x

52. Smetana JG, Villalobos M, Tasopoulos-Chan M, Gettman DC, Campione-Barr N. Early and middle adolescents' disclosure to parents about activities in different domains. / Adolesc. 2009;32(3):693-713. doi:10.1016/j. adolescence.2008.06.010

53. Grotevant HDC, Cooper C. Individuation in family relationships: A perspective on individual differences in the development of identity and role-taking skill in adolescence. Hum Dev. 1986;29(2):82-100.

54. Skoe EEA, Lippe ALvd. Personality development in adolescence: a cross national and life span perspective. Tromso: Taylor \& Francis[. 1998.

55. Sanders RA. Adolescent psychosocial, social, and Cognitive Development. Pediatr Rev. 2013:34 (8):354-359. doi:10.1542/pir.34-8-354

56. Mittendorff K, Brok Pd, Beijaard D. Students' perceptions of career conversations with their teachers. Teach Teach Educ. 2011;27(3):515-523. doi:10.1016/j.tate.2010.10.005

57. Mittendorff K, Brok Pd, Beijaard D. Career conversations in vocational schools. Br / Guid Couns. 2010;38(2):143165. doi:10.1080/03069881003601007

\section{Case histories}

\section{Tim}

Tim is 18 years old and frequently absent from school. He reports sick, but the school suspects motivation issues. When he is consulted, Tim continues to hide behind physical complaints. He says he went to the general practitioner who, according to Tim, wants to refer him to a specialist. Because it takes a long time, the school requests a consultation with the YHCP. With Tim's permission, the YHCP confers with the general practitioner. It appears that Tim has not yet been to see the general practitioner with his complaints. When the YHCP confronts him with this, the real truth emerges: Tim does not want to go to bakery school, but is afraid to talk about this at home. His father wants him to continue the family bakery business. The school supports Tim in discussing this with the parents and together they look for a solution. 


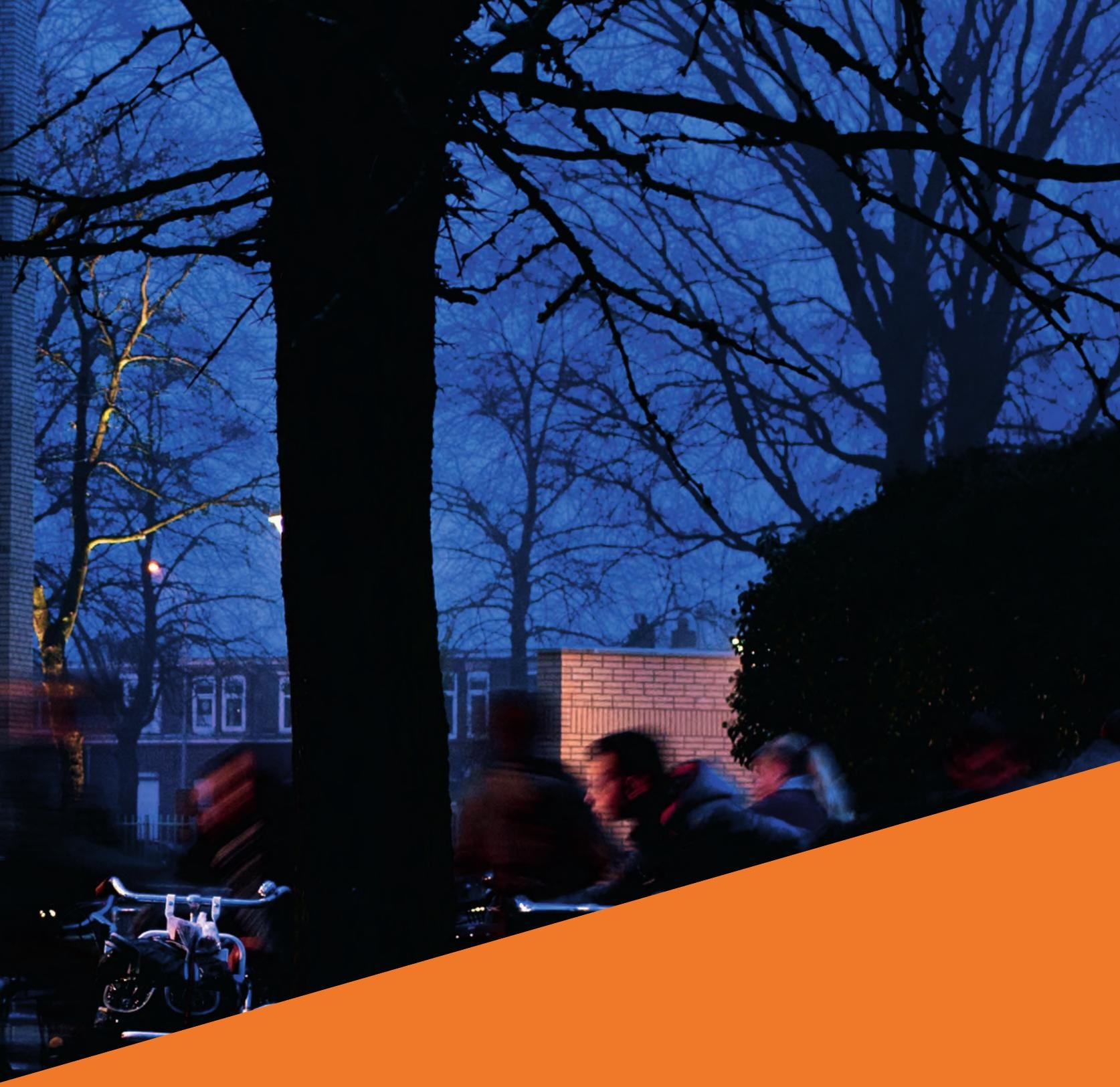

Chapter 8: General discussion and concluding remarks 


\section{Chapter 8}

\section{Chapter 8: General discussion and concluding remarks}

This thesis is a study into addressing medical absenteeism among students. The individual impact of school absenteeism on young people's development and future as well as the health, social and economic impact is high and calls on public health to contribute to reducing school absenteeism, especially when the absenteeism is associated with health-related issues. The Dutch MASS intervention consists of an integrated approach in which schools, in direct collaboration with YHCPs, are able to reach students and their parents, to discuss aspects of the student's medical absence, and to design and monitor a management plan to optimize students' health and maximize students' participation in school activities, ultimately aiming to reduce medical absenteeism among students. The preceding chapters of this thesis deal with two main topics; firstly the development and evaluation of the MASS intervention in pre-vocational secondary education (part I, chapters 2, 3, 4), and secondly the implementation and dissemination as well as the potential of the MASS intervention for other target populations such as primary school children and intermediate vocational students (part II, chapters $5,6,7$ ). In this chapter the main findings of the study are presented thematically and interpreted, followed by a discussion of the strengths and limitations of the study and implications for future research. Finally, a general reflection on the results and the intervention is presented, including the issue of addressing medical absenteeism in the current policy climate, leading to overall concluding remarks.

\section{Part I. The development and evaluation of the MASS intervention in pre-vocational education}

In part I we investigated the first version of the MASS intervention in a pilot study (chapter 2), after which the intervention was fine-tuned. This refined version of the MASS intervention (described in 1.6.) was evaluated in a practice-driven intervention study in the primary target group. Chapter 3 describes the health condition of the population reached and in chapter 4 results on the effectiveness of the intervention are presented.

\subsection{Fine-tuning the MASS intervention}

The pilot study revealed that, when questioning the students and their parents, $97 \%$ of the parents agreed that 'It is important for my child to go to school daily' and $84 \%$ of them indicated that they considered it important that the school pays attention to medical absenteeism counselling. However, only $56 \%$ of the students and parents recognized that it was important for the YHCP and the school attendance officer to cooperate in case of medical absenteeism, and $33 \%$ acknowledged that medical absenteeism counselling benefits from contact with the YHCP. It was often unclear for students and their parents what the YHCP could mean for them with regard to medical absenteeism. The study also revealed that the school attendance officer, the municipal officer dealing with school absence, played a substantial role in the execution of this pilot version of MASS, either after students failed to turn up for the consultation with the YHCP, or because students continued to miss (too many) classes although they were considered able to attend classes regularly. These results were explained by the fact that school absenteeism 
was considered a responsibility of compulsory education. This was reflected in the approach of medical absenteeism in the pilot version of MASS, which was particularly repressive: the school and school attendance officer were focusing primarily on gaining insight into'possibly illegitimate' medical absenteeism and on being able to enforce the principles of compulsory education. Consequently, the YHCP was expected to check on the legitimacy of the absence. This may have caused students' frequent failure to appear at the YHCP's consultation and the satisfaction on the consultation with the YCHP not being very high.

The findings above caused the intervention to be refined at several points. First, referral of the student and parents to the YHCP in case his/her absence rate meets one of the MASS-criteria was included in school's absence policy as being the first step towards implementation (first adjustment). Consequently, in cases of not showing up at the consultation with the YHCP it was up to the school instead of the school attendance officer to call on students and parents. Also the emphasis of the dialogue about medical absenteeism was shifted from the wish to maintain compulsory education to the wish to share concerns about students' well-being and future prospects with students and their parents. This resulted in a recommendation to enter into dialogue by stressing a mutual wish that the student is able to attend classes and to graduate (second adjustment). The emphasis was on informing students and their parents well about the aim of this school's new policy on medical absenteeism. The need for this was also confirmed by our qualitative study on the factors that influence the dissemination of MASS from schools perspective (chapter 5 ). The participants in this study emphasized the importance of adequate communication about the purpose of the intervention to secure their relationship with students and their parents, and the wish to share their concerns. The third adjustment concerned the role of the YHCP. The YHCP no longer was asked to label the medical absence according to legitimacy, but to focus on designing a management plan aiming to optimize students' health and maximize students' participation in school activities, together with the students, their parents and school. These refinements were expected to improve the attendance rate of and the satisfaction of students and parents about the consultation with the YHCP. As a consequence the school attendance officer's role in the approach became less prominent. Schools and YHCPs became the main partners in the execution of the intervention. By designing the plan together the alliance between YHCPs and students and their parents could be optimized which will probably lead to more satisfaction about the consultation with the YHCP. It is recommended to investigate this in future research.

For reasons of applicability and objectivity, and as stated by Hawkrigg and Payne [1], there is a need to bring forward criteria for intervening with an absence. Initially, in the pilot study, one of the criteria to intervene with the absence and refer the student to the YHCP was the criterion 'reported sick more than 16 hours per four school weeks, in somewhat isolated periods'. This criterion was chosen because the same criterion was applied to report truancy to the school attendance officer. The identical criterion was supposed to make it easier for the school to implement MASS. However, in practice this criterion was experienced as not unequivocal and therefore led to many discussions. Due to this ambiguity, the identification of students and referral to the YHCP were influenced by the personal vision of the school personnel. According 
to the YHCPs, this might have led to less enrolment of students, allowing for failure to identify students in need of counselling. In addition, school personnel asked for more objectivity to avoid discussions on when to intervene with the absence, as stated in our qualitative study (chapter 5). Experts agreed to introduce the criterion 'reported sick four times in 12 school weeks'. As the criterion 'more than six consecutive school days' was perceived as clear and applicable, the MASS-criteria to intervene with the absence were changed to: 'reported sick four times in 12 school weeks' or 'more than six consecutive school days'. These criteria were applied in the practice-driven intervention study on the health condition and effectiveness. Together with the refinements already discussed, this was the fourth adaptation of the intervention.

YHCPs' supposition that students could have been missed by using the unequivocal criterion in the pilot study was confirmed by the study results. Although the criterion used in the pilot study had a lower threshold than the criterion used in the intervention study, and actually should identify more students, fewer students had been enrolled in a year's time: in the pilot study $6.3 \%$ of the school population had been referred to the YHCPs, compared to nearly $12 \%$ in the intervention study. When considering the students' characteristics, which were not quite comparable between the pilot and intervention study, these could also reflect the new criterion being experienced as more unequivocal: in the pilot study more female $(79 \%)$ and third-year students had been referred to the YHCP in a year's time, whereas in the intervention study, female students ( $59.8 \%$ ) and students in the second school year were slightly over-represented in the study group. The study outcomes of the intervention study are more in line with previous research findings in the Netherlands that medical absenteeism is the highest in the first school years [2], and that there is a female:male gender ratio of 6o:40 with respect to medical absenteeism $[3,4,5]$, confirming the criterion having been applied well.

\subsection{Main findings and reflections on the students' health condition: disentangling the roles for school and YHCP}

From the pilot study it emerged that half of the students with extensive medical absenteeism and who had been seen by the YHCP suffered from physical health issues, and their medical absenteeism was often rooted in multiple (psychosocial) issues. The great diversity of these issues was also evident. It was decided to distinguish between diagnosed diseases and physical complaints not (yet) diagnosed or diagnostic unclassifiable, and to unravel the multiple psychosocial issues when designing the intervention study. As a result, it became possible to indicate more clearly the role of the school and the YHCP. Because practice shows that students initially present the disease that underlies their absence if they have one, the subdivision between 'whether or not there is a diagnosed disease' is also used as a starting point for our reflections on the students' health condition, from which the potential role for the school and the YHCP can be argued.

\section{The role for school and YHCP in case there is a diagnosed disease}

The health condition of the students involved in the effectiveness study of MASS was described in chapter 3 . It showed that $43.5 \%$ of the students with medical absenteeism who visited the YHCP had a diagnosed disease, and two-thirds of these students experienced additional problems. These additional problems may include psychosocial problems, lifestyle problems and sleeping difficulties that are related to the disease and may occur in cases of a chronic or mental disease, 
or an injury. For example, having a chronic disease can be stressful for both children, their parents and their environment $[6,7]$, and can affect students' achievement and ability to learn [8]. This means that, in practice, when the absence appears to be related to a diagnosed disease, attention should always be paid to issues that interfere with students' school attendance, such as feeling different from their school friends, lacking confidence to deal with their complaints at school and lagging behind in school work. These issues may raise barriers for going to school.

School can play a role by helping students and parents to reflect on such issues and to arrange support or educational adjustments. In case of a diagnosed disease the YHCP should see to a proper (adherence to the) medical treatment of the student, especially when there are no additional problems, since school absenteeism could indicate that the disease is not being managed appropriately $[1,3]$.

\section{The role for school and YHCP in case there is no diagnosed disease}

More than half of the students' increased absence (51.5\%) involved students lacking a diagnosed disease. These students appeared to have physical complaints not yet diagnosed $(40.4 \%)$, child-related problems (34.9\%), family-related problems (33.9\%), school-related psychosocial problems $(18.8 \%)$, lifestyle problems $(16.5 \%)$ and sleeping difficulties $(7.3 \%)$. To start with the role for school, being aware of our study findings can help schools to discuss the absence in case there is no diagnosed disease, with a focus on school-related psychosocial, lifestyle and sleeping problems. Schools can ask for and react to school-related problems such as learning problems, a troublesome relationship with a teacher or fellow students, or bullying. In the Netherlands about $8 \%$ of male and $5 \%$ of female students are being bullied in secondary schools $[9,10]$, and Dutch adolescents who have committed suicide have been bullied in the past more often [11]. Nowadays various programmes are available to handle bullying [12], and recently this issue was given high priority in school policy: from August 2015, all schools are obliged to apply an anti-bullying programme [13]. With regard to lifestyle problems such as media usage and the use of alcohol and drugs, schools can make students and their parents aware of the impact of these problems on student's well-being and school performance. With regard to lifestyle problems, an abundance of studies has shown consistent negative impact of excessive media usage on children's health [14, 15], partly through lack of sleep. Research demonstrates that suboptimal sleep affects how well students are able to learn and may adversely affect school performance [16]. Alcohol use, more than other drugs, is extremely widespread among adolescents $[17,18]$ and is also negatively associated with school performance and school dropout [19]. Moreover, excessive use of alcohol and drugs is usually part of a living pattern including other risk factors for problems at school [19]. In addition, the YHCP can identify emerging mental and physical diseases, for example when physical complaints have not yet been diagnosed. The early detection of chronic diseases is based on the 'growing into deficit'-theory $[20,21]$. Also in cases of psychosocial problems a mental disease not yet diagnosed could be present. The YHCP's professional secrecy provides an opportunity to discuss lifestyle and psychosocial problems confidentially.

In view of schools' fear of damaging their relationship with the parents or overlooking something important because of their limited medical knowledge, as stated by the school staff who participated in the qualitative study (summarized as 'role conflicts', see chapter 5), the opportunity to consult the YHCP is essential for schools when addressing medical absenteeism. 
The participants affirmed that MASS solves these so-called 'role conflicts' satisfactorily. It also appears to be essential to provide confidentiality as this seems to be one of the key factors for effective collaboration [20].

\subsection{Main findings and reflections on the effectiveness of the MASS intervention}

The pilot study showed promising results and indicated a decrease of the extent of medical absenteeism at student level: four months after the consultation at the YHCP, $63 \%$ of the 66 identified students did no longer meet with the MASS-criteria for medical absenteeism applied at the time. In the subsequent study on effectiveness of the refined MASS intervention on student level these findings were confirmed (chapter 4). The intervention appeared to be effective for pre-vocational secondary students with increased absence rates who were referred to the YHCP: the level of absenteeism decreased from 8.5 days reported sick in 12 school weeks prior to the consultation with the YHCP to 5.7 days after 3 months, and to 4.9 days after 12 months. The number of absence periods fell from 3.9 in 12 school weeks to 2.5 after 3 months, and to 2.2 after 12 months. In the control group the absence days initially decreased from 10.4 to 9 in 12 school weeks, after which an increase to 9.3 was measured. The number of absence periods initially decreased from 4.4 to 3.4 , after which an increase to 3.7 was measured. The number of absence days per period remained approximately the same in both groups. It was concluded that this personalized approach of medical absenteeism by way of systematic identification of students with extensive medical absenteeism and consistent referral to the YHCP who designs a management plan, is more effective than 'care-as-usual'. The effectiveness of the intervention is demonstrated primarily by a decrease in the number of periods (frequency) of reporting sick. This is in line with a study of the 12-months effectiveness of an intervention called 'SHARP-at work', a personalized five-step problem-solving process for reducing recurrent medical absence in workers with common mental disorders. Arends et al. [23] demonstrated that the effectiveness of the intervention 'SHARP-at work' was shown by a lower incidence of recurrent medical absence. To gain more insight in what the underlying mechanism of effectiveness of MASS is or how the intervention works, and what are the critical elements, more research is recommended. It is also recommended to investigate the effectiveness of MASS at other educational levels.

The pilot study also indicated a decrease of the extent of medical absenteeism at school level: a decrease in medical absenteeism of 1.1 school days per student per school year (from 8.4 to 7.3 school days) was measured. In the control schools, no decrease was observed (from 8.0 to 8.1 school days). However, the decrease was limited and might have indicated a trend rather than an effect. The effectiveness of MASS at school level still needs to be studied. There are several reasons to investigate this after the intervention has been applied for a longer period of time. First, MASS can be labelled as a complex intervention (see paragraph 8.4). Rogers proposes that time and the innovation itself, in addition to communication channels and social systems, are main elements that influence the implementation and spread of an innovation, implicating that the more complex the intervention is the longer the implementation takes [24]. Moreover, implementing MASS starts with intervening with extensive medical absence at the individual student level. This approach can potentially result in more comprehensive management of all students with medical absenteeism, also when their absence rate is not yet meeting MASS-criteria, because school personnel is more aware of the consequences of the absence and more used to entering into 
a conversation about medical absenteeism. The addition of more comprehensive management of all students with medical absenteeism can be referred to as addressing medical absenteeism at school level. According to previous research [25, 26], interventions which were formerly centred on individuals may be even more effective by successfully including an institutional level. This may be of importance for measuring MASS's effectiveness at school level. Only $12 \%$ of the students meet the MASS-criteria and thus go through the MASS-trajectory of referral to a YHCP. Its impact on their absence level will probably not influence the absence rate at school level significantly.

\section{Part II. Implementation and dissemination aspects of the MASS intervention, and adjustment to other target groups}

In part II of the study we focused on barriers and facilitators for sustainable implementation and dissemination of the MASS intervention (chapter 5 ) and on the potential of MASS for other target populations such as primary school children (chapter 6) and intermediate vocational students (chapter 7). Below the results are presented and discussed thematically, followed by the presentation of the implications and recommendations for future research and practice.

\subsection{Implementation aspects of the MASS intervention}

As discussed earlier, several refinements had already been introduced after the pilot study: the inclusion of MASS in school's absence policy, the emphasis on the dialogue being conducted for reasons of concern and not from a wish to enforce compulsory education, adequate communication about the purpose of the intervention, a focus on designing a management plan that aims to optimize students' health and maximize students' participation in school activities, together with the student, his/her parents and school, and well-defined unequivocal MASScriteria. The main barriers and facilitators for having MASS implemented at schools were studied in chapter 5. School staff who participated in the qualitative study confirmed that MASS indeed facilitated entering into a dialogue since it provided a framework to enter into dialogue and an opportunity to consult the YHCP: they did no longer have to fear damaging their relationship with parents or overlooking something important because of their limited medical knowledge. They stated some more advantages of MASS: the fact that students and parents do not have to share their personal affairs with school, the objective medical professional assessment of the student's health situation, including clear feedback on school-related issues and educational adjustments needed, and the acquisition of a better understanding of what influences students' well-being and what a particular disease or circumstance means for students' functioning. The participants in our study were convinced that these advantages would lead to students and parents feeling taken seriously about their complaints, and to less frustration and better guidance of the student by school.

Despite the perceived advantages schools indicated, the study findings also revealed two main challenges for school when implementing MASS: the actual questioning of students and their parents about the context of medical absence, and the follow-up to the feedback from the YHCP. It was recognized that in order to ensure appropriate follow-up, it was essential for schools themselves to first discuss the context of the medical absence with students and their parents before referring to the YHCP. School staff asked for training in having a constructive dialogue 
about medical absence with parents and students. Research is recommended on how school personnel can be trained effectively in conducting a constructive dialogue with students and their parents in case of extensive medical absenteeism.

In line with the definition of a complex intervention in the new Medical Research Council Guidance [27], MASS can be labelled as a complex intervention because of the number of stakeholders and actions involved, and the great diversity of underlying problems that may cause the absence. For adequate implementation, commitment is required at all organizational levels within schools, while at the same time it is a challenge to achieve the full support of all involved. This is an acknowledged challenge when implementing and disseminating a complex intervention $[24,27]$. Furthermore, as also noted by school staff, exaggerated expectations of intervention outcomes which are not realized at short term can form an obstacle to the sustainability of MASS (chapter 5).School staff suggested that when implementing MASS one should focus at the onset on noticeable short-term effects such as increased awareness in school, students and parents informed of the level and impact of medical absenteeism on school matters, and less frustration due to shared responsibility and a better understanding of students' situations. MASS enables preventive action, resulting in better quality of care for students 'in need'. In this way MASS can contribute positively to achieving schools' direct goal of helping as many students as possible to graduate, which may also be seen as a relevant outcome measure.

\subsection{Dissemination aspects of the MASS intervention}

As both schools and YHCPs work together in the delivery of MASS, MASS operates on the boundary between school and health care. To secure widespread implementation and dissemination of MASS and for finding structural funding, there is a need for intersectoral health policy to put the topic'addressing medical absenteeism' not only on the agendas of municipalities and youth health care agencies but also on schools' agendas. Many participants of the qualitative study (chapter 5) foresee difficulties in this respect. Therefore, it is vital that MASS matches schools' aims.

When questioning school staff on their reasons to pay attention to extensive medical absenteeism, they stated that their main reason to address medical absenteeism, and thus to adopt MASS, was their wish to provide timely and adequate care and support to students who are in need, in collaboration with parents and out of a shared sense of responsibility. Moreover, the interviews clearly showed that MASS appears to improve parental involvement in school and the quality of care for students, thus supporting schools in maximizing the number of students graduating. Therefore, MASS can be a tool for improving parental involvement in school. These were important additional reasons for schools to adopt the intervention. Nowadays, parental involvement in school and 'inclusive education' policy are major topics for schools to deal with, and arranging proper care for students 'in need' in turn becomes very important. Those are important arguments in favour of putting the subject 'addressing medical absenteeism' on schools' agendas.

\subsection{Potential target populations: primary school children respectively intermediate vocational education students}

MASS intervention potential for use with other populations, such as children in primary schools or students from intermediate vocational schools, were also explored. From the results of our 
explorative case-control study of the factors associated with for extensive medical absenteeism among primary school children (chapter 6 ) and our explorative qualitative study of intermediate vocational students' experiences with sickness reporting (chapter 7 ), it emerges that there is also a role for schools and YHCPs in primary school and intermediate vocational education.

The study in primary schools showed that low school motivation and family-related factors such as incomplete families and families with financial problems were associated with extensive medical absenteeism of the child. It was suggested that effectively addressing medical absenteeism in primary school requires a broad and integrated approach. Schools would have to focus on ensuring a child's school connectedness, and YHCPs on improving the conditions of the child's upbringing. By using extensive medical absenteeism as a criterion for intervening, reaching families at risk can be improved. After identifying the underlying problems of the child's absence, YHCPs can make use of more outreaching methods through $\mathrm{YHC}$ services and can arrange support for families and children [28]. Future research on the situation of primary school children at the time the extensive medical absenteeism occurs can provide more insight in their actual needs.

In the explorative qualitative study of intermediate vocational students' experiences on their sickness reporting, the study findings demonstrated that their medical absenteeism does not only depend on legitimate medical reasons but also on the extent to which they are able to take responsibility for their lives, on how the school treats them and on the latitude the school's policy allows. It can be argued that there lies a major role for schools in tackling medical absenteeism by revising their own absence protocols and by acting upon sick reports more consistently. The study acknowledged that when schools arrange for students to report sick themselves, it is important to be able to consider students' ability to take responsibility for their lives. The extent to which students are able to take responsibility for themselves could for instance be assessed during career conversations between students and their career counsellors. The students in our study also had concrete ideas on how school could help them learn to take responsibility, in particular on reporting sick. They suggested to always respond to a sick report by contacting them in person, and by discussing their sick report based on concern rather than control, thus helping them to assess their situation adequately. A number of school-related issues such as lifestyle and motivation problems should be taken into account before referring a student to the YHCP. The YHCP comes into play in cases of health conditions to be investigated.

Since attendance patterns manifest themselves at an early stage in primary school $[4,29]$ and medical absenteeism in adolescence appears to be predictive of medical absenteeism in adulthood [30] it is recommended to further develop MASS for implementation in primary and intermediate vocational education. Adaptation of the programme may be needed. In addition, explorative research in intermediate vocational education is recommended on career counsellors'perceptions of students' medical absenteeism and the added value of carrying out assessments about the extent to which students are able to take responsibility for themselves during career conversations.

\subsection{Strengths of the study}

A number of strengths can be distinguished in the study in this thesis. In the first place, to the best of our knowledge, this is the first time that an intervention for addressing medical 
absenteeism in secondary school has been investigated from public health perspective. Secondly, MASS has been initiated by public health practice at the request of school professionals, because they felt a strong need for such an intervention. This led to a practice-based intervention study including quantitative and qualitative research methods. The involvement of all relevant stakeholders such as students and their parents, educational and health professionals, school staffs and school attendance officers, from the start, has ensured the transferability of the intervention. Thirdly, with regard to the scope, this thesis included all three main stages in intervention research, namely intervention development, and implementation and dissemination aspects [31]. The study findings can be used when developing a viable and final version of the MASS intervention which fits the needs and opportunities of all stakeholders and is accepted by them, thus improving dissemination. Many effective trials are never put into practice, partly due to the fact that the intervention does not fit the needs and possibilities of professionals [32]. This confirms the importance of practice-based research.

\subsection{Limitations of the study}

The first limitation to be discussed here concerns the design of the effect study. To study the effectiveness of the MASS intervention in a real life setting, a quasi-experimental design with an intervention group and a control group was applied. This study design is best suited to circumstances of studying the effectiveness of a practice-based intervention. First of all schools cannot be obliged to implement an intervention so a random assignment of whether or not implementing MASS by school is not applicable. Secondly, random assignment of students to an intervention or control condition within one school applying the intervention meets with ethical objections, because students may be denied a consultation with a YHCP in case of extensive medical absenteeism when they are in the control group. Moreover, contamination of the 'careas-usual' would probably occur because of social interaction. This 'imitation of treatment' of the control condition allowing 'care-as-usual' to be influenced by the MASS intervention will occur the moment school staff notice that an intervention which is examined on its effectiveness is being applied to some of the students. All these arguments speak in favour of the quasiexperimental design and the inability of a Randomized Controlled Trial. Also matching cases and controls on students' health condition or personal factors such as coping mechanisms, which are probably relevant characteristics influencing the effectiveness, is not feasible because a student's health condition and personal characteristics become known only after referral to the YHCP. To ensure internal validity, the intervention and control schools were matched on characteristics such as degree of urbanisation, fields of education and school size. In addition, the data of the control students were recruited retrospectively in schools that had not yet applied the MASS intervention, so no social interaction effects could jeopardize the study outcomes.

The second limitation relates to the effect study's focus on the impact of the MASS intervention on the absence rate of the students. This is only one of the potential relevant outcome measures. It is quite conceivable that in the longer term aspects such as well-being, early diagnosis of diseases and timely provision of proper care and treatment are at least as relevant for students, policy makers and educational and health professionals, as is decreasing school absenteeism and ensuing prevention of school dropout. Such aspects may direct the focus of the future MASS intervention outcome measures to be studied. 
Thirdly, with regard to the description of the health condition of the students with extensive medical absenteeism (chapter 3), the YHCPs did not use the classification systems International Classification of Diseases and Related Health Problems (ICD), the Diagnostic and Statistical Manual of Mental Disorders (DSM) or the Classification for the Nature of Problems of Youth (CAP-J) for categorization of diseases and problems. This was due to the fact that in preventive youth health care, children often have problems that do not cluster to a diagnosis (yet). The International Classification of Functioning, Disability and Health for Children and Youth (ICFCY) may probably fit better to the field of preventive youth health care, but is not yet applied in practice. Therefore, in our study diseases were registered in open fields and categorized by expert agreement afterwards. Physical complaints, sleeping difficulties, lifestyle problems, and psychosocial problems, were all categorized by protocol. Training and peer evaluation took place monthly to standardize the scoring method.

\subsection{Implications for future research}

Some recommendations for future research that result directly from our study findings already have been put forward thematically. In this paragraph more implications for future research are discussed.

To start with, the impact of an intervention is not determined exclusively by its effectiveness. According to Clasgow (RE-AIM model), the impact of a public health intervention depends on five dimensions, namely: Reach, Efficacy, Adoption, Implementation and Maintenance [33]. Implications for future research may derive from these dimensions. Reaching students will mainly depend on a proper registration of the absence by school based upon which students with extensive absence rates can be identified. Basically, due to the unambiguous MASS-criteria for identifying students and the intervention being included in the school's policy, MASS is expected to reach all relevant participants. However, there may be even better criteria that identify even more students in need of counselling for medical absenteeism, which are currently not being reached by MASS. Future research will have to clarify this. With regard to the measurement of the intervention's efficacy, it is recommended to include quality-of-life perspective outcomes to allow evaluation of students' functioning, and their physical and mental health, such as student's ability to cope with a disease or problem and student's well-being. Future widespread implementation should be accompanied by evaluation on aspects such as the adherence to the management plan by student, school and YHCP, and process evaluation on aspects of the intervention being delivered as intended. In addition, future actual adoption and maintenance should be studied over time.

Implications for future research may also concern cooperation aspects. There are indications that cooperation in the care process is effective [34] and that ineffective cooperation can jeopardize the success of interventions that aim to recognize and reach children with needs [22]. The persistent success of MASS will probably also depend on an optimal cooperation between student and parents, school and YHCP. Optimising quality aspects of cooperation will allow for increased effectiveness. Studying for instance the way to approach students and the follow-up on the management plan will allow more adequate evaluation of schools' and YHCPs' functioning in future studies of MASS. 


\subsection{General reflections}

\section{Added value of a biopsychosocial perspective}

Physicians' approaches to patients and the problems they present are strongly influenced by the conceptual models they use. The biopsychosocial model is a conceptual model that assumes that psychological and social factors must be included alongside the biological factors when aiming to understand a person's physical complaint, medical illness or disorder [21, 35, 36]. In 2010 Sameroff proposed an even broader use of this model and integrated it in a unified theory of development: the use of the biopsychosocial perspective to integrate personal development, beyond the medical context [37]. This broad view corresponds to the way the model is used by the YHCPs in this study. They distinguished a wide range of factors that contribute to the medical absence among pre-vocational secondary students. Extensive medical absenteeism among primary school children appears to be associated with many non-health related issues, for instance family-related factors such as incomplete families and families with financial problems, low school motivation (chapter 6), absences depending on the extent to which intermediate vocational students are able to take responsibility for their lives, on how the school treats them and on the latitude the school's policy allows (chapter 7). All these study findings demonstrate that the biopsychosocial model is of added value when wishing to determine all factors responsible for extensive medical absenteeism in the light of Sameroff's concept of how biological, psychological, and social experiences foster and transform each other to explain both adaptive and maladaptive functioning through school careers. The complexity and diversity of the underlying problems make it necessary to arrange a personalized approach and management plan.

\section{Added value of the YHCP}

In paragraph 8.2. we discuss how the role of the school and the YHCP can be derived from 'whether having a diagnosed disease or not'. In paragraph 8.4 . we discuss that is seems to be essential for schools themselves to first address the context of the medical absence with students and their parents before referring to the YHCP. If schools do so, the referral to the YHCP will be determined by the outcome of the dialogue between school, students and parents. If this dialogue does not yield sufficient insight into the causes of the extensive absence and possible solutions for reduction of the absence, the student can be referred to the YHCP.

Summarizing, our research revealed a threefold role for the YHCP: (1) to identify emerging mental and physical diseases, (2) to define and discuss limitations in daily functioning that are causing the school absence, and (3) to discuss psychosocial problems confidentially.

(1) In cases of physical complaints and psychosocial problems, medical assessments can lead to the identification of emerging mental and physical diseases, and thus to better diagnoses and more optimal treatment. This is important because, as we know, most adolescents do not usually visit their general practitioner when experiencing physical complaints or psychosocial problems $[38,39]$. The percentage of adolescents with self-reported health problems such as fatigue, sleeping difficulties, depressive complaints, headache, hyperactivity, constipation and abdominal pain [39] is substantially higher than the percentage of adolescents (8.8\%) visiting a general practitioner for one of these conditions that cannot (yet) be attributed to a specific disease or disorder [40]. Some studies report prevalence rates of mental health problems ranging from $19 \%$ 
to $28 \%[41-45$ ], and even more than half of the female adolescents are suffering from chronic fatigue or headaches [39]. Unmet need for treatment of mental problems is a major issue [46]. Most mental diseases emerge during adolescence and early adulthood and the median age of onset of all mental diseases is approximately 14 years [47]. To start with, much is to be gained from raising parental and child awareness of mental health problems, because there is a large group of adolescents who have mental health problems according to their parents, while the parents think their children have no need for care [48]. Addressing mental health problems is important, because mental health problems in youth often continue into adulthood $[49,50]$, and can have negative consequences for daily life, for instance causing problems with interpersonal relations and with finding a job, and having a higher risk of criminal behaviour [51]. (2) Another added value of the YHCP is that the YHCP can discuss limitations in daily functioning if applicable. Two to three percent of all children experience serious limitations in daily functioning due to a suboptimal health condition, which is often associated with a higher rate of school absence [39]. Identifying and arranging what is needed to improve their daily functioning and to strengthen their coping mechanisms, can relieve their suffering by reduced impact of perceived stress [52]. Subsequently their school participation will be increased [53]. (3) In the third place, psychosocial problems can be discussed in the consultation with the YHCP. For example, of all students, $33.9 \%$ experienced family-related psychosocial problems. From practice we know that parents do not always want schools to know about family issues. The confidentiality of the consultation with the YHCP can provide a solution.

In conclusion, both schools and YHCP have an added value in addressing medical absenteeism. The great diversity of the identified problems calls for a personalized approach with a broad perspective, including medical expertise whenever appropriate. Schools can play a role in raising awareness of the consequences of too much absence on school performance, and in discussing and handling school-related issues. The YHCP can act on health-related issues, discuss limitations in daily functioning, and provide the opportunity for students and their parents to discuss psychosocial problems confidentially. The consultation will lead to a management plan supported by students and their parents, school and YHCP, aiming to increase students' health and wellbeing and decreasing the absence rate.

\section{Developing the final version}

Our study findings have led to a blueprint for the final version of MASS which includes several core elements. The first core element is discussing the medical absence demonstrating concern rather than control, as resulted from our pilot study (chapter 2). After putting forward the need for objective criteria in the pilot study (chapter 2), their advantages were stated by the school staff interviewed (chapter 5). The second core element is the use of the MASS-criteria for intervening with the absence. The study on the health condition (chapter 3 ) showed that by using the MASS-criteria for intervening with the absence, students who appear to have diseases and/or problems and who might benefit from attention and guidance are identified. The third core element is the involvement of a YHCP. The great diversity of underlying issues calls for a broad biopsychosocial perspective including medical expertise, stressing the importance for the involvement of the YHCP. The effect study (chapter 4) proved this to be effective in reducing the absence rate. Moreover, consultation with a YHCP addresses school staff's fear that they might overlook something important because of their limited medical knowledge, which was 
considered of great importance in the qualitative study (chapter 5). These study findings position the involvement of the YHCP as the third core element. The students' health condition (chapter 3) distinguished between the roles and responsibilities of school and YHCPs. The fourth core element derives from the qualitative study (chapter 5): it appears to be essential for schools to first discuss the context of the medical absence with students and their parents before referring to the YHCP to ensure follow-up to the feedback from the YHCP.

When developing the final version of MASS, it is recommended to add elements in line with current policy visions. This will lead to better preconditions for implementation and dissemination because municipalities will be more willing to put the subject of 'addressing medical absenteeism' on their agendas and consequently to implement the intervention. This may increase future interventions' dissemination and impact. For two reasons the element to be introduced here is the element 'empowerment'. Empowerment implies individual strengthening and shared responsibility. First, a focus on empowerment fits the current vision on social inclusion, active citizenship and modern care. There are appropriate methodologies to put empowering into practice [54]. According to MASS, empowering students and their parents can be stimulated for example by more actively involving them in suggesting solutions to reduce the absence and designing the management plan. Secondly, in case of a disease it is recommended to not only focus on diagnosis, cure and care, but also on how to cope with this disease and to manage one's life. This fits the current generally accepted vision of dealing with health issues [55]. Huber stated that being able to participate in work/school and social activities makes people feel healthy despite limitations [55], which may decrease the absence rate in the long term. Another advantage of the inclusion of new elements that formerly were outside the scope of the intervention is an increased intervention effectiveness to be expected, as stated by Van Yperen et al. [25].

\subsection{Addressing medical absenteeism in the light of the current policy climate}

The MASS intervention appears to be relevant to both education and public health. Firstly, because MASS allows both sectors to reach an important target group: students at risk of dropout and students in need of adequate support and care. Secondly, MASS helps to realize 'inclusive education' [56], which is the challenge for future education systems and a major policy issue. Educational adjustments for students with diseases or disorders, psychosocial problems and learning difficulties will become important to optimize their participation in general schools. Substantial medical absenteeism reveals students who may be in need of and might profit from such adjustments. Drafting a management plan that includes the educational adjustments needed, makes it possible for schools to provide education that fits the needs of the student with diseases or problems. This is of great importance given the expected growth in the number of children with chronic illnesses [7, 9] and the challenge to realize 'inclusive education'.'Inclusive education' can ensure that 'addressing medical absenteeism' becomes an issue in schools policies. It is also up to YHC to focus on participation in education and society and to provide advice on how to proceed with children with health problems [9].

As already argued, the great diversity of underlying diseases and problems calls for a personalized approach from a biopsychosocial perspective, including medical expertise. The biopsychosocial and life-span perspective of YHCPs, which incorporates knowledge about family history and 
repeated encounters from birth onwards, makes it possible to interpret the medical absence from a broad perspective, detecting emerging diseases as well as psychosocial problems.

The ultimate goal of preventive youth health care is to prevent a negative health outcome later in life by pro-actively reaching out to youth at risk in health, growth or development. Identifying these children and providing care for them effectively is a major challenge to YHC. Much could be gained when public health services can better reach these children and families. Research shows that these services do not reach all children equally well, particularly not those growing up in problem families $[57,58]$. Our study in primary schools (chapter 6) confirmed this to some extent by showing that extensive medical absenteeism of the child is associated with not fully participating in the $\mathrm{YHC}$ programme. This is at least partly due to the fact that in the Netherlands it is not obligatory to participate in YHC services. The integration of MASS in the school's policy provides a new opportunity for reaching these children and adolescents, because the school determines that students and their parents should visit YCHPs and that this is not optional. Medical absenteeism is the trigger to get in touch with them. By organizing a child-centred and personalized approach, taking the students and their situations as a starting point, education and health care can be adjusted and optimized. This leads to more equal opportunities for all children to participate in society. Discussing the medical absence, demonstrating concern rather than control, allows schools and YHCPs to connect with students and to organize adequate care and guidance. MASS helps YHC services to refocus their service provision.

Incorporating the MASS intervention in the provision of $\mathrm{YHC}$ is also consistent with the current policy of 'Transforming youth care': earlier detection and intervention giving rise to more preventive care finally leading to less costly solutions [59]. This is demonstrated for example by the fact that in our study, students with a mean absence rate of $14 \%$ over one school term were included. According to the literature, this is a 'not-yet-problematic' absence rate. In a previous study, Jones et al. found that $45 \%$ of the students with an absence rate of more than $20 \%$ over three consecutive school terms had psychiatric disorders [5]. Given this, it is likely that some of our students suffer from psychological problems that do not yet cluster into a psychiatric diagnosis. When using the MASS-criteria for intervening in medical absence, a larger part of these students can be identified at an early stage, which may prevent severe mental disease later. Thus future problematic medical absenteeism and illness could be prevented. Whether this really will be the case has to be studied.

\subsection{Concluding remarks}

The MASS intervention was developed at the request of schools that wished to improve their guidance of students with substantial medical absenteeism to finally prevent early school dropout. In the first place our study showed that MASS enables schools to engage in conversation with students and their parents about the medical absence and that referral to the YHCP in cases of extensive medical absenteeism is effective, since the absence rate reduced significantly compared to 'care-as-usual' at school. Secondly, the roles for the school and the YHCP could be disentangled. Furthermore, our study demonstrated the challenges to make the intervention sustainable and what was needed to implement and disseminate MASS, thus making it possible to design a final and further optimized version. For the design of the final version two overarching themes will be of relevance: (a) a personalized approach by school in close cooperation with 
YHCPs and (b) the roles for both schools and YHCPs in tackling the medical absenteeism of students to be substantial and complementary. Thirdly, the scientific evidence gained is of great importance for further pursuing an evidence-informed policy in $\mathrm{YHC}$, and for providing the necessary conditions for dissemination and sustainability. As a result, more professionals can move towards implementation, and above all children (and their parents) will benefit. 


\section{References}

1. Hawkrigg S, Payne DN. Prolonged school non-attendance in adolescence: a practical approach. Arch Dis Child. 2014;99:954-957. doi:10.1136/archdischild-2013-304595

2. NIPO het marktonderzoeksinstituut. Rapport: Schoolverzuim in het Voortgezet Onderwijs. [Report on school absenteeism in secondary school.]. Amsterdam. 2002. http://www.tns-nipo.com/pages/persvannipo/pdf/ schoolverzuimo3.pdf.

3. Kearney CA. School absenteeism and school refusal behavior in youth: A contemporary review. Clin Psychol Rev. 2008;28:451-471. doi:10.1016/j.cpr.2007.07.012

4. Eaton DK, Brener N, Kann LK. Associations of health risk behaviors with school absenteeism. Does having permission for the absence make a difference? / Sch Health. 2008;78(4):223-9. doi:10.1111/j.1746-1561.2008.00290.x

5. Jones R, Hoare P, Elton R, Dunhille Z, Scharpe M. Frequent medical absences in secondary school students: survey and case-control study. Arch Dis Child. 2009;94:763-67. doi:10.1136/adc.2008.140962

6. Eiser C. Growing up with a chronic disease: the impact on children and their families. London: Jessica Kingsley Publishers. 1993.

7. Mokkink LB, Lee JH van der, Grootenhuis MA, Offringa M, Praag BMS van, Heymans HSA. Omvang en gevolgen van chronische aandoeningen bij kinderen. [Scale and impact of chronic diseases in children.]. Tijdschrift Kindergeneeskunde. 2007:75:154-58. doi:10.1007/BFo3061684

8. Taras H, Potts-Datema W. Chronic Health Conditions and Student Performance at School. J Sch Health. 2005;75(7):255-266. DOI: 10.1111/j.1746-1561.2005.00034.X

9. Hamberg-van Rheenen HH, Meijer SH, Gils PF van, Savelkoul M. Gezond opgroeien. Verkenning jeugdgezondheid. [Growing up healthy. Survey youth health] RIVM, Bilthoven. 2014. Rapport 270752001/2014.

10. Van Dorsselaer S, Zeijl E, Van den Eeckhout S, ter Bogt T, Vollebergh W. HBSC 2005, Cezondheid en welzijn van jongeren in Nederland. [Health and well-being of Dutch youth.]. Utrecht: Trimbos-instituut, 2007.

11. Bijker L, Boere-Boonekam MM, Duijst WLIM, Ghoncheh R, Sijperda O, Kerkhof AJFM. Suïcides onder jongeren in de periode 1996-2012. De beschikbaarheid en kwaliteit van lijkschouw- en jeugdgezondheidszorgdossiers.

[Suicide among young people between 1996-2012. Availability and quality of autopsy and youth health care files] TJCZ. 2014;4:66-70.

12. NJI. Databank Effectieve Jeugdinterventies. [Database effective youth interventions.]. http://www.nji.nl/nl/ Databanken/Databank-Effectieve-Jeugdinterventies

13. Ministerie OCW. [Ministry of Education, Culture and Science.]. The Hague, the Netherlands. http://www. rijksoverheid.nl/ministeries/ocw

14. Strasburger VC, Jordan AB, Donnerstein E. Health Effects of Media on Children and Adolescents. Pediatrics. 2010; $125(4): 756$-767. doi: $10.1542 /$ peds.2009-2563

15. Rosen LD, Lim AF, Felt J, Carrier LM, Cheever NA, Lara-Ruiz JM, Mendoza JS, Rokkum J. Media and technology use predicts ill-being among children, preteens and teenagers independent of the negative health impacts of exercise and eating habits. Comp Hum Beh. 2014; 35:364-375. doi:10.1016/j.chb.2014.01.036

16. Taras H, Potts-Datema W. Sleep and Student Performance at School. J Sch Health. 2005;75 (7):248-254. DOI: 10.1111/j.1746-1561.2005.00033.x

17. Poelen EAP, Scholte RH), Engels RCME, Boomsma DI, Willemsen C. Prevalence and trends of alcohol use and misuse among adolescents and young adults in the Netherlands from 1993 to 2000. Drug Alcohol Depen. 2005:79:413421. doi:10.1016/j.drugalcdep.2005.03.020

18. Johnston LD, O'Malley PM, Miech RA, Bachman JC, Schulenberg JE. Monitoring the Future national survey results on drug use: 1975-2014: Overview, key findings on adolescent drug use. Ann Arbor: Institute for Social Research, the University of Michigan, 2015.

19. Ter Bogt T, Van Lieshout M, Doornwaard S, Eijkemans Y. Middelengebruik en voortijdig schoolverlaten. Twee onderzoeken naar de actuele en gepercipieerde rol van alcohol en cannabis in relatie tot spijbelen, schoolprestaties, motivatie en uitval. [Substance use and early school leaving. Two studies into the actual and perceived role of alcohol and cannabis in relation to truancy, school records, motivation and dropout.]. Utrecht: University Utrecht and Trimbos-instituut, 2009 .

20. Syurina EV, Hens K, Feron FJM. Literature Review: Use of Family History for Primary Paediatric Care as the Next Step Towards use of Genomics in Healthcare. Curr Pediatric Rev. 2013;9(4): 353-372. doi:10.2174/1573396309 04131223112559

21. Snyderman R, Langheier J. Prospective health care: the second transformation of medicine. Cenome Biol. 2006;7:104. doi:10.1186/gb-2006-7-2-104

22. Weist MD, Mellin EA, Chambers KL, Lever NA, Haber D, Blaber C. Challenges to Collaboration in School Mental Health and Strategies for Overcoming Them. J School Health. 2012;82:97-105. doi: $10.1111 / j .1746-1561.2011 .00672 . x$ 
23. Arends I, Klink JJL van der, Rhenen W van, Boer MR de, Bültmann U. Prevention of recurrent sickness absence in workers with common mental disorders: results of a cluster-randomised controlled trial. Occup Environ Med 2014;71:21-29. doi:10.1136/oemed-2013-101412

24. Rogers EM. Diffusion of Innovations. 2003. http://teddykw2.files.wordpress.com/2012/o7/everett-m-rogersdiffusion-of-innovations.pdf.

25. Yperen TA van, Steege M van der, Addink A, Boendermaker L. Algemeen en specifiek werkzame factoren in de jeugdzorg. Stand van de discussie. [Common and specific factors in child and youth care. State of the debate.] Utrecht: Nederlands Jeugdinstituut, 2010.

26. Saan H, Haes W de. Gezond effect bevorderen. Het organiseren van effectieve gezondheidsbevordering. Het Nationaal Instituut voor Gezondheidsbevordering en Ziektepreventie. [Promote healthy effect. Organizing effective health promotion. The Dutch Centre for Ethics and Health (CEG).]. Woerden: 2005. http:// www.nigz.nl.

27. Craig P, Dieppe P, Macintyre S, Michie S, Nazareth I, Petticrew M. Developing and evaluating complex interventions: the new Medical Research Council guidance. BMI. 2008;337:a1650. doi: 10.1136/bmj.a1655

28. Rots-de Vries MC, Goor LAM van de, Stronks K, Garretsen HFL. Evaluation of an assertive outreach intervention for problem families: intervention methods and early outcomes. Scandinavian Journal of Caring Sciences $2011 ; 25(2): 269-276$.

29. Basch CE. Healthier students are better learners: A missing link in school reforms to close the achievement gap. I School Health. 2011;81:593-598. doi:10.1111/j.1746-1561.2011.00632.x

30. Mittendorfer-Rutz E, Hensing G, Westerlund H, Backheden M, Hammarström A. Determinants in adolescence for adult sickness absence in women and men: a 26 -year follow-up of a prospective population based cohort (Northern Swedish cohort). BMC Public Health. 2013;13(1):75. doi:10.1186/1471-2458-13-75

31. Nutbeam D. Evaluating health promotion: progress, problems and solutions. Health Promot Int. 1998;13(1):27-44. doi:10.1093/heapro/13.1.27

32. Glasziou P, Altman DG, Bossuyt P, Boutron I, Clarke M, Julious S, Michie S, Moher D, Wager E. Reducing waste from incomplete or unusable reports of biomedical research. The Lancet. 2014;383(9913):267-276. DOI: http://dx.doi. org/10.1016/So140-6736/13)62228-X

33. Glasgow RE, Vogt TM, Boles SM. Evaluating the Public Health Impact of Health Promotion Interventions: The REAIM Framework. 1999.

34. Rutte F, Pijpers F, Timmermans M. Literatuuronderzoek: samenwerken aan het gezond en veilig laten opgroeien van kinderen. [Literature review: working together to make healthy and safe growing up of children possible.]. NC): 2014. https://www.ncj.nl/toolbox-basispakket-jgz/samenwerken.

35. Engel GL. The need for a new medical model: a challenge for biomedicine. Science. 1977;196(4286):129-36. doi:10.1126/science. 847460

36. Engel GL. The need for a new medical model: A challenge for biomedicine. Fam Syst Med. 1992;10/3):317-331. doi:http://dx.doi.org/10.1037/hoo8g26o

37. Sameroff A. A Unified Theory of Development: A Dialectic Integration of Nature and Nurture. Child Dev. 2010;81(1):6-22. doi: 10.1111/j.1467-8624.2009.01378.x

38. Theil A, Verkerk PH, Buiting E. Snel terug naar school. [Quickly back to school.]. Medisch Contact. 2007;62:31-32.

39. Wijga AH, Scholtens S, Van Oeffelen AAM, Beckers M. Klachten en kwalen bij kinderen in Nederland: Omvang en gevolgen geïnventariseerd, 2010. [Complaints and diseases among children in the Netherlands: Inventory of size and consequences, 2010]. Rapportnummer 260136001. Bilthoven: RIVM.

40. Linden MW van der, Westert GP, Bakker DH de, Schellevis FG. Tweede nationale studie naar ziekten en verrichtingen in de huisartspraktijk: klachten en aandoeningen in de bevolking en in de huisartspraktijk. Utrecht: Nivel, 2003.

41. CBS Centraal Bureau Statistiek [Statistics Netherlands]. Statline. Gerapporteerde gezondheid en leefstijl [Reported health and lifestyle]. 2000-2006. http://statline.cbs.nl/.

42. Ferdinand RF, Reijden M van der, Verhulst FC, et al. Assessment of the prevalence of psychiatric disorder in young adults. Br J Psychiatry 1995; 166:480-8. DOI: 10.1192/bjp.166.4.480

43. Verhulst FC, Ende I van der, Ferdinand RF, et al. The prevalence of DSM-III-R diagnoses in a national sample of Dutch adolescents. Arch Gen Psychiatry 1997:54:329-36. doi:10.1001/archpsyc.1997.01830160049008

44. Wittchen HU, Nelson CB, Lachner G. Prevalence of mental disorders and psychosocial impairments in adolescents and young adults. Psychol Med 1998;28:109-26. DOI: 10.1017/So033291797005928

45. Patel V, Flisher AJ, Hetrick S, et al. Mental health of young people: a global public-health challenge. Lancet 2007;369:1302-13. DOI:10.1016/S01406736/07/60368-7

46. Demyttenaere K, Bruffaerts R, Posada-Villa J, et al. Prevalence, severity, and unmet need for treatment of mental disorders in the World. Health Organization World Mental Health Surveys. The WHO World Mental Health Survey Consortium. Jama. 2004;291:2581-90. doi:10.1001/jama.291.21.2581 
47. Kessler, R., Amminger, G.P., Aguilar-Gaxiola, S., Alonso, I., Lee, S., \& Ustin, T.B. (2007). Age of onset of mental disorders: a review of recent literature. Curr Opin Psychiatr, 20, 359-64. doi: 10.1097/YCO.obo13e32816ebc8c

48. Jansen DE, Wiegersma P, Ormel J, Verhulst FC, Vollebergh WA, Reijneveld SA. Need for mental health care in adolescents and its determinants: The TRAILS Study. Eur I Public Health, 2013;23(2):236-41. doi:10.1093/ eurpub/ckso87

49. Caspi A, Moffitt TE, Newman DL, et al. Behavioral Observations at Age 3 Years Predict Adult Psychiatric Disorders: Longitudinal Evidence From a Birth Cohort. Arch Gen Psychiatry, 1996. 53(11): p. 1033-1042. doi:10.1001/ archpsyc.1996.01830110071009

50. Hofstra MB, van der Ende J, Verhulst FC. Adolescents' self-reported problems as predictors of psychopathology in adulthood: 10-year follow-up study. Br | Psychiatry. 2001;179:203-9. DOI: 10.1192/bjp.179.3.203

51. Fergusson DM, Horwood LJ, Ridder EM. Show me the child at seven: the consequences of conduct problems in childhood for psychosocial functioning in adulthood. I Child Psychol Psychiatry 2005;46:837-49. DOI: 10.1111/j.1469-7610.2004.00387.x

52. Thorsteinsson EB, Ryan SM, Sveinbjornsdottir S. The Mediating Effects of Social Support and Coping on the Stress-Depression Relationship in Rural and Urban Adolescents. Open Journal of Depression. 2013;2(1):1-6. http:// dx.doi.org/10.4236/ojd.2013.21001

53. Ebata AT, Moos RH. Coping and adjustment in distressed and healthy adolescents. / Appl Dev Psychol. 1991;12(1):33-54. doi:10.1016/0193-3973/91)g0029-4

54. Regenmortel T. van (2009). Empowerment als uitdagend kader voor sociale inclusie en moderne zorg. I Soc Intervention: Theory and Practice. 2009;18(4):22-42.

55. Huber M, Knottnerus IA, Green L, Horst H van der, Jadad AJ, Kromhout D, et al. How should we define health? BMJ. 2011;343(4163):235-237. doi:10.1136/bmj.d4163

56. Schuman H. Passend Onderwijs - pas op de plaats of stap vooruit? [Inclusive education - marking time or step forward?]. Tijdschrift voor orthopedagogiek. 2007;46:267-280.

57. De Jeugdgezondheidszorg beter in positie. [Youth health care in better position.]. Utrecht: Inspectie voor de Cezondheidszorg [Healthcare Inspectorate], 2014. http://www.rijksoverheid.nl/documenten-en-publicaties/ rapporten/2014/11/06/de-jeugdgezondheidszorg-beter-in-positie.htm/

58. Samenwerkend Toezicht Jeugd. Vormgeving zorg en ondersteuning aan gezinnen met geringe sociale redzaamheid. [Cooperating inspection youth. Shaping care and support to families with little social resilience.]. Ministerie OCW. [Ministry of Education, Culture and Science.]. The Hague, the Netherlands. 2014. http://www.rijksoverheid. $\mathrm{nl} /$ documenten-en-publicaties/rapporten/2014/05/15/vormgeving-zorg-en-ondersteuningaan-gezinnen-met-geringe-sociale-redzaamheid.html

59. Bosscher N. De decentralisatie en transformatie van de Nederlandse jeugdzorg. [The decentralisation and transformation of the Dutch youth care system.]. 2014. http://www.youthpolicy.nl/yp/downloadsyp/PublicationsThe-decentralisation-and-transformation-of-the-Dutch-youth-care-system.pdf. 

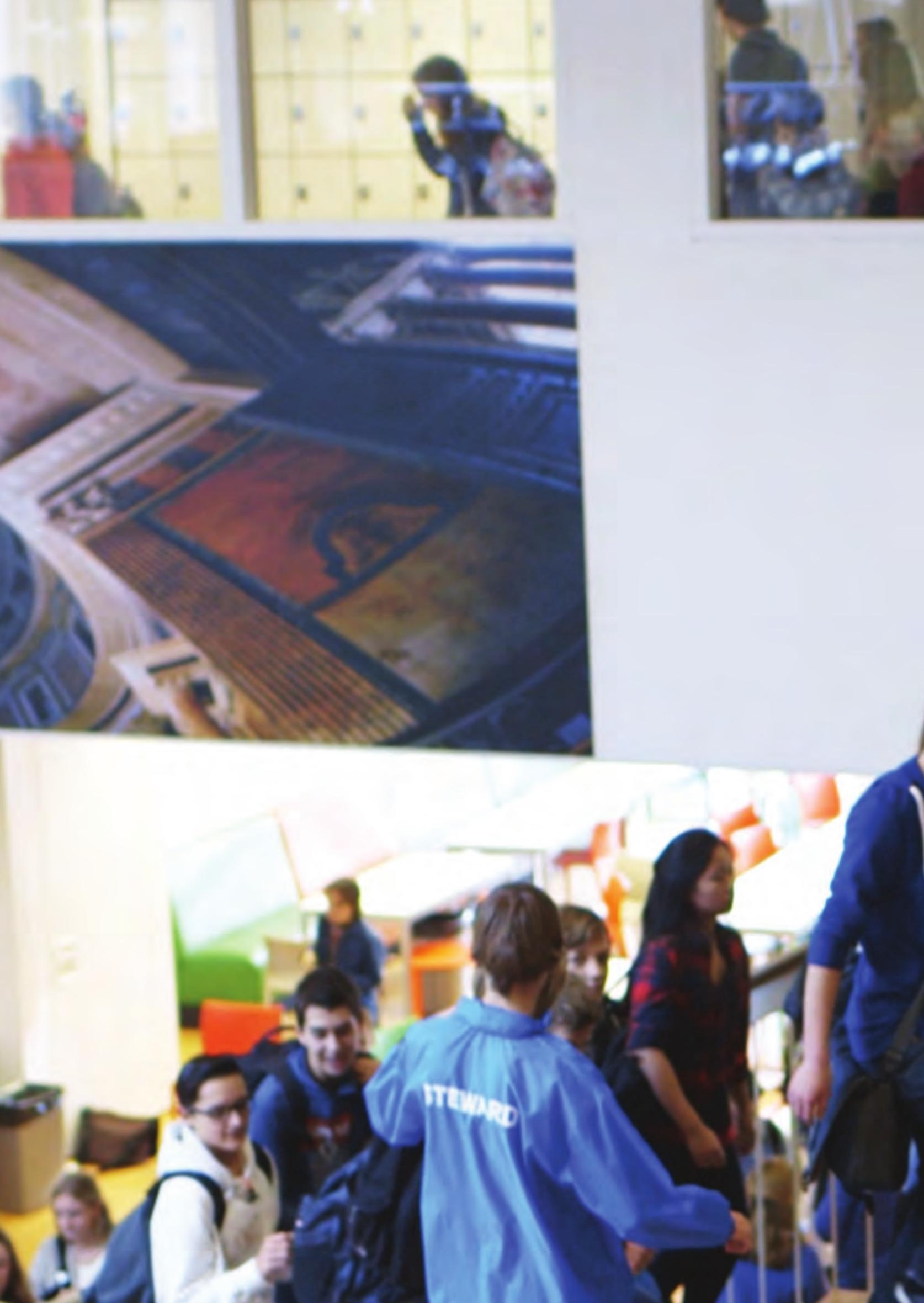



\section{Summary}

School absenteeism does not only impact on young people's personal development and therefore on their future, but it also has a huge impact on society, both socially and economically. Substantial school absenteeism negatively affects students' social and emotional development, and causes students' educational development to stagnate, which may lead to moving down to a lower level of education or even early school dropout. The impact of school absenteeism due to sickness reporting, so-called medical absenteeism, can be explained by the consequences of the absence itself and by the direct influence of suboptimal health on school results and personal development. Looked at from a life-time perspective, both health problems and lesser educational achievement in youth may be followed by a lower socioeconomic status in adulthood. Such a lower socioeconomic status may in turn cause a transgenerational transmission of less favourable health which in turn may cause a downward spiral. It is to be expected that such a downward spiral can be avoided by adequately addressing medical absenteeism, and consequently creating optimal educational opportunities and health for young people. This may contribute to driving back socioeconomic health differences. School absenteeism must therefore not only be seen as a problem for education but also as a serious problem for other sectors, including public health care.

In the Netherlands preventive youth health care $(\mathrm{YHC})$ is an important field of application within (public) health care. Its goal is to foster the optimal trajectory for growth and development in children and to provide (anticipatory) the necessary care and support, to lessen or even prevent reduced health in later life. In this way, YHC aims not only to optimize the personal well-being and future of children, but also to reduce socioeconomic health differences. YHC does not only contribute to the personal well-being and future of vulnerable children, but also to reducing socioeconomic health differences. Because of its socio-medical expertise and biopsychosocial perspective, $\mathrm{YHC}$ is pre-eminently able to intervene with school absenteeism due to sickness reporting. YHC can contribute to reducing school absenteeism and in this way contribute to the reduction of socioeconomic health differences.

Because no interventions and agencies existed that paid attention to medical absenteeism among students, the intervention 'Medical Advice for Sick-reported Students', acronym MASS (In Dutch: 'Medische Advisering van de Ziekgemelde Leerling', acronym M@ZL) was developed in close partnership between the YHC department of the Regional Public Health Service, secondary schools and the municipal school attendance service for compulsory education in West Brabant, the Netherlands. The MASS intervention has an integrated and personalized approach in which school personnel and youth health care physicians (YHCPs) play a major role. MASS provides a clear framework in which school personnel, in direct collaboration with YHCPs, is able to reach students and their parents, discuss aspects of the student's medical absence, and design and monitor a management plan that aims to optimize students' health and maximize their participation in school activities.

This thesis endeavours to contribute to gaining a better understanding of medical absenteeism among pre-vocational secondary education students, primary school children and intermediate vocational students, and to study the effectiveness of the MASS intervention. Research has taken place into the health condition of pre-vocational secondary education students with extensive 
medical absence, and into the implementation and the effectiveness of the intervention in pre-vocational secondary schools (part I, chapter 1, 2, 3). Exploratory research into aspects of medical absenteeism in primary and intermediate vocational education aimed at eventually adapting the intervention for use with these new target groups (part II, chapter 4, 5, 6).

In chapter 1 the background, the general objective and aims of the thesis are described in terms of policy context on reducing school absenteeism. Additional attention is paid to the impact of school absenteeism on young people's development and future, to factors associated with medical absenteeism based on literature research, and to the perspective on and added value of the YHCP in addressing medical absenteeism. A description of the MASS intervention and its presumed potential results are part of this chapter. The characteristics of practice-driven research are described to introduce the research design. MASS has been developed by means of a participative bottom-up approach and has been implemented in real-life conditions from the onset, for which this kind of research is suitable.

Chapter $\mathbf{2}$ describes the pilot study that focused on evaluating the intervention in prevocational secondary education with a view to its acceptability, feasibility and practicability, from the perspectives of both the professionals, and students and parents. In addition the study looked for possible outcome measurements and indications of effectiveness. The pilot study was partly qualitative and descriptive and partly quantitative. The findings provided indications for further development of the intervention. The adapted intervention, as described in chapter 1 , then became the subject of a larger-scale practice-driven intervention study, the results of which are described in chapter 3 and 4 .

In chapter 3 the health condition and characteristics of those pre-vocational secondary education students who met the MASS-criteria for extensive medical absenteeism (i.e. reported sick four times in 12 school weeks or more than six consecutive school days) are described, from the biopsychosocial perspective of YHC. Based on analysis of data from school files, medical assessments and Strengths and Difficulties Questionnaires (SDQs) of 493 students who had been referred to the YHCP over the course of one school year (2011-2012), their health condition was described. This study revealed that when using the threshold criteria for extensive medical absenteeism to intervene with the absence, students with a mean absence rate of $14 \%$ in 12 school weeks are identified. If students had a diagnosed disease, it seemed that with about twothirds of them their medical absence was also based on problems at home or in school. More than half of the students' absence was caused by mental or physical problems, often in combination with problems at home or in school, rather than by a diagnosed disease. It was concluded that the great diversity of these underlying problems calls for a personalized approach, and that a broad biopsychosocial perspective and medical expertise are needed to distinguish between emerging mental and physical diseases, psychosocial and lifestyle problems.

Chapter 4 reports on the intervention's effectiveness in pre-vocational secondary education, based on a quantitative study with a quasi-experimental character. The change in the level of medical absenteeism of students with extensive medical absenteeism in seven schools that had applied the MASS intervention, was compared to the change in the level of medical absenteeism of students with extensive medical absenteeism who visited one of the seven control schools that 
had not applied the MASS intervention but had been offering 'care as usual'. The intervention appeared to be effective for pre-vocational secondary education students with increased absence rates. It was concluded that personalized management of medical absenteeism by systematic identification of students with extensive medical absenteeism through use of the MASS-criteria, and consistent referral to a YHCP who subsequently designs and monitors a management plan, is more effective than 'care-as-usual'. The effectiveness of the intervention is shown primarily by a decrease in the number of periods reported sick, one of the indicators of the extent of medical absenteeism. The difference between aspects of volume of medical absenteeism in number of absence periods and days per period is important for understanding that the effectiveness of the intervention.

Chapter $\mathbf{5}$ presents a study that aims to explore factors that influence the adoption and (sustainable) dissemination and implementation of MASS, from schools' perspectives. In nine secondary schools that were applying MASS school principals and special education needs coordinators were questioned, using semi-structured interviews. The following research questions were leading the interviews: what motivates school staff to pay attention to medical absenteeism, what are their experiences in applying MASS, and what are facilitators and obstacles when implementing MASS, including considerations of sustainability? The study revealed that according to the interviewees schools' initial reasons for implementing MASS relate to the individual student: their concerns about students' well-being and future prospects and the wish to share these concerns with students' parents. According to those interviewed MASS also improves parental involvement in school and the quality of care for students. Moreover, in their perception, MASS supports schools in achieving their primary goal, namely increasing the number of students that graduate. All these factors promote the acceptability and usefulness of MASS, thereby supporting its adoption and dissemination. School personnel, as stated by the interviewees, is convinced that reducing medical absenteeism improves educational outcomes and emphasizes the benefit of working together with YHCPs. According to the interviewees, adequate communication about the purpose of the intervention with all stakeholders and the training of mentors in conducting a constructive dialogue about medical absenteeism with students and their parents are preconditions for success. They stated that in order to achieve a sustainable implementation of the approach of medical absenteeism, agenda setting is needed. The issue is of great importance not only for the health sector but also for the educational sector and needs to be put on schools' agendas. To achieve this, an intersectoral health policy and collaboration are needed.

Since attendance patterns become manifest already at an early stage, it is important to find a way to minimise school absenteeism already in primary school. Chapter $\mathbf{6}$ describes a study of the factors that indicate an increased risk of medical absenteeism in general primary school, ultimately aimed at tailoring the intervention to suit this new target group. The school and YHC files of primary school children with extensive medical absenteeism and of those with a minimum of medical absenteeism were studied in a practice-based retrospective matched casecontrol study. The study showed that, in general primary schools, there is a higher incidence of extensive medical absenteeism among children growing up in disadvantaged families. Low school motivation was also found to be associated with extensive medical absenteeism. It was concluded that as well as in pre-vocational secondary education as in primary education medical 
absenteeism would require a broad and integrated approach by school personnel as well as YHC professionals, focusing not only on biomedical and health aspects but also on the psychosocial context and home environment of the child.

Due to the high number of school dropouts in intermediate vocational schools and the need of school personnel to also address medical absenteeism among their students according to MASS, an exploratory research on sickness reporting by intermediate vocational students is conducted. Chapter 7 describes a qualitative study in intermediate vocational schools of students' perceptions of medical absenteeism, using semi-structured interviews. The aim of the study was to explore the reasons for medical absenteeism of students. Here also the ultimate objective was to find leads for adapting the intervention to this educational level. The following research questions were leading the interviews: what, according to the students, are their reasons for medical absence, and what factors, according to the students, influence their sickness reporting? As Veerman's model was used as theoretical foundation to adapt the MASS intervention to intermediate vocational education, this study also aimed to investigate to what extent Veerman's model applies to the medical absence of students in intermediate vocational education. The conclusion was that intermediate vocational students have different views on their medical absence. Besides medical reasons, feelings of being able to take own responsibility and the way the school context is perceived can also play a role in medical absence. This variety in backgrounds and the sometimes impulsive character of sick reporting, call for great diversity in the guidance of intermediate vocational students who report sick. In determining the guidance needed, one should take the student's own view on the absence as a starting point. Our study shows that Veerman's model does not seem applicable to the medical absence of intermediate vocational students.

Finally, in chapter $\mathbf{8}$ the findings presented in the preceding chapters are combined and presented and considered thematically, including implications for practice and suggestions for future research. Subsequently, the strengths and limitations of the study are presented and discussed, followed by general reflections on the study findings. Moreover, designing a final version of the intervention and securing sustainable dissemination in the current policy climate are considered.

The studies presented have demonstrated that the MASS intervention is effective for prevocational secondary students with increased absence rates: systematic identification of students with extensive medical absenteeism by using the MASS-criteria, followed by consistent referral to a YHCP who designs and monitors a management plan that aims to optimize students' health and maximize students' participation in school activities and that is being monitored, is more effective than 'care-as-usual'. The great diversity of students' health condition calls for a personalized approach and the use of a biopsychosocial perspective that includes medical expertise. Through a joint effort of school staff and YHCPs, students and parents, the educational and health outcomes of these students can be optimized, leading to a diminished volume of medical absenteeism.

The policy climate provides a foundation without which change will not be sustainable. An educational policy focus on the prevention of early school dropout, and on inclusion of students with disabilities and special education needs in general schools ('Inclusive Education') will contribute to putting medical absenteeism on schools' agendas. The current youth (health) care policy climate 
with a focus on more preventive care ('Transforming Youth Care') will put medical absenteeism on the agendas of (public) health care and municipalities. Together these two policies may be expected to contribute to a sustainable and widespread dissemination of the MASS intervention. 



\section{Samenvatting}

Schoolverzuim is niet alleen van grote invloed op de individuele ontwikkeling van jonge mensen, en daarmee op hun toekomst, maar heeft ook een enorme maatschappelijke impact in zowel sociaal als economisch opzicht. Omvangrijk schoolverzuim beïnvloedt de sociale en emotionele ontwikkeling van leerlingen negatief en veroorzaakt een stagnatie in hun leerontwikkeling. Dit kan terugval naar een lager onderwijsniveau of zelfs voortijdig schoolverlaten tot gevolg hebben. De impact van schoolverzuim als gevolg van ziekmelding, het zogeheten ziekteverzuim, kan verklaard worden door de gevolgen van het schoolverzuim zelf en door de directe invloed van suboptimale gezondheid op schoolresultaten en de persoonlijke ontwikkeling. Gezien in levensloopperspectief kunnen zowel gezondheidsproblemen als lagere onderwijsprestaties op hun beurt een lagere sociaaleconomische status op volwassen leeftijd tot gevolg hebben. Deze lagere sociaaleconomische status kan vervolgens weer leiden tot de transgenerationele overdracht van minder gunstige gezondheid, resulterend in een neerwaartse spiraal. Naar verwachting zal deze neerwaartse spiraal worden voorkomen door een adequate aanpak van ziekteverzuim, waarbij bijtijds de onderwijskansen en de gezondheid van jonge mensen worden geoptimaliseerd. Dit kan een bijdrage leveren aan het terugdringen van sociaaleconomische gezondheidsverschillen. Ziekteverzuim moet daarom niet alleen gezien worden als een probleem voor de onderwijssector maar ook als een serieus probleem voor meer sectoren, waaronder de publieke gezondheidzorgzorg.

In Nederland is de jeugdgezondheidszorg (JCZ) een belangrijk toepassingsgebied van de publieke gezondheidszorg. Het doel van de preventieve JCZ is het optimaliseren van de groei en ontwikkeling van kinderen en het (anticiperend) bewerkstelligen van benodigde ondersteuning en zorg, waardoor een verminderde gezondheid in het latere leven kan worden beperkt of zelfs voorkomen. De JCZ beoogt daarmee niet alleen het persoonlijk welbevinden en de toekomst van het kind te optimaliseren, maar eveneens sociaaleconomische gezondheidsverschillen te reduceren. Vanwege haar sociaal-medische expertise en biopsychosociale perspectief is de JCZ bij uitstek in staat te interveniëren bij ziekteverzuim. JCZ kan zo een bijdrage leveren aan het terugdringen van schoolverzuim en daarmee van sociaaleconomische gezondheidsverschillen.

Omdat er geen interventies en voorzieningen bestonden die gericht waren op aandacht voor leerlingen met ziekteverzuim, is de interventie 'Medische Advisering van de Ziekgemelde Leerling', afgekort M@ZL, ontwikkeld. Dit gebeurde in nauwe samenwerking tussen de JCZafdeling van de GCD, scholen voor voortgezet onderwijs en de gemeentelijke leerplichtafdeling in West-Brabant. De interventie M@ZL kent een integrale en gepersonaliseerde aanpak waarbij schoolpersoneel en jeugdartsen een belangrijke rol spelen. M@ZL voorziet in een duidelijk kader waarin schoolpersoneel, in directe samenwerking met jeugdartsen, de mogelijkheid heeft om leerlingen en hun ouders te bereiken, aspecten van het ziekteverzuim van de leerlingen te bespreken, en een plan van aanpak te ontwikkelen en te monitoren dat is gericht op het optimaliseren van de gezondheid van leerlingen en het maximaliseren van hun deelname aan schoolactiviteiten.

Dit proefschrift wil een bijdrage leveren aan het krijgen van meer inzicht in het ziekteverzuim bij leerlingen in het voorbereidend middelbaar beroepsonderwijs (vmbo), het primair onderwijs (po) en het middelbaar beroepsonderwijs (mbo), en aan onderzoek naar de effectiviteit van de 
interventie M@ZL. Hiervoor is de gezondheidstoestand van vmbo-leerlingen met omvangrijk ziekteverzuim onderzocht en is onderzoek gedaan naar de implementatie, verspreiding en effectiviteit van de interventie op het vmbo (deel I, hoofdstukken 1, 2 en 3). Daarnaast is verkennend onderzoek verricht naar aspecten van ziekteverzuim op het po en mbo, met als uiteindelijk doel het verkrijgen van aanknopingspunten voor mogelijke aanpassing van de interventie voor gebruik bij deze nieuwe doelgroepen (deel II, hoofdstukken 4, 5 en 6).

In hoofdstuk 1 worden de achtergrond en de algemene uitgangspunten en doelen van het proefschrift beschreven in relatie tot de context van het beleid om schoolverzuim terug te dringen. Daarnaast wordt ingegaan op de impact van schoolverzuim op de ontwikkeling en de toekomst van jongeren, op factoren die op basis van literatuuronderzoek gerelateerd zijn aan ziekteverzuim, en op het perspectief en de toegevoegde waarde van de jeugdarts bij de aanpak van ziekteverzuim. Ook een beschrijving van de interventie M@ZL en de te verwachten resultaten ervan maken onderdeel uit van dit hoofdstuk. De kenmerken van praktijkgestuurd onderzoek worden beschreven als introductie op de onderzoeksopzet. M@ZL is ontwikkeld door middel van een participatieve benadering van onderaf en is vanaf de start geïmplementeerd in de praktijk, waardoor deze vorm van onderzoek meest aangewezen is.

Hoofdstuk 2 beschrijft de pilot, gericht op de evaluatie van de interventie op het vmbo met betrekking tot acceptatie, haalbaarheid en bruikbaarheid, vanuit het perspectief van zowel de beroepskrachten als de leerlingen en hun ouders. Daarnaast werd er gezocht naar mogelijke uitkomstmaten en aanwijzingen voor effectiviteit. Deze pilot was deels kwalitatief en beschrijvend en deels kwantitatief van aard. De bevindingen gaven aanknopingspunten voor verdere ontwikkeling van de interventie. De aangepaste interventie, zoals beschreven in hoofdstuk 1 , was vervolgens onderwerp van een grootschaliger praktijkgestuurde interventiestudie, waarvan de resultaten in hoofdstuk 3 en 4 worden beschreven.

In hoofdstuk 3 worden de gezondheidstoestand en de kenmerken van de vmbo-leerlingen die voldeden aan de M@ZL-criteria voor ziekteverzuim (vier maal ziekgemeld in 12 schoolweken of meer dan zes opeenvolgende schooldagen) beschreven, vanuit het biopsychosociale perspectief van de JCZ. De gezondheidstoestand van 493 leerlingen die waren verwezen naar de jeugdarts in een schooljaar (2011-2012) werd beschreven op basis van analyse van de gegevens uit schooldossiers, medische onderzoeken en Strengths and Difficulties Questionnaires (SDQ's). Het onderzoek wees uit dat de toepassing van de drempelcriteria om te interveniëren bij omvangrijk ziekteverzuim leidde tot de signalering van leerlingen met een gemiddelde afwezigheid van $14 \%$ in 12 schoolweken. Wanneer leerlingen een gediagnosticeerde ziekte hadden, bleek dat bij ongeveer twee derde van hen eveneens problemen thuis of op school aan het ziekteverzuim ten grondslag lagen. Bij meer dan de helft de leerlingen werd het verzuim veroorzaakt door psychische of lichamelijke klachten, vaak in combinatie met problemen thuis of op school en niet door een gediagnosticeerde ziekte. De conclusie was dat de grote diversiteit van deze achterliggende problematiek vraagt om een gepersonaliseerde benadering, en dat een breed biopsychosociaal perspectief en sociaal-medische expertise nodig zijn om onderscheid te kunnen maken tussen opkomende psychische en lichamelijke ziektes, psychosociale problemen en leefstijlproblemen.

Hoofdstuk 4 doet verslag van de effectiviteit van de interventie op het vmbo, op basis van een kwantitatieve studie met een quasi-experimentele opzet. Veranderingen in de omvang 
van het ziekteverzuim van leerlingen met omvangrijk ziekteverzuim op zeven scholen die de interventie M@ZL hadden toegepast, werden vergeleken met veranderingen in de omvang van het ziekteverzuim van leerlingen met omvangrijk ziekteverzuim op zeven controlescholen waar de interventie M@ZL niet was toegepast maar waar de gebruikelijke zorg was verleend. De interventie bleek effectief te zijn voor vmbo-leerlingen met omvangrijk ziekteverzuim. Hieruit werd de conclusie getrokken dat de gepersonaliseerde benadering van ziekteverzuim door middel van systematische signalering van leerlingen met omvangrijk ziekteverzuim door gebruik te maken van de M@ZL-criteria, en consequente verwijzing naar jeugdartsen, die vervolgens een plan van aanpak ontwikkelen en monitoren, effectiever is dan het verlenen van de gebruikelijke zorg. De effectiviteit van de interventie bleek vooral uit de afname van het aantal ziekteverzuimperiodes, één van de factoren van de totale ziekteverzuimomvang.

In hoofdstuk $\mathbf{5}$ wordt een onderzoek beschreven dat is gericht op het verkennen van factoren die de adoptie en (duurzame) verspreiding en implementatie van M@ZL beïnvloeden vanuit het perspectief van scholen. Op negen scholen voor voortgezet onderwijs waar M@ZL werd toegepast werden schooldirecteur en zorgcoördinator geïnterviewd met behulp van halfgestructureerde vragenlijsten. De volgende vragen gaven richting aan de interviews: wat beweegt schoolpersoneel om aandacht te besteden aan ziekteverzuim, wat zijn hun ervaringen met het toepassen van M@ZL, en welke faciliterende en belemmerende factoren hebben ze bij de implementatie van M@ZL ervaren, ook met betrekking tot duurzaamheid? De studie liet zien dat deze scholen in eerste instantie vooral M@ZL implementeerden vanuit het belang van individuele leerlingen: hun bezorgdheid om het welzijn en het toekomstperspectief van hun leerlingen en hun wens om deze zorg te delen met de ouders van die leerlingen. Volgens de geïnterviewden wordt door mentoren ook een positieve invloed ervaren van M@ZL op de betrokkenheid van ouders bij de school en op de kwaliteit van de leerlingenzorg. Tevens ondersteunt M@ZL in hun beleving bij het bereiken van het primaire onderwijsdoel van een zo hoog mogelijk slagingspercentage. Al deze factoren bevorderen de acceptatie en bruikbaarheid van M@ZL. Schoolmedewerkers zijn er volgens de geïnterviewden van overtuigd dat het terugdringen van ziekteverzuim de onderwijsresultaten verbetert en benadrukken de voordelen van samenwerking met jeugdartsen. De geïnterviewden gaven aan dat adequate communicatie met alle betrokkenen over het doel van de interventie en training van mentoren in het voeren van een constructief gesprek over ziekteverzuim met leerlingen en hun ouders voorwaarden zijn voor succes. Ze stelden dat voor een duurzame implementatie van de aanpak van ziekteverzuim agendasetting van het onderwerp nodig is. Het thema is niet alleen voor de gezondheidszorg maar ook voor het onderwijs van groot belang en zou op de beleidsagenda van scholen moeten worden geplaatst. Om dit te kunnen bereiken is intersectoraal gezondheidsbeleid en samenwerking noodzakelijk.

Omdat verzuimpatronen zich al in een vroeg stadium aftekenen, is het belangrijk om een manier te vinden om schoolverzuim al op het primair onderwijs tot een minimum te beperken. Hoofdstuk 6 beschrijft een onderzoek naar de factoren die een verhoogd risico op ziekteverzuim aangeven, met als uiteindelijk doel het geschikt maken van de interventie voor deze nieuwe doelgroep. De school- en JGZ-dossiers van basisschoolleerlingen met omvangrijk ziekteverzuim en van basisschoolleerlingen met het minste ziekteverzuim werden bestudeerd in een praktijkgericht vergelijkend retrospectief patiënt-controle-onderzoek. Het onderzoek toonde aan dat op reguliere basisscholen een omvangrijk ziekteverzuim vaker voorkomt bij een groep kinderen die opgroeit in kansarme gezinnen. Een lage schoolmotivatie bleek ook gerelateerd te 
zijn aan omvangrijk ziekteverzuim. De conclusie werd getrokken dat ziekteverzuim, net als op het vmbo, ook in het primair onderwijs een brede en integrale benadering vraagt, zowel van het schoolpersoneel als van de professionals in de JCZ, waarbij niet alleen wordt gekeken naar biomedische en gezondheidsaspecten maar ook naar de psychosociale context en de thuissituatie van het kind.

Vanwege het hoge aantal voortijdig schoolverlaters op het mbo en de behoefte bij schoolpersoneel om ook op het mbo ziekteverzuim aan te pakken volgens de methode M@ZL, is explorerend onderzoek naar ziekteverzuim mbo-leerlingen gedaan. Hoofdstuk 7 beschrijft een kwalitatief onderzoek naar de opvattingen over ziekteverzuim bij mbo-leerlingen, waarbij gebruik werd gemaakt van halfgestructureerde interviews. De studie had tot doel om de redenen voor het ziekteverzuim van leerlingen te verkennen. Ook hier was het uiteindelijke doel om aanknopingspunten te vinden voor aanpassing van de interventie voor dit onderwijsniveau. De volgende onderzoeksvragen gaven richting aan de interviews: wat zijn de redenen voor ziekteverzuim volgens de leerlingen en welke factoren beïnvloeden volgens de leerlingen hun ziekmeldingen? Omdat het model van Veerman werd gebruikt als theoretische onderbouwing om de M@ZL-interventie aan te passen aan het mbo, werd de studie ook gebruikt om te onderzoeken in welke mate het model van Veerman van toepassing is op het ziekteverzuim van mbo-leerlingen. De conclusie was dat leerlingen in het mbo verschillend denken over hun ziekteverzuim. Naast medische redenen kunnen hun beleving of ze eigen verantwoordelijkheid kunnen nemen en de wijze waarop de schoolomgeving wordt ervaren ook een rol spelen bij ziekteverzuim. Die verscheidenheid in achtergronden, in combinatie met de soms impulsieve aard van de ziekmelding, vragen om een grote diversiteit in de begeleiding van leerlingen in het mbo die zich ziek melden. Bij het bepalen van de mate van begeleiding die de leerlingen nodig hebben, zouden derhalve hun eigen ideeën over hun verzuim als uitgangspunt genomen moeten worden. Het model van Veerman blijkt uit onze studie niet van toepassing op het ziekteverzuim van mbo-leerlingen.

Tenslotte worden in hoofdstuk $\mathbf{8}$ de bevindingen uit de eerdere hoofdstukken gecombineerd en thematisch gepresenteerd en beschouwd, inclusief de consequenties voor de praktijk en suggesties voor verder onderzoek. Daaropvolgend worden de sterkten en beperkingen van de studie gepresenteerd en besproken, gevolgd door een algemene beschouwing op de onderzoeksresultaten. Ook de doorontwikkeling tot een definitieve versie van de interventie en de mogelijkheid voor duurzame verspreiding in het huidige beleidsklimaat worden besproken.

De gepresenteerde onderzoeken hebben uitgewezen dat de interventie M@ZL effectief is voor leerlingen in vmbo met een omvangrijke verzuimomvang: systematische signalering van leerlingen met omvangrijk ziekteverzuim door het gebruik van de M@ZL-criteria, gevolgd door consequente verwijzing naar de jeugdarts, die een plan van aanpak maakt en monitort dat gericht is op het optimaliseren van de gezondheid van de leerling en het maximaliseren van deelname aan schoolactiviteiten, is effectiever dan gebruikelijke zorg. De grote verscheidenheid in de gezondheidstoestand van leerlingen vraagt om een persoonlijke benadering en om toepassing van een biopsychosociaal perspectief, inclusief medische expertise. Door de gezamenlijke inspanning van schoolpersoneel, jeugdartsen, leerlingen en ouders kunnen de onderwijs- en gezondheidsresultaten voor deze leerlingen worden geoptimaliseerd, waardoor de ziekteverzuimomvang wordt teruggedrongen. 
Het beleidsklimaat biedt een noodzakelijk fundament om duurzame verandering te bewerkstelligen. Binnen het onderwijsbeleid zullen zowel het beleid ter voorkoming van voortijdig schoolverlaten (vsv-beleid) als het beleid gericht op het re-integreren van leerlingen met beperkingen en speciale onderwijsbehoeften op reguliere scholen (Passend Onderwijs) bijdragen aan het agenderen van het onderwerp ziekteverzuim bij scholen. Het huidige jeugd (gezondheids) zorgklimaat met een nadruk op meer preventieve zorg (Transformatie leugdzorg) zal het onderwerp ziekteverzuim op de agenda plaatsen bij (publieke) gezondheidszorg en gemeenten. In combinatie zullen deze beleidslijnen naar verwachting bijdragen aan een duurzame en brede verspreiding van de interventie M@ZL. 



\section{Dankwoord}

Ongelooflijk dankbaar ben ik dat ik mijn promotietraject heb mogen doorlopen en afronden. Begeleiding, facilitering en persoonlijk geluk bleken hiervoor de bouwstenen, bemoediging het cement. Het was een traject vol afwisseling en tegenstrijdige gevoelens. Perioden van 'eenzame afzondering' en 'samen vieren' wisselden elkaar voortdurend af. Ik heb bovendien nog nooit met zoveel verschillende mensen samengewerkt aan een project. It takes a village to write a thesis! Het is tijd iedereen te bedanken.

Prof. dr. Feron, beste Frans, toen de CCD West-Brabant in 2009 met M@ZL de innovatieprijs won was jij het die ons feliciteerde. Dat raakte me. Ik vond dat zo collegiaal. Toen ik besloot te promoveren wist ik meteen dat ik jou zou vragen mijn promotor te worden. Niet alleen ben je bekend met het werk van een jeugdarts en begrijp je daardoor zo goed wat ook mij als jeugdarts drijft, je hebt bovendien een goed zicht op de doelgroep en een duidelijke visie op gepersonaliseerde zorg en je bent een enorme inspirator. Je was er vanaf het begin van overtuigd dat het me zou lukken, tenminste dat straalde je uit, en dat had ik nodig. Je legde de lat voor mij steeds weer wat hoger. Je liet me worstelen en gaf me tegelijkertijd vertrouwen in mijn eigen kunnen. Ik heb jouw betrokkenheid zeer gewaardeerd. Dankjewel, voor je warme betrokkenheid en je enthousiaste begeleiding, voor alle ritten naar Tilburg, waar het overleg met het promotieteam vier jaar lang met enige regelmaat plaatsvond. Dankjewel voor altijd weer heerlijke koffie en gezellige lunches als ik voor overleg met jou naar Maastricht kwam. Het voelde daardoor als goed thuiskomen in mijn geboortestreek. Mijn kinderen zullen de heerlijke Limburgse vlaaien gaan missen!

Dr. Rots-de Vries, beste Carin, onze samenwerking startte bij het aanbieden van de interventie M@ZL aan de Interventiedatabase Cezond en Actief Leven in 2010, waarna we een eerste onderzoeksidee naar de effectiviteit van M@ZL op papier hebben gezet. Later is dat uitgewerkt tot de onderzoeksopzet die een groot deel van mijn promotieonderzoek bestreek. Dat jij mijn copromotor zou worden lag daarom voor de hand. Heel veel dank voor je kritisch meelezen en becommentariëren van de stukken die voorlagen.

Prof. dr. Van de Coor, beste len, de samenwerking tussen de CGD West-Brabant en de Academische Werkplaats Publieke Gezondheid bij Tranzo bracht ons bij elkaar. En ik heb daar enorm mee geboft! jij was niet alleen op wetenschappelijk gebied altijd prettig positief kritisch, met je verfijnde taalgevoel was jij ook een enorme steun bij het precies verwoorden van wat ik nou eigenlijk wilde zeggen. Bovendien was jij de ouder die vooral in het begin best kritisch was ten aanzien van al die aandacht voor een ziekmelding. Juist jouw 'lekenvisie' hielp mij om de interventie M@ZL vanuit het ouderperspectief te blijven zien. Dankjewel dat je mijn promotor wilde zijn. Ik heb dat zeer gewaardeerd!

Dr. Matthijssen, beste Jolanda, voor de analyse ben jij na enige tijd als tweede copromotor aan het promotieteam toegevoegd en van onschatbare waarde gebleken. Ongelooflijk hoe goed jij telkens weer wegwijs kunt uit al die data. jij kunt toveren met SPSS! Heel veel dank voor je betrokkenheid, voor al die vrijgemaakte uren, voor je inzet, die enorm en voor jou altijd weer zo vanzelfsprekend was. 
In dit proefschrift zijn ook twee studies beschreven die ik met andere onderzoekers heb uitgevoerd. Dr. Groffen, beste Daniëlle, ondanks je drukke werkzaamheden was je bereid de analyse van het onderzoek op het primair onderwijs voor je rekening te nemen. Ik heb dat zeer gewaardeerd! Onze samenwerking duurde kort en we hebben elkaar daarna bijna niet meer gesproken. Nu ben ik dan toch in de gelegenheid je te bedanken voor je hulp, die zomer, weet je nog?

Dr. De Rijk, beste Angelique, jij bent als geen ander thuis in kwalitatief onderzoek en in de psychologische en sociologische theorieën over arbeidsongeschiktheid en re-integratie in het arbeidsproces. Heel veel dank voor al je ondersteuning bij het uitvoeren, analyseren en beschrijven van het onderzoek op het mbo. Mooi dat ik met jou een allereerste aanzet heb mogen en kunnen geven tot het verbinden van school- en arbeidsparticipatie.

Ike Kroesbergen, tijdens het promotietraject was jij vaak bereid om mee te denken, te luisteren en tips te geven. Het was destijds jouw idee de interventie aan te bieden aan de databank, wat een gouden greep bleek te zijn. Het heeft zeker bijgedragen aan het verkrijgen van de ZonMwsubsidie voor het onderzoek en aan het regionaal en landelijk wegzetten van de interventie M@ZL. Ook heb je de moeite genomen om mij kandidaat te stellen voor de Flora van Laarprijs. Heel hartelijk dank hiervoor. Beste Monique (de Beer), bedankt voor je hulp bij het genereren en gebruiksklaar maken van de data uit de jeugdmonitor voor mijn onderzoek.

Vele studenten hebben me enorm geholpen bij het verzamelen en analyseren van de data en het meeschrijven aan de artikelen: Jeanne America, Nathalie Claassen, Maud Dautzenberg, Marlou van de Loo, Winke Swinkels en Marlieke van Mook, heel veel dank! Jullie hebben met z'n allen zeer veel werk verzet. Zonder jullie was het me zeker niet gelukt om nu al klaar te zijn met mijn promotieonderzoek. Voor alle 'English polishing' dank ik Thea Meinema, het echtpaar Morgan en Myrte Maathuis van harte.

Geen promotieonderzoek zonder data, geen promotie zonder deelnemers en enthousiaste uitvoerders. Ik dank alle leerlingen en ouders, administratief medewerkers, mentoren, zorgcoördinatoren, schooldirecteuren, jeugdartsen en leerplichtambtenaren voor het verzamelen van de onderzoeksgegevens: het invullen van vragenlijsten en registratieformulieren, het uitdraaien van verzuimoverzichten, en het geven van interviews. Jasper de Wit, bedankt voor de software die je hebt ontwikkeld om de tellingen mogelijk te maken. Je hebt er heel wat tijd en werk aan gehad, zomaar, belangeloos. Je hebt me daarmee enorm veel uren werk uit handen genomen. Ik ben je daar zeer erkentelijk voor!

Ik dank Prof. dr. E. Dompeling, Prof. dr. J.F.M. Metsemakers, Prof. dr. J.L.L. van der Klink en Dr. F. Pijpers voor hun bereidheid om zitting te nemen in de beoordelingscommissie.

Al vele jaren is er vanuit de CGD West-Brabant aandacht voor de wegens ziekte verzuimende leerling. Het is dan ook geen toeval dat juist in West-Brabant M@ZL is ontwikkeld. Het is voorjaar 1990 als ik door jou, Frans (Frans Pijpers), wordt ingewerkt als jeugdarts. We zitten in een kamer aan het eind van de gang op de GTS (Cemeentelijke Technische School, later de Van Cooth Scholengemeenschap genoemd), een vmbo-school in Breda-Noord. We zijn tweedeklassers aan het screenen. jij bent even weg en als je terug komt vertel je dat het niet lukt een verzuimoverzicht te genereren van de leerlingen van de school. Twee belangrijke 
lessen leerde ik hieruit: dat jeugdgezondheidszorg veel meer is en kan dan het op gezette tijden uitvoeren van een 'gezondheidscheck' bij kinderen en jongeren, en dat de samenwerking met de school essentieel is voor de uitvoer van jeugdgezondheidszorg. lij wist als eerste in Nederland 'gezondheid' op de agenda van het onderwijskansenbeleid te zetten, dat zich in die tijd ondermeer richtte op het voorkomen van schooluitval. In het verlengde daarvan vroeg jij toen al aandacht voor leerlingen met ziekteverzuim. Frans, je hebt altijd belangstelling blijven houden voor de aanpak van ziekteverzuim, dat ook recent nog resulteerde in het kritisch meelezen met het handboek'M@ZL voor JCZ-instellingen'. Als kers op de taart heb je mijn proefschrift beoordeeld, wat ik zeer waardeer. Heel hartelijk dank voor al je belangstelling en betrokkenheid.

Vanuit bovengenoemde agendasetting van gezondheid en ziekteverzuim werd de werkwijze 'ziekteverzuimbegeleiding door de jeugdarts' destijds ontwikkeld en jarenlang door een aantal voscholen en jeugdartsen in West-Brabant uitgevoerd. Beste Ine (Ine Dijkmans), jij ondersteunde het goed en vraaggericht wegzetten van deze werkwijze. Na het interviewen van zorgcoördinatoren en jeugdartsen beschreef jij jaar na jaar uitvoerig de meerwaarde van het hebben van aandacht voor het ziekteverzuim van jongeren voor alle betrokken partijen en niet in de laatste plaats voor de jongeren zelf. Ik mocht daar als uitvoerend jeugdarts en collega getuige van zijn en heb veel bewondering voor de gedrevenheid waarmee je dat deed. En Ike (Ike Kroesbergen), jij ondersteunde al die tijd de uitvoer van deze werkwijze met het interpreteren van de cijfers en het verbinden van de praktijk met onderzoek en beleid. Al die rapporten van jullie hand en met zoveel zorg samengesteld! Ze waren jammer genoeg niet voldoende voor de gemeenten. In 2005 werd de geldkraan dichtgedraaid. Dank je wel, Ine, dat je al die jaren de kar met zoveel verve hebt getrokken.

En altijd weer was er de vraag vanuit scholen. Ook in 2005, toen het Anne-Marie van Nieuwenhuizen was die, destijds zorgcoördinator van Tessenderlandt, een vmboscholengemeenschap in Breda-Zuid, bij de GGD een warm pleidooi hield om toch vooral door te gaan met'ziekterverzuimbegeleiding door de jeugdarts'. Erwas geen geld, 'slechts' een enthousiaste zorgcoördinator, een jeugdarts (Marian Prop) en twee leerplichtambtenaren (John van Oorschot en Liesbeth van der Lee). Ik wilde de mogelijkheden heel graag exploreren en wierp mij op als projectleider. Ik had net een cursus projectmanagement gevolgd, dus dat zou moeten lukken. Echter, ik wilde dit alleen doen onder voorwaarde dat we vanaf het begin zouden inzetten op het wegnemen van de obstakels, die in de eerdere uitvoer steeds werden ervaren door alle partijen, en op het duurzaam wegzetten van de werkwijze. Samen bespraken we de kaders: we zouden elkaars expertise en (on)mogelijkheden respecteren en onze werkzaamheden complementair aan elkaar laten zijn. En zo ontwikkelden we in een aantal sessies de interventie M@ZL. Liesbeth, dank je wel voor de naam M@ZL, door jou bedacht en toen echt nog wel origineel met zo'n apenstaartje. Bij duurzaamheid hoort niet alleen een duidelijk herkenbare naam, maar ook een theoretische onderbouwing verkregen door gedegen wetenschappelijk onderzoek. Mijn woorden 'Eigenlijk zou je er dan een promotieonderzoek van moeten maken'werden door Firmin Polderman opgevangen. $\mathrm{Na}$ intern overleg, waarvoor ik je zeer dankbaar ben Firmin, werd mij gevraagd of ik dat dan zou willen doen. Vanuit de gedachten 'Niet geschoten altijd mis' en 'Ik kan het altijd proberen' heb ik mijzelf een kans willen gegeven. En het is gelukt! Dankzij alle steun die ik heb mogen ontvangen.

Dank aan de directeur van de GGD West-Brabant, Annemieke van de Zijden, voor de ruimte en ondersteuning die ik heb gekregen om mijn promotieonderzoek tot een goed eind te brengen. 
Bernadette van Oers, je bent een leidinggevende met visie. Na elk gesprek met jou ben ik weer een beetje wijzer. Dank voor al je bemoedigende woorden en vertrouwen. Dank ook aan het managementteam van de CGD, dat mij kandidaat stelde voor de verkiezing 'Meest invloedrijke persoon publieke gezondheidszorg 2014 '!

Ook ben ik heel veel dank verschuldigd aan mijn collega's bij de CGD West-Brabant en in het land. Mijn collega-jeugdartsen wil ik heel hartelijk danken voor hun inzet bij het verzamelen van de onderzoeksgegevens en hun enthousiasme bij de uitvoer van M@ZL. Marian Prop dank ik in het bijzonder. Lieve Marian, jij was vanaf het begin enorm betrokken en altijd bereid mee te denken, te registreren, te stimuleren. Zonder jouw tomeloos enthousiasme en grote inzet was het me nooit gelukt zoveel onderzoeksmateriaal te verzamelen. Wij delen duidelijk de passie voor M@ZL. En aan alle jeugdartsen in het land, die ik tegen kom tijdens scholingen, overleggen, projecten en congressen: jullie enthousiaste reacties hebben mij altijd aangemoedigd om door te gaan en kregen vorm in de Flora van Laarprijs in 2013. Ik heb dat ervaren als een enorme erkenning van mijn werk en inzet! Dank jullie wel daarvoor! Het winnen van de verkiezing 'Meest invloedrijke persoon publieke gezondheidszorg 2014' heb ik gezien als een bevestiging dat wij als jeugdgezondheidszorg-professionals heel veel kunnen bereiken als we samen maar een vuist maken. De vele collega's van aanpalende disciplines wil ik eveneens heel hartelijke danken. Ik noem hier graag Janca Beun bij naam. Lieve Janca, fantastische mens! Je positieve instelling en energie, je luisterend oor en je schaterende lach maken je tot een geweldige collega. Je bent een harde werker, die heel goed kan verbinden en altijd bereid is een stap extra te zetten. Met zoveel bezieling vertel je iedereen over M@ZL! De tegeltjeswijsheid 'Je kunt beter stom werk doen met leuke collega's dan andersom' is wat betreft die leuke collega's zeker waar. Marian en Janca, het was voor mij vanaf het begin duidelijk dat, mocht het me lukken, ik jullie als mijn paranimfen zou vragen. Fijn dat jullie ook tijdens dat'laatste uur' achter me willen staan.

Door de samenwerking tussen de GCD West-Brabant en de Universiteit Tilburg kreeg ik tijdens mijn promotieonderzoek niet alleen begeleiding vanuit de Academische Werkplaats Publieke Gezondheid bij Tranzo, maar ook al die jaren een werkplek, op de donderdagen. En dat was heel erg prettig. Ik heb op Tranzo veel fijne collega-onderzoekers mogen ontmoeten. Er was altijd een heel goede en positieve sfeer en de mogelijkheid om met iemand te sparren. Dankjewel, Tranzo, voor de gastvrijheid.

Tijdens mijn onderzoeksperiode heb ik ook heel intensief en prettig samengewerkt met leerkrachten en docenten, intern begeleiders en zorgcoördinatoren, schooldirecteuren en projectleiders, subsidieverstrekkers en beleidsmedewerkers. Een van de hoogtepunten was mijn samenwerking met Jaap Oomen. Beste Jaap, wat heb ik genoten van ons uitstapje naar Den Haag in 2011! We hebben toen samen heel bevlogen verteld over M@ZL op een bijeenkomst, die door de beide ministeries OCW en VWS was georganiseerd. Je betrokkenheid bij het wel en wee van je leerlingen heb ik als zeer inspirerend ervaren.

En dan last but not least bedank ik graag heel hartelijk mijn lieve Vincent, Olivier, Tim en Fleur. Lieve Vincent, tu es formidable! Vanaf het begin stond je achter mijn promotieonderzoek. Je hebt ervoor gezorgd dat ik er tijd en energie voor heb kunnen vrijmaken. De afgelopen jaren zat ik in een emotionele achtbaan en jij hebt ervoor gezorgd dat ik niet uit de bocht ben gevlogen. Ik moest dit onderzoek doen, voor alle kinderen die het niet zo gemakkelijk hebben, die niet gezegend zijn 
met een optimale gezondheid en opgroeisituatie, die daardoor buiten de boot dreigen te vallen, die onze aandacht verdienen, omdat ik hen net zoveel voorspoed gun als dat ik zelf heb mogen ervaren. Daarom dit onderwerp, daarom dit onderzoek, en je begreep het. Fleur, Olivier en Tim, jullie dank ik voor jullie eindeloos luisteren naar al mijn verhalen, meestal aan de keukentafel en 's avonds tijdens het eten. Volgens mij vonden jullie het ook best wel stoer dat jullie moeder weer aan de studie was. Ja, ook als je al ouder (lees: oud) bent, kun je nog een heel nieuwe uitdaging aangaan! Vincent, Tim, Fleur en Olivier, sorry voor al die uren boven op mijn kamertje en al die tijd dat ik wel bij jullie was maar in gedachten bij een of ander probleem waarover weer nagedacht moest worden. Ik dank jullie voor jullie onvoorwaardelijke steun. Jullie zijn mijn alles!

En dan toch ook een woord van dank aan mijn lieve ouders, die mijn promotie helaas niet hebben mogen meemaken. Jullie wil ik danken voor het warme nest waarin ik mocht opgroeien. Ik kijk met heel veel dankbaarheid en warmte terug op mijn eigen jeugd, en hoe belangrijk is dat voor je geluk en succes in je latere leven! I $k$ weet dat jullie ongelooflijk trots zouden zijn geweest en had jullie dit geluksmoment ook zeer gegund. Ik mis jullie nog steeds en al helemaal op zo'n momenten. Ik waardeer het enorm dat jullie, pa en ma Vanneste, Walter en Liesbeth, met zoveel welgemeende interesse bovengenoemde leegte voor mij proberen op te vullen.

Vele familieleden en vrienden hebben me afgelopen jaren bemoedigd en ondersteund, ieder op zijn eigen manier. Marc en Eline, ik noem jullie graag bij naam. Jullie weten als geen ander hoe het is om een dergelijk traject te doorlopen en zijn me gedurende de afgelopen jaren van grote steun geweest, door mij aan te moedigen en van tijd tot tijd uit te leggen hoe dat werkt, die wetenschappelijke wereld. En dan, natuurlijk, mijn lieve vrienden van de Eatup-club: Frank, Inge, John, Marieke, Stef en Suus. Jullie warme interesse, bemoediging, humor, tips en begrip, gegoten in overheerlijke diners en avonden gezellig samen, zijn mij zeer tot steun geweest! Dank jullie wel voor jullie vriendschap, die mij zoveel waard is. We blijven vrienden totdat we oud en seniel zijn. En dan worden we weer opnieuw vrienden...

Nogmaals heel veel dank aan iedereen die mij zo heeft gesteund: zij weten wie ze zijn en wat ze voor me betekend hebben. 



\section{Valorisation}

In practice-based research valorisation is continually being addressed, for example in refining the intervention for reasons of practicability, suitability and acceptability, in arguing the roles of each stakeholder involved, and in presenting the challenges for implementation and dissemination, thus ensuring that the intervention will fit the needs and possibilities of professionals.

Ultimately, our study contributes to consensus in school absenteeism policy on absenteeism among students in cases of sickness reporting; firstly by stating that medical absenteeism is not primarily an issue for school attendance officers to deal with but mainly for schools and YHCPs. Schools and YHCPs are quite capable and appropriate partners for handling medical absenteeism. Our research also provides input on how to deal with actual medical absenteeism of individual students: a dialogue about medical absenteeism should be motivated by concern and not by the wish to enforce compulsory education. This more open attitude based on interest and concern allows school to look differently at medical absenteeism, leading to less frustration and better support for students. The consultation with a YHCP ensures a good relationship between school and parents. Moreover, schools are provided with a new standard for a medical absence rate which should be acted upon: well-defined and manageable criteria for intervening with the absence. In 2014, Hawkrigg and Payne [1] recommended that health professionals should intervene as soon as there is a pattern of 'sustained' school absence. They recognized that a standard for this pattern was lacking. Now an effective approach for addressing school absenteeism due to sickness reporting, including criteria for intervening with the absence, are finally available.

As mentioned before, our study is the first regarding effectiveness of an intervention to address medical absenteeism in secondary schools, and the effect study shows preliminary evidence that the intervention works in actual practice. Currently, evidence-informed policy is considered to be of great importance for the organization of efficient care. There is a growing awareness that it is necessary to use evidence to achieve more at less cost. Therefore, proving the effectiveness of an intervention has become a prerequisite for its implementation and widespread use. The preliminary evidence justifies the implementation of MASS on a wider scale, accompanied by further evaluation studies [2]. Our qualitative study provided insights in the main challenges for implementation and dissemination and will be helpful in improving commitment to and use of the intervention. Preliminary research on the cost-effectiveness already showed that the benefits of MASS are a fivefold of the costs [3].

Moreover, our study findings have led to a blueprint for the final version of MASS based on core elements. Defining these core elements is essential for monitoring the implementation and securing programme integrity of the intervention in case of widespread use. As mentioned before, the effectiveness of a public health programme is also influenced by its quality of implementation aspects and its impact by dissemination aspects [4]. Defining possibilities for local adjustments and thereby forging joint ownership is a key principle to ensure widespread adoption and feasibility of the implementation $[5,6]$. And as mentioned by Rogers, to attain sustainability interventions must be adaptable to some extent [7], the so-called need for re-invention. In the case of MASS, local adjustments may be for example the physical location of the consultation with the YHCP 
and determining which school professional will enter into conversation with students and their parents about the medical absence.

The intervention has been disseminated in several ways over the past years, mostly at the request of schools and youth health care organisations. In 2014 the needs to start implementing the intervention in other regions have been surveyed together with YHCPs and policy makers of other Regional Public Health Services. This survey was funded by ZonMw, the Dutch Organization for Health Research and Development, and resulted in a manual for $\mathrm{YHC}$ services to address medical absenteeism according to MASS, including support materials for schools to implement MASS. Our study and this manual ensure that MASS will be recognized as'Functional intervention' by the intervention database of the RIVM [8]. In the same year, the RPH service West Brabant developed training courses for YHCPs about how to implement and carry out the MASS intervention and training courses for mentors and career counsellors about how to discuss the medical absenteeism with students and their parents. These courses have been developed with help of RIVM, the National Institute for Public Health and the Environment.

As stated before, agenda setting and funding are pre-exquisites for a sustainable implementation and widespread dissemination of an intervention. Regarding agenda setting, from 1 January 2015 , 'absenteeism guidance' is officially included in the basic task package for YHC services (In Dutch: Basispakket JGZ). In addition it is possible now to use funding for preventive medical assessments in adolescence for implementing MASS in secondary and intermediate vocational schools [9], whereupon financial resources are accessible. Currently, the intervention is implemented in six RPHS-regions in the Netherlands. It is important to monitor the implementation and secure programme integrity of the intervention in case of widespread use. Unfortunately, in the Netherlands the development of and research on interventions is fragmented. There is no institution yet that is responsible to deploy and maintain an effective intervention nationally. 


\section{References}

1. Hawkrigg S, Payne DN. Prolonged school non-attendance in adolescence: a practical approach. Arch Dis Child. 2014;99:954-957. doi:10.1136/archdischild-2013-304595

2. Stronks K, Mackenbach JP. Evaluating the effect of policies and interventions to address inequalities in health: lessons from a Dutch programme. E I Public Health. 2005;16(4):346-353. doi:10.1093/eurpub/cki157

3. Dam P, Prinsen B. Investeren in opvoeden en opgroeien loont! [Investing in educating and growing up pays off!]. 2013. https://www.vng.nl/files/vng/201300912-brochure investeren in opvoeden en opgroeien loont.pdf

4. Glasgow RE, Vogt TM, Boles SM. Evaluating the Public Health Impact of Health Promotion Interventions: The RE-AIM Framework. 1999.

5. Flay B, Phil D. Efficacy and effectiveness trials (and other phases of research) in the development of health promotion programs. Prev Med. 1986;15:451-74. doi:10.1016/oog1-7435(86)goo24-1

6. Wimbush E, Watson J. An evaluation framework for health promotion: theory, quality and effectiveness. Evaluation. 2000;6:301-21. doi:10.1177/135638900000600302

7. Rogers EM. Diffusion of Innovations. 2003. http://teddykw2.files.wordpress.com/2012/o7/everett-m-rogersdiffusion-of-innovations.pdf.

8. Veerman, JW, Yperen TA van. (2007). Degrees of freedom and degrees of certainty: A developmental model for the establishment of evidence-based youth care. Evaluation and Program Planning 30 (2007) 212-221. doi:10.1016/j. evalprogplan.2007.01.011

9. Handreiking adolescentencontactmoment: de JCZ in beeld bij adolescenten. [Handbook preventive medical assessments in adolescence: YHC in picture by adolescents.]. http://www.ggdghorkennisnet.nl/thema/uitvoeringjgz/publicaties/publicatie/6476-handreiking-ncj-biedt-handvatten-nieuw-contactmoment-adolescenten. 



\section{The way MASS works}

Johan is 12 years old and in the first class of pre-vocational secondary school. On a Monday morning in September his mother reports him sick. The mentor phones the mother the same day to ask how he is and whether she can be of any help to Johan. She asks mother to keep her informed of Johan's well-being. When Johan is reported sick for the fourth time, the mentor invites Johan and both his parents to a meeting in school. In this meeting she discusses her wish to refer Johan to the Youth Health Care Physician (YHCP) because of his extensive absence and persistent complaints. She explains she needs the YHCP's advice to be able to provide proper care and support for Johan. Jointly they fill out the referral form, in which they indicate that Johan participates well during lessons, enjoys himself in school, and that his scores are up to standard. They also indicate that Johan was diagnosed with PDD-NOS (Pervasive Developmental DisorderNot Otherwise Specified) two years ago, for which he was treated by the mental health service (CCZ). They add the absence registration.

One week later I meet Johan and his parents for consultation. During the consultation the parents tell me that Johan has been home sick for a week already with tiredness and physical complaints. One Friday morning at school he became very short of breath and got a pain in his chest. After this Johan has had several 'attacks'. Every time this happens, mother panics. Twice already they ended up in the emergency ward. The medical examinations by the general practitioner and in the emergence ward show no evidence of a physical cause for Johan's complaints. Meanwhile Johan has been referred to the paediatrician. Johan says he enjoys school and has good contact with his mentor. His scores are fine. Father helps him with his homework. To his regret Johan no longer participates in physical education and sports classes. He had opted for the sports class after all! Also he no longer uses his bike to go to school, mother takes him in the car. Mother in particular is afraid that there is something serious going on. Father is much more matter-of-fact and encourages Johan to go to school. During the consultation my contact with Johan is quite good. He looks at me when he is talking and he is quite well able to voice his views. However, during the physical examination Johan clearly has huge problems with being touched. I suggest that Johan's complaints may have something to do with his 'sensitivity' to change. After all the switch from primary school to secondary school is a huge step! I ask them to consider this and to discuss it with the mentor. We all agree that, starting tomorrow, Johan will go back to school every day, with a $50 \%$ work load. Johan himself indicates that he will be able to do this. Also that going back home from school if he is not feeling well is no longer an option. We ask the mentor to make a schedule with them and to create an opportunity for Johan to withdraw for a while to calm down when things are difficult. The parents contact Johan's mentor to arrange these matters. I will consult the general practitioner and the paediatrician and we agree to meet again in two weeks' time. I also inform the mentor of all agreements recorded in a 'management plan'.

The mentor tells me that it is becoming obvious that, while Johan is doing really well in class, he is always on his own during breaks. Others call him names. His classmates, who have difficulties with this, have approached the mentor about it. When I contact the general practitioner and the paediatrician, I hear that the consultation with the paediatrician again has provided no indications of a somatic cause. The paediatrician is able to set the parents' minds at rest, prescribes relaxation therapy for Johan and refers him back to me. 
When I meet with them two weeks later, they seem to have been reassured by the paediatrician. They say that Johan managed to keep to the schedule reasonably well. Sometimes he still wants to go home due to tiredness. This usually happens during a break. I again discuss the possible relation between his complaints and the tensions that seem to appear especially during time off. And yes, the mentor has already discussed this with them. I suggest to recommence the support of the mental health service. They agree and promise to make an appointment. I inform the mental health service of this.

One month later we meet again. Johan tells me that the relaxation therapy is not really working yet, but that the therapist is quite nice. The mental health service intake has taken place and sessions will start in 2 days. Johan himself suggests increasing his time in school and we make a series of concrete agreements. The breaks proceed better now, he joins a group of classmates. I propose that the mental health service will support further reintegration and inform the mental health service. I agree to call them in a month to hear how things are going. If they want to contact me before, they know how to get in touch. The mentor has arranged the breaks to be less stressful for Johan. School can play an important role here. In addition, monitoring absence is also the school's responsibility. I agree with the mental health service that they will let me know if care and/or reintegration come to a standstill. It is the responsibility of the YHCP to coordinate the support with all stakeholders and to monitor the care.

Right before the Christmas holidays I call the mother. Johan is doing well. He is back in school full-time and the mental health service support has been terminated.

Yvonne Vanneste 


\section{Case histories}

\section{Kevin}

It is September when Kevin is referred to the YHCP by the Career Counsellor. Kevin is 17 years old, is in Intermediate Vocational Education and, due to extensive medical absenteeism, in the 2nd class of the Media Design course for the third time already. He indicates that he has suffered severe headaches over the last two years. Elaborate examinations in hospital have not delivered a medical explanation. At the end of the last school year the school offered him one more opportunity because of his medical situation. Because Kevin is absent mostly from school, but not from his trainee placement, the school suspects motivation issues. The YHCP thinks it might be an Attention Deficit (Hyperactivity) Disorder. Kevin's file shows that he had problems with concentration from an early age on. After he starts with medication and counselling, Kevin is doing better. He is also more receptive to counselling from school in order to plan his activities and assignments. The YHCP advises the schoo to continue monitoring his sickness absence and to discuss each absence report with Kevin.

\section{Jeroen}

Jeroen ( 16 years old) is in the first class of Intermediate Vocational Education and often reports sick. When the Career Counsellor asks, he always indicates stomach ache as the reason for his absence. Jeroen usually does not look at you when you are talking to him. The teachers find him lazy and indifferent. The Career Counsellor suspects he has motivation issues. During the consultation with the YHCP it turns out he is being kept at home to work in the household. Mother is chronically ill. He was too ashamed to talk about this in school. With the permission of Jeroen and his mother, who is present at the consultation, the school is informed. Together with the school opportunities for additional counselling by school are explored. 



\section{Publications, presentations and contributions related to this thesis}

\section{Publications present thesis}

Y.T.M. Vanneste, F.J.M. Feron, M.C. Rots-de Vries, L.A.M. van de Goor. Medische Advisering Ziek gemelde Leerlingen. [Medical Advice Sick-reported Students.].Samenvatting presentatie NCVCZ congres/abstract Dutch Health Congress 2011. TSC. 2011;3:44-45.

Y.T.M. Vanneste, J.J.P. Mathijssen, L.A.M. van de Coor, M.C. Rots-de Vries, F.J.M. Feron. Extensive medical absenteeism among secondary school students: an observational study on their health condition from a biopsychosocial perspective. Open | Prev Med. 2015;5:111-121. http://dx.doi. org/10.4236/ojpm.2015.53013

\section{Publications outside this thesis}

Herman Pranger (editor). De jeugdarts dringt ziekteverzuim terug. [The youth health care physician reduces medical absenteeism.]. Brochure'Binden \& Bouwen': De West-Brabantse aanpak van schooluitval in de praktijk. Vsv-commissie West-Brabant. [Brochure 'Connect \& Construct': The West Brabant approach to dropout in practice. Dropout Committee West Brabant Region 34.]. 2010. http://www.aanvalopschooluitval.nl/userfiles/file/2010/1\%20tot\%2037\%20Binden_ Bouwen_2.pdf

Yolanthe van der Ree and Rob de Blok (editors). Interview Yvonne Vanneste. Nepziek is ook spijbelen. Medische advisering ziekgemelde leerlingen - M@ZL. [Faking sick also is playing truant. Medical Advice Sick-reported Students - MASS.]. Brochure 'Samen school maken'. De kracht van preventieve inzet in het onderwijs. Landelijk Platform Onderwijs en Jeugdzorg. [Brochure 'Creating school together'. The potential of prevention in education. National Forum for Education and Youth.]. 2010. http://www.aanvalopschooluitval.nl/userfiles/file/projectenbank/ Samen_school_maken1.pdf

Y.T.M. Vanneste, F.J.M. Feron, M.C. Rots-de Vries, L.A.M. van de Goor. Medische Advisering Ziek gemelde Leerlingen. [Medical Advice Sick-reported Students.]. Samenvatting presentatie NCVGZ congres/abstract Dutch Health Congress 2011. TSC. 2011;3:44-45.

Yvonne T.M. Vanneste, Maud M.F. Dautzenberg, Daniëlle A.I. Groffen, len A.M. van de Goor, Frans J. M. Feron. Verkenning van risicofactoren van omvangrijk ziekteverzuim in het basisonderwijs. [Exploring risk factors for extensive medical absenteeism in primary school.]. Samenvatting / abstract EUSUHM.TSC. 2013;45(6):132.

Yvonne T.M. Vanneste, Marlou H.A. van de Loo, Frans J. M. Feron, Carin M.C. Rots-de Vries, len L.A.M. van de Coor. De aanpak van ziekteverzuim in het voortgezet onderwijs volgens M@ZL, vanuit het perspectief van de scholen. [Addressing medical absenteeism in secondary school according to the MASS intervention, from schools' perspectives.]. Samenvatting / abstract EUSUHM. TJCZ. 2013;45(6):131.

Interview Yvonne Vanneste. Ziekteverzuim eerder in beeld. [Identification of medical absenteeism at an earlier stage.]. Regionaal bureau leerplicht West-Brabant. [Regional agency Compulsory 
Yvonne Vanneste. Ziek gemeld, en dan...? [Reported sick, then what to do...?]. JA! Ledenblad van de AJN. [Members magazine Dutch youth health care physicians.]. 2015.

Yvonne T.M. Vanneste, Jolanda J.P. Mathijssen, Ien L.A.M. van de Goor, Carin M.C. Rots-de Vries, Frans J. M. Feron. Effectiviteit van een interventie voor de aanpak van ziekteverzuim van vmboleerlingen door inzet van jeugdartsen. [Effectiveness of an intervention for addressing medical absenteeism among pre-vocational secondary students.]. Samenvatting / abstract EUSUHM. TJGZ. August 2015. Accepted for publication.

S. de Poot, Y.T.M. Vanneste, A. de Rijk, F.J.M. Feron. Ziekteverzuimbegeleiding van leerlingen op het middelbaar beroepsonderwijs: een kwalitatief onderzoek onder studieloopbaanbegeleiders. [Supervision medical absenteeism of students in intermediate vocational education: a qualitative study among student career counsellors.]. TSC. Submitted for publication.

\section{Presentations, workshops and lectures}

10 december 2009. Workshop. Titled: M@ZL, gedeelde zorg is half (weer) beter. [MASS, shared care is much better.]. Jaarcongres JGZ. [Annual Conference youth health care.]. Ede, the Netherlands.

12 March 2010. Workshop. Titled: Zo houden we ze binnen de school! Over een benadering van voortijdig schoolverlaten vanuit Public Health. [How we keep them inside the school! About an approach to Early School Leaving by Public Health.]. Jaarlijks nationaal congres 'Jeugd in onderzoek'. [Annual national congress Youth Research.]. Ede, the Netherlands. http://www. jeugdlinq.nl/documents/jeugdlinq/informatie/100312 congresbundeljeugdinonderzoek.pdf

24 September 2010. Workshop. Titled: Schoolverzuim in Brabant: M@ZL-project. [School absenteeism in West Brabant: the MASS project.]. Congres centra voor jeugd en gezin. [Congress centers for youth and family.]. Putten, the Netherlands. http://www.ggdghor.nl/media/filebank/ 52d215b2238d4545ba634914b5cc29cc/brochure-congres-cjg.pdf

7 October 2010. Presentation. Titled: Snel terug naar school is veel beter. [Quickly back to school is much better.]. 4de Studiedag Integrale Zorg georganiseerd door NVK en JCZ. [4th Seminar integrated care organised by Dutch Association of Pediatrics and youth health care.]. Utrecht, the Netherlands.

21 October 2010. Lecture about the MASS intervention. Regional Public Health Service Amsterdam. Amsterdam, the Netherlands.

2 November 2010. Presentation. Presenting the National Guideline 'Quickly back to school is much better', for a comprehensive approach to medical absenteeism among children and adolescents. Jaarlijks congres van Ingrado. [Annual Congress National Ingrado, the national professional association for school attendance officers.]. Utrecht, the Netherlands.

17 November 2010. Workshop. Titled: Schoolziekteverzuim: Willen we er wat mee? Wat kunnen 
we er mee? [Medical absenteeism among students: Do we want to do something with it? What can we do with it?']. MBO conferentie 'Maatwerk in het MBO'. [Intermediate vocational conference 'tailor-made solutions']. Amersfoort, the Netherlands.

11 November 2010. GGD begeleidt pubers bij ziekteverzuim: project M@ZL! [Public health Service supervises adolescents with medical absenteeism: the MASS project!]. Kennistafels ministerie OCW; 'Aanval op schooluitval'. [Expertise tables Ministry of Education, Culture and Science; 'Drive to reduce dropouts'.]. The Hague, the Netherlands. http://www. aanvalopschooluitval.nl/userfiles/Projecten\%2okennistafels.pdf

1 March 2011. Presentation. Titled: De landelijke handreiking en het M@ZL-project. [The national guideline and the MASS project.]. At the invitation of Ministry of Education, Culture and Science and the Ministry of Health, Welfare and Sport. The Hague, the Netherlands.

7 April 2011. Presentation. Titled: Medische Advisering Ziek gemelde Leerlingen. [Medical Advice Sick-reported Students.]. NCVCZ congress. [Dutch Health Congress.]. Amsterdam, the Netherlands.

17 May 2011. Lecture. Titled: Snel terug naar school is veel beter. Ziekteverzuimbegeleiding van leerlingen door de jeugdarts: over de landelijke handreiking, de resultaten van evaluatieonderzoek en de stand van zaken met betrekking tot implementatie. [Quickly back to school is much better. Absenteeism guidance of students by the youth health care physician: over the national guideline, the results of evaluation and the status of implementation.]. Training Course youth health care physicians, Academic Medical Centre Amsterdam. The Netherlands.

9-11 June 2011.Presentation.Titled:The M@ZL-project: guidance of students frequently absent from secondary school for medical reasons by youth health care physicians. EUSUHM-2011: The 16 th Congress of the European Union for School and University Health and Medicine; 'Education and health from childhood to adult life'. Moscow, Russia.

6 October 2011. Presentation. Titled: En dan wordt een leerling ziek gemeld.... [And then, a student is reported sick....]. Werkconferentie, georganiseerd door de gemeente Assen, om te komen tot een integrale aanpak van schoolziekteverzuim aan de hand van de landelijke handreiking 'Snel terug naar school is veel beter'. [Conference organised by the Assen municipality in order to achieve an integrated approach of medical absenteeism among students according to the Nation Guideline 'Quickly back to school is much better'.]. Assen, the Netherlands. http://www. rechtopleren.nl/download/304/Uitnodiging_Ziekteverzuim_NEW_HR_pdf

10 May 2012. Presentation.Titled: M@ZL, an intervention for addressing medical absenteeism in secondary school. An example of good practice in reducing Early School Leaving. at the ESN Spring Seminar-2012: 'Vulnerable Youth in Transition: Care and Support into Adulthood'. European Social Network. Rome, Italy.

12 September 2012. Presentation. Titled: CGD begeleidt pubers bij ziekteverzuim: succesvol project M@ZL! [RPH Service supervises adolescents in absenteeism: successful MASS project!]. VNG congress. [Dutch Association Local Authorities Congress.]. Amersfoort, the Netherlands. 
6 June 2012. Lecture. Titled: Samenwerken aan ziekteverzuimbeleid; zorgwekkend verzuim: wat is dat? [Working together towards medical absenteeism policy; when do we need to concern about medical absence?]. Kenniscafé rondom langdurig zieke leerlingen \& zorgwekkend schoolverzuim. [Meeting about students who are prolonged absent from school \& worrisome absenteeism.]. Goes, the Netherlands.

1 November 2012. Presentation. Titled: De interventie M@ZL: Van pilot naar evidence-based. [The MASS intervention: from pilot to evidence-based'.]. AJN afdeling Zuid-Holland. [Association youth health care physicians South Holland department.]. Utrecht, the Netherlands,

28 June 2012. Lecture. Lezing tijdens een regionale scholingsdag voor jeugdartsen in het kader van schoolverzuim: 'Samen werken aan ziekteverzuimbeleid'. [Lecture during a regional training day for youth health care physicians about school absenteeism: 'Working together towards absenteeism policy'.]. GCD Zuid-Holland, RPHS South Holland. Dordrecht, the Netherlands.

25 September 2012. Lecture. Samen werken aan ziekteverzuimbegeleiding. Welke rol is er weggelegd voor de jeugdarts? [Working together on medical absenteeism guidance. What role is for the youth health care physician?]. PAOG, Post Academic Education in Medicine. Maastricht, the Netherlands.

20 november 2012. Presentation. Titled: Pubers en ziekteverzuim. [Medical absenteeism in adolescence.]. Ouderavond Onze Lieve Vrouwen Lyceum: 'Durf jij nee te zeggen? Over pubers en grenzen'. [Parent Meeting Secondary School: 'Dare you to say no? About limiting adolescents.]. Breda, the Netherlands.

13 December 2012. Workshop. Titled: 100\% geslaagd! De interventie M@ZL: Van pilot naar evidence-based, van kansen zien tot landelijke implementatie. [100\% succeeded! The MASS intervention: from a pilot to an evidence-based intervention, from seeing opportunities to implementing nation-wide.]. JCZ jaarcongres: 'Kansen door verandering; de JCZ en de ontwikkelingen in de zorg voor jeugd'). [Annual Conference youth health care: Opportunities by change; $\mathrm{PCH}$ and developments in care for youth.]. Ede, the Netherlands.

28 maart 2013. Lecture. Themabijeenkomst verzuimbegeleiding. Symposium voor artsen (in opleiding) die betrokken zijn bij het coschap sociale geneeskunde en Eerstelijnsgeneeskunde. [Thematic meeting 'absenteeism support'. Symposium for physicians (in training) involved in Social Medicine and Primary Care.]. Nijmegen, the Netherlands.

27-29 June 2013. Presentation. Titled: Perceptions on addressing medical absenteeism in secondary school. The findings of a qualitative study. EUSUHM-2013: Breaking down the barriers. The 17 th Congress of the European Union for School and University Health and Medicine 'Education and health from childhood to adult life'. London, United Kingdom.

27-29 June 2013. Presentation. Titled: Exploring determinants of extensive medical absenteeism in primary school; results from a matched case-control study. EUSUHM-2013: Breaking down the barriers. The 17th Congress of the European Union for School and University Health and Medicine 'Education and health from childhood to adult life'; London, United Kingdom. 
5 February 2014. Workshop. Titled: M@ZL. [The MASS intervention.]. Startconferentie 'Alles is gezondheid...Het Nationaal Programma Preventie 2014-2016'. [Start Conference 'Everything is health... The Dutch National Prevention Programme 2014-2016'.]. National Institute for Public Health and the Environment. Ministry of Health, Welfare and Sport. The Hague, the Netherlands.

17 April 2014. Presentation. Titled: Aanpak van ziekteverzuim volgens de methode M@ZL. [Addressing medical absenteeism by the MASS intervention.]. Symposium 'Ziekteverzuim op het VO en MBO - van signalering tot aanpak en behandeling'. [Symposium 'Medical absenteeism in secondary and intermediate vocational education - from identification to approach and treatment'.]. Alkmaar, the Netherlands.

11 November 2014. Workshop. Titled: Ziekteverzuim van mbo-leerlingen? Wat kunnen we er mee? [Medical absenteeism among intermediate vocational students: What can we do with it?]. MBO en gemeentelijk jeugdbeleid: dit werkt! Conferentie passend onderwijs en MBO, georganiseerd door de VNG, de MBO Raad en het Nederlands Jeugdinstituut in opdracht van het ministerie van OCW. [Intermediate Vocational Education and municipal youth policy: this works! Conference Inclusive Education' and Intermediate Vocational Education, organized by the Dutch Association Local Authorities, the Intermediate Vocational Education Council and Dutch Youth Institute, commissioned by the Ministry of Education, Culture and Science.] Assen, the Netherlands. http://www.nji.nl/nl/Congressen/MBO-en-jeugdbeleid-dit-werkt

9 March 2015. Poster presentation. Titled: Een (kosten)effective aanpak van ziekteverzuim op het voortgezet onderwijs. [A (cost)effective intervention for addressing medical absenteeism in secondary school]. Congres Jeugd-in-onderzoek: 'Van weten wat werkt naar doen wat werkt' [Congress Youth-in-research: 'From knowing what works to doing what works'], Nieuwegein, the Netherlands.

12 March 2015. Presentation. Titled: Meer M@ZL geeft minder ziekteverzuim. [More MASS provides less absenteeism.]. Landelijke studiedag SOLK, Somatisch Onvoldoende verklaarde Klachten. [National conference SOLK, Somatic Insufficient Explained Complaints.]. Utrecht, the Netherlands.

8 April 2015. Presentation. Titled: De interventie M@ZL. De aanpak van ziekteverzuim van vmbo-leerlingen met behulp van de inzet van jeugdartsen. [The MASS intervention. Addressing medical absenteeism in pre-vocational education through the deployment of youth health care physicians.]. NCVGZ congress, Dutch Health Congress. Utrecht, the Netherlands.

23 April 2015. Workshop. Titled: Leerlingen die verzuimen wegens ziekte: de interventie M@ ZL. ['Students who are absent because of sickness: the MASS intervention.]. Werkconferentie Ingrado Utrecht, Working conference Ingrado, the national professional association for school attendance officers. Utrecht, the Netherlands.

4-5 June 2015. Presentation. Titled: Addressing medical absenteeism in pre-vocational secondary students: effectiveness of a public health intervention. EUSUHM-2015: The 18th Congress of the European Union for School and University Health and Medicine 'Education and health from childhood to adult life', Tallin, Estonia. 
18 June 2015. Presentation. Titled: SOLK, Somatisch Onvoldoende verklaarde Klachten, en ziekteverzuim: hoe kunnen jeugdartsen en kinderartsen hierbij samenwerken? [SOLK, Somatic Insufficient Explained Complaints and medical absenteeism: how we may be able to work together?]. Regional periodic training for youth health care physicians and paediatricians in West Brabant, Breda, the Netherlands.

5 October 2015. Accepted for workshop. Titled: Met M@ZL minder schoolziekteverzuim. [With MASS less medical absenteeism among students.]. Landelijke studiedag 'Voor de Jeugd Dag', georganiseerd door de ministeries VWS en Ven], en de VNG. [National conference 'For the Youth Day', organized by the Ministry for Health, Welfare and Sports, Ministry of Security and Justice and the Association of Dutch Municipalities.]. Amsterdam, the Netherlands.

14-17 October 2015. Accepted for poster presentation. Titled: Addressing medical absenteeism among students: effectiveness of a Dutch public health intervention. European Public Health Conference-2015. Milan, Italy.

11-13 November 2015.Accepted for poster presentations: 1. Titled: The Dutch preventive health care for adolescents, including the MASS intervention, as an input for discussing international experiences of preventive health care for adolescents: what works best? 2. Poster presentation, Titled: Towards a better understanding of medical absenteeism in adolescence: a qualitative study among Dutch intermediate vocational students. The 2015 AAAH (Australian Association for Adolescent Health) National Youth Health Conference in Melbourne, Australia.

\section{Contributions}

\section{Courses}

2012-present. Het geven van onderwijs aan TNO in 'schoolverzuim en de rol van de jeugdarts'. [Teaching about school absenteeism and the role of the youth health care physician.].Youth health care physician Training, TNO - Nederlandse Organisatie voor toegepast-natuurwetenschappelijk onderzoek, Dutch Organisation for Applied Scientific Research. Leiden, the Netherlands.

2013-present. De ontwikkeling en uitvoering van de leergang 'De jeugdarts: sleutelrol bij verzuimbeleid'. [Development and carrying out of the course entitled 'The youth health care physician: a key player in addressing medical absenteeism.]. NSPOH, Dutch School of Public and Occupational Health, post academic training for youth health care physicians. Utrecht, the Netherlands.

2013. Deelname projectgroep extra contactmoment, resulterend in handreiking 'De JGZ in beeld bij adolescenten'. Samen bouwen aan gezondheid en gezond gedrag voor duurzame participatie van jongeren. [Contribution to the development of the national guideline 'Youth health care being visible to adolescents'. Working together to build health and healthy behaviours for sustainable youth participation]. Utrecht, the Netherlands. http://www.ggdghorkennisnet.nl/ thema/uitvoering-jgz/publicaties/publicatie/6476-handreiking-ncj-biedt-handvatten-nieuwcontactmoment-adolescenten

2014-present. De ontwikkeling en uitvoering van de scholing voor jeugdartsen: 
'Ziekteverzuimbegeleiding door de jeugdarts volgens de methodiek M@ZL'. [The development and carrying out of the training for and teaching of youth health care physicians: addressing medical absenteeism according to the MASS intervention.]. Meanwhile, all youth health care physicians of three Regional Public Health Services have been trained. GGD Academy, RPHS West Brabant. Breda, the Netherlands.

2014. De ontwikkeling van de M@ZL-training voor mentoren: 'Het bespreekbaar maken van ziekteverzuim met leerlingen en hun ouders'. [The development of the MASS training for mentors: 'Entering into conversation about medical absenteeism with students and their parents'.]. CGD Academy, RPHS West Brabant. Breda, the Netherlands.

\section{Handbooks}

2010. Vanneste YTM, Lanser H. Snel terug naar school is veel beter. Landelijke handreiking voor een integrale aanpak van schoolziekteverzuim bij kinderen en jongeren. [Quickly back to school is much better. National guideline for a comprehensive approach to medical absenteeism among children and adolescents.]. https://www.nvab-online.nl/content/snel-terug-naar-schoolveel-beter

January 2014. Yvonne Vanneste. Handboek voor een integrale aanpak van ziekteverzuim op het MBO volgens M@ZL. [Handbook for an integrated approach of medical absenteeism in intermediate vocational education according to the MASS intervention.]. http://www. ggdwestbrabant.nl/mazl

October 2014. Yvonne Vanneste. Handboek integrale aanpak van ziekteverzuim volgens M@ZL op het voortgezet onderwijs. Handboek voor JCZ-instellingen. [Manual for an integrated approach of medical absenteeism in secondary school according to the MASS intervention. Handbook for youth health care services]. http://www.ggdwestbrabant.nl/mazl

\section{Media}

30 August 2012. Yvonne Vanneste. West-Brabant investeert in aanpak schoolverzuim. Opiniestuk. [West Brabant invests in approach to school absenteeism due to sick reports. Opinion article.]. BN De Stem, Regional Newspaper.

12 October 2013. Interviewing Yvonne Vanneste about 'Youth health care for adolescents'. Radio interview.

16 October 2013. Contribution to the Evening News by Yvonne Vanneste with respect to the subject 'Youth health care for adolescents'.

24 October 2014. Jacques Hendriks. Meer M@ZL geeft minder verzuim. Interview met Yvonne Vanneste. [More MASS, less medical absenteeism. Interviewing Yvonne Vanneste.]. BN De Stem, Regional Newspaper.

20 November 2014. Onderzoeker Yvonne Vanneste en Loes Ypma (PvdA) over schoolverzuim. [ResearcherYvonne Vanneste and politician Loes Ypma (Labor Party) about school absenteeism.]. Radio interview. 


\section{Awards}

In December 2009, the Regional Public Health Service West Brabant was awarded first prize for the MASS intervention by the professional association youth health care, because of its innovative character. The innovation prize is an annual prize and has been created to encourage new developments and contribute to the professionalization of the YHC.

In November 2013, Yvonne Vanneste received the Flora van Laar Prize in 2013. This national prize is awarded every two years to a person who has conducted pioneering research or innovative activity in the youth health care.

In January 2015, Yvonne Vanneste was declared the most influential person of public health 2014. This prize is awarded annually by the Dutch Association for Public health in the Netherlands. 



\section{About the author}

Yvonne Vanneste-van Zandvoort was born in 1961 in Heerlen, the Netherlands. After completing Cymnasium- $\beta$, she started to study Medicine at Utrecht University in 1980. In 1987 she obtained her medical degree, after which she started to work as a medical professional at the ER in the former Laurens hospital in Breda. In the summer of 1990, Yvonne first met Flora van Laar (1925-2001), a youth health care physician with a passion for professionalism and innovation. This encounter turned out to be a milestone in Yvonne's career. Flora's enthusiasm inspired her to become a youth health care physician too. Since May 1990, Yvonne works at the Regional Public Health Service West Brabant (CGD West-Brabant).

In 1995, she graduated as a medical specialist in Community Health and Social Medicine in the field of Child and Youth Health Care at the University in Leiden. Yvonne's work as an executive youth health care physician consisted primarily of preventive adolescent health care, and of social medical consultation to the municipalities about childcare and school matters. For six years, she focused her work on addressing medical absenteeism among students. In 2009, she developed the intervention 'Medical Advice for Sick-reported Students', with the acronym MASS (In Dutch: 'Medische Advisering van de Ziekgemelde Leerling', acronym M@ZL) for which the Regional Public Health Service West Brabant was awarded first prize by the Dutch Medical Association Youth Health Care Physicians (AJN). This annual innovation prize was to be the first step towards her PhD trajectory and to the research presented in this thesis. In 2010, commissioned by the Dutch Medical Association Youth Health Care Physicians and financially supported by the Ministry of Education, Culture and Science and the Ministry of Health, Welfare and Sport, Yvonne became project leader and chief editor of the national guideline 'Quickly back to school is much better', which presented schools, municipalities and YHC services with a comprehensive approach to medical absenteeism among children and adolescents. In December 2010 she started her PhD trajectory on a study into addressing medical absenteeism among students, at Maastricht University and within the Academic Collaboration Public Health (AWPG) at Tranzo, Tilburg University. Since 2012 Yvonne teaches on 'Medical absenteeism and the role of the youth health care physician' at the Youth Health Care Physician Training at TNO, in Leiden. In collaboration with the NSPOH (Dutch School of Public and Occupational Health, in Utrecht), she developed the post academic training for youth health care physicians entitled 'The youth health care physician: a key player in addressing medical absenteeism'. In November 2013, Yvonne Vanneste received the biennial Flora van Laar Prize for her pioneering and innovative work in the field of Youth Health Care.

In 2014, she wrote two manuals, one for school staff and one for youth health care services, about an integrated approach of medical absenteeism in school according to the MASS intervention. In the same year, together with the GCD Academy at the Regional Public Health Service West Brabant, she also developed a MASS training for youth health care physicians, and for mentors and career counsellors. In January 2015, Yvonne Vanneste was acclaimed the most influential person of public health 2014 by the Dutch Association for Public Health.

Yvonne Vanneste is married to Vincent and mother of Olivier (1994), Tim (1995) and Fleur (1997). She lives in Breda, the Netherlands. 